


\section{APPLICATIONS OF CONTEMPORARY MANAGEMENT \\ APPROACHES IN SUPPLY CHAINS}

Edited by Hakan Tozan and Alper Ertürk 
Applications of Contemporary Management Approaches in Supply Chains

http://dx.doi.org/10.5772/58741

Edited by Hakan Tozan and Alper Erturk

\section{Contributors}

Ana Paula Barroso, Virgínia Helena Machado, Helena Carvalho, Virgílio Cruz Machado, Roberta Pinna, Pier Paolo Carrus, Fabiana Marras, Cesar Martinez-Olvera, Sheng-Pen Wang, Lynn Fish, Isaias Badillo-Pina, Ricardo Tejeida-Padilla, Oswaldo Morales-Matamoros, Abraham Briones, Alper Ertürk, Hakan Tozan, Eser Kayhan Tekin

\section{(c) The Editor(s) and the Author(s) 2015}

The moral rights of the and the author(s) have been asserted.

All rights to the book as a whole are reserved by INTECH. The book as a whole (compilation) cannot be reproduced, distributed or used for commercial or non-commercial purposes without INTECH's written permission. Enquiries concerning the use of the book should be directed to INTECH rights and permissions department (permissions@intechopen.com).

Violations are liable to prosecution under the governing Copyright Law.

\section{(cc) BY}

Individual chapters of this publication are distributed under the terms of the Creative Commons Attribution 3.0 Unported License which permits commercial use, distribution and reproduction of the individual chapters, provided the original author(s) and source publication are appropriately acknowledged. If so indicated, certain images may not be included under the Creative Commons license. In such cases users will need to obtain permission from the license holder to reproduce the material. More details and guidelines concerning content reuse and adaptation can be foundat http://www.intechopen.com/copyright-policy.html.

\section{Notice}

Statements and opinions expressed in the chapters are these of the individual contributors and not necessarily those of the editors or publisher. No responsibility is accepted for the accuracy of information contained in the published chapters. The publisher assumes no responsibility for any damage or injury to persons or property arising out of the use of any materials, instructions, methods or ideas contained in the book.

First published in Croatia, 2015 by INTECH d.o.o.

eBook (PDF) Published by IN TECH d.o.o.

Place and year of publication of eBook (PDF): Rijeka, 2019.

IntechOpen is the global imprint of IN TECH d.o.o.

Printed in Croatia

Legal deposit, Croatia: National and University Library in Zagreb

Additional hard and PDF copies can be obtained from orders@intechopen.com

Applications of Contemporary Management Approaches in Supply Chains

Edited by Hakan Tozan and Alper Erturk

p. cm.

ISBN 978-953-51-2045-2

eBook (PDF) ISBN 978-953-51-5145-6 


\section{We are IntechOpen, \\ the world's leading publisher of Open Access books}

Built by scientists, for scientists

\section{$3,800+$}

Open access books available

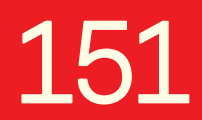

Countries delivered to

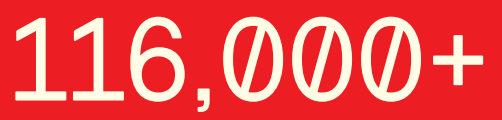

International authors and editors
$120 \mathrm{M}+$

Downloads

Our authors are among the

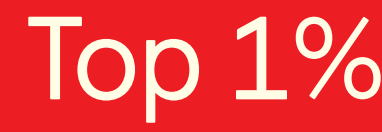

most cited scientists

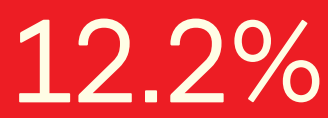

Contributors from top 500 universities

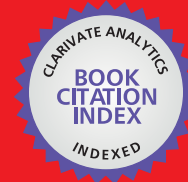

WEB OF SCIENCE ${ }^{\mathrm{TM}}$

Selection of our books indexed in the Book Citation Index in Web of Science ${ }^{\mathrm{TM}}$ Core Collection (BKCI)

Interested in publishing with us?

Contact book.department@intechopen.com

Numbers displayed above are based on latest data collected.

For more information visit www.intechopen.com

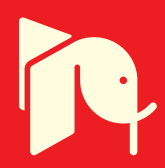





\section{Meet the editors}

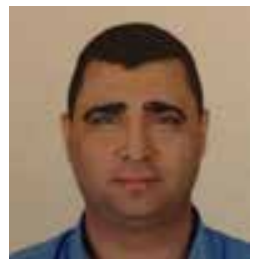

Hakan TOZAN (PhD) is currently Associate Professor and Head of Department of Industrial Engineering at Turkish Naval Academy. He obtained his PhD from Marmara University, Turkey. His research interests include operations research, fuzzy logic, decision support systems, supply chain optimization and production planning and control.

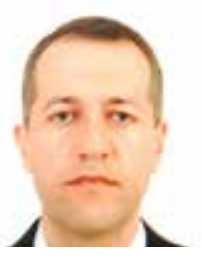

Alper Ertürk (PhD) is currently Associate Professor of Management and Head of Social Sciences Department at Turkish Naval Academy. He obtained his PhD in organizational behavior from Gebze Institute of Technology, Turkey. His research interests include leadership, organizational trust, cognitive styles, and perceptions of workplace fairness. 



\section{Contents}

Preface XI

Chapter 1 Corporate Social Responsibility in Supply Chains 1

Eser Kayhan Tekin, Alper Ertürk and Hakan Tozan

Chapter 2 Quantifying the Supply Chain Resilience 13

A.P. Barroso, V.H. Machado, H. Carvalho and V. Cruz Machado

Chapter 3 Modeling the Production and Replenishment Decisions in a Supply Chain when the Vendor Has Limited Space 39 Sheng-Pen Wang

Chapter 4 Modeling the Supply Chain Management Creation of Value A Literature Review of Relevant Concepts 57 César Martínez-Olvera and Yasser A. Davizon-Castillo

Chapter 5 Managerial Best Practices to Promote Sustainable Supply Chain Management \& New Product Development 83 Lynn A. Fish

Chapter 6 Emerging Trends in Healthcare Supply Chain Management An Italian Experience 117

Roberta Pinna, Pier Paolo Carrus and Fabiana Marras

Chapter 7 A Systems Science/Cybernetics Perspective on Contemporary Management in Supply Chains 139 Isaías Badillo, Ricardo Tejeida, Oswaldo Morales and Abraham Briones 



\section{Preface}

In today's rapidly changing business environment, strong influence of globalization and information technologies drives practitioners and researchers of modern supply chain management interested in applying different contemporary management paradigms and approaches into supply chain process. In order to foster their performance and sustainability, business practitioners and academic researchers seek ways to consolidate new ideas and experiences. Hence, the field of supply chain management has evolved from inventory, warehouse, and transportation management to a more complex and holistic structure by integrating current trends, theories, models and practices in the management science field throughout supply chains. However, although application of different management approaches extends the opportunities, it also brings challenges for management of supply chains from first to last step.

This book intends to provide a guide for researchers, graduate students, and practitioners on incorporating every aspect of contemporary management paradigms into overall supply chain functions such as procurement, warehousing, manufacturing/production, logistics/ transportation and disposal. With this book, graduate students will comprehend how to integrate different organizational theories and management approaches into a supply chain; researchers will be able to explore the individual and combined influences of specific organizational theories, trends and methodologies on the supply chains; and practitioners will be able to see their supply chains from a more holistic perspective and thus fathom how to incorporate modern management applications into their supply network.

By examining state-of-the-art organization and management theories, trends and issues, this book shall serve to capture the contemporary applications in the field of supply chain management. Hence, we hope that the readers of this book will gain a broader perspective of the supply chain management.

Hakan TOZAN

Turkish Naval Academy Dept. of Industrial Engineering Chair of Naval Operations Research Program Tuzla/Istanbul, TURKEY

Alper ERTÜRK

Turkish Naval Academy Dept. of Social Sciences Tuzla/Istanbul, TURKEY 

Chapter 1

\title{
Corporate Social Responsibility in Supply Chains
}

\author{
Eser Kayhan Tekin, Alper Ertürk and Hakan Tozan \\ Additional information is available at the end of the chapter
}

\section{Introduction}

In today's business world, growing attention is being paid on the business concept; "Corporate Social Responsibility" (hereafter, CSR), mostly because of environmental concerns, regulatory impacts, commercial benefits and reputation in front of the society. Increasing number of companies initiates and implements practices considered as CSR activities.

Concept of Corporate Social Responsibility (CSR) has been first introduced by Bowen (1952) and states that while implementing strategies and making their decisions, organizations should act taking into consideration society's values [1]. At the end of 1970s, after development and inclusion of Stakeholder Theory into the management literature, CSR has been defined as covering all the relevant stakeholders. In this respect, Carroll (1979) defined CSR as sensitivity of an organization about the stakeholders' expectations on the management of social, environmental, economic, ethic and legal issues [2].

Towards the end of 1980s, concept of sustainable development has been introduced and has focused on economic, social and environmental factors that organizations should consider. Sustainable development emphasizes how today organizations can fulfill their needs without jeopardizing the needs of the future generations [3]. Concepts of social responsibility and sustainable development have been developed separately and social responsibility mainly focuses on social issues as human rights while sustainable development mainly focuses on environmental issues [4]. Nevertheless, in the recent management literature, those two concepts are being used together.

Even though the term "CSR" includes the word "corporate", CSR covers the issues related to both social and environmental matters. On the other hand, CSR practices cannot be considered distinct and even should be integrated to other organizational strategies or activities. Another important issue is that CSR practices are mainly based on the principle of volunteering. That is why those practices should be carried out by participation of relevant stakeholders. 
During recent years, there have been several factors that force or stimulate organizations concentrate on CSR and especially environmental applications [5]. Among those, laws and regulations turning CSR applications into mandatory implementations are considered the most important factors. Another important factor is possible negative financial consequences that might be faced by the organizations ignoring or not complying with social or environmental responsibilities.

Companies have realized the crucial importance of environment, started to adapt several strategies and changed their ways of doing business. From the environmental perspective, those companies involve the environmental issues as an important part of social responsibility. Especially when it comes to manage supply chains, it becomes also important to consider whether all suppliers and other companies in the chain implement CSR activities and practices. All companies including suppliers take responsibility to do no harm to the environment, to reduce waste and pollution, to control gas emissions, and to comply with governmental regulations whilst at the same time to reduce their cost and to increase their profit.

Increasing concerns about the environment stimulates governments and international organizations, such as European Union, European Commission, to promulgate new laws and regulations. Thus all actors, including suppliers and manufacturers, in the product life cycle take their own responsibilities on environmental issues. Furthermore, companies are obliged to meet the standards and criteria in force to stay competitive in the market and to keep their sustainable growth.

In addition to the environmental issues and regulatory concerns, social issues keep its crucial importance. Although CSR activities require a great amount of investment, companies need to integrate CSR concept to their processes for higher customer satisfaction and loyalty, better corporate image and reputation, higher productivity, lower costs and thus higher business profitability.

Changes in the behaviors of consumers whose awareness and sensitivity on social and environmental issues increase constitute another reason to implement CSR applications. Research has yielded that consumers prefer the products of companies that attach more importance to protecting environment and put emphasis on activities related to social responsibility [6]. Research has also revealed that reputation and positive image of companies that initiate CSR activities increase in front of society and enhanced reputation provides advantage to those companies.

As a result, no matter in which field companies operate, in order to stay in the competition, they should determine their CSR strategies and plan their relevant activities. Next section will explain the different CSR areas which are considered important for supply chains.

\section{Areas of social responsibility in supply chains}

Supply Chain Management is a process comprised of several distinct but interconnected functions and activities. Internal and external transportation management, warehousing, 
inventory management, acquisition management, logistics service providers management, resource management, packaging and assembly, customer services are among the most important ones. It is also possible to break down the supply chain management process into two main flows; i.e. forward flow and reverse flow. Taking into consideration those processes, main areas of social responsibility in supply chains are [7, 8]:

- Organizational practices

- Ethical practices

- Environmental practices

- Practices of human rights and working conditions

- Practices of occupational health and safety

- Practices to establish relationship with society

Table 1 summarizes activities and practices considered good examples for the CSR areas listed above.

\begin{tabular}{|c|c|}
\hline Relevant CSR Areas & Sample Practices \\
\hline Organizational Practices & $\begin{array}{l}\text { - Determining CSR goals for purchasing function } \\
\text { - Determining and defining roles and responsibilities of human resources related to } \\
\text { CSR in logistics } \\
\text { - Providing relevant training in CSR to the suppliers } \\
\text { - Sharing of CSR activities and practices with all relevant stakeholders } \\
\text { - Implementing a mechanism to receive feedback from stakeholders regarding CSR } \\
\text { practices }\end{array}$ \\
\hline Ethical Practices & $\begin{array}{l}\text { - Not accepting gifts, free services, etc. from suppliers (especially during supplier } \\
\text { selection process) } \\
\text { - Not creating illegitimate pressures on suppliers } \\
\text { - Not sharing price and service information about suppliers with other irrelevant } \\
\text { stakeholders } \\
\text { - Not favoring any particular supplier just because of managers' preferences and } \\
\text { assuring a fair selection process } \\
\text { - Assuring all departments meet ethical standards in independent purchasing } \\
\text { process } \\
\text { - Not creating illegitimate advantage in competition by using contract items } \\
\text { - Not giving out wrong information on purpose } \\
\text { - Not using specific items pointing out specific suppliers in contracts }\end{array}$ \\
\hline Environmental Practices & $\begin{array}{l}\text { - Purchasing and using recycled materials for packaging } \\
\text { - Supporting and encouraging suppliers on reducing waste (especially hazardous } \\
\text { waste) } \\
\text { - Putting special emphasis on producing recyclable and reversible materials in } \\
\text { production and design }\end{array}$ \\
\hline
\end{tabular}




\begin{tabular}{|c|c|}
\hline CSR Areas & Sample Practices \\
\hline & $\begin{array}{l}\text { - Meeting standards for protecting environment in the processes of lifecycle } \\
\text { management, production, packaging and storing } \\
\text { - Supporting suppliers to implement processes that are appropriate for sustainable } \\
\text { environmental protection }\end{array}$ \\
\hline $\begin{array}{l}\text { Practices of human rights and } \\
\text { working conditions }\end{array}$ & $\begin{array}{l}\text { - Not keeping some suppliers out of cycle, just because they have managers from } \\
\text { different backgrounds } \\
\text { - Having procedures and also having mechanisms to monitor providing equal } \\
\text { opportunity for each employee working in all supplier companies } \\
\text { - Having appropriate procedures in place to assure that all employees can benefit } \\
\text { from all their legal rights, are working in accordance with rules, regulations and } \\
\text { national/ international standards } \\
\text { - Assuring that physical and psychological working conditions comply with all rules } \\
\text { and regulations in place }\end{array}$ \\
\hline $\begin{array}{l}\text { Practices of occupational health } \\
\text { and safety }\end{array}$ & $\begin{array}{l}\text { - Having appropriate procedures in place to assure that working conditions do not } \\
\text { jeopardize human health and safety } \\
\text { - Assuring that all safety, security and protection measures are in place for all } \\
\text { activities } \\
\text { - Having procedures in place to assure that sensitive and delicate products are } \\
\text { stored under appropriate conditions }\end{array}$ \\
\hline $\begin{array}{l}\text { Practices to establish relationship } \\
\text { with society }\end{array}$ & $\begin{array}{l}\text { - Developing and carrying out programs for training and development of local } \\
\text { suppliers } \\
\text { - Actively participating into and organizing non-for-profit social activities, such as } \\
\text { volunteer work, charities, public auctions, etc. } \\
\text { - Supporting sport activities and public education }\end{array}$ \\
\hline
\end{tabular}

Table 1. Examples of CSR Applications in Supply Chain Management (Adapted from [8])

Among those aforementioned activities, ensuring that all activities and functions comply with national / international rules, regulations and standards and working with suppliers that fulfill same requirements constitute the most important factors for CSR in supply chains. This issue is also important to stay competitive in market and to have a sustainable growth in terms of strategic perspective.

\section{Green supply chain management}

In general terms, Green Supply Chain Management (GSCM) can be defined as reflecting a company's consideration and sensitivity about environmental issues to all other supply chain processes. GSCM also assures that companies consider not jeopardizing the environment in all supply chain functions.

Companies usually perceive the GSCM practices as factors that increase the cost in general. However, research has yielded that GSCM practices help companies to reduce general costs, 
increase productivity, foster innovation, save resources and increase competitive advantage [9]. Besides those tangible benefits, GSCM practices also play important roles in increasing employees' job satisfaction and commitment, promoting customer loyalty and pleasure, enhancing their reputation in the eyes of the society.

Main goal of GSCM is to assure that environmental practices are applied in the all phases of the process from procurement of raw material to the delivery to the consumer; such as purchasing, production, packaging, warehousing, distribution, assembly. Long-term goal of GSCM is to keep under control all the processes, reduce the chemical waste, lessen the gas emissions and eliminate all the activities that may be hazardous to the nature.

In the scope of GSCM, companies generally use three basic approaches [10]:

- Reactive approach

- Proactive approach

- Value seeking approach

Companies adapting reactive approach, usually apply procedures compliant with rules and regulations in force, such as practices of human rights, minimum resource usage, supply recycled products. Hence, reactive companies have a low level of GSCM.

On the other hand, companies adapting proactive approach, apply procedures to prevent possible problems that may arise in the future, instead of struggling with past problems. Thus, proactive companies develop programs and policies on how to implement and control green supply chain applications.

Companies adapting value seeking approach systematically integrate their environmental policies into their long-term business strategies, reflect those policies to their decisions and share this with all their stakeholders. Besides, they establish a close communication with their suppliers and stakeholders, and encourage them to integrate environmental policies to their own business processes.

From the systems management approach, GSCM constitutes of a series of interconnected, not independent, activities through a long process from the suppliers to the customers. Hence, GSCM should be applied on the whole process in a holistic manner. Thus, to achieve a successful GSCM, all activities and practices through the process should consider GSCM principles.

During the last decade, research on GSCM has focused on the stages of the product life cycle and emphasized the importance of greening approach in material selection and purchasing, company's supplier selection, waste management, packaging, manufacturing and production, regulatory compliance [11].

In addition, some other important issues in GSCM include selection of environmental performance criteria and indicators, relationship between environmental and economic performance. To measure achievement of GSCM, companies define success factors in accordance with their areas of activity [5]. Determining and measuring those success factors help companies to 
understand the effectiveness of environmental policies and indicate how well those policies are integrated into the business processes. In this framework, some success factors that can be used to measure the effectiveness of environmental policies are as follows:

- Amount of energy and raw material spent

- Amount of waste produced and exposed to the nature

- Amount of hazardous material used in the production process of goods and products

- Amount of fuel usage and gas emission in the production, storage and transportation

- Amount of recycled material through the processes

- Number of partnerships with suppliers on the area of environmental awareness

- Level of reputation of the company in terms of environmental sensitivity in front of the public eye

Companies adapting GSCM practices may evaluate the effectiveness of their activities and processes in terms of environmental issues and may alter their plans and strategies if necessary.

\section{Applications of social responsibility in the process of supply chains}

As aforementioned in detail, socially responsible applications and practices should be placed in all the phases and steps throughout the supply chain process from procurement of the raw materials to the delivery of products to the customer. In this respect, this section will give specific examples of socially responsible applications in each phase and function.

\subsection{Social and environmental practices in procurement and purchasing}

Social responsibility in procurement and purchasing can be defined as performing all purchasing activities in accordance with the CSR principles and taking into consideration CSR principles in the decision-making process [6]. If a company complies with the relevant standards on environmental issues and involves its applications in the processes, procurement and purchasing processes can be important activities to spread the CSR concept to the suppliers.

One of the first CSR practices that can be integrated into the procurement and purchasing is to prefer recycled and/or recyclable materials [12]. In addition to the purchasing of recyclable raw materials, giving precedence to the procurement of technologies that consume less energy and produce less waste is another important practice [13].

Besides, from a holistic perspective, choosing right suppliers that also apply CSR concepts in their own processes and also comply with relevant rules and regulations plays an important role in procurement process. In this respect, before initiating the procurement processes with suppliers, it should be verified that the suppliers also adapt CSR applications in their own processes as required. 


\subsection{Social and environmental practices in production}

Social responsibility in production process take place both in forward and reverse supply chain management activities. In general terms, CSR in production includes the design of the product taking into consideration CSR principles and the production without giving any damage or hazard to the environment [13].

Among the most important long-term goals in the environment-friendly production process, to implement the systematic mechanism reducing the amount of waste and to dispose the waste without giving any hazard to the nature are considered the key practices.

Another important goal of CSR in production is to assess each phases of the product life-cycle in order to determine the possibilities of re-production, re-usage and re-cycling of the materials used in the production process. If any possibility is determined, this should be integrated into the production processes for the benefit of society [5].

\subsection{Social and environmental practices in distribution and transportation}

Social responsibility in distribution and transportation means developing required transportation and distribution capability while maintaining and enhancing environmental, economic and social sustainability [8].

CSR in transportation has been conceptualized during 1990s and has focused on environmental and economic aspects of a sustainable transportation process [14]. Most important effects towards the environment include emission of greenhouse gas, emission of gas which is hazardous for the ozone layer, discharge of hazardous waste produced during transportation.

Socially responsible practices in transportation area include giving opportunities to local transportation companies, carefully monitoring that the traffic rules and regulations are followed all the time, implementing mechanisms increasing safety and security performance in transportation.

\subsection{Social and environmental practices in packaging}

For more than 20 years, there is already a pressure on the companies to lessen the negative effects of the packaging material on the environment. Laws and regulations that have been put in effect lately increase the importance of CSR in packaging function. Recently, influence of packaging process on the environment is considered in the framework of product life-cycle from a more holistic approach.

Under the CSR concept in packaging process, there are several activities to be considered, such as storage, warehousing, protection of the product against deterioration. Throughout those processes, CSR in packaging requires the usage of recycled and non-hazardous material, reduction of waste, reduction of energy consumption and design the process in such a way that does not harm the ecosystem [15].

In packaging, size of the package is a usually neglected but an important factor, since the size directly determines the amount of material used. By having well-designed packages, compa- 
nies may increase the efficiency in resource usage. In addition, small size of a package helps companies to formulate their loadings in the most optimum way and reduce their transportation costs.

\subsection{Social and environmental practices in warehousing}

Social responsibility in warehousing is a relatively new concept. CSR in warehousing starts with choosing the location of warehouses by taking into consideration all relevant environmental and social issues.

In addition, providing a healthy and safe storage for products is another important activity. Even more importantly, warehouses used to store hazardous material without threatening the environment constitute a vitally important issue in CSR. Offering spare or extra materials for the benefit of the society is also an activity considered under the CSR concept. Finally, as in the other supply chain functions, taking all safety precautions and safety measures for the workers' health and safety in warehousing is also an important activity [8].

\section{Reverse supply chain management}

In general terms, Reverse Supply Chain Management is defined as the series of activities or the process used to retrieve a used product from a consumer and either dispose of it or reuse it [16]. This concept also emphasizes activities in functions of transportation, warehousing, inventory management and collaboration with partners [17].

From a business viewpoint, although implementation and controlling the reverse supply chains require an important amount of investment, it brings economic and competitive advantage, as well as strategic importance to the companies adapting them. First of all, companies implementing reverse supply chains can reduce their costs by reducing the amount of raw materials, and reselling products after being scrapped $[18,19,20]$.

Reverse supply chain helps the company to generate its green image and enhance its reputation in front of the society. It also gives the company an opportunity to build stronger relationships with the customers.

Reverse supply chain management deals with all activities from the end-customer to the suppliers. According to Vogt et al. (2002), waste treatment activities include reverse distribution of products, return of unsold goods, product returns, product recalls and waste management [21]. Dyckhoff et al. (2004) prioritized the reverse supply chain activities as reuse of product, remanufacturing, recycling and disposal of goods [22].

A majority of reverse supply chains start with the activity of product acquisition from the customer [16]. During this phase, used products or materials are retrieved from the customer. Product commercial returns and recalls, acquisition of defective or damaged goods, waste stream are among the activities for product retrieval from the customer. Product acquisition is the most important phase for a profitable reverse supply chain [16]. 
Another important activity for reverse supply chains is inspection. Since customers return the sold products for several different reasons, inspection plays an important role before going further in the process. Inspection process include activities, such as disassembling, eyeinspection, testing, sorting and rating of the product $[16,20]$. Finally, to increase the value obtained from the returned product, most appropriate disposition alternative should be selected.

Prahinski and Kocabaşoğlu (2006) proposed four different product recovery strategies which are direct reuse, product upgrade, materials recovery and waste management [17]. Reconditioning is conducted if it is decided to reuse or upgrade the product. As the returned product is reconditioned, then the next phases of the process are re-distribution and re-sale of the product. Anderson and Brodin (2005) also emphasized the role of the customer in this whole process. Since the customer is the actor who uses and returns the product, he/she determines the quality and the current state and condition of the product [23].

Finally, reverse supply chain management is a holistic and integrated approach to managing waste and reduce the amount of hazardous material. In this respect, this process is very effective in CSR concept and is being adapted by a lot of companies.

\section{Discussion and conclusion}

Under the strong influence of increasing competition, globalization, communication and information technologies, companies trying to keep their positions in the market and to maintain a sustainable growth are increasingly inclined to apply corporate social responsibility activities and practices.

Corporate Social Responsibility (CSR) can be defined as companies' voluntary integration of social and environmental concerns in their business processes and in their relationships with other companies and stakeholders [8]. As companies successfully adapt social and environmental practices, they can achieve economic benefits by reducing costs, increasing productivity and profits, enhancing corporate image and reputation. However, for supply chains to be successful in terms of CSR, companies, including all suppliers and manufacturers in the chain, need to increase their own awareness and act in a socially and environmentally responsible manner. Moreover, they are obliged to comply with the environmental laws and regulations, to meet national and international standards and to integrate CSR practices in their business processes.

Supply chains are increasingly put under pressure mainly by customers and stakeholders to implement CSR management systems across the chain. All companies throughout the chain are obliged to implement practices and initiate activities on economic, environmental, and social aspects to maintain their sustainability. To transfer and share the CSR responsibility across the chain, companies adapt several practices, such as establishing written supplier requirements, monitoring supplier performance if they meet the requirements and contributing suppliers' awareness on social and environmental issues [8]. 
Since companies interact very closely and the success of the supply chain depends on the intercompany relationships throughout the chain, it becomes more and more important that all actors in the chain apply CSR principles in their own processes. Thus, collaboration on the CSR matters among the members of the chain is a crucial factor.

In their recent study, Seuring and Muller (2008) proposed four key factors to increase the success of CSR implementation across the supply chains, namely (1) Determining pressures and incentives for CSR applications across supply chains, (2) Identifying and measuring the impact of those applications, (3) Addressing and managing different issues at the supplierbuyer interface, and (4) Managing, implementing, and integrating CSR applications into all business processes of all actors, taking into consideration whole product life cycle [24].

In terms of forward supply chains, from the procurement of raw materials to the delivery of the product to the end-user, companies systematically integrate CSR principles to their business processes and functions, including purchasing, warehousing, storage, packaging, transportation and distribution. In addition, in terms of reverse supply chains, companies also integrate relevant practices from retrieving the product from the customer to the reusage, remanufacturing, recycling and disposal.

As a reflection of successful CSR applications across the supply chains, all companies enhance their reputations in front of the public. And thus, they should integrate social responsibility into their business strategies to assist their customer relationship management. Supply chain managers should adapt relevant CSR strategies to manage their supply chains in a more socially responsible manner to be able to foster their companies' relationship and interactions with the customers and all stakeholders. Adapting CSR focused management strategies will also help companies to develop future markets and customers. However, although the positive financial consequences of CSR applications are proposed in several studies, CSR introduces less quantifiable considerations relating to the natural environment and social issues.

As aforementioned in previous sections, trends towards integration of sustainability concepts into legislations and promulgation of relevant rules, regulations and standards by national and international organizations alter the nature of competition and the business environment in which supply chains operate. These changes force companies across the chains not only address and adapt new strategies, such as reverse supply chain practices, but also adapt their existing processes and procedures and generate new design, production, management and monitoring systems. These applications and modification will help companies to reduce the uncertainty in the business environment.

In this chapter, we try to summarize and present a framework in a holistic approach for addressing the issues, practices and activities for supply chains under the corporate social responsibility concept. We believe that the information presented here will help supply chain managers to better comprehend the importance of CSR applications and how they can implement those in their own areas of responsibility.

However, there is still a certain limitation about the practical uncertainty on the success of CSR applications across the supply chains in different business and cultural contexts. Thus, future research should specifically focus on empirical studies to further contribute on how social 
responsibility can be more effectively and efficiently integrated into the functions and the processes of the supply chains.

\section{Author details}

Eser Kayhan Tekin, Alper Ertürk* and Hakan Tozan

*Address all correspondence to: aerturk@dho.edu.tr

Turkish Naval Academy, Turkey

\section{References}

[1] Bowen, H.R. Social Responsibilities of the Businessman, New York: Harper \& Row; 1953.

[2] Carroll, A.B. A Three Dimensional Conceptual Model of Corporate Social Performance. Academy of Management Review 1979, 4(4), 497-505.

[3] Nemli, E. Sürdürülebilir Gelişme: Ekonomi ile Çevre Arasındaki Denge. Sunum, Kalder-Çevre Uzmanlık Grubu, İstanbul; 2005.

[4] Lehtonen, M. The Environmental Social Interface of Sustainable Development: Capabilities, Social Capital, Institutions. Ecological Economics 2004, 49(2), 199-214.

[5] Büyüközkan, G. \& Vardaloğlu, Z. Yeşil Tedarik Zinciri Yönetimi. Lojistik Dergisi 2008, 8, 66-73.

[6] Maignan, I., Hillebrand, B., \& McAlister, D. Managing Socially Responsible Buying: How to Integrate Non-Economic Criteria into Purchasing Process. European Management Journal 2002, 20(6), 641-648.

[7] Carter, C.R. \& Jennings, M.M. Logistics Social Responsibility: An Integrative Framework. Journal of Business Logistics 2002, 23(1), 145-180.

[8] Ciliberti, F., Pontrandolfo, P., \& Scozzi, B. Logistics Social Responsibility: Standart Adoption and Practices in Italian Companies. International Journal of Production Economics 2008, 113, 88-106.

[9] Van Hoek, R.I. From Reversed Logistics to Green Supply Chains. Supply Chain Management 1999, 4(3), 129-134.

[10] Kopicki, R., Berg, M.J., Legg, L., Dasappa V., \& Maggioni, C. Reuse and Recycling Reverse Logistics Opportunities. Council of Logistics Management, Oak Brooks, IL; 1993. 
[11] Srivastava, S.K. Green Supply Chain Management: A State-of-the-Art Literature Review. International Journal of Management Reviews 2007, 9(1), 53-80.

[12] Zhu, Q., Sarkis, J., \& Lai, K. Initiatives and Outcomes of Green Supply Chain Management Implementation by Chinese Manufacturers. Journal of Environmental Management 2007, 85, 179-189.

[13] Sarkis, J. A Strategic Framework for Green Supply Chain Management. Journal of Cleaner Production 2003, 11, 397-409.

[14] Feitelson, E. Introducing Environmental Equity Dimensions into the Sustainable Transport Discourse: Issues and Pitfalls. Transportation Research 2002, 7(2), 99-118.

[15] James, K., Fitzpatrick, L., Lewis, H., \& Sonneveld, K. Sustainable Packaging System Development. In: L.Filho (Ed.), Handbook of Sustainability Research, Frankfurt, Germany: Peter Lang Scientific Publishing; 2005.

[16] Guide, V. \& van Wassenhove, L. The Reverse Supply Chain. Harvard Business Review 2002, 80(2), 25-26.

[17] Prahinski, C. \& Kocabaşoğlu, C. Empirical Research Opportunities in Reverse Supply Chain. The International Journal of Management Science 2006, 34, 519-532.

[18] Erol, İ., Nurtanış Velioğlu, M., \& Sivrikaya Şerifoğlu, F. AB Uyum Yasalari ve Sürdürülebilir Kalkinma Bağlaminda Tersine Tedarik Zinciri Yönetimi: Türkiye'ye Yönelik Araştirma Firsatlari ve Önerileri. İktisat, İşletme ve Finans 2006, 21, 86-106.

[19] Erol, İ., Nurtanış Velioğlu, M., Sivrikaya Şerifoğlu, F., Büyüközkan, G., Aras, N., Demircan Çakar, N., \& Korugan, A. Exploring Reverse Supply Chain Management Practices in Turkey. Supply Chain Management: An International Journal 2010, 15(1), 43-54.

[20] Wei, Y. Reverse Supply Chain Management. Unpublished Masters Thesis, University of Gothenburg; 2011.

[21] Vogt, J., Pienaar, W., \& de Wit, P. Business Logistics Management: Theory and Practice. Oxford: Oxford University Press; 2002.

[22] Dyckhoff, H., Lackes, R., \& Reese, J. Supply Chain Management and Reverse Logistics. Springer; 2004.

[23] Anderson, H. \& Brodin, M.H. The Consumer's Changing Role: The Case of Recycling. Management of Environmental Quality: An International Journal 2005, 16, 77-86.

[24] Seuring, S. \& Muller, M. Core Issues in Sustainable Supply Chain Management: A Delphi Study. Business Strategy and the Environment 2008, 17, 455-466. 
Chapter 2

\title{
Quantifying the Supply Chain Resilience
}

\author{
A.P. Barroso, V.H. Machado, H. Carvalho and \\ V. Cruz Machado \\ Additional information is available at the end of the chapter \\ http://dx.doi.org/10.5772/59580
}

\section{Introduction}

In the current economic environment, increasingly global, there is the general awareness that companies are able to better compete if they act together, in supply chains, and thereby competitiveness can be increased [1]. Therefore, supply chains are becoming vital to the competitiveness of many companies and businesses.

The adoption of modern management paradigms, philosophies, strategies, policies and/or practices to improve effectiveness and reduce operating costs, such as lean manufacturing, Just-In-Time, strategic inventory, reduced product lifecycle and outsourcing, have created highly efficient supply chains. Although these new ways of managing have yielded attractive business benefits, they reduced the slack available to deal with uncertain events [2] and promoted the business globalization, increasing complexity of the extended networks, which amplifies the adverse impact of problems that can arise. In addition, the interconnection and interdependence among companies in a global supply chain makes them more vulnerable to a range of risks [3-6].

Supply chains are subjected to more risks than ever, which are numerous and constantly evolving, and derive both from within and outside of the company. Avoiding such risks or reducing their negative effects is a challenge for today management. Nevertheless, some risks cannot be avoided [2] and with today's complex global supply chains, fragmentary solutions and specific initiatives are no longer enough to cope with the multifaceted nature of risks.

One way to deal with supply chain risk is to increase confidence in the supply chain [7], i.e. confer to the supply chain the ability to be resilient. A resilient supply chain must develop resilience capabilities [8] to react to the negative consequences of unexpected events and to return quickly to its original state, the one before the risk occurrence, or to move to a new best state after being affected by the risk [9-11], and continue business operations as efficiently as 
possible. Increase resilience and reduce the likelihood of risk events occurring is the aim of supply chain risk management [12].

Although some recent studies highlighted the importance of quantifying the ability of companies and supply chains to overcome the negative effects of risks [13], the assessment of the supply chain resilience has not been attempted so far [2]. The main goal of this chapter is to fill this gap by proposing a quantitative index to measure the supply chain resilience to a risk based on the resilience index of its companies.

The chapter begins by defining and discussing central concepts in the scope of supply chain management, such as risk, sources of risk and supply chain risk. Since numerous risks that can occur and their characteristics and possible adverse effects to both company and supply chain, some strategies used to mitigate the negative effects of risk on a supply chain and make it more resilient are discussed. Then, the resilience index of a company to a risk is presented based on the concept of the resilience triangle. Finally, the resilience index of a supply chain to a risk is determined by aggregating the resilience index of companies that constitute the supply chain.

To illustrate how the proposed resilience index in both the individual company and the supply chain can be determined a case study is presented. The case study is the continuation of other case study developed in a previous work and is a real sub-set of companies which belong to a Portuguese automotive industry supply chain composed by one automaker, two 1st-tier suppliers, two 2nd-tier suppliers, and one outsource entity, structured in three-echelons [14]. The supply chain is disrupted due to a transportation interruption of material between two suppliers. To make resilient both the company and the supply chain, one strategy widely used to mitigate the negative effects of risk on supply chains based on the creation of redundancy is considered. Based on the results of the simulation of two scenarios developed in the previous work, the resilience indexes of companies and supply chain are determined. The two scenarios analysed consider the transportation interruption of material between two suppliers but in one scenario no strategy mitigation is adopted, whereas in the other scenario a strategy is adopted. In each scenario the resilience indexes of each company are determined based on the order fulfilment that is one of the important criteria to judge the level of the customer service of the company. This is the relative ability of the company to satisfy the customer. The fulfilment rate is a performance measure of the order fulfilment, expressed as a percentage of the total order. Finally, the resilience index of the supply chain is computed depending on the aggregation method implemented and then analysed.

The chapter proposes a tool that allows to quantifying the resilience of a company and a supply chain to a risk. The uncertainty of the future is usually modelled using scenarios [15]. So, by the comparison of scenarios, this proposal allows to help managers improving the decision making regarding the selection of mitigation strategies that promote greater supply chain resilience to a risk.

\section{Supply chain risk}

The body of literature on risks and supply chain risks has increased since events such as 9/11 and Hurricane Katrina. Additionally, the susceptibility of supply chains to risk is increased by 
globalisation and certain management initiatives such as the increased use of outsourcing, dependence on single suppliers, complexity and interdependency of supply base, increased competition and customers more demanding and with higher expectations, tendency toward increase regulation, and more unpredictable threats. Not all risk is negative if it provides a competitive advantage, but companies should be aware how much risk they can handle.

\subsection{Risk}

Supply chains are subjected to more risks than ever, which are numerous and constantly evolving, and derive both from within and outside of the company. They are also becoming more costly. Avoiding such risks or reducing their negative effects is a challenge for today management. Nevertheless, some risks cannot be avoided and with today's complex global supply chains, fragmentary solutions and specific initiatives are no longer enough to cope with the multifaceted nature of risks.

Multiple definitions of risk exist in the literature. Reference [16] consider risk "in line with common usage in the sense that it relates to supply chain vulnerability, as at risk: vulnerable; likely to be lost or damaged" and propose a classification in three classes: i) Internal to the organization, ii) External to the organization but internal to the supply chain, and iii) External to the supply chain. However, there are some definitions of risk, most of which related to its influence on business outcomes, as can be visualised in Table 1 .

\begin{tabular}{ll}
\hline Reference & Risk definition \\
\hline$[16]$ & $\begin{array}{l}\text { Risk is used in line with common usage in the sense that it relates to supply chain vulnerability, as at } \\
\text { risk: vulnerable; likely to be lost or damaged }\end{array}$ \\
\hline$[17]$ & $\begin{array}{l}\text { Risk is the negative deviation from the expected value of a certain performance measure, resulting in } \\
\text { undesirable consequences for the local company }\end{array}$ \\
\hline$[18]$ & $\begin{array}{l}\text { Risk is the expected outcome of an uncertainty event, i.e. uncertain events lead to the existence of } \\
\text { risks }\end{array}$ \\
\hline
\end{tabular}

Table 1. Some risk definitions

\subsection{Sources of risk}

There is a consensus that the sources of risk become more important as the complexity of modern supply chains increases. The adoption of more suitable actions for mitigating the negative effect of risks depends on the risk source. Knowing its source, it may be possible to act in order to avoid or reduce the probability of occurrence of the risk and consequently its negative effect on business outcomes. There are a high number of sources of risk that have the potential to adversely affect both revenue and cost, reducing the performance and competitiveness of the supply chain. Classification clarifies the relevant dimensions of potential sources of risk in supply chain. 
Based on literature review, two main categories of sources of supply chain risk are defined: i) external and ii) internal to the supply chain. Each of them is, in turn, segmented by some authors.

The external to the supply chain category encompasses the sources of risk arising from the environment in which the supply chain is involved. It includes, on one hand, aspects that influence demand at the level of the end customer and, on the other hand, events that, when they materialize, have a severe impact on the area of their occurrence. Examples of these are i) the natural catastrophes such as tsunamis, earthquakes, hurricanes, and floods [17]; ii) the human-made catastrophes which are acts, intentional or not, caused by humans such as computer viruses, destructive competitive acts, sabotage and terrorist attacks [19-21]; iii) the implementation of laws and policies affecting the supply chain, such as trade and transportation laws, as well as the degree and frequency of changes in these laws and policies [17, 22-23]; and iv) a significant increase in the product demand (volume) or an unforeseen change in the specifications of the product considered [24-25]. However, this category relates to events which are outside the sphere of influence of supply chain managers.

Sources of risk within supply chain can arise from within of each company's supply chain or from the interaction between them. However, regardless of the place of origin, sources of risk can be generated in: i) resources-human, financial, infrastructure, material, energy, and equipment-such as vandalism, sabotage, labour strikes, industrial accidents [26-27], loss of a supplier [28], information technology problems or breakdowns [26], breakdown in machinery, equipment malfunctions and systemic failures [29]; and ii) management processes which include all sources of risk resulting from the decision making at management process.

For a thorough review on supply chain risk and risk management literature we recommend $[5,30-33]$.

\section{Supply chain risk management}

As the goal of risk management is ultimately to mitigate negative influences and ensure the company's success [34], supply chain risk management aims to identify the potential sources of supply chain risk and implement appropriate actions or strategies through a coordinated approach among supply chain members, to avoid or reduce supply chain vulnerability [18, 35-36].

\subsection{Supply chain risk management process}

The supply chain risk management process entails a systematic application of management policies, procedures and practices in carrying out a sequence of activities of identifying, analysing, evaluating, treating, monitoring and communicating risk. It is an iterative process composed by four main activities, Risk Identification, Risk Assessment, Responding to Risk, and Monitoring and Review. This process can be used to provide the supply chain with some characteristics that make it more resilient to risk. 
After the Risk Identification activity the Risk Assessment activity is done, being critical in the supply chain risk management process. In this activity is performed the analysis and the evaluation of risk. In addition, is determined the degree of exposure of assessed risks, expressed as likelihood and impact, and also the risks are ranked. Having identified and assessed the relevant risks, management should determine how to respond (next activity in the process).

According to reference [12] the aim of supply chain risk management is to increase resilience and reduce the likelihood of risk events occurring, which is a different perspective of [18, 35-36]. Thus, the Responding to Risk activity of the supply chain risk management process should identify and analyse the actions that minimize the adverse effects of risk, i.e. those that allow mitigating the risk, and also select and implement the most appropriate regarding the resilience of the supply chain.

\subsection{Mitigation strategies to respond to risk}

Generally, risk responses can include risk avoidance, acceptance, transference and mitigation. When possible, risk avoidance option is appropriate if the risk has been evaluated as unacceptable or intolerable. Responding to risk can be made through risk mitigation, which requires specific strategies to reduce or even eliminate the risk likelihood, or the risk impact, or both. There is much literature that suggests strategies to deal with company and supply chain risks $[10,29,37-42]$.

There are many means available to control the negative effects in performance outcomes caused by risks within supply chains. A fundamental strategy would be to try to maintain supply chain performance measures of consistent fulfilment of orders, delivery reliability, and customer satisfaction.

Supply chain companies may also take a proactive or reactive strategy to respond to risk. A proactive strategy makes changes to its practices before the risk occurrence. Supply chain entities that adopt this approach are often trying to avoid a potential future threat or to capitalize on a potential future opportunity. When a supply chain entity makes changes in its practices only after the risk has already occurred, it reacts to a risk and a reactive change occurs.

Reference [43] describes two general approaches for dealing with risks: contingency and mitigation strategies. Contingency strategies are, in essence, more reactive in nature, whereas mitigation strategies are more proactive [41, 44-45]. Mitigation strategies imply taking actions before the risk occurs in order to reduce this event's occurrence or to reduce its impact. Therefore, the company or the supply chain incurs the cost of the mitigating action whether or not an unanticipated event or outcome occurs [29].Conversely, contingency strategies involve actions taken only after a disruptive event has happened. Reference [43] also highlights that more than one strategy can be used to manage risks.

Multiple potential sources of risk produce varying effects on a supply chain and complicate the selection of a risk mitigation strategy. There are eight risk mitigation strategies addressed by reference [26], which can be classified into either redundancy or flexibility strategies and utilized in practice [24, 43, 46-47]. Specifically, increase capacity, increase inventory and have 
redundant suppliers are redundancy strategies. Increase responsiveness, increase flexibility, aggregate demand, increase capacity and have more clients are flexibility strategies. Reference [26] developed a matrix that shows how each strategy acts in mitigation of the seven types of risks (these risks do not include systems risk and intellectual property risks). An analysis of the matrix proposed by these authors reveals that the implementation of some strategies mitigate some types of risk, but increase the likelihood of other types.

As the lack of redundancy makes companies vulnerable to changes in business environment, reference [48] posits redundancy as a good risk management strategy. However, some strategies based on redundancy can get very costly and supply chains should re-examine the trade-offs between efficiency and redundancy [16].

Reference [19] encourages companies to examine their risk levels and consider keeping strategic inventory reserves to protect against catastrophic events. Reference [5] provides a review of supply chain risk management and classifies strategies for supply chain robustness in two categories: those that increase the supply chains efficiency, and those that increase its resilience. Strategies which make the supply chain more efficient increase a facility's operational ability to handle a risk; business continuity planning within single sites tends to focus on this approach. Resilience, however, focuses on the ability of the company to sustain operation and recovery quickly in the face of a risk.

Reference [49] proposed similar strategies and expanded Tang's list to include expansion of capacity whereas reference [50] proposed risk insurance, information sharing, and relationship development.

\section{Supply chain resilience}

One way to deal with supply chain risk is to increase confidence in the supply chain, i.e. confer to the supply chain the ability to be resilient. Probably, in the long term, the key to supply chain remaining competitive is to be resilient. A resilient supply chain must develop resilience capabilities to react to the negative consequences of unexpected events and to return quickly to its original state, the one before the risk occurrence, or to move to a new best state after being affected by the risk, and continue business operations as efficiently as possible. Increase resilience and reduce the likelihood of risk events occurring is the aim of supply chain risk management [12].

The increase in the occurrence of risks that has been observed in the last few years at the global level, and the need for the supply chain to be ever more competitive, has created the need, on the part of managers, to take measures in order to make supply chains resilient to risk.

Supply chain resilience is receiving increased attention in the business, as well as in the academic press. There seems to be widespread recognition that supply chain risks have the potential to cause significant negative economic impacts $[38,51]$. So, resilience helps to recover system states after incidents take place rather than prevent incidents from occurring [52]. 
In a supply chain company context, resilience is defined as the ability of a supply chain entity to react to risk and return to its original state or a more desirable one [16, 53-54]. Multiple definitions of supply chain resilience exist in the literature and some of these are presented in Table 2.

\begin{tabular}{ll}
\hline Reference & Supply chain resilience definition \\
\hline [8] & $\begin{array}{l}\text { The capacity for complex industrial systems to survive, adapt, and grow in the face of turbulent } \\
\text { change. }\end{array}$ \\
\hline [16] & $\begin{array}{l}\text { The ability of a system (supply chain) to return to its original state or move to a new, more desirable } \\
\text { state after being disturbed. }\end{array}$ \\
\hline [53] & $\begin{array}{l}\text { The ability to react to the negative effects caused by disturbances that occur at a given moment in } \\
\text { order to maintain the supply chain's objectives. }\end{array}$ \\
\hline and recover from them by maintaining continuity of operations at the desired level of connectedness \\
and control over structure and function."
\end{tabular}

Table 2. Definitions of supply chain resilience

\subsection{Supply chain resilience assessment}

The question on "how to assess the supply chain resilience" still has no answer. Reference [58] specify some resilience properties: i) amount of change the system can undergo and still retain the same controls on function and structure; ii) degree to which the system is able of selforganization; and iii) ability to build and increase the capacity for learning and adapting. Reference [58] also argues that to understand the resilience of a system, it must be clearly defined - resilience of "what to what". It is vital to define what system state is being considered and what failure modes are involved.

\subsection{Resilience triangle}

Reference [20] outlined a graph that illustrates how risks would affect companies' performance which can be measured by sales, production levels, profits and customer service. Additionally, the graph shows different phases of the system's performance response: after a risk the performance decreases but as actions are taken the system's performance will gradually be 
restored. Reference [20] characterizes companies' response to risk in eight phases, including i) eventual preparation to risk, ii) disruptive event occurrence, iii) first response, iv) initial impact, v) full impact, vi) recovery preparation, vii) recovery and viii) long term impact. These phases can be observed plotting the company response to risk along the time as can be illustrated using the "resilience triangle" (Figure 1), which helps to visualize the magnitude of the risk negative impact on system (company or supply chain) performance. The concept of a "resilience triangle" emerges from disaster research and represents the loss of functionality from damage and risk [59]. Therefore, the company's performance evolution along the time can be used to analyse supply chain resilience.

References [59-60] highlight the relation between a disruptive event and business indicators. When deciding which supply chain performance should be analysed we consider the supply chain's objective, which is satisfying customers.

The depth of the triangle represents the disruption severity, i.e., the severity or magnitude of loss damage, and the length of the triangle represents the recovery time, i.e., the damping time. The smaller the triangle is, the more resilient the company or supply chain is. Therefore, the "resilience triangle" should be minimised. Actions, behaviours, and properties of companies and networks can contribute for reducing the area of the "resilience triangle" [59].

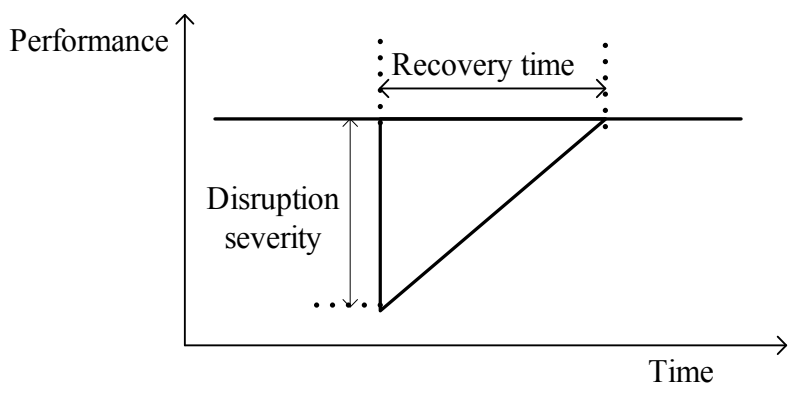

Figure 1. "Resilience triangle"

In this approach it is necessary to use proper performance measures which should be done according to the supply chain type. To analyse different scenarios in an automotive supply chain, the authors in prior simulation studies, see [14, 61], proposed the next performance measures: i) lead time ratio (average value of the ratio between the actual and the promised lead time for all the orders delivered by a company to its direct customers), ii) total cost (sum of production, material, holding inventory and transportation cost), and iii) fulfilment rate.

\subsection{Company resilience index}

In two simulation studies covering a three echelon of an automotive supply chain, the authors verified that when a supply chain is affected by a risk the performance of the supply chain companies is jeopardized [14,61]. Moreover, even when the risk affects only one company, its 
negative effects are propagated along the supply chain creating performance patterns analogous to the resilience triangle [59].

From a resilience perspective it is important to analyse the companies' behaviour in a specific time period, for example between $t 0$ and $t 1$, in which the performance was affected and also recovered, Figure 2. Out of this range the company performance is no affected by the risk negative effects. Therefore, the triangle area is proposed as a proxy to assess the individual companies' resilience.

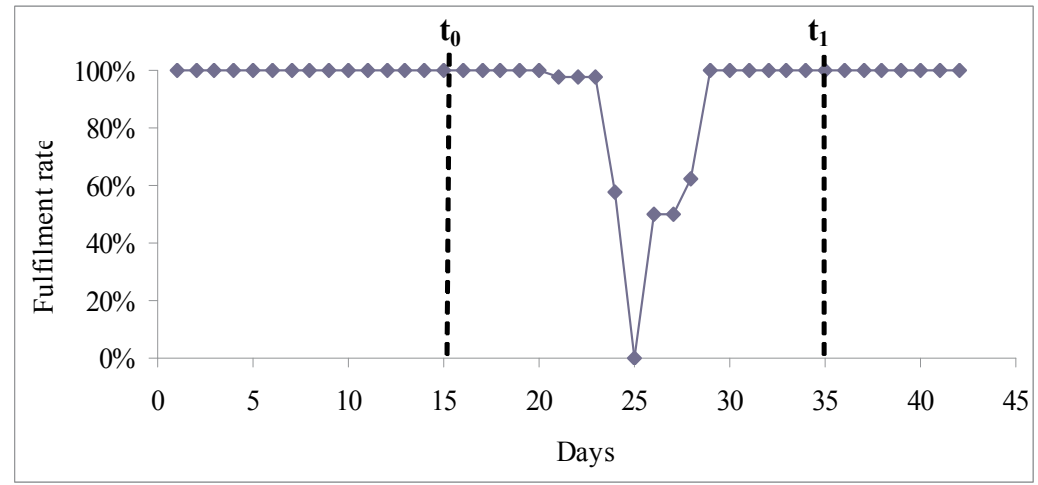

Figure 2. "Resilience triangle" pattern in simulation results (Adapted from reference [14])

Considering that company performance is measured at the end of each period $t$ (between $t_{0}$ and $\left.t_{1}\right)$, a curve is generated with the performance along time $\left(P_{i t}\right)$. If there are no risks, the performance level of each company $i$ is given by $P_{i}$. When a company is affected by the risk, a triangle pattern emerged showing the loss of company performance. However, some periods after the company performance recovers to the initial state $P_{i}$. To compute the triangle area a simple algorithm based on straight line approximations between the performance measure values for consecutive time periods is used [62]. The resilience index for a company $i$ is computed using Equation 1:

$$
R_{i}=1-\frac{\int_{t_{0}}^{t_{1}}\left(P_{i}-P_{i t}\right) \partial t}{P_{i}\left(t_{1}-t_{0}\right)} \cong 1-\frac{\sum_{t=t_{0}}^{t_{1}}\left(P_{i}-P_{i t}\right)}{P_{i}\left(t_{1}-t_{0}\right)}=1-\frac{\sum_{t=t_{0}}^{t_{1}}\left(1-P_{i t} / P_{i}\right)}{P_{i}\left(t_{1}-t_{0}\right)}
$$

where,

$R_{i}:$ is the resilience index of company $i$;

$P_{i}$ : is the performance level of company $i$ when it is not affected by the negative effects of a risk; 
$P_{i t}:$ is the performance level of company $i$ in time period $t$;

$t_{0}$ : is the lower limit of the time period based on which the company resilience index is determined; usually prior to the time instant at which the performance level is affected by the negative effects of the risk;

$t_{1}$ : is the upper limit of the time period based on which the company resilience index is determined; generally corresponds to a time instant at which the performance level is already recovered from the negative effects of the risk;

The resilience index of company $i\left(R_{i}\right)$ is from 0 to 1 . The value of $R_{i}$ equal to 0 means that company $i$ is no resilient to the disruption, i.e., performance $P_{i t}$ of company $i$ is null during the period of time from $t_{0}$ to $t_{1}$. The value of $R_{i}$ equal to 1 means that company $i$ is resilient to the disruption and is able to sustain its performance, i.e. performance $P_{i t}$ of company $i$ is equal to $P_{i}$ during the period of time from $t_{0}$ to $t_{1}$.

\subsection{Supply chain resilience index}

Since the supply chain is a network of companies, the assessment of supply chain resilience to risks needs to reflect the perspective of the network. In this line, reference [63] proposed a hierarchical index to measure companies' and supply chain level of greenness and resilience, considering that the overall supply chain behaviour is affected by the aggregation of the supply chain company behaviour. In this paper, the same hierarchical approach will be used; the intention is to develop an index to assess the overall supply chain resilience $\left(R_{S C}\right)$ based on the supply chain companies' resilience indexes.

Aggregation is always a potential area of methodological controversy in the field of composite index construction [64-65]. There are various linear methods for aggregation; the most common are additive, multiplicative and additive weighting [64-66]. However, for modelling the supply chain resilience based on a linear model is necessary to admit that there are no synergy and conflict effects among the supply chain companies' performance indicators [64], i.e. they should be independent [66-67]. Moreover, linear additive aggregation only can be applied when all indicators have the same measurement unit, and implies that poor performance in some indicators can be compensated by sufficiently high values of other indicators [64]. The multiplicative aggregation is appropriate when it entails partial (non-constant) compensability, i.e. compensability is lower when the composite indicator contains indicators with low values [64].

The right selection of the components of composite indexes and their weights are also critical for the aggregation process. Despite these concerns, reference [68] suggest that composite indexes should remain relatively simple in terms of their construction and interpretation. The choice of the most adequate aggregation method depends on the purpose of the composite indicator, as well as the nature of the subject being measured [69].

In literature there are few attempts to develop an overall supply chain resilience index. Reference [63] proposes an additive function of the individual companies' indexes for the supply chain resilience. According with reference [70] the reliability of a supply network is 
computed by multiplying the individual reliability of each company. To those authors the reliability can be used as a measure of the ability of a supply network to withstand disruption risks, which is a resilience property.

As we intend to propose an index for the overall supply chain resilience $\left(R_{S C}\right)$ based on the resilience indexes of individual companies, the subsequent four approaches are considered. Following the suggestion of reference [63], the additive model is used to compute the overall supply chain resilience index (Equation 2). The resilience of each company has equal importance in determining the supply chain resilience. In this approach the lower values of resilience indexes of some supply chain companies are compensated by the higher values of other companies.

$$
R_{S C}=\frac{1}{n} \times \sum_{i=1}^{n} R_{i}
$$

If a reliability perspective is considered, $R_{S C}$ should be computed by multiplying the resilience indexes of supply chain companies (Equation 3). This approach assumes that a company with a low resilience to risk implies low resilience of the supply chain in which it operates, i.e. if a company is vulnerable to a risk the supply chain will be vulnerable too. Thus, from the viewpoint of the supply chain, low resilience index value of a company promotes low resilience of the remaining companies, leading to low supply chain resilience index value.

$$
R_{S C}=\prod_{i=1}^{n} R_{i}
$$

A third approach to determine the $R_{S C}$ is considering a network perspective where the system resilience is function of the lower value of company resilience (Equation 4). This approach considers that the resilience of a supply chain is given by its weakest link. It does not take in consideration possible interactions among companies to improve the overall resilience.

$$
R_{S C}=\operatorname{Min}(R i)
$$

The overall resilience index can be also constructed considering a constraint approach. Companies of the supply chain that could interrupt the material flow to the customer are critical. In this approach only the sub-set of these critical companies (designated by $m$ ) is considered for calculating the resilience of supply chain (Equation 5). When one of these companies is not able to sustain its performance the whole supply chain fails.

$$
R_{S C}=\prod_{y=1}^{m} R y
$$




\section{Resilience index of an automotive supply chain: Case study}

To illustrate the application of the proposed resilience index in both the individual company and the supply chain, some results of the case study developed by [14] will be used. The case is based on a simulation study that will be briefly described below.

The simulation study developed by [14] was conducted within a Portuguese automotive supply chain characterized by a lean production environment. The pressures to reduce costs and lead time, as well as the globalization and trend in consumer demand for highly customized products, makes this type of supply chain extremely vulnerable to risks [71-72].

The supply chain under study, represented in Figure 3, incorporates six companies in three echelons:

- One automaker;

- Two 1st-tier suppliers: Supplier 1 and Supplier 3, and one outsource company: Supplier 2; and

- Two 2nd-tier suppliers: Supplier 4 and Supplier 5.

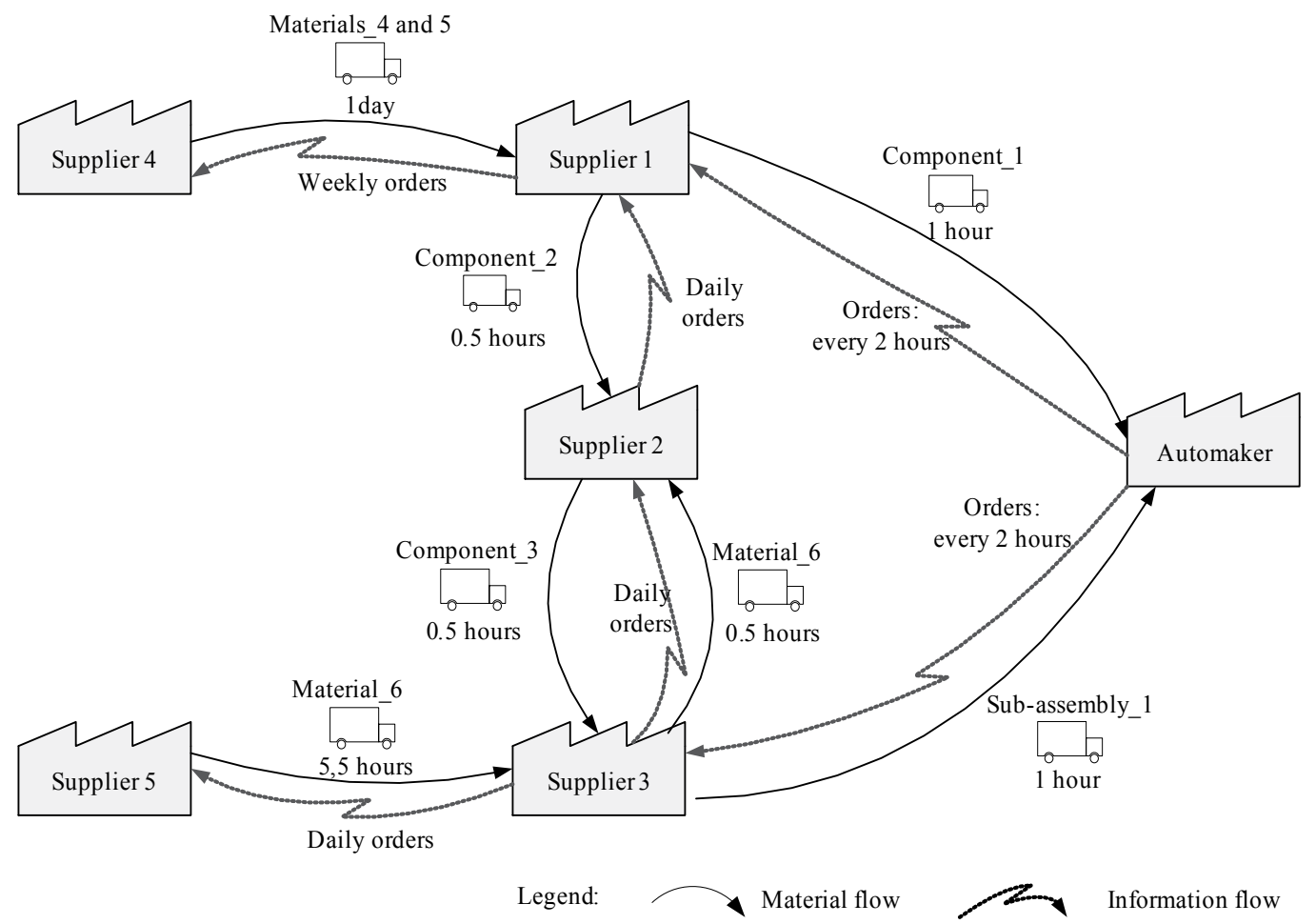

Figure 3. The automotive supply chain under study (Adapted from [14]) 
The automaker is the supply chain final customer and pulls the material from suppliers. Every two hours the automaker places an order of Sub-assembly_1 to Supplier 3 and an order of Component_1 to Supplier 1. If it is not possible to deliver the complete order, these suppliers supply the order partially. Due to lean production environment a risk occurrence, like a delivery failure, can cause the halts of the automaker production line, which represents a high cost to the supply chain. So, the supply of Component_1 and Sub-assembly_1 is critical.

To evaluate the performance of each supply chain company during a time period the fulfilment rate is used (Equation 6). The fulfilment rate of a supplier $i$ in a time period $t$ is defined by the ratio between the number of units delivered on-time from suppliers to their 1st-tier customers and the total number of units ordered by 1st-tier customers.

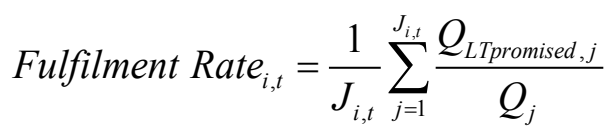

where,

$J_{i, t}:$ is the total number of orders placed by 1st-tier customers to supplier $i$ during time period $t$; $Q_{j}$ : is the number of units of the order $j$;

$Q_{L T \text { promised }, j}$ is the number of units of the order $j$ delivered in the promised lead time LT;

$t$ : is the analysed time period.

In the study of [14] is considered the disruption in the transportation of Material_6 from Supplier 5 to Supplier 3. As Supplier 3 has inventory to satisfy Material_6 demand for only three days and there are no alternative suppliers for this material, the interruption of the flow of Material_6 between Supplier 5 and Supplier 3 occurs. So, the supply chain is highly vulnerable to this particular risk.

To analyse the effects of the disruption occurrence on each company and also on the overall supply chain performance, reference [14] designed four scenarios. The base case scenario (scenario 1) corresponding to the representation of the current supply chain (without disruption occurrence). Scenario 2 corresponds to the same supply chain nevertheless affected by the disruption. Scenarios 3 and 4 were designed from scenario 2, based on the implementation of redundancy and flexibility strategies, respectively.

\subsection{Scenarios to analyse}

The objective of this chapter is to measure the resilience of the supply chain to a risk based on the company's resilience index proposed. With this goal the daily fulfilment rates of the different supply chain company resulted from scenarios 2 and 4 of reference [14] are used. In scenario 2 the current supply chain is affected by a transportation disruption in day 15, which causes an interruption in the flow of Material_6 from Supplier 5 to Supplier 3 during seven days. In Scenario 4 the effects of a mitigation strategy, based on redundancy, on resilience of 
the supply chain are analysed. The redundancy strategy is defined by increasing from 3 to 7 days the inventory level of Material_6 in Supplier 2. The two scenarios have the same input values, such as demand patterns, bill of materials, inventory data, resource data, transportation time and cost data, and contemplate the occurrence of the same disruption.

The interruption of the material flow between two supply chain companies, not always all the companies are affected the same way by its negative effects. In scenario 2 the performance of Supplier 1 and Supplier 4 is not affected by the transportation disruption, as the two suppliers are able to sustain the performance level even when the others lost performance after the disruption occurrence. So, Figure 4 shows only the fulfilment rate simulation results of scenario 2 , for the supply chain companies which are affected by the disruption occurrence (Suppliers 2,3 and 5).

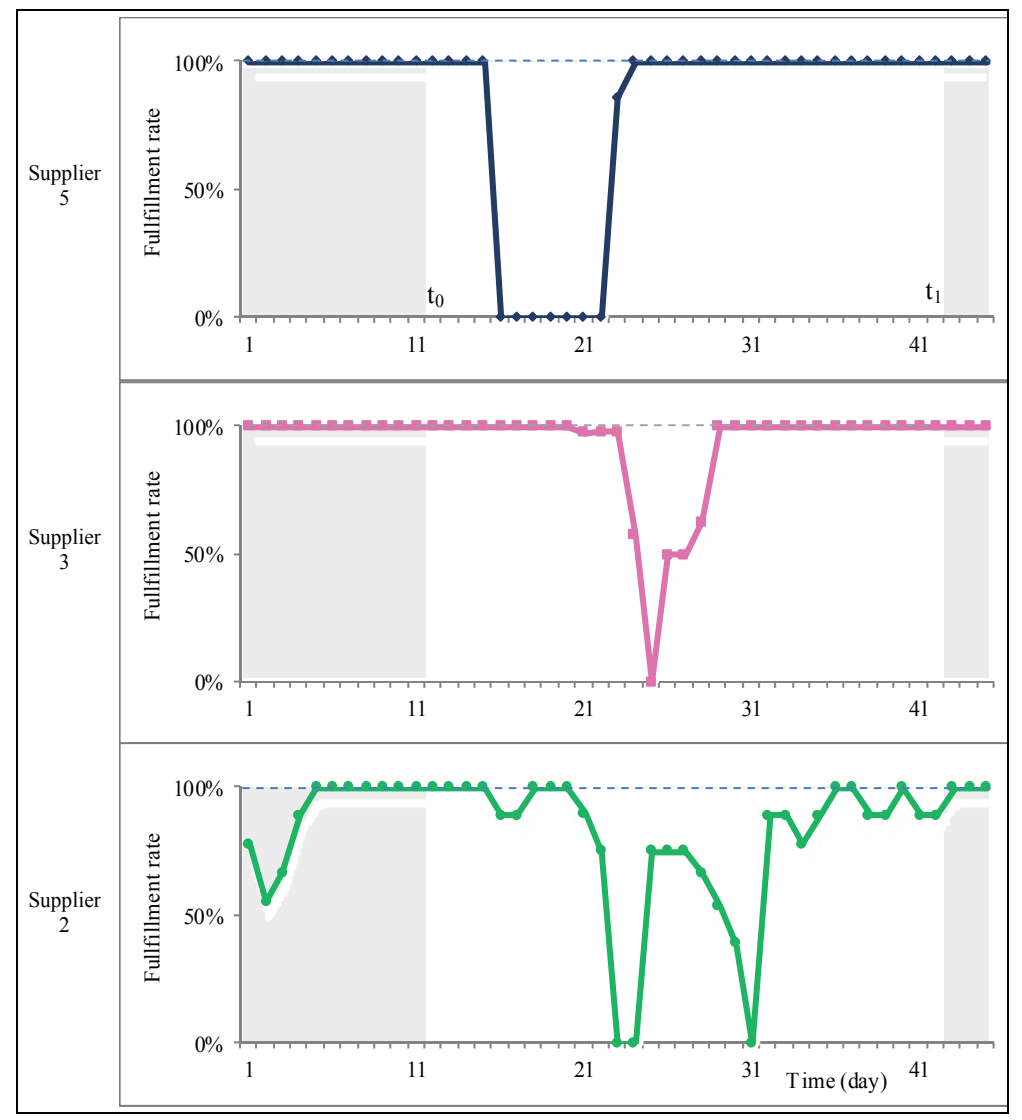

Figure 4. Fulfilment rate results for some supply chain companies of scenario 2

From the analysis of Figure 4 it is possible to verify that the supply disruption of Material_6 affects the performance of supply chain companies in cascade; firstly Supplier 5, and then Suppliers 3 and 2. 
The fulfilment rate results, Figure 4, show clearly the inability of Supplier 5 to delivery Material_6 on-time to Supplier 3. During the period that the disruption is active, from day 16 to day 22, Supplier 5 fulfilment rate decreases abruptly to zero, since it is impossible to deliver the Material_6 to Supplier 3. When the risk fades away Supplier 5 is able to recover to the initial state, delivering all the late orders at once and, consequently, increasing the fulfilment rate.

To sustain the supply of Sub-assembly_1 to the Automaker, Supplier 3 uses its safety stock of Material_6 to overcome the delivery failure of Supplier 5; the safety stock of Material_6 in the Supplier 3 is defined by the quantity which allows meeting demand for three days. Therefore, after three days without deliveries of Material_6 from Supplier 5, the Supplier 3 has a shortage of Material_6 and fails to satisfy the Automaker. When the risk fades away Supplier 3 is unable to delivery all the late orders at once. It requires four days to restore its normal behaviour.

Supplier 2 also uses its safety stock to maintain its production, but after three days without deliveries from Supplier 3 the materials have all been used and it cannot fulfil the customer's orders (Supplier 1 and Supplier 3). The low performance of downstream companies of Supplier 2 affects Supplier 2's performance due to not being able to cope with the material shortage. The fulfilment rate of the supply chain upstream companies affects fulfilment rate of Supplier 2, since it is not able to cope with the material shortage. In the time period under analysis the Supplier 2 suffers two waves of material shortage, the first one caused by the disruption occurrence, and the second one when Supplier 3 delivers the first order after the disruption, since Supplier 2 uses all the recently delivered material to produce the late orders, leading to another stockout situation. As shown in Figure 4, Supplier 2 has daily fluctuations due to the daily uncertainties.

Considering the fulfilment rate performance measure and a time window of 30 days (between $t_{0}=12$ and $t_{1}=42$, Figure 4 ) the supply chain company resilience index is computed for each scenario using Equation 1.

Afterward, supply chain companies' resilience indexes for scenarios 2 and 4 are analysed.

\subsection{Companies' resilience indexes for scenario 2}

In scenario 2 Supplier 5 is enable to deliver on-time Material_6 to Supplier 3, between days 16 and 22 (Figure 4), consequently, it fulfilment rate decreases abruptly to zero in that time period, Table 3. As Supplier 5's performance behaviour based on fulfilment rate drops, it means that it is not able to mitigate the overall disruption negative effects.

\begin{tabular}{lccccccccccccc}
\hline Period & $\ldots$ & 12 & 13 & 14 & 15 & 16 & $\ldots$ & 22 & 23 & 24 & 25 & $\ldots$ & 42 \\
\hline Fulfilment rate & $\ldots$ & 1.00 & 1.00 & 1.00 & 1.00 & 0.00 & 0.00 & 0.00 & 0.86 & 1.00 & 1.00 & 1.00 & 1.00 \\
\hline
\end{tabular}

Table 3. Supplier 5 fulfilment rate and respective resilience index for scenario 2 
Being $P_{i}$ the performance level of company $i$ when it is not affected by the disruption negative effects, $P_{i t}$ the performance level of company $i$ in time period $t$, and using Equation 1, the resilience index of each supply chain company is determined, Table 4.

Considering Supplier 5, and it fulfilment rate performance measure during a time window of 30 days, a resilience index of 0.76 is obtained, Table 4 , which translates the level of resilience of Supplier 5 to the disruption.

\begin{tabular}{llllll}
\hline Supply chain company & Supplier 1 & Supplier 2 & Supplier 3 & Supplier 4 & Supplier 5 \\
\hline Resilience index & 1.00 & 0.78 & 0.90 & 1.00 & 0.76 \\
\hline
\end{tabular}

Table 4. Supply chain companies' resilience index for scenario 2

After the disruption Supplier 3 is able to deliver all the late orders at once, increasing the fulfilment rate to the maximum value. However, Supplier 3's performance is negatively affected by the disruption and, consequently, its resilience index is equal to 0.90 . Due to daily fluctuations, resulting from the daily uncertainties, and the behaviour provoked by the transportation disruption Supplier 2 has a low resilience index, 0.78. Not all supply chain companies are affected by the disruption. Supplier 1 and Supplier 4 maintain their normal behaviour, being maximum their resilience index.

Clearly, when there are no mitigation strategy implemented (scenario 2) by supply chain companies and the transportation disruption occurs Supplier 5 is the less resilient supply chain company (the one that is directly affected by the disruption), followed, respectively, by Supplier 2 and Supplier 3, the ones that have greater dependencies of Supplier 5 regarding the supply.

\subsection{Companies' resilience indexes for scenario 4}

To analyse the effects of the transportation disruption on each supply chain company and on the overall supply chain performance an alternative scenario is considered (scenario 4). Scenario 4 is designed based on scenario 2 and the implementation of a strategy based on redundancy in Supplier 2, corresponding to Supplier 3 demand of Component_3 (that results of the transformation of Material_6 in the Supplier 2) for seven days. When the transportation disruption occurs, the strategy based on redundancy is effective in overcoming the negative disruption effects although Suppliers 5 and 2 continue to be affected their normal behaviour due the disruption effects (Figure 5). So, although the strategy reduces the negative effects of the disruption it continues to propagate its effects along the supply chain. These results are in line with the ones obtained by reference [24] which state also that redundancies can promote inefficiencies in the supply chain.

The resilient index of each supply chain company for each scenario is according to the ability of each company to respond to the transportation disruption (Table 5). With the implementation of redundancy strategy (scenario 4) all supply chain companies increased it resilient index. 


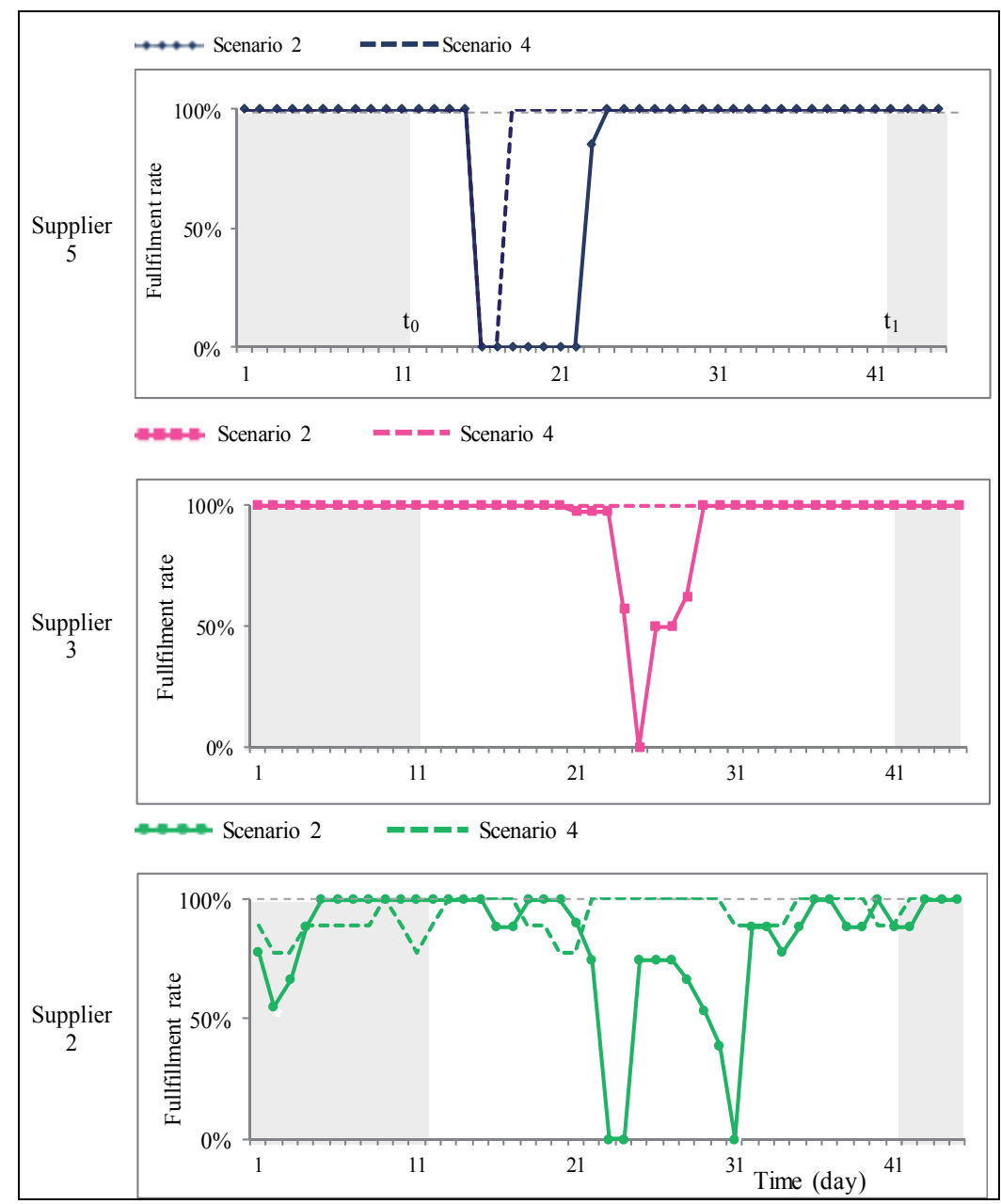

Figure 5. Fulfilment rate results comparison of scenarios 2 and 4

In scenario 4 the resilience index of Supplier 5 increased from 0.73 to 0.93 and the resilience index of Supplier 2 increased from 0.78 to 0.96 (not being the maximum value due to its dayto-day uncertainties). It was maximum the resilience index of the other supply chain companies.

\begin{tabular}{llllll}
\hline Supply chain company & Supplier 1 & Supplier 2 & Supplier 3 & Supplier 4 & Supplier 5 \\
\hline Scenario 2 & 1.00 & 0.78 & 0.90 & 1.00 & 0.76 \\
\hline Scenario 4 & 1.00 & 0.96 & 1.00 & 1.00 & 0.93 \\
\hline
\end{tabular}

Table 5. Supply chain companies' resilience index for scenarios 2 and 4 


\subsection{Supply chain resilience indexes}

The supply chain resilience index can be computed based on the supply chain company indexes using different methods of company indexes aggregation such as proposed in Equations $2-4$. The supply chain resilience index for both each scenario and each aggregation procedure is presented in Table 6.

\begin{tabular}{lll}
\hline Aggregation procedure & Scenario 2 & Scenario 4 \\
\hline Additive method & 0.89 & 0.98 \\
\hline Multiplicative method & 0.53 & 0.89 \\
\hline Network perspective & 0.76 & 0.93 \\
\hline Constraint approach & 0.90 & 1.00 \\
\hline
\end{tabular}

Table 6. Supply chain resilience indexes by scenario and aggregation procedure

Regardless the aggregation method used to determine the supply chain resilience index, from Table 6 it can be verified that:

- When the disruption occurs and there are no resilient strategies available to avoid and/or overcome the negative effects caused by it (scenario 2) supply chain companies lose performance, therefore, the supply chain resilience index is low;

- The implementation of a strategy based on redundancy (scenario 4) allows achieving high values for supply chain resilience indexes supporting the development of resilience in supply chain to the disruption.

From the resilience indexes computed for the case study we note that:

- Different scenarios result in different resilience indexes for each supply chain company;

- Different scenarios result in different supply chain resilience indexes for the same aggregation method of supply chain company resilience indexes;

- Different aggregation methods of supply chain company resilience indexes result in different supply chain resilience indexes for the same scenario;

- Supply chain resilience indexes are higher for the scenario where is applied a strategy to mitigate the disruption negative effects.

\section{Conclusions}

Supply chain risks are increasing in number and frequency, affecting the normal operation and stability of the supply chain and hence the ability of supply chains to fulfil commitments. Therefore, supply chains must be resilient to risks to overcome their vulnerabilities and to react effectively to its negative effects. 
The resilience of a supply chain company to risks may be obtained by reducing the probability of occurrence of the disturbance and/or reducing its negative effects on the supply chain entity. Thus, managers must take measures in order to mitigate the potentially negative effects of risks, whether on the directly affected company, or on other supply chain companies that may be affected, due to the relationship of dependency between supply chain companies. So, the strategies adopted should mitigate the negative impact of determined risks, the ones that have high negative impact and likelihood. However, it is not possible to implement strategies to mitigate any negative effects of risks because the supply chain becomes inefficient. Thus, the strategies adopted should mitigate the negative impact of specific risks, for example, the ones that have high negative impact and the ones that have high probability of occurring. Therefore, to adopt the most suitable mitigation strategies, whether proactive or reactive, it is necessary to identify in advance the risks that can potentially occur and to estimate their potential negative effect(s). Subsequently, it is essential to identify not only the risks that may affect a supply chain, and thus their companies, but the risk sources as well.

It is common sense that is need to measure for improving. To develop suitable supply chain strategies to mitigate risks it is crucial to assess the supply chain resilience to risks. To measure the resilience of a supply chain to a risk based on the company's resilience index, two resilience indexes are proposed, the company resilience index and the supply chain resilience index. The company resilience index is determined based on a performance indicator measured during a time period that entails both the risk occurrence and the recovering from the risk. The resilience index of a supply chain is determined by aggregating its company's resilience index.

Considering that the overall supply chain performance behaviour is affected by the supply chain company performance behaviour, the supply chain resilience should be measure based on the companies' resilience index. In this paper a supply chain resilience index is proposed which follows a hierarchical approach based on the aggregation of supply chain companies' resilience index. As the aggregation is a potential area of methodological controversy in the field of index construction, in this chapter four approaches are proposed.

The resilience index of a supply chain company is determined based on the concept of the resilience triangle. Generally, a key performance measure associated to the customer service level worsens due to the negative effect of the risk and needs some periods of time to recover the value it had before the risk materializes. The behaviour of the key performance measure over time depicts a triangle which area represents the loss of supply chain company performance, i.e. the negative effects of the risk. To achieve the supply chain resilience index the companies' resilience indexes of the supply chain are aggregated using an additive model, a multiplicative model, a network perspective and a constraint approach.

To test and operationalize the supply chain resilience index, the results of a supply chain case study developed previously are used. The case study is related to the Portuguese automotive upstream supply chain in which four scenarios were simulated, the transportation disruption between two companies was considered, and a mitigation strategy based on redundancy was implemented. Scenario 2 corresponds to the current supply chain case study with disruption occurrence. Scenario 4 corresponds to the current supply chain case study with the disruption occurrence under the mitigation strategy. The results of the simulation study allowed to 
obtaining the supply chain companies' fulfilment rate along time for each supply chain company and each scenario.

For every company and every scenario, the proposed resilience index based on the company fulfilment rate is computed and its value allows capturing the resilience of company to the disruption considered.

Generally, in the presence of the disruption is expectable that most companies' resilience index are higher when resilience strategies are implemented (case of scenario 4) showing the company's ability to reduce the negative effects of risk. As the scenario 4 shows, implementing a mitigation strategy only one company suffers the negative effects of disruption and only for a short period of time. The companies which depend on it have not been greatly affected by this behaviour.

When a resilience strategy is deployed the supply chain resilience indexes are higher reflecting the system ability in reducing the risk negative effects.

The resilience indexes proposed in this chapter offer a holistic perspective on the supply chain resilience improvement which the decision makers could consider the implementation of mitigation strategies. The resilience indexes also provides managers with a way to assess the resilience of different supply chain redesign scenarios, to improving the decision making process. Moreover, it gives them a dash-board to identify improvement opportunities within the company as well as with their supply chain partners.

There are a number of issues that arise when attempting to create supply chain indexes such as subjectivity, bias, weighting, mathematical combinations, selection of key performance indicators, and source of the data. Future research should focus on these issues and may be carried out to test the proposed index using in-depth longitudinal case studies. It is also necessary a deep study on how to combine the various key performance measures into a supply chain company resilience index.

\section{Acknowledgements}

This research is funded by Fundação para a Ciência e Tecnologia (PEst-OE/EME/UI0667/2014).

\section{Author details}

A.P. Barroso*, V.H. Machado, H. Carvalho and V. Cruz Machado

*Address all correspondence to: apb@fct.unl.pt

UNIDEMI, Departamento de Engenharia Mecânica e Industrial, Faculdade de Ciências e Tecnologia, FCT, Universidade Nova de Lisboa, Caparica, Portugal 


\section{References}

[1] Min H, Zhou G. Supply Chain Modeling: Past, Present and Future. Computers \& Industrial Engineering 2002;43 231-249.

[2] Soni U, Jain V, Kumar S. Measuring Supply Chain Resilience Using a Deterministic Modeling Approach. Computers \& Industrial Engineering 2014;74 11-25.

[3] Christopher M, Towill DR. Supply Chain Migration from Lean and Functional to Agile and Customized. Supply Chain Management 2000;5 206-213.

[4] Norrman A, Jansson U. Ericsson's Proactive Supply Chain Risk Management Approach after a Serious Sub-Supplier Accident. International Journal of Physical Distribution \& Logistics Management 2004;34 434-456.

[5] Tang CS. Robust Strategies for Mitigating Supply Chain Disruptions. International Journal of Logistics Research and Applications: A Leading Journal of Supply Chain Management 2006;9(1) 33-45.

[6] Golgeci I, Ponomarov SY. Does Firm Innovativeness Enable Effective Responses to Supply Chain Disruptions? An Empirical Study. Supply Chain Management: An International Journal 2013;18 No 6, pp. 604-617.

[7] Christopher M, Lee H. Mitigating Supply Chain Risk through Improved Confidence. International Journal of Physical Distribution \& Logistics Management 2004;34(5) 388-396.

[8] Pettit TJ, Fiksel TJJ, Croxton KL. Ensuring Supply Chain Resilience: Development of a Conceptual Framework. Journal of Business Logistics 2010;31 1-21.

[9] Peck H. Drivers of Supply Chain Vulnerability: An Integrated Framework. International Journal of Physical Distribution \& Logistics Management 2005;35 210-232.

[10] Ji G, Zhu C. Study on Supply Chain Disruption Risk Management Strategies and Model: proceedings of the 5th International Conference Service Systems and Service Management-Exploring Service Dynamics with Science and Innovative Technology, ICSSSM'08, 30 June-2 July 2008, Melbourne.

[11] Carvalho H, Maleki, M, Cruz-Machado V. Links between Supply Chain Disturbances and Resilience Strategies. International Journal of Agile Systems and Management 2012;5 203-234.

[12] Pujawan IN, Laudine HG. House of Risk: a Model for Proactive Supply Chain Risk Management. Business Process Management Journal 2009;15(6) 953-967.

[13] Schmitt AJ, Singh M. A Quantitative Analysis of Disruption Risk in a Multi-Echelon Supply Chain. International Journal of Production Economics 2012;139 22-32.

[14] Carvalho H, Barroso AP, Machado VH, Azevedo SG, Cruz-Machado V. Supply Chain Resilience: A Simulation Study: proceedings of the International Conference 
on Instrumentation, Measurement, Circuits and Systems, ICIMCS2011, 12-13 Dec 2011, Hong Kong, 1015-1020.

[15] Peterson GD, Cumming GS, Carpenten SR. Scenario Planning: a Tool for Conservation in an Uncertain World. Conservation Biology, 2003;17(2) 358-366.

[16] Christopher M, Peck H. Building the Resilient Supply Chain. The International Journal of Logistics Management. 2004;15 1-14.

[17] Wagner SM, Bode C. An Empirical Examination of Supply Chain Performance along Several Dimensions of Risk. Journal of Business Logistics 2008;29(29) 307-325.

[18] Manuj I, Mentzer JT. Global Supply Chain Risk Management Strategies. International Journal of Physical Distribution and Logistics Management, 2008;38(3) 192-223.

[19] Sheffi Y. Supply Chain Management under the Threat of International Terrorism. The International Journal of Logistics Management, 2001;12 1-11.

[20] Sheffi Y. The Resilient Enterprise - Overcoming Vulnerability for Competitive Advantage. The MIT Press; 2006.

[21] Faisal MN, Banwet DK, Shankar R. Supply Chain Risk Mitigation: Modeling the Enablers. Business Process Management Journal, 2006;12 (4) 535-552.

[22] Kleindorfer PR, van Wassenhove LN. Managing Risk in Global Supply Chains. In: Gatignon H, Kimberly JR, Gunther RE. (ed.) The INSEAD-Wharton Alliance on Globalizing. Cambridge: Cambridge University Press; 2004. 288-305.

[23] Cavinato JL. Supply Chain Logistics Risks - From the Back Room to the Board Room. International Journal of Physical Distribution and Logistics Management 2004;34 (5) 383-387.

[24] Tang CS, Tomlin B. The Power of Flexibility for Mitigating Supply Chain Risks. International Journal of Production Economics 2008;116 12-27.

[25] Melnyk SA, Rodrigues A, Ragatz G. Using Simulation to Investigate Supply Chain Disruptions. Supply Chain Risk. In: Zsidisin GA, Ritchie B. (ed.) A Handbook of Assessment, Management, and Performance. United Kingdom: Lightning Source UK Ltd.; 2009. 103-122.

[26] Chopra S, Sodhi MS. Managing Risk to avoid Supply-Chain Breakdown. MIT Sloan Management Review 200;446(1) 53-61.

[27] Spekman RE, Davis EW. Risky Business: Expanding the Discussion on Risk and the Extended Enterprise. International Journal of Physical Distribution and Logistics Management 2004;34 (5) 414-433.

[28] Giunipero L, Eltantawy RA. Securing the Upstream Supply Chain: A Risk Management Approach. International Journal of Physical Distribution and Logistics Management 2004;34 (9) 698-713. 
[29] Kleindorfer PR, Saad GH. Managing Disruption Risks in Supply Chains. Production and Operations Management 2005;14 (1) 53-68.

[30] Tang CS. Perspectives in Supply Chain Risk Management. International Journal of Production Economics 2006;103 451-488.

[31] Zsidisin GA, Ritchie B. Supply Chain Risk: A Handbook of Assessment, Management and Performance. New York, NY: Springer; 2008.

[32] Tang O, Musa SN. Identifying Risk Issues and Research Advancements in Supply Chain Risk Management. International Journal of Production Economics 2011;133 25-34.

[33] Sodhi MS, Son BG, Tang CS. Researchers' Perspectives on Supply Chain Risk Management. Production and Operations Management 2012;21(1) 1-13.

[34] Diehl D, Spinler S. Defining a Common Ground for Supply Chain Risk Management - a Case Study in the Fast-Moving Consumer Goods Industry. International Journal of Logistics: Research and Applications 2013;16(4) 311-327.

[35] Jüttner U, Peck H, Christopher M. Supply Chain Risk Management: Outlining an Agenda for Future Research. International Journal of Logistics Research and Applications 2003;6(4) 197-210.

[36] Jüttner U. Supply Chain Risk Management-Understanding the Business Requirements from a Practitioner Perspective. The International Journal of Logistics Management 2005;16(1) 120-141.

[37] Norrman A, Jansson U. Ericsson's Proactive Supply Chain Risk Management Approach after a Serious Sub-Supplier Accident. International Journal of Physical Distribution and Logistics Management 2004;34(5) 434-456.

[38] Hendricks K, Singhal V. An Empirical Analysis of the Effect of Supply Chain Disruptions on Long-Run Stock Price Performance and Equity Risk of the Firm. Production and Operations Management. 2005;14(1) 35-52.

[39] Hillman M. Strategies for Managing Supply Chain Risk. Supply Chain Management Review 2006;10(5) 11-13.

[40] Pickett CB. Prepare for Supply Chain Disruptions Before they Hit. Logistics Today 2006;47(6) 22-25.

[41] Stecke KE, Kumar S. Sources of Supply Chain Disruptions, Factors that Breed Vulnerability, and Mitigating Strategies. Journal of Marketing Channels 2008;16(3) 193226.

[42] Kull T. The Risk of Second-Tier Supplier Failures in Serial Supply Chains: Implications for Order Policies and Distributor Autonomy. European Journal of Operational Research 2008;186(3) 1158-117. 
[43] Tomlin B. On the Value of Mitigation and Contingency Strategies for Managing Supply Chain Disruption Risks. Management Science 2006;52(5) 639-657.

[44] Craighead CW, Blackhurst J, Rungtusanatham, MJ, Handfield, RB. The Severity of Supply Chain Disruptions: Design Characteristics and Mitigation Capabilities. Decision Sciences 2007;38 131-156.

[45] Tuncel G, Alpan G. Risk assessment and Management for Supply Chain Networks: A Case Study. Computers in Industry 2010;61(3) 250-259.

[46] Rice JB, Caniato F. Building a Secure and Resilient Supply Network. Supply Chain Management Review 2003;7, 22-30.

[47] Sheffi Y, Rice JB. A Supply Chain View of the Resilient Enterprise. MIT Sloan Management Review 2005;47(1), 41-48.

[48] Taleb NN, Goldstein DG, Spitznagel MW. The Six Mistakes Executives Make in Risk Management. Harvard Business Review 2009;87(10) 78-81.

[49] Cucchiella F, Gastaldi M. Risk Management in Supply Chain: A Real Option Approach. Journal of Manufacturing Technology Management 2006;17 (6) 700-720.

[50] Ritchie B, Brindley C. An Emergent Framework for Supply Chain Risk Management and Performance Measurement. Journal of the Operational Research Society, 2007;58 1398-411.

[51] Hendricks KB, Singhal VR. The Effect of Supply Chain Glitches on Shareholder Wealth. Journal of Operations Management 2003:21(5) 501-522.

[52] Dinh LTT, Pasman H, Gao X, Mannan MS. Resilience Engineering of Industrial Process: Principle and Contributing Factors. Journal of Loss Prevention in the Process Industries 2012;25(2) 233-241.

[53] Barroso AP, Machado VH, Cruz-Machado V. Supply Chain Resilience Using the Mapping Approach. In: Pengzhong Li (ed.) Supply Chain Management. Rijeka: InTech; 2011. 161-184. Available from http:// http://www.intechopen.com/books/ supply-chain-management/supply-chain-resilience-using-the-mapping-approach (accessed 5 October 2014)

[54] Ponomarov SY, Holcomb MC. Understanding the Concept of Supply Chain Resilience. The International Journal of Logistics Management 2009;20 124-143.

[55] Datta PP, Christopher M, Allen P. Agent-based Modelling of Complex Production/ Distribution Systems to Improve Resilience. International Journal of Logistics: Research and Applications 2007;10(3) 187-203.

[56] Zhao K, Kumar A, Harrison TP, Yen J. Analyzing the Resilience of Complex Supply Network Topologies against Random and Targeted Disruptions. IEEE Systems Journal 2011;5(1) 28-39. 
[57] Melnyk SA, Closs DJ, Griffis SE, Zobel CW, Macdonald JR. Understand Supply Chain Resilience. Supply Chain Management Review 2014;January/February 34-42.

[58] Carpenter S, Walker B, Anderies JM, Abel N. From Metaphor to Measurement: Resilience of What to What?. Ecosystems 2001;4 765-781.

[59] Tierney K, Bruneau M. All-Hazards Preparedness, Response, and Recovery-Conceptualizing and Measuring Resilience: A Key to Disaster Loss Reduction. TR News 2007;250 14-17.

[60] Asbjørnslett BE. Assessing the Vulnerability of Supply Chains. In: G. A. Zsidisin GA, Ritchie B(ed.), Supply Chain Risk: A Handbook of assessment, Management and Performance. New York: Springer; 2008. 15-33.

[61] Carvalho H, Barroso AP, Machado, VH, Azevedo SG, Cruz-Machado V. Supply Chain Redesign for Resilience using Simulation. Computers \& Industrial Engineering 2012;62 329-341.

[62] Suwanruji P, Enns ST. Evaluating the Performance of Supply Chain Simulations with Tradeoffs Between Multiple Objectives: proceedings of the 2004 Winter Simulation Conference, 2004; 2 338-342.

[63] Azevedo SG, Govindan K, Carvalho H, Cruz-Machado V. Ecosilient Index to Assess the Greenness and Resilience of the Upstream Automotive Supply Chain. Journal of Cleaner Production 2013;56 131-146.

[64] Nardo M, Saisana M, Saltelli A. Tarantola S. Tools for Composite Indicators Building. European Commission, Institute for the Protection and Security of the Citizen Econometrics and Statistical Support to Antifraud Unit; 2005.

[65] Zhou P, Ang BW, Poh KL. Comparing Aggregating Methods for Constructing the Composite Environmental Index: An Objective Measure. Ecological Economics 2006;59 305-311.

[66] Curwin J, Slater R. Quantitative Methods for Business Decisions. Índia: Cengage Learning. Integra; 2007.

[67] Farmer TA. Testing the Robustness of Multiattribute Utility Theory in an Applied Setting. Decision Sciences 1987;18 178-193.

[68] Singh R, Murty H, Gupta S, Dikshit A. An Overview of Sustainability Assessment Methodologies. Ecological Indicators 2009; 9 189-212.

[69] Fetscherin M. The Determinants and Measurement of a Country Brand: The Country Brand Strength Index. International Marketing Review 2010;27 466-479.

[70] Adenso-Diaz B, Mena C, García-Carbajal S, Liechty M. The Impact of Supply Network Characteristics on Reliability. Supply Chain Management: An International Journal 2012;17 263-276. 
[71] Svensson GA. Conceptual Framework for the Analysis of Vulnerability in Supply Chains. International Journal of Physical Distribution \& Logistics Management 2000;30 731-750.

[72] Thun J-H, Hoenig D. An Empirical Analysis of Supply Chain Risk Management in the German Automotive Industry. International Journal of Production Economics 2011;131 242-249. 
Chapter 3

\title{
Modeling the Production and Replenishment Decisions in a Supply Chain when the Vendor Has Limited Space
}

\author{
Sheng-Pen Wang \\ Additional information is available at the end of the chapter \\ http://dx.doi.org/10.5772/59612
}

\section{Introduction}

This research was motivated by the problems encountered by Chang Gung Memorial Hospital (CGMH), a medical center in Taiwan affiliated with the author's university. Started since 1976, there are now up to 8 CGMHs in Taiwan, including three medical centers and one children's hospital. CGMH is the biggest hospital chain in Asia, with around 10,576 beds and more than 26,000 outpatient visits every day in 2011. Currently, the main supplier of beds and stretchers to all the group hospitals is Chang Gung Medical Technology Co. Ltd. This subsidiary company of CGMH, established in 2009, is a small specialist manufacturer with little storage space available. Managers in the hospital's supply chain department are asked to investigate a better cooperation and coordination mechanism with suppliers. In particular, as both the hospital (buyer) and the manufacturer (vendor, or supplier) are in the same organization, therefore they can be seen as two parties in a vertically integrated supply chain or members working towards the common goal. The department general manager may act as a central decision maker and, in a hope, to find a win-win paradigm for both parties and for the associated medical group.

Maximizing customer value and profit for each supply chain member requires effective and efficient management of product and service flows through information sharing and coordinated decision making. In most of the studies in production and distribution coordination, researchers consider no limit for the capacity of a warehouse. This however, can be one of the most important issues in a real-world problem. A new business on high street where space is very expensive can be one example. Though the main goal of supply chain and inventory management in a hospital is to reduce the cost of healthcare without sacrificing customer service, a limited warehouse capacity at the side of any party in a supply chain can differentiate the production and inventory decisions. Most recently, Priyan and Uthayakumar (2014) 
proposed an integrated inventory model for pharmaceutical products in a two-layer supply chain consisting of a pharmaceutical company and a hospital; Gebicki et al. (2014) investigated different management approaches for a medication inventory system and found that policies that incorporate drug characteristics in ordering decisions can address the tradeoff between patient safety and cost. However, they did not address the important issue of space constraints.

In any joint economic lot sizing (JELS) model, there is a central decision maker and those involved parties follow the centralized decisions in implementing inventory management. Literature has shown that if both the manufacturer and the buyer are willing to cooperate and jointly plan their inventory control decisions, the resulted system cost can be less than that of planning separately. An extensive review on JELS model and its variants up to 1989 can be found in Goyal and Gupta (1989). Ben-Daya et al. (2008) presented another comprehensive review on JELS and provided some extensions of this important problem. Glock (2012) included the most updated review of existing works on JELS models while focusing on coordinated inventory replenishment decisions between buyer and vendor and their impact on the performance of the supply chain. Goyal (1977) started analyzing the single buyer single vendor integrated production-inventory problem under the assumption of having infinite production rate for the vendor and lot-for-lot policy for the shipments. If $n$ stands for the number of transportation batches in a production cycle, the lot-for-lot policy means $n=1$. In this policy, each production lot is sent to the buyer as a single shipment; this implies that the entire production lot should be ready before shipment. Banerjee (1986) generalized Goyal's model by incorporating a finite production rate for the vendor while retaining the lot-for-lot policy. This study is actually the one that coined the term JELS. Goyal (1988) further generalized Banerjee's model by relaxing the lot-for-lot policy. He assumed the vendor delivers an integral number $(n>1)$ of equal-sized shipments to the buyer, but only after the entire lot has been produced.

In the models discussed so far, it was assumed that shipments are delayed until the whole production cycle is completed. In contrast, the non-delayed shipments policy means the production processes exist where partial shipments to the buyer can be made. Lu (1995) first admitted the non-delayed equal-sized shipments in the JELS problems; it allows the vendor to deliver shipments during production, which is the relaxation of the assumption made by Goyal (1988) about completing a lot before starting shipments. A similar treatment of partial shipments to integrated inventory-production problems can be found in Agrawal and Raju (1996), Kim and Ha (2003), Wee and Chung (2006), and Teng (2009). Partial shipment obviously helps the inventory holding costs decrease in $n(n>1)$ since shipping batches to the buyer leads to an earlier depletion of inventory at the vendor.

On the other hand, it is clear that space constraints could have some major effects on inventory operations and decisions in a supply chain, restrictions have to be considered when determining order and production quantity. However, because the addition of capacity constraints dramatically increases the difficulty in solving integrated production distribution models, the advancement of capacity-limited inventory research has been surprisingly slow. Hoque and Goyal (2000) developed an optimal solution procedure for an integrated production inventory system with unequal shipments from the vendor to the buyer, and under the capacity 
constraint of transport equipment. Lee and Wang (2008) studied the impact of buyer's available warehouse capacity on the inventory decisions under a consignment stock agreement. In such a scenario, the buyer pays for items only when they are used and further has the guarantee that the inventory never drops below a predetermined level. Wang and Lee (2013) proposed a general JELS model in determining the production and shipment policy for a two-layer supply chain, and attained a specific threshold value which defines those existing JELS problems as a special case of the proposed model, while the supplier's warehouse capacity exceeds it. Most recently, Hariga et al. (2014) considered a supply chain where the single vendor manages its multiple retailers' inventory under a contract that specifies maximum stock levels allowed by the retailers. They proposed a heuristic and found a near optimal delivery schedule with unequal shipments in an iterative approach.

Since an equal-shipment policy is attractive and easy to implement, we assume a non-delayed equal-sized shipment policy in the studied vertically integrated supply chain where the hospital (buyer) observes a deterministic demand of a certain type of medical items and order lots from the manufacturer (vendor also the supplier). The vendor manufacturers the requested products in lots and delivers shipments during production to the buyer in batches with equal-size and partial shipment policy. While taking the vendor's limited warehouse capacity into account, this research models the case as a generic JELS problem and finds the optimal number of shipments and the production lot and delivery batch size such that the joint vendorbuyer cost is minimized. The present study then extends Wang and Lee's (2013) and specifies the closed-form expressions of capacity thresholds, which define those existing JELS problems are just special cases of the proposed model once the manufacturer's warehouse capacity exceeds either the lower bound or the upper limit.

Our main contribution lies in the development of inventory replenishment decisions for the members of a hospital supply chain working together towards a reduction of total system costs; the proposed general JELS model can be applied to accommodate the warehouse capacity restriction of any supplier in manufacturing or service industry. The remainder of this chapter is organized as follows. In Section 2 we present the assumptions and notations, and develop the general JELS model. In the third section we characterize the optimal lot sizing decisions subject to the manufacturer's warehouse capacity limit. In the fourth section a numerical example is used to observe how the vendor's warehouse capacity influences replenishment policies such as the manufacturer's production lot sizes. Finally, conclusions are given in Section 5.

\section{The capacitated JELS model}

In this chapter, as the single vendor and the single buyer are in the same organization, a JELS model with non-delayed equal-shipments is formulated to study the inventory decisions under vendor's warehouse capacity constraints. For easy tractability with Wang and Lee (2013), we use the same assumptions and notations defined as follows.

$D$ demand rate seen by the buyer, units/year 
$P$ supplier (the manufacturer) production rate, units/year

$S_{b}$ buyer order processing cost per replenishment, \$/order

$S_{s}$ supplier production setup cost, \$/setup

$h_{b}$ buyer's annual holding cost per item, \$/unit-year

$h_{s}$ supplier's annual holding cost per unit of finished goods, \$/ unit-year

$W$ the manufacturer's warehouse capacity, units

$I_{\text {max }, m}$ maximum manufacturer inventory level, units

$I_{\max , b}$ maximum buyer inventory level, units

TC total relevant costs of the system per time unit, \$/year

$Q$ quantity transported per delivery to the buyer, units/order

$n$ number of transport operations per production batch, a positive integer

$u$ number of shipments delivered in each cycle before manufacturer's inventory level reaches $I_{m a x, m}$ an non-negative integer

$v$ number of shipments delivered in each cycle after manufacturer's inventory level hits $W$ till production run stops, an non-negative integer

The following assumptions are made in deriving the proposed JELS models.

a. The demand rate is constant, as the case hospital is a medical center which observes large and stable demand for a particular medical supply.

b. $\quad P>D$ or the utilization rate $\rho=D / P<1$; which ensures the problem is not trivial.

c. The just-in-time delivery in the same organization justifies the assumption of zero lead time for replenishments delivered from the supplier to the buyer.

d. No shortages and backorders are allowed to sustain high healthcare quality.

e. As in Hill (1999), this study assmes $h_{b}>h_{s}$, which is reasonable, as stock value usually increases as a product moves down the supply chain and the associated holding costs increase accordingly. This implies that, before completing production and turning to utilize buyer's space, the manufacturer has the incentive to store products in his own warehouse as much as possible.

The decision variables are $Q>0$, and non-negative integers $n, u$, and $v$. Figure 1 illustrates the trend of both parties' inventory levels where the manufacturer's warehouse capacity is given at $W$. Specifically, in each production cycle a vendor incurs a setup cost $S_{s}$ and manufacturers a product in lots at a rate $P$; each production lot $\left(Q_{s}\right.$, units/batch) is delivered to the designated buyer in $n$ shipments $\left(Q_{s}=n Q\right)$. The buyer's order cost is $S_{b}$ per shipment. The vendor and the buyer incur inventory holding $\cos t s h_{b}$ and $h_{s}$, respectively. Note that once the manufacturer's maximal inventory level $\left(I_{\max , m}\right)$ reaches the ceiling $(W)$ after $u$ replenishments in a cycle, the 
replenished interval might be no longer confined to $Q / D$ due to the manufacturer's limited space.

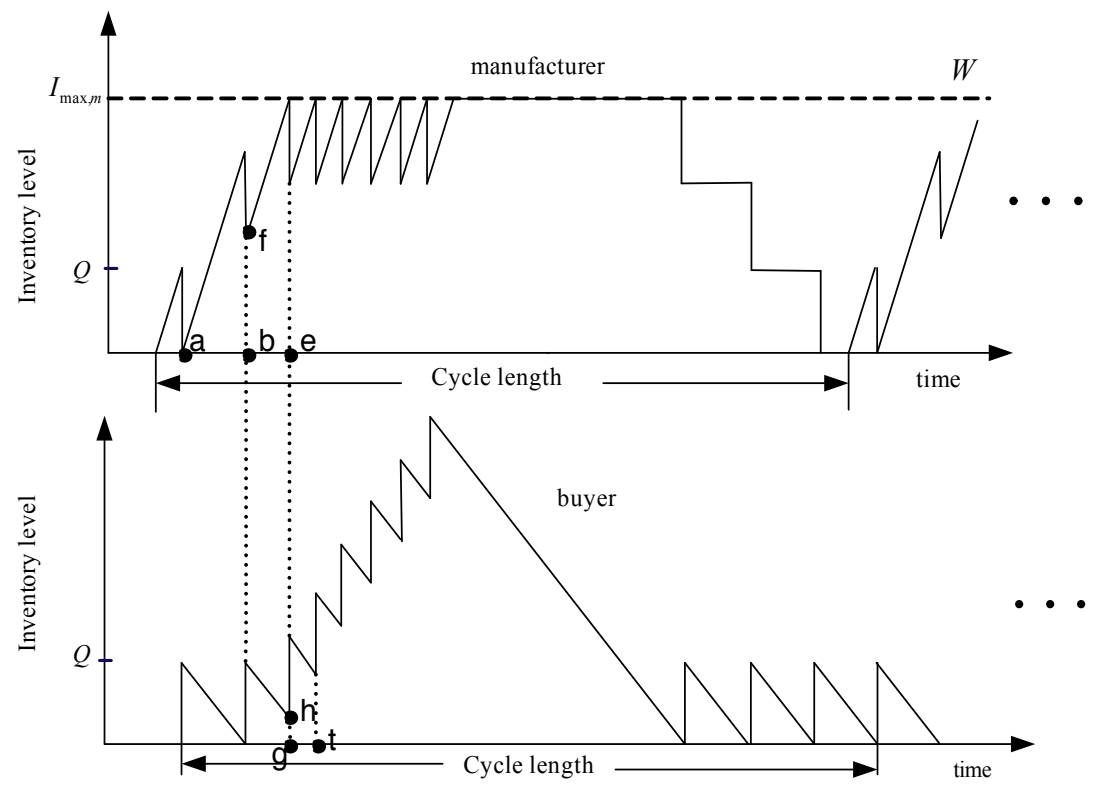

Figure 1. Trend of inventory levels of two parties when the manufacturer warehouse capacity is not "big enough," where $u=2, v=6$, and $n=11$.

The objective in the proposed generic JELS model is to view the system as an integrated whole and determine the production lot size and shipments schedule that minimizes $T C$, the annual total relevant cost in the supply chain. The annual total relevant cost consists of four components, and three among them are on the supplier's side. First, as there is $D / Q_{s}$ production batch in a year, and it costs $S_{s}$ per setup, the manufacturer production setup cost is $\frac{D}{n Q} S_{s}$. Secondly, since the quantity transported per delivery is $Q$, the manufacturer can fulfill the buyer's annual demand by $D / Q$ replenishments; given that each order processing costs $S_{b}$, the replenishment cost thus is $\frac{D}{Q} S_{b}$. The third component on the supplier's side is the manufacturer's finished goods inventory holding cost, which depends on both the number of shipments before reaching the maximum inventory level $(u)$ and the number of delivery since the manufacturer's warehouse is full $(v)$ and can be expressed as

$$
\left\{\frac{Q}{2}\left[(1-\rho)\left(n-\frac{v^{2}}{n}-\frac{2 u v}{n}+\frac{v}{n}-1\right)-\left(\frac{2 v}{n}-1\right) \rho\right]+\frac{I_{\max , m}}{n} v \rho\right\} h_{s^{\prime}}
$$


where the term inside the bracket and before $h_{s}$ is the manufacturer's time-weighted inventory over a cycle. Finally, the only one component accounted for the buyer is the inventory holding cost incurred on the buyer's side, which is

$$
\left\{\frac{Q}{2}\left[(1-\rho)\left(\frac{v^{2}}{n}+\frac{2 u v}{n}-\frac{v}{n}+1\right)+\left(\frac{2 v}{n}+1\right) \rho\right]-\frac{I_{\max , m}}{n} v \rho\right\} h_{b} .
$$

Readers are referred to Wang and Lee (2013) for the detailed proofs of (1) and (2), where mathematical derivations are analogous to Joglekar's (1988, p. 1395). By adding up three cost components in the supplier's side and the only buyer's cost (2), the total annual relevant cost, $T C$, can be expressed as

$$
T C(n, u, v, Q)=\frac{D}{Q}\left(\frac{S_{s}}{n}+S_{b}\right)+\frac{Q}{2} \Psi(n, u, v)-\frac{I_{\text {max }, m}}{n} v \rho\left(h_{b}-h_{s}\right),
$$

where

$$
\Psi(n, u, v)=\left[(1-\rho)\left(\frac{v(v+2 u-1)}{n}+1\right)+\frac{2 v \rho}{n}\right]\left(h_{b}-h_{s}\right)+(1-\rho) n h_{s}+\rho\left(h_{b}+h_{s}\right) .
$$

The proposed JELS model with manufacturer's warehouse capacity limits thus is a constrained optimization problem as to minimize (3) subject to the following three constraints:

$$
I_{\max , m} \leq W
$$

$Q \leq I_{\text {max }, m}$ and

$$
u+v<n
$$

The manufacturer's maximal inventory level, $I_{\max , m}$, is naturally at least as much as the quantity transported per delivery to the buyer $(Q)$, and not greater than the given limited space in (5). Instead, constraint (6) specifies that, once the manufacturer's inventory level reaches $I_{\max , m}$ after $u$ replenishments, there will be at most $(n-1)$ shipments delivered until the production run stops in each cycle. Lemma 1 spells out $u$ in terms of $I_{\max , m}$ and $Q$ as follows.

Lemma 1: The nonnegative integer $u$ equals $\left\lfloor\frac{\frac{I_{\text {max }, m}}{Q}-1}{\frac{1}{\rho}-1}\right\rfloor$, where $\lfloor x\rfloor$ denotes the largest integer not greater than $x$. 
Proof of Lemma 1: Since $u$ is the number of shipments delivered in each cycle before manufacturer's inventory level reaches $I_{\max , m^{\prime}}$ and during this period the replenishment interval is confined to $Q / D$, the manufacturer's maximal inventory level thus satisfies both inequalities (i) $\quad(u-1) \frac{Q}{D} P-(u-2) Q<I_{\max , m^{\prime}} \quad$ and $\quad$ (ii) $\quad(u) \frac{Q}{D} P-(u-1) Q \geq I_{\max , m} . \quad$ These hold both $(u-1)\left(\frac{1}{\rho}-1\right)<\frac{I_{\max , m}}{Q}-1$, and $u\left(\frac{1}{\rho}-1\right) \geq \frac{I_{\max , m}}{Q}-1$. It concludes the proof that the nonnegative integer $u$ satisfies $\frac{\frac{I_{\max , m}}{Q}-1}{\frac{1}{\rho}-1} \leq u<\frac{\frac{I_{\max , m}}{Q}-1}{\frac{1}{\rho}-1}+1$.

Intuitively, the total relevant cost decreases as the manufacturer's warehouse capacity increases. This observation is justified as the following Lemma 2, and whose proof can be found in Wang and Lee (2013).

Lemma 2: TC in (3) is non-increasing with respect to $W$.

Lemma2 states the annual total relevant cost decreases as the manufacturer's warehouse space becomes bigger until it is "big enough." If the manufacturer's warehouse capacity is not "big enough," the resulting JELS policy will raise the system cost to keep up the inflexibilities on the buyer's always constant replenishment interval and maximal inventory level. From the definition of $v$, the fact that $v \neq 0$ happens only in the case the manufacturer's limited warehouse is not "big enough." By complementarities in constrained optimization, the constraint (5) will be binding, or equivalently, $I_{\max , m}=W$. This is also justified by the assumption that $h_{b}>h_{s}$ because lower unit holding cost on the supplier side will drive more utilization in manufacturer's warehouse. The total annual cost of the proposed model in (3) will be modified as

$$
T C(n, u, v, Q)=\frac{D}{Q}\left(\frac{S_{s}}{n}+S_{b}\right)+\frac{Q}{2} \Psi(n, u, v \neq 0)-\frac{W}{n} v \rho\left(h_{b}-h_{s}\right)
$$

And the resulting $\frac{\partial T C}{\partial W}=-\frac{1}{n} v \rho\left(h_{b}-h_{s}\right)<0$, which justifies Lemma 2 that the total cost is strictly decreasing when the vendor's warehouse capacity is not "big enough."

\section{Characteristics of the proposed model}

The vendor's warehouse capacity is definitely a key factor to the objective of the capacitated JELS model. Figure 2 depicts the trends of the vendor's and buyer's inventory levels where the manufacturer's warehouse space imposes no constraints on the JELS model. The is the basic counterpart presented in Goyal (1988), Lu (1995) and Pibernik et al. (2011), to mention just a few. Note that in this JELS model without warehouse capacity constraints, the maximum buyer's inventory level is always constant at $Q$, and the replenishment intervals are always constant with length $Q / D$, and total cost function for the uncapacitated JELS model is known as 


$$
T C_{U}(n, Q)=\frac{D}{Q}\left(\frac{S_{s}}{n}+S_{b}\right)+\frac{Q}{2}\left\{[(n-1)-(n-2) \rho] \cdot h_{s}+h_{b}\right\}
$$
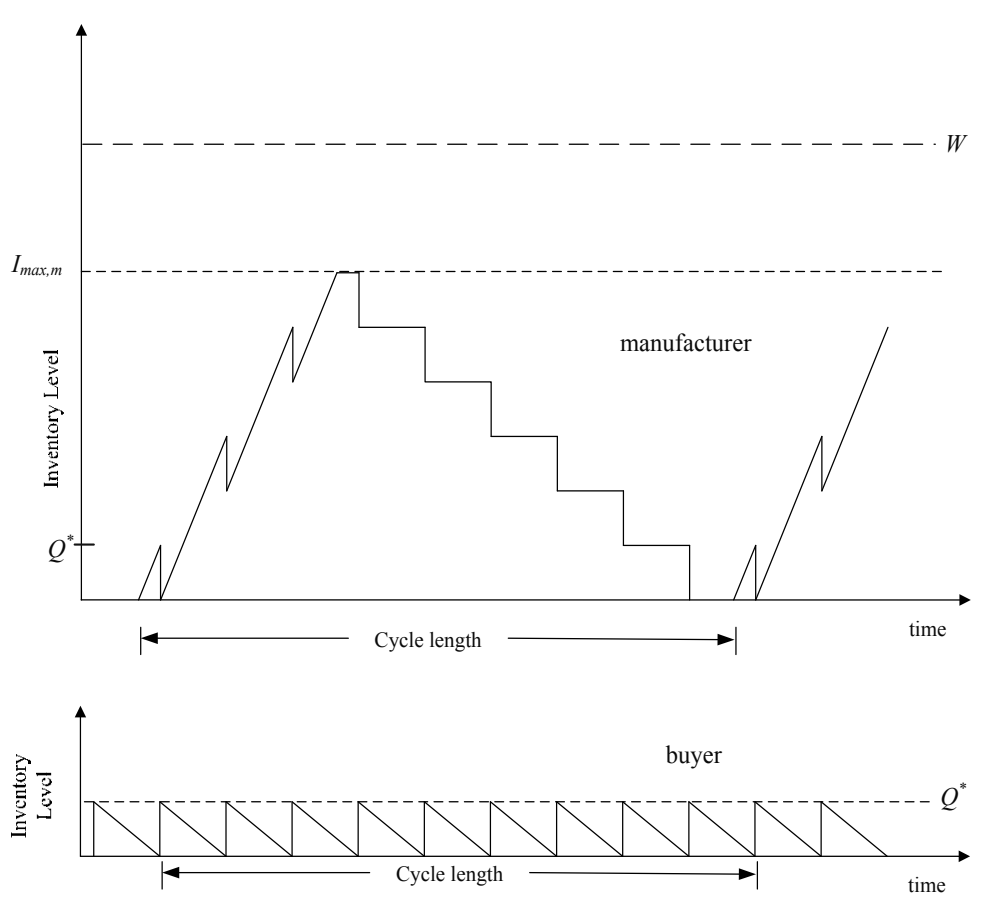

Figure 2. Trend of inventory levels of two parties when the manufacturer warehouse capacity is "big enough" or unlimited, where $u=3, v=0$, and $n=9$.

Readers can refer to Kim and Ha (2003) and Wang and Lee (2013) about the proofs for the following facts: total cost (7) in the uncapacitated JELS model is a convex function of $(n, Q)$, and its minimum is uniquely attained at

$$
n_{U}^{*}=\left\lfloor\frac{1}{2}\left(1+\sqrt{1+4 \frac{S_{s}\left[(2 \rho-1) h_{s}+h_{b}\right]}{(1-\rho) S_{b} h_{s}}}\right)\right\rfloor,
$$

and

$$
Q_{U}^{*}=\sqrt{\frac{2 D \cdot\left(\frac{S_{s}}{n_{U}^{*}}+S_{b}\right)}{\left[\left(n_{U}^{*}-1\right)-\left(n_{U}^{*}-2\right) \rho\right] \cdot h_{s}+h_{b}}} .
$$


We then state in Lemma 3 the vendor's maximum inventory levels while the manufacturer's warehouse capacity is "big enough" as shown in Figures 2. Proof of Lemma 3 can be, again, referred to Wang and Lee (2013).

Lemma 3: In the JELS model without warehouse capacity constraints, the manufacturer's maximum inventory levels, $I_{\max , m^{\prime}}$ is

$$
\operatorname{Max}\left\{\left[n_{U}^{*}-1-\left\lfloor\left(n_{U}^{*}-1\right) \rho\right\rfloor\right] Q_{U}^{*},\left[\left[\left(n_{U}^{*}-1\right) \rho\right\rfloor\left(\frac{1}{\rho}-1\right)+1\right] Q_{U}^{*}\right\},
$$

where $\left(n_{U}^{*}, Q_{U}^{*}\right)$ are explicitly expressed in (8) and (9), respectively.

As in Lemma 3, the vendor's maximum inventory level helps to identify whether or not the given supplier's warehouse capacity is "big enough," or if the constraint $I_{\max , m} \leq W$ is active. For simplicity, we denote (10) as the upper bound of capacity threshold, $U B$, that is,

$$
U B=\operatorname{Max}\left\{\left[n_{U}^{*}-1-\left\lfloor\left(n_{U}^{*}-1\right) \rho\right\rfloor\right] Q_{U}^{*}, \quad\left[\left\lfloor\left(n_{U}^{*}-1\right) \rho\right\rfloor\left(\frac{1}{\rho}-1\right)+1\right] Q_{U}^{*}\right\} .
$$

\section{Case 1: $W \geq U B$}

In this case the given manufacturer's warehouse capacity is "big enough," constraint (5) is not binding and the corresponding Lagrange multiplier will be zero, or $v=0$. Furthermore, from $(4), \Psi(n, u, v)$ can be simplified as

$$
\Psi(n, u, v=0)=[n-1-(n-2) \rho] \cdot h_{s}+h_{b^{\prime}}
$$

which is independent of $u$ and $v$. Accordingly, the cost function (3) can be rewritten as

$$
T C(n, u, v=0, Q)=\frac{D}{Q}\left(\frac{S_{s}}{n}+S_{b}\right)+\frac{Q}{2}\left\{[n-1-(n-2) \rho] h_{s}+h_{b}\right\} .
$$

Note that (11) is exactly the counterpart presented in (7), which depends only on $n$ and $Q$. Once $W>U B$, any more space of the manufacturer's warehouse does not reduce the total cost in (11); similarly, the maximal inventory levels of both parties are kept constant. We summarize the results in Theorem 1 and, again, the proof can be referred to Wang and Lee (2013).

Theorem 1: If the manufacturer's warehouse capacity is "big enough," as shown in Figure 2, or if $W>U B$, then the vendor's and buyer's maximal inventory levels are $I_{\max , m}=$ $\operatorname{Max}\left\{\left[n_{U}^{*}-1-\left\lfloor\left(n_{U}^{*}-1\right) \rho\right]\right] Q_{U}^{*}, \quad\left[\left\lfloor\left(n_{U}^{*}-1\right) \rho\right\rfloor\left(\frac{1}{\rho}-1\right)+1\right] Q_{U}^{*}\right\}, \quad$ and $I_{\max , b}=Q_{U}^{*}, \quad$ respectively, and $\left(n_{U}^{*}, Q_{U}^{*}\right)$ are in (8) and (9). 
However, if the manufacturer's warehouse capacity is not "big enough," in this case, constraint (5) is active and the decision variables $\left(n_{U}^{*}, Q_{U}^{*}\right)$ as (8) and (9) will no longer be necessarily optimal to the capacitated JELS problems. In fact, lower unit holding cost in the supplier side drives full utilization in manufacturer's warehouse under the assumption of $h_{b}>h_{s}$. In the following, we turn to the situation that the vendor's warehouse capacity is "too small."
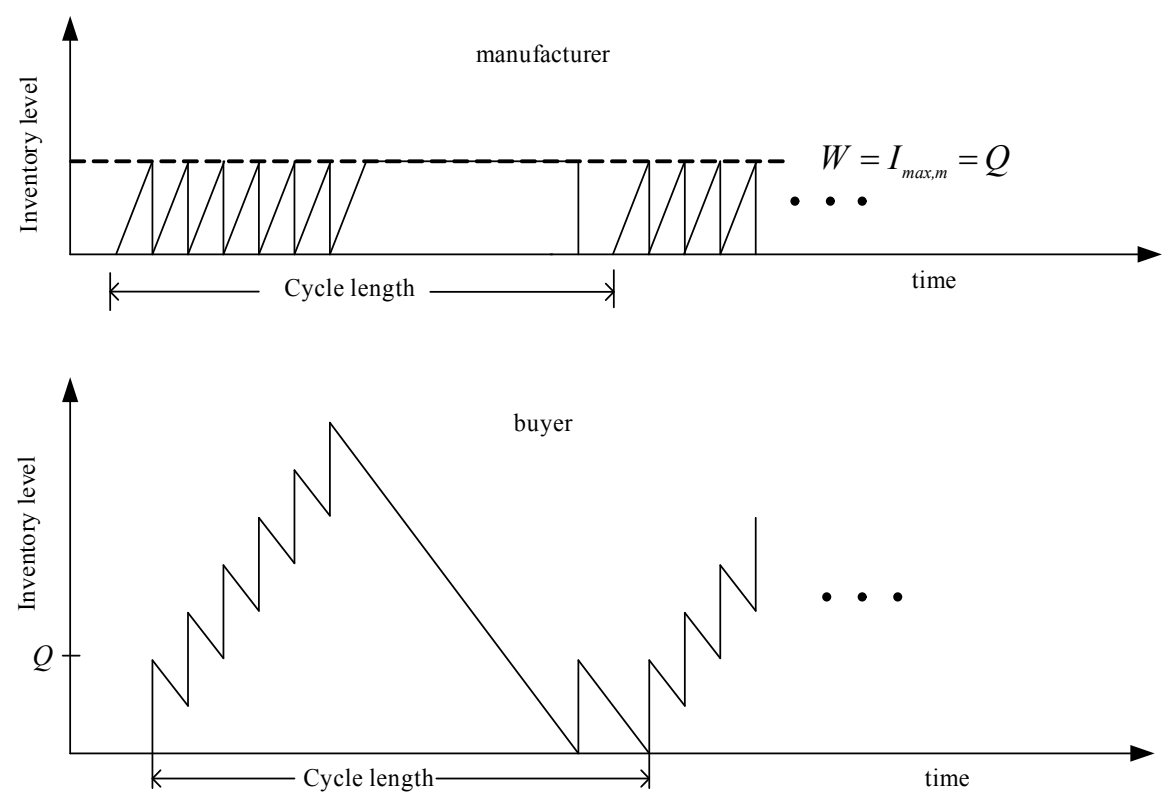

Figure 3. Trend of inventory levels of two parties when the manufacturer warehouse capacity is "too small" or $Q=I_{\max , m}=W$, where $u=0, v=6$, and $n=7$.

\section{Case 2: $W \leq L B$}

In case the supplier's warehouse capacity is "too small" as illustrated in Figure 3, where, except for the last replenishment, the manufacturer delivers a lot size consecutively to the buyer as soon as the manufacturer's warehouse is full of inventory. Under this circumstance, either quantity transported per delivery or the vendor's maximum inventory level is as small as the warehouse capacity, or $Q=W$ and $I_{\max , m}=W$. This implies that $u=0$ and $v=n-1$, the largest integer satisfying (6) on the number of replenishments in each cycle. Expression (4) can be represented in terms of the only variable $n$ as the follows.

$$
\Psi(n, u=0, v=n-1)=\left[\left(2-\frac{2}{n}\right)-\left(3-\frac{4}{n}\right) \rho\right] \cdot h_{s}+\left[\left(n-2+\frac{2}{n}\right)-\left(n-5+\frac{4}{n}\right) \rho\right] \cdot h_{b} .
$$

In this case that vendor's warehouse capacity is "too small," the annual cost function (3) for the proposed capacitated JELS model can be accordingly rewritten as 


$$
T C_{L}(n, Q)=\frac{D}{Q}\left(\frac{S_{s}}{n}+S_{b}\right)+\frac{Q}{2}\left\{\left[2-\frac{2}{n}-\left(1-\frac{2}{n}\right) \rho\right] h_{s}+\left[n-2+\frac{2}{n}-\left(n-3+\frac{2}{n}\right) \rho\right] h_{b}\right\}
$$

Note that (12) is independent of $u$ and $v$, and is close to the cost function in Braglia and Zavanella's (2003, p. 3798) consignment contract model. Using the same argument as showing the convexity of $T C_{U}(n, Q)$ in (7), it is straightforward to prove that $T C_{L}(n, Q)$ in (12) is also a convex function of $(n, Q)$, and there exists an unique optimal solution, denoted as $\left(n_{L}^{*}, Q_{L}^{*}\right)$. Let

$$
\Omega(n)=\frac{S_{s}}{n}+S_{b}
$$

and

$$
H(n)=\left[2-\frac{2}{n}-\left(1-\frac{2}{n}\right) \rho\right] h_{s}+\left[n-2+\frac{2}{n}-\left(n-3+\frac{2}{n}\right) \rho\right] h_{b^{\prime}}
$$

then (12) can be rewritten as

$$
\operatorname{TC}_{L}(n, Q)=\frac{D}{Q} \Omega(n)+\frac{Q}{2} H(n) .
$$

Taking the first derivative of (13) with $Q$ and setting it equal zero, as that in Grubbstrom and Erdem (1999), then

$$
Q_{L}^{*}=\sqrt{\frac{2 D \Omega(n)}{H(n)}}
$$

Inputting (14) to (13), we obtain $T C_{L}(n, Q)=\sqrt{2 D \Omega(n) H(n)}$, which is without variable $Q$. Thus, the optimal solution $n_{L}^{*}$ is an integer that minimizes $\Omega(n) H(n)$. As detailed in Lemma 4, solving for $n_{L}^{*}$ involves with solving a cubic polynomial function; additional assumptions have to make to guarantee the existence of exactly one positive root.

Lemma 4: Total cost (12) is a convex function of $(n, Q)$, and its minimum is uniquely attained at $\left(n_{L}^{*}, Q_{L}^{*}\right)$ under some conditions.

Proof of Lemma 4: We first treat $n$ as a continuous variable and take the partial derivative of $Z(n)=\Omega(n) H(n): Z^{\prime}(n)=\frac{1}{n^{3}}\left(A n^{3}+B n^{2}+C n+D\right)$. Let $f(n)=A n^{3}+B n^{2}+C n+D$, and the coefficients are $\mathrm{A}=(1-\rho) S_{b} h_{b}, \quad \mathrm{~B}=0, \quad \mathrm{C}=\left[(2-3 \rho) S_{s}-2(1-\rho) S_{b}\right] h_{b}-\left[(2-\rho) S_{s}-2(1-\rho) S_{b}\right] h_{s^{\prime}}, \quad$ and $D=-4 S_{s}(1-\rho)\left(h_{b}-h_{s}\right)$. If the following three assumptions are made: 
i.

$$
0<\rho<\frac{2}{3}, \Rightarrow(2-3 \rho)>0
$$

ii.

$$
S_{s}>\frac{2(1-\rho)}{2-3 \rho} S_{b} \Rightarrow(2-3 \rho) S_{s}-2(1-\rho) S_{b}>0 ; \text { and }
$$

iii.

$$
h_{b}>\left[1+\frac{2 \rho S_{s}}{(2-3 \rho) S_{s}-2(1-\rho) S_{b}}\right] h_{s^{\prime}}
$$

then the signs for these coefficients are: $A>0, B=0, C>0$, and $D<0$.

Since $Z^{\prime}\left(n \rightarrow 0^{+}\right)=\lim _{n \rightarrow 0^{+}} \frac{1}{n^{3}} \cdot D<0$, and $Z^{\prime}(n \rightarrow+\infty)=A+\lim _{n \rightarrow+\infty}\left(\frac{C}{n^{2}}+\frac{D}{n^{3}}\right)>0$, the intermediate value theorem implies that there exists at least a positive $n^{*}$ such that $Z^{\prime}\left(n^{*}\right)=0$. But the determinant for $f(n)$ is $\triangle=-4 B^{3} D+B^{2} C^{2}-4 A C^{3}+18 A B C D-27 A^{2} D^{2}=-4 A C^{3}-27 A^{2} D^{2}$, which is negative and it implies that cubic equation $f(n)=0$ has exactly one real root $n^{*}$ and a pair of complex conjugate roots.

Let $Q=\frac{C}{3 A}>0$, and $R=\frac{-D}{2 A}>0$, then the unique real root of $f(n)=0$ can be expressed as $n^{*}=\sqrt[3]{R+\sqrt{Q^{3}+R^{2}}}+\sqrt[3]{R-\sqrt{Q^{3}+R^{2}}}$. The optimal solution $n_{L}^{*}$ minimizing $Z(n)=\Omega(n) H(n)$ is either $\left\lfloor n^{*}\right\rfloor$ or $\left\lfloor n^{*}\right\rfloor+1$.

Note that the integral solution $n_{L}^{*}$ cannot be formulated in a closed form as $n_{U}^{*}$ shown in (8). Therefore, the complexity makes it impossible to express $Q_{L}^{*}$ in terms of the given parameters. For the two-layer supply chain where the vendor's warehouse capacity is "too small," we denote $Q_{L}^{*}$ as the lower bound of capacity threshold, $L B$, that is, $L B=Q_{L}^{*}$. Note that, unlike the definition of $U B$, here $L B$ is independent of $n_{L}^{*}$.

Theorem 2: If $W \leq L B$, or the manufacturer's warehouse capacity is "too small," then the maximal inventory levels of the two parties are $I_{\max , m}=W=Q^{*}$, and $I_{\max , b}=\left\{\begin{array}{ll}W, & \text { if } n^{*}=1 \\ {\left[\left(n^{*}-1\right)-\left(n^{*}-2\right) \rho\right] \cdot W,} & \text { if } n^{*} \geq 2\end{array}\right.$, respectively, where $n^{*}$ is optimal to minimize $\operatorname{TC}_{L}(n$, $Q=W)$ in (12).

Proof of Theorem 2: Referring to Figure 3, the manufacturer will ship a lot size $Q=W$ to the buyer once the accumulative product reaches full warehouse, that is, $I_{\max , m}=W$. When $n=1$, the manufacturer adopts the lot-for-lot policy and the buyer's maximal inventory level is the same as that of the manufacturer, which is $W$. If $n \geq 2$, it takes the manufacturer $Q / P$ to make one batch of $Q$, while during the same time the buyer's inventory level reduces by $(Q / P) D$. Consequently, the buyer's inventory level increases $(Q-D Q / P)$ each time a new batch $Q$ arrives. Since there are $(n-2)$ shipments before the last delivery, the buyer's maximum inventory level is $(n-2)(Q-D Q / P)+Q$, which equals 


$$
[(n-1)-(n-2) \rho] Q
$$

We complete the proof by replacing in (15) the optimal $Q$ with the vendor's warehouse capacity $W$, while the optimal $n^{*}$ is attained from minimizing $T C_{L}(n, Q=W)$ by Lemma 4 .

Case 3: $L B<W<U B$

If the vendor's warehouse capacity is smaller than the ceiling threshold $(U B)$, then constraint (5) will be binding by complementarities in constrained optimization, or equivalently, $I_{\max , m}=W$, and thus the auxiliary integral variable $v \geq 1$. In addition, if the vendor's warehouse capacity is greater than the floor threshold $(L B)$, then $u \geq 1$ as well. The total annual cost of the proposed model in (3) will be modified as

$$
T C(n, u, v, Q)=\frac{D}{Q}\left(\frac{S_{s}}{n}+S_{b}\right)+\frac{Q}{2} \Psi(n, u, v \neq 0)-\frac{W}{n} v \rho\left(h_{b}-h_{s}\right),
$$

where it is obvious to see both the variables $u$ and $v$ influence the replenishment decisions in the capacitated JELS model. Readers are referred to Wang and Lee (2013) for the note that $T C(n, u, v, Q)$ in (16) is not a convex function of $W$ since the marginal costs are not monotonic, and for the detailed proof of the following Theorem 3 on how the supplier's limited warehouse capacity affects the maximum inventory levels of two parties while achieving the optimal replenishment policy.

Theorem 3: If $L B<W<U B$, or the manufacturer's warehouse capacity is neither "big enough" nor "too small," then the maximal inventory levels of two parties are $I_{\max , m}=W$, and $I_{\max , b}=Q^{*}\left[\left(u^{*}+v^{*}\right)(1-\rho)+2 \rho\right]-\rho W$, respectively, where $\left(Q^{*}, u^{*}, v^{*}\right)$ are optimal to minimize cost function (16).

\section{Numerical illustration}

For illustration, this chapter considers a similar example used by Banerjee (1986), Goyal (1988), Lee (2005), and Wang and Lee (2013), in which the parameters are $S_{s}=3000, S_{b}=25, h_{s}=4$, $h_{b}=5, P=3200$, and $D=1000$. When there is no manufacturer's warehouse capacity constraint imposed in the traditional model, then $n_{U}^{*}=12$ from (8). Input $n_{U}^{*}$ to (9) to obtain the optimal replenishment lot size $Q_{U}^{*}=122.75$ units/order. Consequently, the manufacturer's production batch size, $Q_{s}=n Q$, is 1,473.05 units/batch, and the annual system cost for the uncapacitated JELS model, $T C_{U}\left(n_{U}^{*}, Q_{U}^{*}\right)$ in (7), is $\$ 4,480.51$ per year. From (10) in Lemma 3, the manufacturer's

maximal inventory level, $I_{\max , m}$, will be 982.03 units, which also defines the upper bound of capacity threshold $U B=982.03$. It means that in the proposed general JELS model, a manufacturer's warehouse space is called "big enough" only if it exceeds 982.03 units, and in this case, $v=0$. The total annual cost for this two-party supply chain cannot be reduced further even when 
the manufacturer possesses a larger warehouse capacity than the threshold $U B$. This is similar to the influence of warehouse capacity to the profitability of the steel firm in Italy (Zanoni and Zavanella, 2005).

On the other hand, if the vendor's warehouse capacity fails to be "big enough," the capacity constraint $I_{\text {max }, m} \leq W$ is binding, and the annual total cost strictly increases as the manufacturer's warehouse capacity decreases. The facts that $u \geq 1, v \geq 1$, and hence $Q^{*}<W$ remain true until the vendor's warehouse capacity is "too small." As depicted in Figure 3, the lot-for-lot delivery policy is adopted while the vendor's warehouse capacity is "too small," we proceed to define the lower bound of capacity threshold $L B=122.75$ units. It means that in the proposed general JELS model, a manufacturer's warehouse space is called "too small" only if $W<L B$, and in this case, $u=0$ and $I_{\max , m}=Q^{*}=W$; that is, the vendor's maximal inventory level is bounded by the warehouse capacity, which also defines the optimal quantity transported per delivery to the buyer.

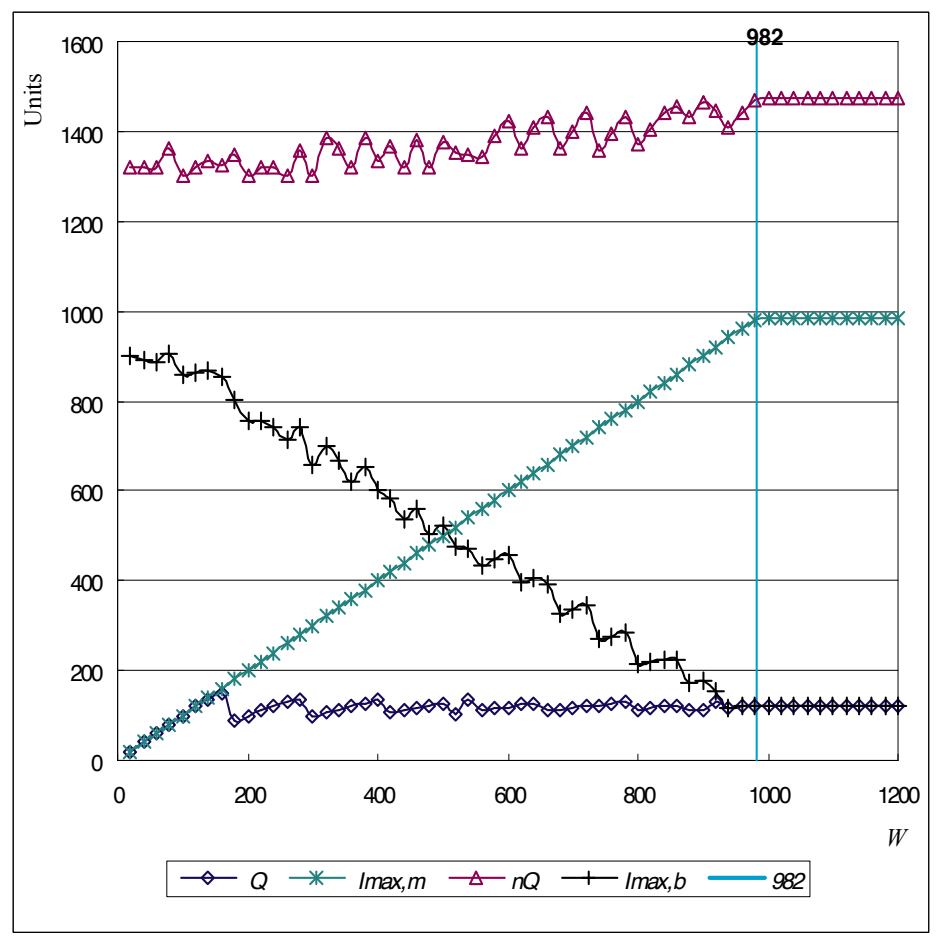

Figure 4. Impact of $W$ on the optimal $Q, I_{\max , m^{\prime}} n Q=Q_{S^{\prime}}$ and $I_{\max , b^{\prime}}$ respectively.

While achieving the optimal production and distribution decisions for the proposed general JELS model, Figure 4 shows the impact of $W$ on the manufacturer's product batch size and each replenishment lot size, as well as on the buyer's maximum inventory levels of two parties, respectively. As the manufacturer's warehouse capacity increases to be "big enough," some 
interesting findings against our intuition are: (i) neither the manufacturer's production batch size $\left(Q_{s}\right)$ nor the buyer's replenishment lot size $(Q)$ is increasing monotonically; (ii) while the buyer's maximum inventory level $\left(I_{\max , b}\right)$ is not decreasing monotonically, it comes down with the same size of one replenishment $(Q)$ when the manufacturer's warehouse capacity is greater than 982.03 units; and (iii) instead the vendor's maximal inventory level is increasing monotonically and with the same size of warehouse capacity $\left(I_{\max , m}=W\right)$, while it equals the replenishment lot size $\left(I_{\max , m}=Q\right)$ when the vendor's warehouse capacity is less than 122.75 units.

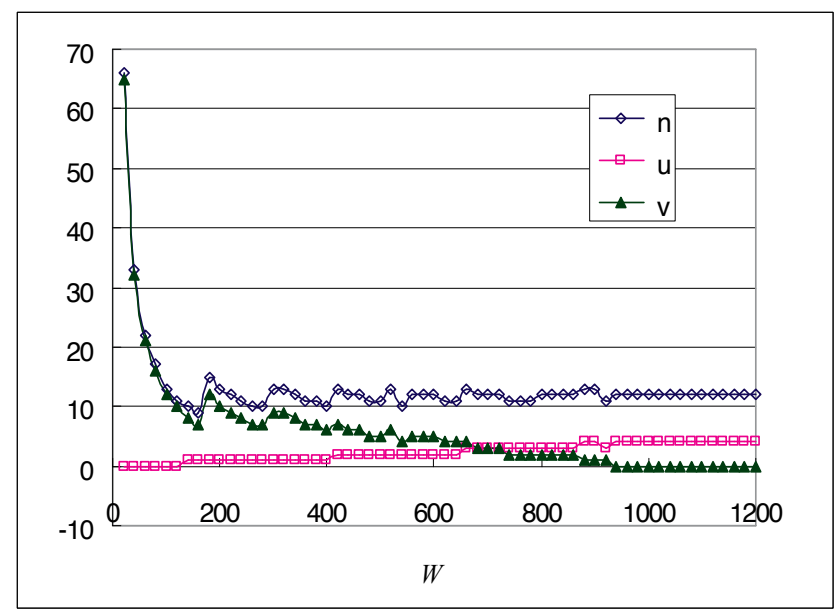

Figure 5. Impact of $W$ on the integral decision variables $n, u$, and $v$, respectively.

In addition, Figure 5 depicts the impact of $W$ on the integral decision variables, $n, u$, and $v$, and justifies the facts that $v=0$ when $W \geq U B=982.03$, and $u=0$ when $W \leq L B=122.75$ units, respectively. Note that the number of transport operations per production batch, $n$, does not show any monotonic property with respect to the vendor's warehouse capacity. As shown in the figure, $u$, the number of shipments delivered in each cycle before manufacturer's inventory level reaches $I_{\max , m^{\prime}}$ has one tilt down from $u=4$ to $u=3$ somewhere as takes the test value at 920 units. This phenomenon might be due to multiple solutions for $u$ and $v$, since the integral decision variables are discrete and not continuous. Though we conjecture that the auxiliary variable $u$ might increase monotonically as $W$ increases from $L B$ to $U B$, investigation on the mathematical properties is too complex to be completed in the present study and we leave it as future research.

\section{Conclusions}

This chapter intends to extend the study in Wang and Lee (2013). Specifically, this chapter proposes a general JELS model for a supply chain with one buyer and one vendor, both 
belonging to the same organization. The vendor is also the manufacturer and has limited warehouse capacity, which greatly influences the production and distribution decisions. By taking into account the vendor's warehouse capacity constraints, this research aims to minimize the annual total costs in the two-layer supply chain, which consist of the production setup, replenishment cost, and the inventory holding cost of finished goods on both the manufacturer's and buyer's sides. This study specifies the upper and lower capacity threshold values, $U B$ and $L B$, for classifying the manufacturer's warehouse space as "big enough" or "too small," respectively. In particular, the traditional basic JELS problems, where no capacity constraints are imposed, are just special cases of the proposed model with inactive capacity constraint.

The proposed model characterizes the maximal inventory levels of both parties in three distinct situations whether the supplier's given warehouse space is either "big enough," or "too small," or "medium in between." Impact of the vendor's warehouse capacity constraint on the inventory control policy is also investigated. Smaller space available on the supplier side drives higher total cost in the supply chain; however, neither the manufacturer's production lot nor the replenishment lot size is monotonically increasing as the manufacturer's available space increases. If the vendor's warehouse capacity is "too small," the supplier's optimal replenishment lot size equals her warehouse capacity. Once the supplier has "big enough" warehouse space, the total cost is kept flat and both the manufacturer's optimal production and replenishment lot sizes are kept constant as well. This chapter can offer an insight for the supplychain managers seeking for better coordination and cooperation, in particular, when the supplier's warehouse capacity is scarce. This chapter can also provide a guideline for planners regarding whether their companies should expand or reduce their current warehouse capacity to maintain the supply chain system economically.

\section{Acknowledgements}

The author would like to thank for anonymous reviewers for their valuable comments. This research is partially supported by Taiwan Ministry of Science and Technology under Grant MOST 103-2221-E-182-030.

\section{Author details}

\section{Sheng-Pen Wang*}

Address all correspondence to: wangsp@mail.cgu.edu.tw

Department of Industrial and Business Management, Chang Gung University, Kwei-Shan, Taoyuan 333, Taiwan 


\section{References}

[1] Agrawal K, Raju A. Improved Joint Economic Lot Size Model for a Purchaser and A Vendor. In: Khan MK, Wright CS, Whalley R. (eds.) Advanced Manufacturing Processes, Systems, and Technologies. London: ASME Books; 1996. p579-587.

[2] Banerjee A. A Joint Economic-Lot Size Model for Purchaser and Vendor. Decision Science 1986;17(3) 292-311.

[3] Ben-Daya M, Darwish M, Ertogral K. The Joint Economic Lot Sizing Problem: Review and Extensions. European Journal of Operational Research 2008;185(2) 726-742.

[4] Braglia M, Zavanella L. Modelling an Industrial Strategy for Inventory Management in Supply Chains: The 'Consignment Stock' Case. International Journal of Production Research 2003;41(16) 3793-3808.

[5] Gebicki M, Mooney E, Chen S-J, Mazur LM. Evaluation of Hospital Medication Inventory Policies. Health Care Management Science 2014;17(3) 215-229.

[6] Glock CH. The Joint Economic Lot Size Problem: A Review. International Journal of Production Research 2012;135(2) 671-686.

[7] Goyal SK. An Integrated Inventory Model for a Single Supplier-Single Customer Problem. International Journal of Production Research 1977;15(1) 107-111.

[8] Goyal SK. A Joint Economic-Lot-Size Model for Purchaser and Vendor: A Comment. Decision Science 1988;19(1) 236-241.

[9] Goyal SK, Gupta Y. Integrated Inventory Models: The Buyer-Vendor Coordination. European Journal of Operational Research 1989;41(3) 261-269.

[10] Grubbstrom RW, Erdem A. The EOQ with Backlogging Derived without Derivatives. International Journal of Production Economics 1999;59(1) 529-530.

[11] Hariga M, Gumus M, Daghfous A. Storage Constrained Vendor Managed Inventory Models with Unequal Shipment Frequencies. Omega 2014;48 94-106.

[12] Hill RM. The Optimal Production and Shipment Policy for the Single-Vendor SingleBuyer Integrated Production-Inventory Problem. International Journal of Production Research 1999;37(11) 2463-2475.

[13] Hoque MA, Goyal SK. An Optimal Policy for a Single-Vendor Single-Buyer Integrated Production-Inventory System with Capacity Constraint of the Transport Equipment. International Journal of Production Economics 2000;65(3) 305-315.

[14] Joglekar PN. Comments on a Quantity Discount Pricing Model to Increase Vendor Profits. Management Science 1988;34(11) 1391-1398.

[15] Kim SL, Ha D. A JIT-Splitting Model for Supply Chain Management: Enhancing Buyer-Supplier Linkage. International Journal of Production Economics 2003;86(1) 1-10. 
[16] Lee W. A Joint Economic Lot Size Model for Raw Material Ordering, Manufacturing Setup, and Finished Goods Delivering. Omega 2005;33(2) 163-174.

[17] Lee W, Wang S-P. Managing Level of Consigned Inventory with Buyer's Warehouse Capacity Constraint. Production Planning and Control 2008;19(7) 677-685.

[18] Lu L. A One-Vendor Multi-Buyer Integrated Inventory Model. European Journal of Operational Research 1995;81(2) 312-323.

[19] Pibernik R, Zhang Y, Kerschbaum F, Schropfer A. Secure Collaborative Supply Chain Planning and Inverse Optimization-The JELS Model. European Journal of Operational Research 2011;208(1) 75-85.

[20] Priyan S, Uthayakumar R. Optimal Inventory Management for Pharmaceutical Company and Hospital Supply Chain in a Fuzzy-Stochastic Environment. Operations Research for Health Care 2014; http://dx.doi.org/10.1016/j.orhc2014.08.001

[21] Teng J-T. A Simple Method to Compute Economic Order Quantities. European Journal of Operational Research 2009;198(1) 1289-1293.

[22] Wang S-P, Lee W. 2013. A Joint Economic Lot-Sizing Model for the Hospital's Supplier with Capacitated Warehouse Constraint. Journal of Industrial and Production Engineering 2013;30(3) 202-210.

[23] Wee H-M, Chung C-J. 2006. A Note on the Economic Lot Size of the Integrated Vendor-Buyer Inventory System Derived without Derivatives. European Journal of Operational Research 2006;177(2) 1289-1293.

[24] Zanoni S, Zavanella L. Model and Analysis of Integrated Production-Inventory System: The Case of Steel Production. International Journal of Production Economics 2005;93-94(Spec.Iss.) 197-205. 
Chapter 4

\title{
Modeling the Supply Chain \\ Management Creation of Value - A Literature Review of Relevant Concepts
}

\author{
César Martínez-Olvera and \\ Yasser A. Davizon-Castillo \\ Additional information is available at the end of the chapter
}

http://dx.doi.org/10.5772/59656

\section{Introduction}

The increased competition in the global market has obliged firms to maintain high customer service levels while at the same time, to reduce cost and maintain profit margins [1]. The paradigm shift in business practices-going from the "product-driven orientation" of the past to today's "customer-driven orientation" - is characterized by increased demand variability, product variety, amounts of customer-specific products, and shortening product life cycles [2]. In this context, firms need to be able to produce and deliver a variety of customized products at low cost, high quality and short lead time [3], while possessing high reliability and flexibility to ever-changing requirements [4]. On the other hand, the competitiveness of a company is continuously tested and determined by its participation in networks of customers, distributors, partners and suppliers [5]. This trend of globalization has forced individual firms to compete as part of supply chain (SC) links, that is, the SC of the enterprise versus the SC of its competitors [6], [7]. Therefore, the ultimate success of a company depends on its managerial capability to make strategic alliances with other reliable partners, to efficiently handle the flow of products up to the end consumers [8]. From here the idea that that the ultimate success of any enterprise is coupled with the destiny of its SC [9], [10], [11]. This changes the focus of competitiveness from the local manufacturing company to the international SC [12], [13]. Improving the overall performance of this scenario requires taking a holistic perspective [14], because at the end, the SC performance improvement depends on the individual SC partners performance, and their willingness and ability to inter-coordinate their activities [15]: by proceeding in this way, sub-optimal SC decisions-i.e. the cost saving of an individual firm 
could mean increased costs to the supply chain as a whole-can be avoided [16]. This degree of SC integration can be achieved through SC management [1], [17].

\subsection{A supply chain management formulation}

In his published work of 1999, [18] stated that the competitiveness level of the current industrial scenarios (at that time) made of SC management (SCM) a topic of interest. Since that day, several books and articles have been written about it and even today there is a diversity of interpretations and understandings of SCM, as there is a lack of agreement on the precise definition of it [7]. However, a random sample of the work of various authors in the SC arena - i.e. [19], [20], [21], [22], [23], [24], [25], [26], [27], [28], [29], [30], and [31]-allows the identification of a set of basic SCM concepts:

- Achievement of overall value-adding performance.

- Coordination of geographically-distributed independent companies.

- Operation as a whole unit.

- Synchronization of interrelated business processes.

- Suppliers' supplier to customers' customer scope.

- Strategic, tactical, and operational scale.

- Materials, information, and cash flows context.

- Set of objectives and constraints.

In this paper we summarize these concepts in the following SCM formulation:

$\mathrm{SC}$ value creation $=f\{\mathrm{BP}$ synchronization, $\mathrm{S} \& \mathrm{D}$ elements realignment, $\mathrm{C} \& \mathrm{O}$ fulfillment $\}$ where :

1. SC value creation; the primary goal of SCM is the creation of value...

2. BP synchronization; result of synchronizing the geographically-distributed Ss-Cc interrelated business processes of the independent companies (so they work as a whole unit) ...

3. S\&D elements realignment; based on the realignment of the SC partners' static and dynamic elements (i.e. network structure and decision-making processes) affecting the material, information, and cash flows...

4. $\mathrm{C} \& \mathrm{O}$ fulfilment; in the face of internal/external constraints and local/global objectives.

\subsection{SC design \& modeling}

In general terms, a SC can be considered as 1) composed by inbound logistics, component suppliers, final assembly plants, and outbound logistics echelons [32], [33], [34], [35], where the relevance of the physical functions (i.e. transportation and storage) to the efficient supply, 
are prior to the market mediation functions, i.e. supply and demand matching [36]; and 2) these echelons can have convergent and divergent interactions [37], and are characterized by a value-adding process, information inputs, disturbances, and a decision-making process [27]. As SCs are multi-layer dynamic systems, where linear flows are uncommon [38], each SC member has its own information sources [5], and decisions are made to optimize their own interest [39], SC management (SCM) becomes highly complex. A discipline that can aid in the overcoming of these issues is SC design: according to [1], the optimal platform provided by a proper SC design can improve the efficiency and effectiveness of the SCM practice. Within this context, the SC design problem consist of making the strategic (i.e. plants/warehouses location), tactical (i.e. supplier/distribution channel/transportation mode selection), and operational (raw material/semi-finished/finished product flows) decisions to satisfy customer demands while minimizing the total costs [40], taking into account that some of the critical design parameters-such as customer demands, prices and resource capacities-are generally uncertain [41]. Moreover: SC design has a strong impact on overall profitability and success [40], therefore, there is a need of SC models that provide a better understanding of the SC complexity [42], and insight of the consequences of managerial decision making rather than to predict future quantitative behavior [43]. SC modeling involves identifying the SC elementsi.e. the structure of the network, the hierarchy of decisions, the randomness of the various inputs and operations, and the dynamic nature of interactions among SC elements [44]-and translate them into the elements of the model, i.e. goals, constraints, and decision variables [6]. For this reason it has been suggested that in order to be efficient, SCM requires the modeling of the SC [45]: if the effect of operational decisions taken at each echelon need to be checked against their consequences on the SC as a whole [46], then a SC model can be built and used for this purpose [47].

\subsection{Current challenges}

\subsubsection{The SCM formulation challenge}

The implementation of the previous SCM formulation proves to be a challenge: authors like [1], [13], [15], [17], [38], [39], [48], [49], [50], [51], and [52] recognize the fact that SC partners operate independently, with their own objectives which are often conflicting. [22], and [39] go further and states that the promises of mutual benefits are rarely realized as SC members tend to seek their own profit, by working on an opportunistic local perspective. [39], [53], and [54] attribute this to the fact each SC member seeks to maximize their own objective (i.e. to maximize throughput and lower costs) rather than that of the entire system. Overcoming these problems require the entire SC to have a level of information sharing and collaboration that is uncommon to most businesses [55], mostly because each SC member operates as an independent, decentralized decision-maker that may not be willing to share necessary sensitive information (for fear of information leak or fear of a weak negotiation position) to plan and control the supply chain in a proper way [52], [56], [57]. In this context, making consumer demand data available to every echelon of the SC is often naïve: if the retailer informs that he is facing an inventory shortage, the supplier gains a strong negotiation position; if the supplier declares that he is overstocked, then it is the retailer who has an advantage. Now, even if a dominant SC member 
controls segments of the SC, in general, no SC member can control the entire SC [39], [58]. Moreover, trying to find the best set of trade-offs for any one entity often leads to sub optimize the SC performance, and independently managing entities in SC can result in very poor overall behavior [7]. In fact, in a dominance relationship, one SC partner is satisfied while the rest are not, where in an interdependent relationship, all SC partners are satisfied [5]. Also, within each partners' site, the story is repeated as the marketing, distribution, planning, manufacturing, and purchasing functions are still operated independently [1], [50], i.e. purchasing and selling contracts are often negotiated with very little information regarding capability and/or inventory levels.

\subsubsection{The SC design \& modeling challenge}

Even though the discipline of SC design has been gaining importance due to the increasing competitiveness introduced by the market globalization [59], it presents a big challenge. With an increasing SC complexity due to the need of a quick response to market opportunity windows [60], and the fact that the structure and operation of the SC is influenced by market and product characteristics [58], it becomes essential for the businesses-in order to retain its competitive edge (and deliver products to customers in an efficient and effective way)-the dynamic reconfiguration of the SC from time-to-time [61]. This dynamic SC reconfiguration calls for serious research attention [15], as it presents several challenges:

- In the ideal world, SCs are designed focused upon customer efficiency [16], with an integration of the decisions and operational activities of the business partners [39]; in real life, SC are designed focused upon factory effectiveness [16], as traditionally, managers focus on the management of their internal operations to improve profitability [39].

- It involves the re-establishment of the sophisticated real-time cooperation in operation and decision-making (across different tasks, functional areas, and organizational boundaries), in order to deal with the uncertainties proper of a mass customization, quick response, and high-quality service environment [15].

- Most of the published research (in the area of SC design), focus on high level strategic issues (i.e. generic guidelines for business executives) rather than specific tools for plant managers [62].

\subsection{Research objective and structure of the paper}

In view of the previous sections, the main objective of this paper is to present a literature review of the concepts relevant to the modeling of value creation in a SCM context: Section 2 reviews the concept of SCM value and its governance mechanisms; Section 3 reviews the current SC modeling practices and their shortcomings; Section 4 establishes the conditions and abilities necessary for a successful SCM value creation, the modeling requirements of a SC model to be used for SCM purposes, and futures research venues; Section 5 presents the concluding remarks. 


\section{SCM value creation}

As the focus of SCM has shifted from production efficiency to customer-driven and partnership synchronization approaches [15], its objective is to optimize the order fulfillment process [63], which is basically driven by customer issues [64], and influenced by the profitability of all the SC members [65]. [31] states that the objective of SCM is to synchronize supply with demand in order to drive down costs whilst increasing customer satisfaction. [1], and [4] claim that the ultimate goal of a SC is to meet the specified high customers' service levels while at the same time maintaining overall profit margins, while [36] points out that it is important that the SC maximizes the overall value generated, because sticking to a portion of the chain not only makes no commitment to maximizing overall chain profit but also reduces the whole supply chain profitability. In other words, creating and delivering value to the customer and in turn creating sustainable value for all its stakeholders. For these reasons, the demand for achievement of 'overall value-adding performance' requires putting special attention to the concept of 'value' within the SC: as the SC is formed around a value stream or set of linked activities directly contributing to the customer-perceived value of the product or service [58], authors like [6], [13], [66], and [67] agree that the main goal of a SC is the creation of internal and external value.

\subsection{Internal and external value}

The objective of a business is to make a profit by delivering more value to a customer at a similar cost to the competition, or the same value as the competition at a lower cost [68]. As organizations form part of supply chains, value becomes a more complex and multidimensional characteristic [69]. In this context, two perspectives of value are [70]:

- Internal value (or shareholder perspective, i.e. wealth) refers to the increase of profits that supports the business financial objectives and continuous grow of the SC partners. According to [71], when the strategic priorities of each SC partner are translated into SC objectives, they can be implemented as SC operations. When this translation-implementation process is successful, then a proper alignment between each SC partner strategy and the SC strategy is achieved. [72] highlights the importance of this translation-implementation process, when he states that the SC strategy must allow the rapid alignment of the SC operations in response to the business environment dynamics. [73] suggests that, in order to smooth these SC operations (and act according to the chosen SC strategy), it must be decided where the right capacities and inventories should be positioned. [74] claims that these capacities and inventories (in the form of facilities and stocking locations, production policies, distribution resources, etc.) form the supply chain structure, which needs to be optimized in order to achieve a high level of supply chain performance. [72] relates the creation of internal value to the SC design, which focuses on the design of the supply chain's strategy, structure, processes, operations, and management elements to achieve the market objectives. Finally, in order to remain competitive and profitable, each SC partner needs to realign properly their structural elements [75]. 
- External value (or customer perspective, i.e. satisfaction) refers to providing high quality products that meet the customer needs of price, service, and image. Both [9], and [76] claim that the success or failure of the SC is ultimately determined in the marketplace by the end consumer. [77] points out that the service provided to the end customer is determined by the effectiveness and efficiency of the cooperation of all the companies in the supply chainor in the words of [78]-supply chain competitiveness is something holistic. Therefore, in this customer/market-oriented context [79], the SC as a whole must focus on providing end users (the right customer) with what they want (the right product), how (the right amount/price), where (the right place), and when (the right time) they want it [62], [80]. In this context, [72] relates the creation of external value to the design for SC, which focuses on the design of the product that fits the designed supply chain to fulfill the market requirements. Within this design for SC context, in order to be effective and efficient at the SC level, it is required to simultaneously take into account the SC, product, process, and resource domains [81].

\subsection{Governance mechanisms: The SC $\mathrm{C}^{4}$ concept}

According to [82] there are some governance mechanisms that are necessary precursors to SC value creation: structural mechanisms, i.e. SC partners selection; and behavioral mechanisms, i.e. the sharing of key information, the match of SC partners capabilities, the establishment of mutual trust, and the support of strategic commitments. These behavioral mechanisms resemble the set of "social abilities" exhibited by intelligent software agents [83]: communication (to allow information integration), coordination (to allow the integration of all the involved partners), collaboration (to allow the over-ruling of the involved partners' usual behavior), and cooperation (to allow the detection of feasible common goals). As we are interested in identifying the abilities the SC partners need to exhibit (in order to support the creation of value), the rest of this section analyzes more into detail the SC C ${ }^{4}$ concept (communication, coordination, collaboration, and cooperation). Table 1 shows the similarities between concepts coming from different research disciplines.

\subsubsection{SC integration}

According to [6], and [7], the success of each SC partner depends on the managerial ability to integrate themselves with the rest of the SC. This integration can be achieved through the implementation SCM practices [1], [17]. SC integration can be defined as the process by which the SC partners collaboratively plan, implement, and manage the raw material/information/ cash flows along the SC, so all the players think and act as one-the ideal seamless supply chain [84]-in order to improve individual and collective business operations in terms of speed, agility, real time control, and/or customer response [85]. This requires many decisions relating to the flow of information, product, and funds [40], an inter-organizational, and crossfunctional synergy [8]. In the case of this last, [3] mentions shared goals, communication, a reward system, and conflict resolution as elements that impact its effectiveness. According to [86], a number of studies have found that supply chain integration does not necessarily result in benefits for both suppliers and buyers. [39] attributes this last to the fact that a completely integrated solution - that may result in optimal system performance-is not always in the best 


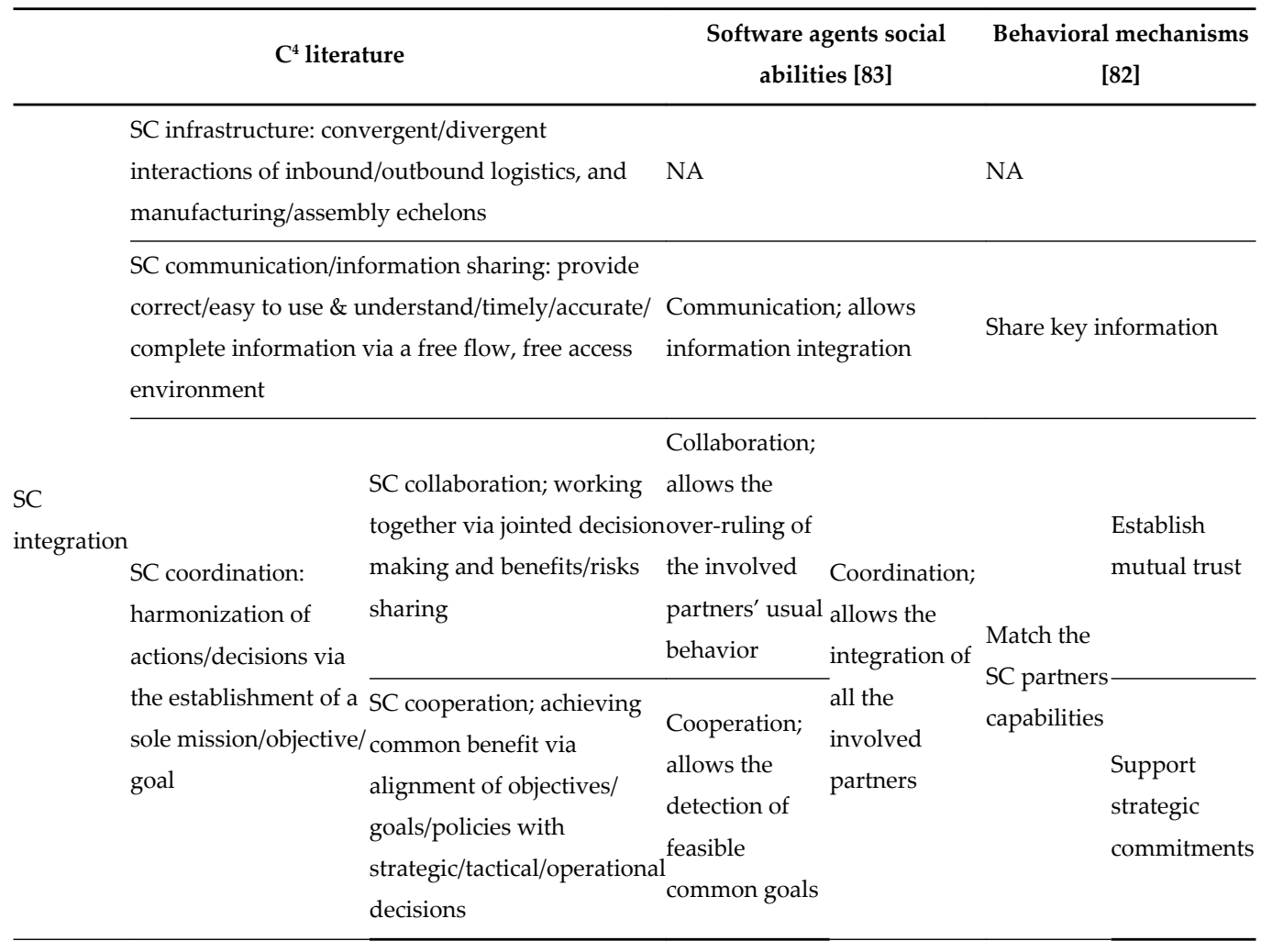

Table 1. Relationship between the SC $C^{4}$ concept and different disciplines

interest of every individual member in the system, as they are more interested in optimizing their individual objectives rather than that of the entire system. In any case, essential elements of SC integration are:

- The SC infrastructure [87].

- The level of SC communication/information sharing [88].

- The degree of SC coordination [89], [90].

\subsubsection{SC communication (information sharing)}

As the level of SC integration needed depends largely on the amount of uncertainty within the SC [91]-an issue that has to be properly dealt with in order to define an effective supply chain policy [8]-the development of an integrated SC requires the management and coordination at different levels of abstraction, i.e. operational and tactical, of material flow [92] and information flow [54], [93]. This in turn depend on the interoperability between business processes, via their standardization, mutual adjustment of practices, or synchronization of the decision centers [94]. As the majority of business processes deal primarily with information-based inputs and outputs, the key to business process integration is improving the accessibility, 
accuracy, availability, granularity, timeliness, and transparency of information flows between activities in a process, [95]. SC information sharing is a key ingredient for SC coordination [63], SC collaboration [56], and SC cooperation [96]. This SC information sharing can be upstream or downstream, partial or complete [96], and must contribute to flexibility rather than add complexity [89]. Therefore, different types of SC may require different SC information sharing strategies [63]. In any case, the deeper the SC information sharing level is, the more benefit and risk is associated [96], as information becomes more uncertain due to transformations, delays and losses throughout the SC [89]. Also, this information sharing needs to be preceded by the necessary incentives for collaboration, mutual trust, and openness [31], as the betterinformed party will have no incentive to share the information with the uninformed party if there is no benefit for them in doing so [97]. At the end, the idea behind information sharing is to minimize the coordination efforts between activities of a process [95]: the fewer steps and handoffs of information in a process, and the less effort is involved with each handoff, the greater the integration of the process.

\subsubsection{SC coordination}

Distributed work requires coordination to manage the interdependencies of the process activities, even though it has no direct impact on the process output [95]. As the SC partners become closer, the more important the coordination of the entire SC becomes [98]. For [18], the coordination is about solving conflicts (among members) via clarification of viewpoints (and their grouping in accordance with different inclinations) in a way that everyone can get to know what other members are thinking. On the other hand, [99] understands SC coordination as the distribution of the right raw materials, production of goods, and services on the right time to the right customers. SC coordination-also called interface management [27]-refers to the act of harmonizing actions, decisions, and objectives among the SC partners for the achievement of the SC goal [22], i.e. the objective of SC operations planning is to coordinate order release decisions (release of materials and resources) in an optimal way (customer service constraints are met at minimal costs) when more than one company (decision authorities) are involved [52]. Therefore, SC members should develop a common mission, goals, and objectives for the group as a whole, while pursuing independent policies at individual members' level [7]. Only if the SC operates in a coordinated manner-from the customer order through the delivery [17] - the SC performance can be optimized [19]. This requires the development of mechanisms that can align the objectives of independent supply chain members and coordinate their decisions and activities so as to optimize system performance [39]. The objective of these mechanisms, called 'coordination mechanisms', is to align the objectives of individual supply chain members, in order to allocate the benefits from coordination among the individual supply chain members [38]: at the core of a coordination mechanism there is an incentive scheme based on the supply chain decision structure and nature of demand, which highlights the behavioral aspects and information need in the coordination of a supply chain. This can be accomplished in two ways [11]: by having less need for information processing or by having more capacity for information processing. However, the dynamics of each SC partner and the market makes SC coordination difficult [17]. For this reason, it is needed that SC collaboration and SC cooperation are in place [28]. 


\subsubsection{SC collaboration and cooperation}

SCs are one of many different forms of inter-enterprise practices [25]. The ideal business model for achieving inter-organization integration is "collaboration", as limited visibility into supplier contracts and performance exposes enterprises to inflated costs, diminished negotiation leverage, missed rebates and saving opportunities, overcharging by suppliers, lowcompliance rates, greater risk of supply, policy and regulatory violations [93]. In the case of SC collaboration, it is often defined as two or more chain members working together to establish a functioning alliance [100] that creates a competitive advantage through a unified approach to value creation [70], which in turn requires considering several points of view [14]. It is achieved by jointed decision making and benefits/risks sharing [22]. Effective collaboration within each SC partner (cross-functional) and between SC partners (cross-enterprise) is essential to achieve supply chain goals, individually and collectively [73]. To implement the strategic SCM shift, from production efficiency to customer-driven, requires high-level collaboration between supply chain partners [15]. However, when getting into a collaborative practice, the closer the relationship, the higher the possibility that the transaction comes true, but also, the higher the uncertainty and risk of being stuck-in and being caught with a single partner [101]. On the other hand, cooperation is necessary for achieving common benefit or win-win situations [30], and maximize profits [15]. A cooperative SC is only possible when goals, policies, and objectives are aligned with the strategic, tactical, and operational decisions of each SC partner [56]: using effective incentive systems such as accounting methods, transfer pricing schemes, quantity discounts, etc., the objective of each partner can be aligned to that of the supply chain as a whole [8]. Cooperation, therefore, is achieved through negotiation rather than central management and control [5].

\section{SC modeling: Current work}

\subsection{Approaches, elements, perspectives, and purposes}

Even though the discipline of SC design has been gaining importance due to the increasing competitiveness introduced by the market globalization [59], it presents a big challenge. With an increasing SC complexity due to the need of a quick response to market opportunity windows [60], and the fact that the structure and operation of the SC is influenced by market and product characteristics [58], it becomes essential for the businesses-in order to retain its competitive edge (and deliver products to customers in an efficient and effective way)-the dynamic reconfiguration of the SC from time-to-time [61]. This dynamic SC reconfiguration calls for serious research attention [15], as it presents several challenges:

- In the ideal world, SCs are designed focused upon customer efficiency [16], with an integration of the decisions and operational activities of the business partners [39]; in real life, SC are designed focused upon factory effectiveness [16], as traditionally, managers focus on the management of their internal operations to improve profitability [39]. 
- It involves the re-establishment of the sophisticated real-time cooperation in operation and decision-making (across different tasks, functional areas, and organizational boundaries), in order to deal with the uncertainties proper of a mass customization, quick response, and high-quality service environment [15].

- Most of the published research (in the area of SC design), focus on high level strategic issues (i.e. generic guidelines for business executives) rather than specific tools for plant managers [62].

In response to the challenges presented in section 1.3.2., a great deal of work has been done in the area SC design \& modeling-i.e. [59] presents an extensive literature review with examples - so is not the intention of this paper to go through it again, but to present the topic divided into four aspects: approaches, elements, perspectives, and purposes.

Regarding the SC modeling approaches; [44], [77], [102], and [103] classify the different approaches for SC modeling, as analytical or simulation models. [42] offers a similar classification: deterministic, stochastic, or hybrid models. [104] divides the approaches in deterministic (where all the parameters are known), stochastic (at least one parameter is unknown but follows a probabilistic distribution), economic game-theoretic, and simulation-based (to evaluate the performance of various supply chain strategies). [105] Zhang suggests combining simulation models with Artificial Intelligence (AI) approaches-i.e. case-based reasoning (CBR), multi-agent systems, and neural networks - to evaluate not only the traditional cost and leadtime decision variables but other qualitative attributes (via interaction and logical protocols). According to [10], traditional supply chain modeling approaches involve the application of optimization, mathematical, simulation, and system dynamics models. Within the analytical (or mathematical) approach, [104] mentions the use of continuous-time differential equation models, discrete-time difference models, discrete event models and classical operational research methods. While these models allow the maximization of certain aspects, simulation models allow a more realistic capture of the SC characteristics and provide a means to evaluate the impact of policy changes [106]. More recently, [107] states that deterministic mathematical models are widely employed and are useful to evaluate the impact of various types of uncertainty on operational performance, while simulation models are employed to incorporate uncertainty in various system parameters, and are useful for evaluating the operational performance of only a particular scenario. Because of this last, simulation models have gained importance in the area of supply chain decision making [42] as powerful tools for analyzing/ designing the whole supply chain in the view of managing its stochastic behavior [108].

Regarding the SC modeling elements; [109] classifies the SC modeling elements into structural (production, transportation) and control (flow, inventory, demand, supply, information) elements. [6] establishes three structures that need to be taken into account before any SC modeling effort: type of SC partnership, structural dimensions of the SC, and process links among the SC partners. [110] states that some requirements of the modeling phase are the modeling of interdependencies, the various levels of abstraction, the modeling of splits and joins, and the modeling of simple and conditional transitions. Regarding the level of abstraction issue, [10] points out that if the focus of the SC model is more on planning and studying behavior at an aggregated level, then a certain level of aggregation must be resorted, as too 
many organizations in the model might lead to such a complex network that making sense of its collective behavior could become virtually impossible.

Regarding the SC modeling perspectives; [32] proposes the SCOPE paradigm, a three dimensional model that includes a discrete breadth perspective (work, business process, SC, and holistic networks elements), the interlinked width perspective (material, information, cash, and capacity elements), and the integrated depth perspective (organization, people, technology, and controls elements). [111] proposes a causal model which contains stakeholders, business, strategy, processes and enabling technology perspectives. [45] proposes the network structure, coordination relationships, coordination mechanisms, and process requirements perspectives. [14] presents a model which contains stakeholders, topology, enabling technology, levels of collaboration, business strategy, and processes perspectives. [105] talks about process, system, and enterprise perspectives. [72] suggests the physical alignment (of the SC with the market requirements), the reconfiguration of production processes (within the SC), and the behavioral and relationship (between the SC members) perspectives.

Regarding the SC modeling purposes; [112] suggests that there is a relationship between the type of model and the use of the model, i.e. optimization models fit the needs of continuous improvement and re-engineering projects while simulation models fit the needs of design for logistics and breakthrough projects. On the other hand, [26] suggests that SC models are either coordination-oriented (de-centralized decision making) or logistics-oriented (centralized decision making).

\subsection{Shortcomings}

Last section can be summarized as follows: traditional SC modeling is quite suitable for modeling SC decisions within a single enterprise, as it employs a centralized decision-making treatment, typically involves a single comprehensive model, and is based on the assumption of information symmetry, that is, every bit of information is known to everyone else or at least available to the model builder/decision maker [10]. In this section we review the issues related to the modeling approaches, analytical models derived, and the use of simulation models.

Regarding the approaches; [43] states that most approaches to SC modeling pay little attention to 1) multiple relationships, and focus on single supply chain;2) the effects of competition and strategy, do not incorporate price competition and/or changing order allocation; and 3) exchanges other than inventory and orders. According to [113], even though in the real world most SC consist of firms that manage both backlogs and inventories simultaneously, most of the recent work considers only pure inventory SC. [65] states that traditional SC models focus solely on determining the profit or revenue-maximizing, or cost-minimizing production schedule. [4] mentions that most of the SC modeling studies deal with the production, distribution and logistics exclusively and ignore the benefits of the integrated approach when in fact, one of the most important issues in multi-plant SC modeling is the integrated process planning and scheduling [8]. Finally, it is the opinion of [15] that due to the highly complex nature of large SCs, the use of formal and quantitative approaches are very difficult. 
Regarding the use of analytical models; are fairly complex and time-consuming to solve [17]; are too simplistic to be of practical use for complex SCs [7], [105], [106], [114]; are limited to address two or three factors at a time that rarely answers both 'what if?' and 'what's best?' questions [53]; the obtained near-optimal models are easily compromised due to unstable market environments [115]; do not capture the truly dynamic behavior of most real-world SC [61]; are high abstraction models for business processes under simplifying assumptions [42], [114]; are not able to handle all the dynamically changing supply chain variables [108]; are either oversimplified, or just qualitatively described, and difficult to be applied for evaluating real SC with quantitative analysis and decisions [15]; ignore the impact of uncertainty on the chain performance, the environment and SC members dynamics, and the complex material relationships that occur if upstream installations fail to serve downstream installations [7], [114]. In the case of uncertainty, in real life, SCs operate within an uncertain demand-supply environment-uncertainty in customer demand/quantity in supply/lead time [36], and uncertainties associated with the estimates of various operating costs and product prices [8]-which have negative effects on operational performance (i.e. cost, profitability, quality, and customer service), so the inclusion of them makes pure mathematical modeling intractable [107].

Regarding the use of simulation models; they strongly focus on the representation of physical interactions between SC partners, and entities related to SC coordination are often implicitly modeled [116]. The majority of these models are steady-state models based on average performance or steady-state conditions, static models which are insufficient when dealing with the dynamic characteristics of the supply chain system, i.e. demand fluctuations, lead-time delays, sales forecasting [104].

\section{Conditions and abilities for SCM value creation: Modeling requirements}

\subsection{Conditions}

The SCM formulation introduced in section 1.1 synthesizes the recurrent basic SCM concepts, present in the work of several different authors through the years. As this formulation considers the goal of SCM to be a function of three elements, in this paper we propose to consider them as the necessary conditions to achieve a SCM value creation. An example of some of the work already validated and reported in the literature, is the following:

- BP synchronization; [117], [44] states that business-process (BP) synchronization is achieved when a properly timing is achieved via a lead time variability reduction. For [94], on the other hand, BP synchronization takes place at the decision level, when two (or more) BPs have a common decision center. [118] mentions that within the workflow management field, an activity can be understood as a sequence of states, and two activities (or BPs, for that matter) can be synchronized through synchronization constraints dependent of their activity states. Finally, the GRAI modeling formalism [119], [120] seems to summarize the last positions, as it considers a decision center (located at the GRAI grids) as the cross between a function and a decision, where there is a time-driven part and an event-driven part: the time-driven part synchronizes the different functions based on the intervals of time 
over which a decision extends and after which a decision needs to be reconsidered; the eventdriven part represents the change of states that triggers a new function-decision interaction (represented by GRAI nets).

- SED elements realignment; [121] states that alignment can be defined as the extent to which the two related variables (independent of any performance anchor) meet the theoretical norms of mutual coherence (match/fit): if a SC partner lacks the capabilities required to meet the needs of the SC, there is an inherent inefficiency in the system. He proposes a matrix that provides the means to align the individual capabilities with the overall SC strategy and practices, in order to achieve the efficient SCM: the closer a firm is to the matrix's diagonal, the more aligned. [122] extends further the concept: SC alignment means making/taking the appropriate SC decisions to match SC objectives with the competitive objectives, making an emphasis on a holistic value creation maximization, so operating policies can be implemented through OW/OQ capabilities (i.e. volume \& mix flexibility, service, dependability \& speed delivery, cost, quality, innovativeness, etc.). With this idea on mind, he develops a five classification criteria to find the SC that best fits the marketplace demand and/or customer needs: forecast uncertainty, demand variability, demand volume, product variety, and delivery time window.

- CEO fulfillment; [41] mentions that the multi-site, geographically dispersed nature of the SC entails the coordination of SC, product, and process decisions, which in turn presents diverse constraints that need to be satisfied. For this purposes, he proposes to formulate a constraint satisfaction problem by 1) incorporating the interdependencies among markets, products' characteristics, production capacities, and multi-site structure; and 2) representing them it as a triple $\langle\mathrm{V}, \mathrm{D}, \mathrm{C}\rangle$, where $\mathrm{V}$ is a set of variables, $\mathrm{D}$ contains all the possible values that can be assumed by $\mathrm{V}$, and $\mathrm{C}$ is a set of constraints on variables in $\mathrm{V}$. The solution space that is free of constraints is expressed as a constraint graph and the solution is found beginning from the root to the leaves.

\subsection{Abilities}

The review of the SC $\mathrm{C}^{4}$ concept (made in Section 2.2.) shows how the behavioral mechanisms for SC value creation can be directly related to the elements composing an integrated SC, and for this reason, in this paper we propose to consider them as the necessary abilities to achieve a SCM value creation. Within this context, we identify four abilities necessary for SCM value creation:

- Communication; ability to share key information by providing an environment of free flow \& access to correct, easy to use \& understand, timely, accurate, and complete information. In this way, communication is possible when the means are in place and the shared information is relevant to each SC partner.

- Coordination; ability to match the SC partners capabilities by harmonizing the individual actions/decisions with the common mission, objectives, and goals. In this way, coordination is possible when each SC partner's actions and decisions are driven by a common goal. 
- Collaboration; ability to establish mutual trust by adjusting the individual behavior in accordance to a jointed decision-making and benefits \& risks sharing. In this way, collaboration is possible when each SC partner's behavior is ruled by decisions taken in agreement and because each SC partner accepts the consequences of those jointed decisions.

- Cooperation; ability to support strategic commitments by aligning the individual strategic, tactical, and operational decisions with the common objectives, goals, and policies. In this way, cooperation is possible when each SC partner's decisions are driven by a common benefit.

It must be noted that the definitions offered differ from the traditional concepts present in the SCM literature, as we consider them to be part of a continuum-in the sense of the types of SC configurations presented by [123], Table 2-of enablers to advance through the stages of the SC management maturity model proposed by [124], as shown in Figure 1.

\begin{tabular}{|c|c|c|c|c|}
\hline \multicolumn{5}{|c|}{ SC configurations [123] } \\
\hline Type & $\begin{array}{c}\text { Goal } \\
\text { congruence }\end{array}$ & Trust level & Information sharing & Decision making \\
\hline communicative & absence & reliability & nearest-neighbor basis & $\begin{array}{l}\text { Myopic (parity- } \\
\text { based) }\end{array}$ \\
\hline coordinated & $\begin{array}{l}\text { weak to } \\
\text { moderate }\end{array}$ & reliability (deterrence-based) & supply chain-wide & $\begin{array}{c}\text { Myopic } \\
\text { (asymmetric) }\end{array}$ \\
\hline collaborative & moderate & $\begin{array}{l}\text { reliability, competency, goodwill } \\
\text { (openness) }\end{array}$ & $\begin{array}{l}\text { supply chain-wide for focal } \\
\text { function }\end{array}$ & $\begin{array}{c}\text { Dyadic } \\
\text { (centralized) }\end{array}$ \\
\hline cooperative & true & reliability, competency, goodwill & web of relationships & $\begin{array}{l}\text { Dyadic (parity- } \\
\text { based) }\end{array}$ \\
\hline
\end{tabular}

Table 2. Types of SC configurations, adapted from [123]

\subsection{Modeling requirements}

Traditional SC modeling approaches are quite limited and indeed unrealistic, considering the fact that most of the SCs involve enterprises with independent ownerships, and that the ability to model information asymmetry and distributed/decentralized mode of controls is required [10]. From this last, we identify three SC modeling needs: 1 ) to represent many realistic features, i.e. different supply chain structures/configurations and production/inventory parameters, in order to validate the concepts of cooperation and collaboration (imbedded in SCM), and to optimize the existing business processes [42];2) to represent the dynamic system nature of the SC by using concepts of state variables, flows, and feedback processes [7]; and 3) to be flexible and parametric for evaluating different scenarios [108]. From here our proposal: SC modeling faces issues dealing with the number and nature of the variables used (scale-related issues), and with the assumptions and extension of the analysis (scope-related issues). The scalerelated issues refer to the characteristics of real-life SCs-i.e. multiple end products, facilities, 


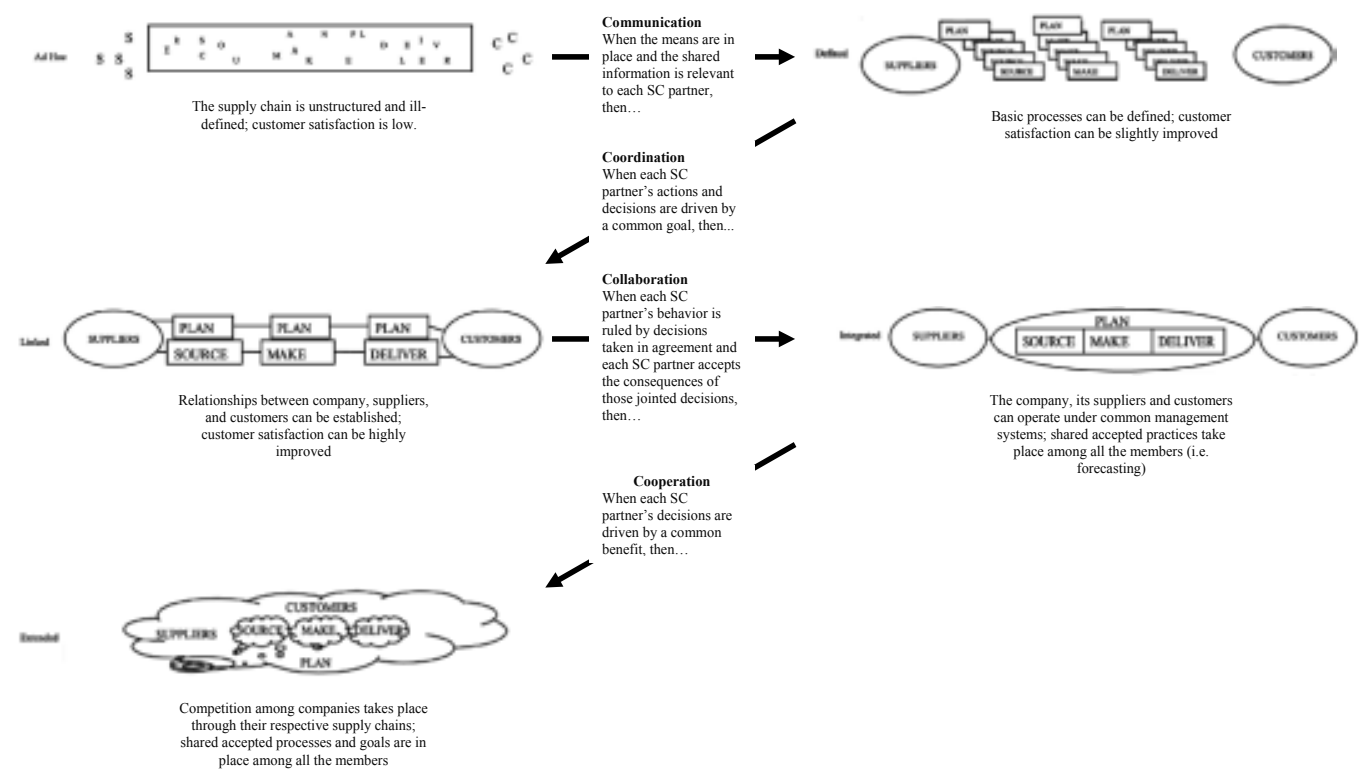

Figure 1. SCM value creation abilities, in the context of [124] SC maturity model

and capacities [49] - that make difficult the modeling effort, as there are a large number of tangible/intangible, dynamically changing variables [103], [125]. The scope-related issues refer to the existing SC models, that are limited by a number of assumptions, focus only on one certain part of the SC, or are not flexible enough to allow easy exploration of innovative policies [106], [126]. We claim that these scale and scope related issues will be overcome when SC modeling becomes comprehensive, dynamic, detailed, and realistic:

- Comprehensive, including all the members of the SC [17]; and dynamic, accommodating the upstream and downstream flows [127]. This calls for a multi-view model, as it is impossible to describe the SC from a single standpoint [45], [115], [126], [128].

- Detailed, including all the strategic, tactical, and operational levels [106]. This calls for a multi-level model, as in practice a SC face more problems concerned with quantitative issues at the operational level than with qualitative issues at the strategic level [48], [129].

- Realistic, based on real-life assumptions [126]. This calls for a multi-stage model, as the goal of SCM is the creation of value, and there is a set of conditions and abilities necessary for this creation to take place.

\subsection{Directions for future research}

As the focus of SCM has shifted from production efficiency to customer-driven and partnership synchronization approaches, its objective is to optimize the order fulfillment process, which is basically driven by customer issues, and influenced by the profitability of all the SC members. For these reasons, the demand for achievement of 'overall value-adding performance' requires putting special attention to the concept of 'value' within the SC: as the SC is 
formed around a value stream or set of linked activities directly contributing to the customerperceived value of the product or service, it is agreed that the main goal of a SC is the creation of internal and external value. If we take into account that:

1. The main goal of a SC is the creation of internal and external value, and that there are some governance mechanisms necessary precursors to SC value creation, i.e. communication, coordination, collaboration, and cooperation (SC C $\left.\mathrm{C}^{4}\right)$.

2. An efficient SCM requires the modeling of the $\mathrm{SC}$, and in order for these models to be useful and realistic, these models need to follow a multi-view, multi-level, multi-stage approach,

then the research challenge becomes then how to represent - for modeling purposes - the set of actions, decisions, goals, objectives, benefits, risks, etc. (discrete value creation conditions), within the SC $\mathrm{C}^{4}$ (continuum value creation abilities) context, and from a multi-view, multilevel, multi-stage perspective. Future research will address this issue.

\section{Concluding remarks}

In order to remain competitive within a global economy context, companies need to compete through their SCs. This demands that companies focus in create value for their customers and shareholders, act in a synchronized way when conducting their business practices, think in terms of strategic and operational impacts, and fulfill constraints and objectives in the process. A way to address this challenge is through the use of SCM practices. There are several issues related to the implementation of a successful SCM practice, which-it has been suggested - can be overcome with the help of SC design. In this paper we reviewed the issues related to the creation of value in a SCM context, as well as the approaches, elements, perspectives, and purposes of SC modeling. The contribution of this paper to the SCM literature is a set of SCM value creation conditions and abilities that need to be taken into account in a multi-view, multilevel, multi-stage context, in order to develop a real-life useful SCM model. It must be noticed the exploratory nature of this research, which does not pretend to be neither comprehensive nor final but instead, the starting point for establishing the basis of the novel discipline of SCM modeling.

\section{Author details}

César Martínez-Olvera ${ }^{1^{*}}$ and Yasser A. Davizon-Castillo²

*Address all correspondence to: martinez.cesar@itesm.mx

1 Industrial Engineering, Tecnológico de Monterrey AGS, Aguascalientes, México

2 Mechatronics Engineering, Universidad Politecnica de Sinaloa, Sinaloa, México 


\section{References}

[1] Altiparmak F., Gen M., Lin L., Karaoglan I. A steady-state genetic algorithm for multi-product supply chain network design. Computers \& Industrial Engineering 2009; $56521-537$.

[2] Hilletofth P. How to develop a differentiated supply chain strategy. Industrial Management \& Data Systems 2009; 109 (1) 16-33.

[3] Emery CR. A cause-effect-cause model for sustaining cross-functional integration. Business Process Management Journal 2009; 15 (1) 93-108.

[4] Tiwari MK, Bachlaus M, Pandey MK, Mahajan C, Shankar R. Designing an integrated multi-echelon agile supply chain network: a hybrid taguchi-particle swarm optimization approach. Journal of Intelligent Manufacturing 2008; 19 747-761.

[5] Harding JA, Lin HK. A manufacturing system engineering ontology model on the semantic web for inter-enterprise collaboration. Computers in Industry 2007; 58 428437.

[6] Min H, Zhou G. Supply chain modeling: past, present, and future. Computers and industrial engineering 2002; 43 231-249.

[7] Pawlak M, Małyszek E. A local collaboration as the most successful co-ordination scenario in the supply chain. Industrial Management \& Data Systems 2008; 108 (1) $22-42$.

[8] Demirli K, Yimer AD. Fuzzy scheduling of a build-to-order supply chain. International Journal of Production Research 2008; 46 (14) 3931-3958.

[9] Agarwal A, Shankar R, Tiwari MK. Modeling the metrics of lean, agile and leagile supply chain: An ANP-based approach. European Journal of Operational Research 2006; 173 211-225.

[10] Govindu R, Chinnam RB. MASCF: A generic process-centered methodological framework for analysis and design of multi-agent supply chain systems. Computers \& Industrial Engineering 2007; 53 584-609.

[11] Meijboom B, Voordijk H, Akkermans H. The effect of industry clockspeed on supply chain co-ordination: Classical theory to sharpen an emerging concept. Business Process Management Journal 2007; 13 (4) 553-571.

[12] Olhager J, Rudberg M. Manufacturing networks and supply chains: an operations Strategy perspective. Omega 2003; 3129 - 39.

[13] Ismail HS, Sharifi H. A balanced approach to building agile supply chains. International Journal of Physical Distribution \& Logistics Management 2006a; 36 (6) 431-444. 
[14] Angelides MC, Angerhofer BJ. A model and a performance measurement system for collaborative supply chains. Decision Support Systems 2006; 42 283- 301.

[15] Deshmukh SG, Jain V, Wadhwa S. Select supplier-related issues in modeling a dynamic supply chain: potential, challenges and direction for future research. International Journal of Production Research 2009; 47 (11) 3013-3039.

[16] Christopher M, Peck H, Towill D. A taxonomy for selecting global supply chain strategies. The International Journal of Logistics Management 2006; 17 (2) 277-287.

[17] Khoo LP, Yin XF. An extended graph-based virtual clustering-enhanced approach to supply chain optimization. International Journal of Advanced Manufacturing Technology 2003; 22 836-847.

[18] Li D, O'Brien C. Integrated decision modeling of supply chain efficiency. International Journal of Production Economics 1999; 59 147-157.

[19] Fox MS, Barbuceanu M, Teigen R. Agent-Oriented Supply-Chain Management. The International Journal of Flexible Manufacturing Systems 2000; 12 165-188.

[20] Barut M, Faisst W, Kanet JJ. Measuring supply chain coupling: an information system perspective. European Journal of Purchasing \& Supply Management 2002; 8 61171.

[21] Robertson PW, Gibson PR, Flanagan JT. Strategic supply chain development by integration of key global logistical process linkages. International Journal of Production Research 2002; 40 (16) 4021-4040.

[22] Simatupang TM, Wright AC, Sridharan R. The knowledge of coordination for supply chain integration. Business Process Management Journal 2002; 8 (3) 289-308.

[23] Chibba A, Horte SA. Supply chain performance - A Meta Analysis. European operations management association \& Production and operations management society Joint conference, Como Lake, June, 16-18; 2003.

[24] Lambert DM, García-Dastugue SJ. Internet-enabled coordination in the supply chain. Industrial Marketing Management 2003; 32 251- 263.

[25] Truong TH, Azadivar F. Simulation based optimization for supply chain configuration design. Proceedings of the 2003 Winter Simulation Conference, 1268-1275; 2003.

[26] Schneeweiss C, Zimmer K. Hierarchical coordination mechanisms within the supply chain. European Journal of Operational Research 2004; 153 687-703.

[27] Lewis I, Talalayevsky A. Improving the interorganizational supply chain through optimization of information flows. The Journal of Enterprise Information Management 2004; 17(3) 229-237. 
[28] Mansouri SA. Coordination of set-ups between two stages of a supply chain using multi-objective genetic algorithms. International Journal of Production Research 2005; 43(15) 3163-3180.

[29] Samaranayake P. A conceptual framework for supply chain management: a structural integration. Supply Chain Management 2005; 10(1) 47-59.

[30] Udin ZK, Khan MK, Zairi M. A collaborative supply chain management framework: Part 1 - planning stage. Business Process Management Journal 2006; 12(3) 361-376.

[31] Bailey K, Francis M. Managing information flows for improved value chain performance. International Journal of Production Economics 2007; 111 (1) 2-12.

[32] Berry D, Evans GN, Mason-Jones R, Towill DR. The BPR SCOPE concept in leveraging improved supply chain performance. Business Process Management Journal $1999 ; 5(3)$ 254-275.

[33] Kehoe DF, Boughton N. Internet based supply chain management: A classification of approaches to manufacturing planning and control. International Journal of Operations \& Production Management 2001; 21(4) 516-524.

[34] Van der Vorst JGAJ, Beulens AJM. Identifying sources of uncertainty to generate supply chain redesign strategies. International Journal of Physical Distribution \& Logistics Management 2002; 32(6) 409-430.

[35] Ydstie BE, Grossmann IE, Perea-Lopez E. A model predictive control strategy for supply chain optimization. Computers and Chemical Engineering 2003; 27 1201-1218.

[36] Heydari J, Kazemzadeh RB, Chaharsooghi SK. A study of lead time variation impact on supply chain performance. International Journal of Advanced Manufacturing Technology 2008; 40(11-12) 1206-1215.

[37] Mills J, Schmitz J, Frizelle G. A strategic review of "supply networks". International Journal of Operations \& Production Management 2004; 24(10) 1012-1036.

[38] Wu C, Xu K, Liu L. A three-layered method for business processes discovery and its application in manufacturing industry. Computers in Industry 2007; 58 265-278.

[39] Wang A, Li X. Coordination mechanisms of supply chain systems. European Journal of Operational Research 2007; 179, 1-16.

[40] Bidhandi HM, Yusuff RM, Ahmad MMHM, Bakar MRA. Development of a new approach for deterministic supply chain network design. European Journal of Operational Research 2009; 198 121-128.

[41] Xu Q, Jiao RJ, Ng NK, Wu Z. Coordinating product, process, and supply chain decisions: a constraint satisfaction approach. Engineering Applications of Artificial Intelligence 2009; 22(7) 992-1004. 
[42] Roder A, Tibken B. A methodology for modeling inter-company supply chains and for evaluating a method of integrated product and process documentation. European Journal of Operational Research 2006; 169 1010-1029.

[43] Allwood JM, Lee JH. The design of an agent for modelling supply chain network dynamics. International Journal of Production Research 2005; 43(22) 4875-4898.

[44] Narahari Y, Garg D, Viswanadham N. Design of Six Sigma Supply Chains. IEEE Transaction on automation science and engineering 2004; 1(1) 38-57.

[45] Li Z, Kumar A, Lim YG. Supply-chain modeling - a coordination approach. Integrated Manufacturing Systems 2002; 13(8) 551-561.

[46] Leach NP, Makatsoris H, Richards HD. Supply chain control: Trade-offs and system requirements. Human Systems Management 1997; 16(3) 159-169.

[47] Gunasekaran A, Patelb C, McGaughey RE. A framework for supply chain performance measurement. International Journal of Production Economics 2004; 87 333-347.

[48] Li D, O'Brien C. A quantitative analysis of relationships between product types and supply chain strategies, International Journal of Production Economics 2001; 73 29-39.

[49] Kaihara T. Multi-agent based supply chain modelling with dynamic environment. International Journal of Production Economics 2003; 85 263-269.

[50] Altiparmak F, Gen M, Lin L, Paksoy T. A genetic algorithm approach for multi-objective optimization of supply chain networks. Computers \& Industrial Engineering 2006; 51 197-216.

[51] Chiadamrong N, Prasertwattana K. A comparative study of supply chain models under the traditional centralized and coordinating policies with incentive schemes. Computers \& Industrial Engineering 2006; 50 367-384.

[52] Boulaksil Y, Fransoo JC. Order release strategies to control outsourced operations in a supply chain. International Journal of Production Economics 2009; 119 149-160.

[53] Shang JS, Li S, Tadikamalla P. Operational design of a supply chain system using the Taguchi method, response surface methodology, simulation, and optimization. International Journal of Production Research 2004; 42(18) 3823-3849.

[54] Robinson EP, Sahin F, Gao LL. Master production schedule time interval strategies in make-to-order supply chains. International Journal of Production Research 2008; 46(7) 1933-1954.

[55] Sahay BS. Supply chain collaboration: the key to value creation. Work Study 2003; 52(2) 76-83.

[56] Chandra C, Kumar, S. Enterprise architectural framework for supply-chain integration. Industrial Management \& Data Systems2001; 101(6) 290-303. 
[57] Kaipia R, Hartiala H. Information-sharing in supply chains: five proposals on how to proceed. The International Journal of Logistics Management 2006; 17(3) 377-393.

[58] Kehoe DF, Dani S, Sharifi H, Burns ND, Backhouse CJ. Demand network alignment: aligning the physical, informational and relationship issues in supply chains. International Journal of Production Research 2007; 45(5) 1141-1160.

[59] ELMaraghy HA, Majety R. Integrated supply chain design using multi-criteria Optimization. International Journal of Advanced Manufacturing Technology 2008; 37 371-399.

[60] Romano P. How can fluid dynamics help supply chain management?. International Journal of Production Economics 2009; 118 463-472.

[61] Dong M, Chen FF. Process modeling and analysis of manufacturing supply chain networks using object-oriented Petri nets. Robotics and Computer Integrated Manufacturing 17, 121-129; 2001.

[62] Huang GQ, Zhang XY, Liang L. Towards integrated optimal configuration of platform products, manufacturing processes, and supply chains. Journal of Operations Management 2005; 23 267-290.

[63] Tan GW, Shaw MJ, Fulkerson B. Web-based Supply Chain Management. Information Systems Frontiers 2000; 2(1) 41-55.

[64] Muckstadt JA, Murray DH, Rappold JA, Collins DE. Guidelines for Collaborative Supply Chain System Design and Operation. Information Systems Frontiers 2001; 3(4) 427-453.

[65] Puigjaner L, Guillen G, Badel, M. A holistic framework for short-term supply chain management integrating production and corporate financial planning. International Journal of Production Economics 2007; 106 288-306.

[66] Dror S, Barad M. House of Strategy (HOS): from strategic objectives to competitive priorities. International Journal of Production Research 2006; 44(18-19) 3879-3895.

[67] Eskandari H, Rabelo L, Shaalan T, Helal M. Value chain analysis using hybrid simulation and AHP. International Journal of Production Economics 2007; 105 536-547.

[68] Wilding R. The supply chain complexity triangle. International Journal of Physical Distribution \& Logistics 1998; 21 599-616.

[69] Ashkenas R, Ulrich D, Jick T, Kerr S. The Boundaryless Organization. San Francisco: Jossey-Bass; 1995.

[70] Bititci US, Martinez V, Albores P, Parung J. Creating and managing value in collaborative networks. International Journal of Physical Distribution \& Logistics Management 2004; 34(3/4) 251-268. 
[71] Schnetzler MJ, Sennheiser A, Schonsleben P. A decomposition-based approach for the development of a supply chain strategy. International Journal of Production Economics 2007; $10521-42$.

[72] Ismail HS, Sharifi H. Achieving agility in supply chain through simultaneous "design of" and "design for" supply Chain. Journal of Manufacturing Technology Management 2006b; 17(8) 1078-1098.

[73] Kampstra RP, Ashayeri J, Gattorna JL. Realities of supply chain Collaboration. The International Journal of Logistics Management 2006; 17(3) 312-330.

[74] Azadivar F, Truong TH. Optimal design methodologies for configuration of supply chains. International Journal of Production Research 2005; 43(11) 2217-2236.

[75] Vernadat F. UEML: towards a unified enterprise modeling language. International Journal of Production Research 2002; 40(17) 4309 - 4321.

[76] Christopher M, Towill D. Supply chain migration from lean and functional to agile and customized. Supply Chain Management 2000; 5(4) 206-213.

[77] Terzi S, Cavalieri S. Simulation in the supply chain context: a survey. Computers in Industry 2004; 53 3-16.

[78] Duclos L, Vokurka R, Lummus R. A conceptual model of supply chain flexibility. Industrial Management \& Data Systems 2003; 103(6) 446-456.

[79] Vonderembse MA, Uppal M, Huang SH, Dismukes JP. Designing supply chains: Towards theory development. International Journal of Production Economics 2006; 100 223-238.

[80] Griffiths J, James R, Kempson J. Focusing customer demand through manufacturing supply chains by the use of customer focused cells: an appraisal. International Journal of Production Economics 2000; 65(1) 111-120.

[81] Martinez-Olvera C, Shunk D. A comprehensive framework for the development of a supply chain strategy. International Journal of Production Research 2006; 44(21) 4511-4528.

[82] Jayaramy J, Kannanz VR, Tan KC. Influence of initiators on supply chain value creation. International Journal of Production Research 2004; 42(20) 4377-4399.

[83] Caridi M, Cigolini R, De Marco D. Improving supply-chain collaboration by linking intelligent agents to CPFR. International Journal of Production Research 2005; 43(20) 4191-4218.

[84] Towill DR, Childerhouse P, Aitken J. Analysis and design of focused demand chains. Journal of Operations Management 2002; 20 675-689.

[85] Manthou V, Vlachopoulou M, Folinas D. Virtual e-Chain (VeC) model for supply chain collaboration. International Journal of Production Economics 2004; 87 241-250. 
[86] Yao Y, Evers PT, Dresner ME. Supply chain integration in vendor-managed inventory. Decision Support Systems 2007; 43 663-674.

[87] Goutsos S, Karacapilidis N. Enhanced supply chain management for e-business transactions. International Journal of Production Economics 2004; 89 141-152.

[88] Kumara S, Surana A, Greaves M, Raghavan UM. Supply-chain networks: a complex adaptive systems perspective. International Journal of Production Research 2005; 43(20) 4235-4265.

[89] Sivadasan S, Efstathiou J, Shirazi R, Alves J, Frizelle G, Calinescu A. Information complexity as a determining factor in the evolution of supply chains. Proceedings of International Workshop on Emergent Synthesis, 237-42; 1999.

[90] Mertins K, Jochem R. Architectures, methods and tools for enterprise engineering. International Journal of Production Economics 2005; 98(2) 179-188.

[91] Van Donk DP, Van der Vaart T. A case of shared resources, uncertainty and supply chain integration in the process industry. International Journal of Production Economics 2005; 96 97-108.

[92] Mason-Jones R, Towill DR. Using the Information Decoupling Point to Improve Supply Chain Performance. International Journal of Logistics Management 1999; 10(2) 13-26.

[93] Mohammed IR, Shankar R, Banwet DK. Creating flex-lean-agile value chain by outsourcing: An ISM-based interventional roadmap. Business Process Management Journal 2008; 14(3) 338-389.

[94] Blanc S, Ducq Y, Vallespir B. Evolution management towards interoperable supply chains using performance measurement. Computers in Industry 2007; 58 720-732.

[95] Berente N, Vandenbosch B, Aubert B. Information flows and business process integration. Business Process Management Journal 2009; 15(1) 119-141.

[96] Li G, Yan H, Wang S, Xia Y. Comparative analysis on value of information sharing in supply chains. Supply Chain Management 2005; 10(1) 34-46.

[97] Hung W, Chu J, Lee CC. Strategic information sharing in a supply chain. European Journal of Operational Research 2006; 174 1567-1579.

[98] Zimmer K. Supply chain coordination with uncertain just-in-time delivery. International Journal of Production Economics 2002; 77 1-15.

[99] Ardalan A, Ardalan R. A data structure for supply chain management systems. Industrial Management \& Data Systems 2009; 109(1) 138-150.

[100] Chiu M, Lin G. Collaborative supply chain planning using the artificial neural network approach. Journal of Manufacturing Technology Management 2004; 15(8) 787796. 
[101] Hallikas J, Virolainen VM, Tuominen M. Understanding risk and uncertainty in supplier networks-a transaction cost approach. International Journal of Production Research 2002; 40(15) 3519-3531.

[102] Raghavan NRS, Viswanadham N. Performance analysis and design of supply chains: a Petri net approach. Journal of the Operational Research Society 2000; 51 1158-1169.

[103] Son YJ, Venkateswaran J. Impact of modelling approximations in supply chain analysis - an experimental study. International Journal of Production Research 2004; 42(15) 2971-2992.

[104] Sarimveis H, Patrinosa P, Tarantilisb CD, Kiranoudis CT. Dynamic modeling and control of supply chain systems: A review. Computers \& Operations Research 2008; $3530-3561$.

[105] Zhang DZ, Akanle OM. Agent-based model for optimizing supply-chain configurations. International Journal of Production Economics 2008; 115 444- 460.

[106] Shah N, Hung WY, Kucherenko S, Samsatli NJ. A flexible and generic approach to dynamic modelling of supply chains. Journal of the Operational Research Society 2004; 55 801-813.

[107] Kadipasaoglu SN, Acar Y, Day JM. Incorporating uncertainty in optimal decision making: Integrating mixed integer programming and simulation to solve combinatorial problems. Computers \& Industrial Engineering 2009; 56 106-112.

[108] Longo F, Mirabelli G. An advanced supply chain management tool based on modeling and simulation. Computers \& Industrial Engineering 2008; 54 570-588.

[109] Swaminathan JM, Smith SF, Sadeh NM. Modeling supply chain dynamics: a multiagent approach. Decision Sciences 1998; 29(3) 607-632.

[110] Huang S, Hu Y, Li C. A TCPN based approach to model the coordination in virtual manufacturing organizations. Computers \& Industrial Engineering 2004; 47 61-76.

[111] Akkermans HA. Renga: a systems approach to facilitating inter-organizational network development. System Dynamics Review 2001; 17(3) 179-193

[112] Appelqvist P, Lehtonen JM, Kokkonen J. Modelling in product and supply chain design: literature survey and case study. Journal of Manufacturing Technology Management 2004; 15(7) 675-686.

[113] Anderson EG, Morrice DJ, Lundeen G. The "physics" of capacity and backlog management in service and custom manufacturing supply chains. System Dynamics Review 2005; 21(3) 217-247.

[114] Chan FTS, Chan HK. The future trend on system-wide modeling in supply chain studies. International Journal of Advanced Manufacturing Technology 2005; 25 820832. 
[115] Kim J, Rogers KJ. An object-oriented approach for building a flexible supply chain model. International Journal of Physical Distribution \& Logistics Management 2005; 35(7) 481-502.

[116] Van der Zee DJ. A Modeling Framework for Supply Chain Simulation: Opportunities for Improved Decision Making. Decision Sciences 2005; 36(1) 65-95.

[117] Narahari, Y., Garg, D., Viswanadham, N. Design of Six Sigma Supply Chains. Proceedings of the 2003 IEEE International Conference on Robotics \& Automation, Tsipei, Taiwan, September 2003, 1737-1742; 2003.

[118] Wu, Q., Pu, C., Sahai, A. DAG Synchronization Constraint Language for Business Processes. Proceedings of the 8th IEEE International Conference on E-Commerce Technology and the 3rd IEEE International Conference on Enterprise Computing, ECommerce, and E-Services, CEC/EEE'06, 10; 2006.

[119] Ducq Y, Vallespir B, Doumeingts G. Coherence analysis methods for production systems by performance aggregation. International Journal of Production Economics 2001; 69 23-37.

[120] Poler R, Lario FC, Doumeingts G. Dynamic modeling of decision systems. Computers in Industry 2002; 49 175-193.

[121] Shah R, Goldstein SM, Ward PT. Aligning Supply Chain Management Characteristics and Interorganizational Information System Types: An Exploratory Study. IEEE transactions on engineering management 2002; 49(3) 282-292.

[122] Bolat B, Ellialtioglu B. A proposed conceptual framework for building supply chain strategies to meet marketplace requirements International Conference on Computers \& Industrial Engineering CIE 2009, 6-9 July 2009, 886-891; 2009.

[123] Lejeune MA, Yakova N. On characterizing the $4 \mathrm{C}^{\prime}$ s in supply chain management. Journal of Operations Management 2005; 23 81-100.

[124] Lockamy A, Smith WI. A strategic alignment approach for effective business process reengineering: linking strategy, processes, and customers for competitive advantage. International Journal of Production Economics 1997; 50(2) 141-153.

[125] Lee YH, Cho MK, Kim YB. A Discrete-Continuous Combined Modeling Approach for Supply Chain Simulation. Simulation 2002; 78(5) 321-329.

[126] Hwarng HB, Chong CSP, Xie N, Burguess TF. Modelling a complex supply chain: understanding the effect of simplified assumptions. International Journal of Production Research 2005; 43(13) 2829-2872.

[127] Narasimhan R, Mahapatra S. Decision models in global supply chain management. Industrial Marketing Management 2004; 33 21- 27. 
[128] Fayez M, Rabelo L, Mollaghasemi M. Ontologies for supply chain simulation modeling. Proceedings of the 37th conference on Winter Simulation Conference, 2364-2370; 2005.

[129] Huang SH, Uppal M, Shi J. A product driven approach to manufacturing supply chain selection. Supply chain management 2002; 7(4) 189-199. 
Chapter 5

\title{
Managerial Best Practices to Promote Sustainable Supply Chain Management \& New Product Development
}

\author{
Lynn A. Fish \\ Additional information is available at the end of the chapter \\ http://dx.doi.org/10.5772/59581
}

\section{Introduction}

Supply chain management is the integration of the activities that procure materials, transform them into intermediate goods and final products, and deliver them to customers [1]. New product development (NPD) processes include design and development along with sourcing through the company's development chain. In order to remain competitive, supply chains must continuously develop and deliver new products and services to the marketplace (e.g. [2-7]). Carefully matching the product characteristics to the appropriate supply chain strategy is critical to being competitive [8] and to aligning appropriate order winners and order qualifiers with customer requirements [9].

Sustainability is a new trend in Supply Chain Management and is a conceptual framework for aligning the 'triple bottom line'-environmental, social and economic dimensions [10]. Environmental sustainability is the most recognized dimension as corporations seek to reduce the natural resource consumption below the natural reproduction in both the processes and products its produces. Environmental considerations include global warming, which can be attributed to 6 greenhouse gases (like carbon dioxide, methane and nitrous oxide), and pollution. In the United States, since industrial activities account for about a third of carbon dioxide emissions and $40 \%$ occur due to transportation, supply chain activities are a primary factor in environmental sustainability [11]. Economic sustainability refers to the profitability of the sustainable efforts. Without economic sustainability, businesses will cease to exist, and this aspect becomes an order qualifier for any product. Social sustainability can be divided into both internal and external dimensions. Internal social sustainability refers to the motivation, skills and loyalty of employees and business partners in the supply chain, while external 
social sustainability refers to the value that is added to the community that the company operates in. Social sustainability is the least researched and developed dimension in NPD [12-14]. In fact, the social aspect is the least research and developed dimension in sustainability as a whole, and the social and ethical dimensions have not been given the same attention by businesses since the measurable results are less tangible [15]. Many business theories view these three dimensions as trade-offs and not necessarily 'win-win' situations. For example, environmental regulations provide social benefits; however, private costs for prevention and clean-up increase, which reduces competitiveness [16]. However, proactively, pollution prevention through product and process design is viewed as superior and more economical to pollution control through waste management [16].

Why sustainability now? Business leaders are confronting resource depletion, recognizing new roles for businesses in economic and social change, and responding to stakeholder demands (e.g. Government, employees, shareholders, environmental groups, nongovernmental organizations (NGOs), and citizens) for information and accountability [17]. Going green can save money and open new revenue streams [18]. Growing pressures exist from government and society to deal with factors contributing to global warming, raw material scarcity, and deterioration of human rights [19]. Other motivations come from consumer's concerns, intrinsic motivations of the companies or legal requirements [14]. Government policy and regulations as well as Corporate Sustainability policy may be the initial drivers for sustainability [20].

Sustainable Supply Chain Management (SSCM) can be defined as "the strategic, transparent integration and achievement of an organisation's social, environmental and economic goals in the systemic coordination of key inter-organisational business processes for improving the long term economic performance of the individual company and its supply chains" [21 p.368]. Sustainable development is grounded in the Brundtland Commission's definition as "a development that meets the needs of the present without compromising the ability of future generations to meet their own needs" [22 p. 43]. SSCM allows companies to maintain control over their supply chain and potentially achieve competitive advantages through enhancing track and traceability from raw materials through to the customer [14]. SSCM can be defined as the management of material, information and capital flows as well as cooperation among companies along the supply chain while addressing goals from all three dimensions of sustainable development (economic, environmental and social) which are derived from customer and stakeholder requirements [23]. Companies can gain competitive advantage through sustainability [24], which in turn affects the whole supply chain [25]. SSCM includes evaluation of the environmental impact, a multi-disciplinary perspective of the entire product life-cycle, and considerations for all stages across the entire value chain for each product [11].

SCM research rarely investigates the social aspects of sustainable development, such as labor practices, gender equity, wealth distribution and fair wage [26].There are a wide range of issues in sustainability development including public policies, political systems, corporate citizenship, international trade, social equity/justice, and economic growth / development. With respect to supply chain strength and environmental performance, one expects that as supply chain strength increases, manufacturing performance (measured through 
costs, quality, delivery and flexibility) are expected to improve. For example, green partnerships are positively associated with quality, delivery and flexibility performance as well as improving environmental performance [26]. Strong competition among suppliers and more demanding customers promotes fair wages and human rights within the corporation and motivates companies to contribute more to the well-being of society through local community involvement.

Firms are increasingly required to offer high quality, innovative products at competitive prices, and to develop supply chains that are sustainable in the long run [11]. NPD is the overall process through which an idea is transformed into a commercial product [27] and includes the idea generation, market research, product design, and detail engineering phases. In order to remain competitive in today's marketplace, SCM must address sustainability issues in NPD. Sustainable product development is the process of developing an improved sustainable product or service for the market [28]. Sustainability integration into NPD is still evolving and is increasing the product design complexity [12]. External factors that encourage sustainable NPD include competitors, governmental agencies, regulatory bodies, while internal factors include top management vision and strategy, and employees [29]. Product designers can significantly influence the product's sustainability over its entire life. Sustainable products addresses fulfilling the users' needs with the purpose of reducing environmental and social impacts of products while providing economic value to the company during the whole product's life cycle [30]. Green NPD, which focuses on the environment and economic sustainability aspects, is fundamentally the same as traditional NPD; however, green NPD increases the complexity [31]. A 2009 Forrester study indicated that $84 \%$ of companies surveyed had green or socially responsible products in NPD or on the market [32]. However, as recently as 2010, there was little knowledge on why and how companies integrate environmental sustainability into NPD [33].

Therefore, there is a need in today's society to address how to integrate sustainability - all three dimensions of ecological, environmental and social - into NPD and SCM. We continue by reviewing key managerial recommendations to address this. Then, since managers use metrics and frameworks to evaluate the system, we review some sustainability metrics and frameworks. We conclude with a summarization of our recommendations.

\section{Managerial recommendations}

Current literature reviews provide limited overviews of difficulties and challenges - such as cost implications, inadequate knowledge and skills, ambiguous laws and regulations, and communication and coordination complexity-in managing sustainability in NPD [31, 34]. While current efforts appear to focus on industry and policy levels, the managerial level lacks direction and attention to integrate sustainability into NPD practices. Previous research in New Product Development (NPD) within Supply Chain Management (SCM) over the past 15 years revealed critical managerial recommendations: top management support and development of an integrated NPD-SCM strategy, resource allocation, financial support, and support for a 
common, shared information system; a focus on marketing demands; supplier/customer integration; integrated networks; a coordinated, cross-functional team; and a clear product vision [35-37]. Based upon experience and a literature review of the cases, empirical reviews, and other available literature, these recommendations are still relevant to NPD in SSCM. As summarized in Table 1, we continue with a discussion of each of these recommendations to incorporate sustainability into NPD in SCM.

\section{Best Practices}

Recommendation: Top Management Support: Development of an Integrated Sustainable NPD-SSCM Strategy,

Resource Allocation, Financial Support and Common, Shared Information System

- Set the sustainable vision, mission, scope, goals and explicit strategic targets that effectively direct NPD decisions towards sustainable products.

- Develop a cohesive sustainable NPD strategy as well as a green company policy.

- Align the organization and its associated supply chains toward delivering sustainable products and services.

- Support through resource allocation, financial support and a common, shared information system.

- Develop specific managerial skills and coordinate processes for all three aspects of sustainability.

- Adopt proactive supply chain practices.

- Align sustainable NPD through processes and products.

- Provide process management support through buyer-supplier integration and such activities as creating a management-level sustainability position and employee sustainability training.

- Encourage social sustainable development through increasing designer social knowledge, improving transparency and encouraging fair trade practices.

- Support the development of a common, shared database for integration.

- Negotiate NPD-SSCM application and align with products and processes.

- Develop a green company policy.

- Create a management sustainability position.

- Increase management knowledge through entrepreneurial and innovation skills.

Recommendation: Focus on marketing demands.

- Develop market planning initiatives with a focus on end customer requirements.

- Incorporate sustainability into NPD by evaluating product safety for the end-user.

- Detect marketing needs for ecological and social demands and restrictions.

- Evaluate market changes to comply with company goals, resources and capabilities.

- Analyze the market for sustainable needs and capabilities.

- Develop procedures and rules to encourage green NPD development.

- Evaluate consumer's care for the environment and community - and how much they are willing to pay to support these concerns - and develop appropriate sustainability strategies.

- Manage environmental impact through goal-oriented and market-based mechanisms that provide flexibility.

- Consider market orientation, green targeting, green positioning, and customer outcomes influence green NPD.

- Use structured management processes to bridge market and process management.

Recommendation: Supplier/Customer Integration

- Select partners with the same guiding sustainability principles.

- Co-evolving, collaboration and joint development of products and processes that discourage pollution. Prevention and innovative environmental technologies, joint knowledge development and development of a code of conduct. 


\section{Best Practices}

- Use environmental requirements in the process of selecting new suppliers as well as the continual evaluation of existing suppliers.

- Develop closer relationship with suppliers by holding regular meetings for enhanced communication, activities that focus on communication and trust-building toward better relationships, and a focus on improving joint decisionmaking.

- Encourage a moderate level of cross-functional integration, and either a low or high level of customer integration into NPD efforts.

- Encourage collaboration and communication between supply chain members through procedures that encourage a proactive sustainability approach.

- Identify risks associated with environmental and social problems prior to public exposure.

- Analyze the entire product lifecycle.

- Develop partners through assistance and teach new methods, training, providing expert knowledge, and financial support.

- Information and data flow between supply chain members encourages collaboration and NPD efforts are more effective.

- Institute activities that ensure that suppliers use environmentally sensitive procedures.

- Pay attention to monetary and non-monetary costs of implementing integration practices in NPD that may outweigh the benefits. A moderate level of cross-functional integration but either a low or extensive level of customer integration (not moderate) in NPD is recommended.

- Encourage social sustainability in the form of decent working conditions by supplier employees by providing training and expert knowledge.

Recommendation: Integrated Networks (Practices/Processes \& Information Technology Management)

- Streamline formal processes and coordination between the stakeholders.

- Use product data management, process improvement management and engineering project management to address the globally-dispersed processes that extend across departments, companies and international borders.

- Incorporate Product Lifecycle Management (PLM) best practices into sustainable NPD, including formalization of processes (such as product-focused sustainable data handling processes, process flexibility improvement; common change management processes for economic and environmental success, and workflow management for economic process execution) and cross-functional work (including cross-company and cross-functional sustainable process alignment).

- Support Enterprise Resource Planning system data interchange between supply chain members.

- Use a product/process approach to avoid un-necessary steps that do not support sustainability efforts.

- Use a central location for data management and storage to reduce data duplication and data inconsistences.

- To mitigate the increased risks associated with SSCM, companies should utilize individual company monitoring, use generalized standards and certifications (such as ISO-14001).

- Establish a central location for data management and storage, and use a common development platform.

- Security concerns across informational boundaries increase with SCM; however, through trust -building procedures, collaboration between supply chain members improves.

Recommendation: Coordinated, Cross-functional Team

- Require and support departmental cross-functional collaboration.

- Must be supported by top management.

- Define development team roles clearly. 


\section{Best Practices}

- Include globally-inclined sustainability experts.

- Collaboration improves through sharing information which focuses the organization on common goals, sharing resources, communication, creating knowledge, using common procedures, trusting and jointly making decisions.

- Remove barriers that inhibit collaboration such as functional silos and silo thinking solely focused on economic development.

- Adopt a product/process approach.

- Encourage a resource-based view that reviews inter-firm resources towards increasing competitiveness.

- Encourage cross-functional and cross-company environmental and social data provisioning.

- Manage key sustainability resources.

- Define and jointly control data management resources.

Recommendation: Clear Product Vision

- Develop a clear definition of products.

- Integrate a seamless product delivery process for new product introduction.

- Match market requirements and value stream objectives.

- Develop a clear, defined, sustainability scope and targets that are operationalized.

- Meet a minimum threshold of acceptable performance.

- Use customized tools, databases, design for sustainability methods, and supply chain tools.

- Respect sustainability issues in process definitions.

- Define roles and responsibilities clearly.

- Educate and encourage NPD designers in sustainability.

- Build active knowledge networks.

- Management needs to establish specific sustainability targets.

- Balance program and project management toward a standardized sustainable product development process.

- Address aesthetic design advantages, which is especially important for sustainable products.

- Encourage use of Design for the Environment, design-oriented work for green operations and green supply chain management.

- Understand the entire lifecycle, the impact upon the environment at each of its stages, and incorporate product attributes and manufacturing processes into design.

- Address remanufacturing design concerns, such as product/component durability, level of re-manufacturability of products, managing the highly unpredictable return stream, consumer preferences between new and re-manufactured products, and supply constraints.

- Consider appropriate alignment of re-manufactured products to its associated reverse supply chain.

- Address Extended Producer Responsibility issues associated with new product and its associated processes.

Table 1. Summary of Key Recommendations and Best Practices in NPD-SSCM

\subsection{Recommendation: Top management support: Development of an integrated sustainable NPD-SSCM strategy, resource allocation, financial support and support a common, shared information system}

Without question, one of the most critical aspects of developing NPD with SSCM is Top Management support. Top Management involvement in sustainable NPD, which are the processes that the company's senior staff use to promote NPD activities [12, 29, 38-40], is 
essential and includes strategy development, resource allocation, financial support and support for a common, shared information system. Top management needs to actively promote sustainability through its vision, mission statement, scope, and goals towards directing NPD decision towards sustainable products [34]. Research supports the best practice in sustainable NPD as developing a sustainability vision and explicit strategic targets [41, 42]. (Unfortunately, in many industries and firms, sustainability pressures and incentives may be absent or fuzzy [34], and companies struggle with developing a sustainable vision [18]). Recent research demonstrates that many companies have some level of sustainability in its strategy and vision [18]. In today's business environment, sustainable NPD is internally-driven as external pressures and incentives are lacking in many industries [18]. A cohesive strategy, and not merely utilizing one sustainability method, tool or metric (such as life-cycle assessment or design for environment), is required to drive sustainable NPD [34]. Due to the wider array of factors, it becomes more difficult to define a strategy, vision and targets. Factors to consider include: environmental benchmarking, policy, and coordination; cross-functional coordination; top management support; and supplier involvement [41, 42]. As management begins to address sustainability, they should focus on what sustainability means for their business and products through defining a sustainability strategy, scope, targets, and processes first, and worry less about the metrics at the beginning [18].

Top management must strategically align the organization and its associated supply chains toward delivering sustainable products and services. Effective sustainable NPD requires coordination efforts with other supply chain members [18]. To be successful, companies should follow a sustainability strategy guided by the triple bottom line and place equal importance on all 3 dimensions of sustainability in decision-making [14]. For example, companies should adopt pro-active supply chain practices, such as learning from partners and other sources to gain knowledge regarding sustainability. In general the ability of companies to be innovative is especially important for SSCM [43].

With respect to environmental sustainability, top management must align green initiatives with the strategic objectives of the firm [11], which may be done through developing a 'green company policy' with a focus on green product innovation [31]. The green company policy indicates the managerial commitment to sustainable NPD through its values, norms and management practices that limit the firm's environmental impact [31]. The existence of a green company policy has a major influence on green product innovation [33]. Green demand and green regulations do not affect green NPD in the same manner in all firms [44] as industry effects on green NPD implementation are strong and significant [45]. Complex interactions between industry environment and firm specific factors exist [31]. Corporate reputation, specifically green leadership, may compensate for low financial and customer performance of green products, and is an outcome of green strategies [31]. A stronger feeling of identification with the organization due to green NPD may also result. A reputation of green leadership is directly related to a reputation of technology leadership as very green product innovations generally require advanced technology development [46]. Traditional NPD literature implies that different performance outcomes should be used for radical products than incremental 
products, and similarly, a different set of performance outcomes should be used for green and non-green products [31].

With respect to social sustainability, companies are starting to recognize the need to create social values along with profit generation and environmental protection, and the concept of corporate social responsibility is growing [26]. Social sustainability issues are difficult to incorporate into sustainable NPD, but through the corporate mission, vision, policies and strategies that top management utilizes, upper management may positively encourage designers to consider social sustainability issues in their decision-making. Additionally, training designers in social sustainability increases their understanding of the complex issues and encourages developing socially sustainable designs and processes. Training documents that promote sustainable NPD include: corporate mission, corporate performance, corporate responsibility, sustainable product attributes (e.g. healthy), sustainable packaging, reduced waste, energy reduction and reduction of carbon emissions [18]. Training employees in sustainability may provide a competitive advantage over other suppliers [18]. As an example, in 2009, Walmart's pledge to broaden its sustainability efforts to all functions within the company, to all parts of the world where it does business, and to work with suppliers (e.g. Unilever and Proctor \& Gamble) and with NGO's (e.g. the China Green Foundation) [47]. Best supply chain practices require more transparency in the supply chain due to social implications of an organization within and outside of the organization [26]. As supply chain strength increases, the supply chain may positively impact upon fair trade throughout the world.

In general, the NPD process with sustainability is generally the same as traditional NPD; however, the underlying features and mechanisms needed to address the increased complexity require specific managerial skills and coordination [31]. Management skills to develop sustainability involve innovation and entrepreneurial skills that encourage supporting sustainability knowledge [18]. Management needs to accept a certain amount of uncertainty in sustainability NPD, and encourage proactive capabilities through exploration, experimentation, double-loop learning, creativity and entrepreneurship [18].

Top management needs to insist on product and process alignment through instilling the product vision across departments. Top management establishes processes and the power to change processes resides with them. Top management provides a strategic view of the product life cycle and oversees change management [12]. Top management is involved in process management through establishing processes with development partners that encourage design team competence and remove process issues [12]. Top Management needs to articulate that sustainability is critical to the company's future and important in all buyer-supplier relationships (and a 'shared focus') as well as proliferating resources to support sustainability efforts through such efforts as creating a management-level sustainability position and employee sustainability training [18]. For example, top management's statements in training documents demonstrate upper management's support for 'protecting the earth's resources as the right thing to do'. Top management is also responsible to develop process that assist in coordinating resources toward a sustainable product design [18].

Top management needs to provide the financial resources in various business areas to encourage employees' knowledge in sustainability to grow, to utilize environmentally 
processes within the organization and supply chain, to develop stronger relationships with their suppliers and customers, and to develop and maintain an integrated, common, shared database. Similarly, top management needs to provide resources and funds to establish a common, shared database [12]. A centralized, thorough, operating product data management system, while expensive, can reduce development costs, shorten time-to-market, improve consistency and data flexibility [12]. Successful data management systems require time, expertise and resources, and a good development application. (It important that top management negotiates the application's capabilities and aligns it with the processes and products).

As an example of this critical recommendation, over the past 20 years, IBM, through its business operations and its products and services, demonstrates the relationship between economic performance and environmental/sustainability leadership [48]. IBM embedded sustainability concepts in its NPD processes and its internal continuous improvement processes. IBM's best practices in sustainable process development include: development, maintenance and integration of business and sustainability strategy; seamless execution and maintenance of operations and sustainability initiatives; develop, promote and maintain a culture of sustainability performance; and build an organization and management system to drive and execute integrated operational and sustainability goals [48].

\subsection{Recommendation: Focus on marketing demands}

In today's customer-oriented environment, another recommendation follows. A NPD-SSCM strategy needs to seamlessly incorporate critical market information into these processes and focus on the end customer. Consumers are increasingly aware of environmental and social responsibility issues and their purchasing decisions are taking these into account [32]. For example, some companies seek sustainability certifications, such as ISO-14000 (for environmental standards) and ISO-26000 (for social responsibility standards), as ways to demonstrate their engagement in sustainability [29]. Companies that lack certification or fewer then their competitors may trigger a loss of trust of negative images to the customer [29]. In response, consumer product strategists are working to bring environmental and socially responsive products to market through focusing on the key stages of the product life cycle [32]. Through product lifecycle management, managers expect operational benefits, such as cost reduction and risk management reduction, and they may influence consumer's experiences, which potentially increases revenues and market share [32]. Gradually, management is recognizing that environmental impacts of products over their life-cycle can best be managed through goaloriented and market-based mechanisms that provide flexibility [11]. While consumer's interested in supporting environmental and social issues grows, it is important that consumer product strategists evaluate the consumer's care for the environment and community - and how much they are willing to pay to support these concerns - as they develop appropriate sustainability strategies [32]. Until product sustainability is treated as unequivocally positive for the end consumer, companies will struggle with sustainability efforts and marketing products that are more sustainable [49]. Therefore, marketing efforts need to understand the end customer and develop strategies to positively influence them. 
As mentioned previously, managers can stimulate green NPD through a green company policy, and through these actions, managers can extend the product's market orientation [31]. Specifically, to build an extended market orientation toward green NPD that can balance green and non-green issues during the NPD process, managers should implement procedures and rules that encourage green NPD [31]. Designers need to balance the consumer's perceived trade-offs between product performance and sustainability [49]. To minimize misunderstandings, a structured management process with market planning and process management is required [12].

Market planning evaluates current market needs and compares them with company capabilities to meet these needs [38-40]. Detection and pursuing an understanding of end customer requirements is necessary to fulfill those requirements [12]. In order to accomplish this, current best NPD into SSCM success factors (which are supported by Product Lifecycle Management (PLM)) includes incorporating sustainability into NPD by evaluating product safety for the end-user, detecting marketing needs for ecological and social demands and restrictions, evaluating market changes to comply with company goals, resources and capabilities, and analyzing the market for sustainable needs and capabilities [12]. Customer feed-back for future products can be incorporated through web-based applications and an integrated database [50]. Changes in market requirements build a source for the next product concepts and need to be evaluated with respect to sustainable new product development, capability for introduction and resource skills [12].

Market orientation, green targeting, green positioning, and customer outcomes influence green NPD [31]. An important driver of successful product innovation strategies is the proposed market orientation (the processing of information about customers and competitors), and taking this a step further, research on sustainable NPD indicates that processing information about non-market stakeholders (regulators and special interest groups) is a critical antecedent of green product introduction [31]. Additionally, the newness of the innovation is another product characteristic that is associated with green NPD as well as market orientation and performance. With respect to the introduction of green NPD into the market, strategies are characterized by the degree to which green aspects are incorporated into green targeting (degree to which a consumer segment values green attributes) and green positioning (degree to which green attributes are used to communicate to the market how the product differs from existing products). Green targeting extends from niche to mass marketing; while green positioning firms may position green attributes at the core or not at all [31]. Greenness and industry type affect green targeting, that is, green products tend to be targeted at a green niche if a green niche is present or emerging [31]. Companies struggle to reconcile greenness with costs [31]. Unfortunately, while green niches are emerging in some markets, market demand for green products in many industries is still low [31]. A positive relationship between green products and reputation may exist as external and internal stakeholders perceptions may be impacted even though the financial outcome may be low. Very green products are often related to very innovative products. 
Managers must understand the importance of marketing of green new products which is very complex due to factors such as greenness of the product and industry factors, which impact upon green targeting and green positioning.

\subsection{Recommendation: Supplier/customer integration}

As [51] advocates there is a definitive link between product characteristics and supply chain structure, as channel structure plays an important role in product success [52]. Selecting the right supplier and forming the right type of relationships is important in building an effective supply network [51]. Improper channel design can increase costs and create adversarial supply chain relationships [8] as innovative products are best delivered through responsive supply chains while functional products are better served through efficient supply chains.

A critical challenge to sustainable supply chains is to select suppliers that follow the same guiding principles with respect to sustainability as the company, and to extend this up the supply chain to not only the direct suppliers but the entire supply chain [15]. Critical sustainability NPD questions to address include [15]:

- Which components should be made or bought?

- Which suppliers should be used for those products that are to be purchased?

- How should product design related issues be coordinated?

- What information technology infrastructure is needed to support supply chain operations?

- What enterprise production and inventory decisions best support optimal operation of the supply chain?

- What transportation strategies should be used to support the supply chain?

- What is the best way to coordinate demand planning and forecasting among all suppliers?

Sustainable supply chains are designed differently from conventional supply chains as an important change lies in searching and selecting the right partners for the supply chain [14]. Selection takes place over time and may include co-evolving, collaboration, and joint product and process development. Co-evolving evolves by improved relationships amongst members. An example is a pork producer forming a partnership with an environmental engineering bureau with similar view on farming [53]. With respect to co-evolving, joint growth in knowledge and partner development on environmental and social issues may assist toward a sustainable supply chain. Jointly implementing a code of conduct would improve the social aspect of SSCM. Collaboration with suppliers and customers is linked to the adoption of pollution prevention and innovative environmental technologies [26]. Sustainable products require internal and external interaction and collaboration in NPD [54]. Collaboration and joint development includes NPD [12, 29-57] and process development [58]. Contract-based alliances raise organizational challenges for trust and data management sharing, interoperability and communication [12]. Joint product and process development includes holding regular meetings for enhanced communication, activities that focus on communication and trustbuilding toward better relationships, and a focus on improving joint decision-making [14]. 
Process alignment and management is easier in collaborative arrangements like Joint Ventures [59]. The more partners trust each other, the higher the quality and intensiveness of information exchange [12].

Buyer-supplier relationships continue to be critical to incorporating sustainability in NPD [18]. Suppliers should be selected based on their technical superiority and cooperativeness so that a close relationship with critical suppliers can be formed [52]. Successful implementation of new and more sustainable product designs depend upon suppliers' willingness to cooperate in sustainability improvements and to implement changes; however, many suppliers have little to no interest in sustainability [18] particularly the further partners are from the end customer. Joint sustainability initiatives emphasize supplier/buyer relationships in NPD/ SSCM lead by top management and linked to metrics [18]. Shared values, goals and understanding are important to the formation of a successful supply chain relationship [18]. An often cited best practice in SSCM is the development of closer relationship with suppliers; however, building close relationships can be difficult [60]. Trust and reliability make the relationship between the partners less exposed to opportunism risks and successful NPD includes process alignment with development partners [12]. Practitioners should pay attention to monetary and non-monetary costs of implementing integration practices in NPD that may outweigh the benefits [61]. Specifically, a moderate level of cross-functional integration, and either a low or extensive level of customer integration (not moderate) in NPD is recommended.

The purchasing manager's role and abilities to recognize environmental issues connected to suppliers is also important in NPD. The coordination between environmental, Research \& Development (R\&D) and purchasing departments has a significant influence on product improvement activities, particularly with respect to the environmental supply chain, and is an important feature of environmental supply chain cooperation [62]. Cooperation with suppliers brings positive effects on supply chain management initiatives as the closer relations to suppliers concerning product-related activities are connected to higher tendencies for cooperation on environmental issues [63].

The supply chain network structure concerns the way supply chain members interact with one another including their long-term relationships, and selection and development of partners [14]. Development of partners may include assistance and teaching of new methods and financial support even in developed countries. Selection may be by abilities [64] and willingness to engage in sustainable practices [53]. Issues surrounding political strength in supplier/customer relationships still exist. Research is still needed to address which company oversees and decides upon final processes, suitability of similar and different sustainability practices between supplier and customers, and differences in sustainability visions between corporations [12].

Information and product data flow across companies is important to successfully establish a joint product development with suppliers toward sustainable products [65]. Extensive data collaboration with suppliers provides a chance to increase supply chain wide master data, which facilitates cross-functional work [12]. 
Environmental innovation and supplier involvement in the buying organization's processes is related to improved environmental performance [26]. Environmental performance as measured by waste recycling, greenhouse gas reduction and environmental innovation is positively related to supply chain strength. As demonstrated by Nestle, improved buyersupplier relationships may lead to better environmental performance [66]. As supply chain strength increases, the network becomes richer, proactive environmental management becomes a competitive advantage and a differentiation factor [26]. Therefore, the adoption of standards (such as ISO14000) and corporate environmental behavior are positively affected by the quality and quantity of supply chain relationships [26]. Building close bonds to a supplier and investing in the supplier's environmental awareness is the most important prerequisite for subsequent environmental work [60].

In any supply chain, supplier-buyer metrics need to be jointly delineated, monitored and managed. Reflective control compares and evaluates the functionality to the needs of the supply chain, through financial metrics, key performance indicators, transparency, and information sharing. An example of reflective control is Qualitative Partner Control and Auditing, whereby certification by a third party, auditing and analysis occur through written scorecards used to evaluate suppliers. An environmental audit of a supplier is a good method to monitor supplier compliance with the requirements; however, audits are not commonly performed [60]. Similarly, corporations need to institute activities that ensure that their suppliers use environmentally sensitive procedures, such as ISO-14000, or participate in an industry's voluntary code of conduct [26]. ISO-14000 represents proof of environmental performance, the supplier's environmental ambitions, advancement of supply chain practices of the customer, and the ambitions of certification bodies [60]. The value of ISO-14000 is a combination of the supplier's own environmental ambitions, advancement of environmental supply chain practices of the customer company and the ambitions of the certification bodies [60]. IKEA, Sony, Ericsson and Volvo established detailed environmental and sustainability qualification schemes for their suppliers [60]. In general, another best practice is to use environmental requirements to select new suppliers and continuously evaluate existing suppliers for sustainable practices. However, when reviewing suppliers located in different countries, the decision-maker should consider the level of environmental legislation enforcement. If the enforcement is weak, a requirement from a customer to demonstrate legislative compliance may carry different meanings, and therefore, requires different attention as compared to countries with advanced legal control and sanction systems [60].

Green purchasing is considered to have the most significant impact upon sustainability as roughly $60 \%$ of the cost of a product can be attributed to purchased materials [67]. Research in green NPD dominates (e.g. [68]) as suppliers play a significant role in green innovations [69]. Within green purchasing research, specific issues addressed include cooperation and communication between supply chain members to achieve a proactive sustainability approach, risk management to identify environmental and social problems prior to public exposure, and analysis of the total life cycle of the product [70].

Life cycle analysis (LCA) addresses the environmental impact of every supply chain stage (from raw material extraction, through material processing, manufacture, distribution, use, 
repair, maintenance, to disposal or recycling), and in particular, focuses on supply chain partnerships. LCA is a comprehensive approach to evaluate environmental impacts of products [71] and it is one of the most commonly discussed pro-active methods used [14]. LCA emphasizes the physical substance flow and chemical changes, such as ozone depletion, smog formation and acidification as it focuses on human health, ecosystem quality and resource use [15]. Chemical and toxic substances negatively influence a company's LCA [72], and therefore, reducing chemical and toxic substance use is of interest to company's pursuing sustainable products [73]. Current research indicates a gap and need for a more holistic, relational research in this area [10]. ISO-14000 provides principles, frameworks, requirements and guidelines for LCA [74-75]. LCA seeks to minimize the negative effects on the environment by looking at all phases of a product's life-cycle and taking action where it is most effective [29]. LCA requires expertise, and assumes detailed information on products, parts, use and production is available for all product life cycle phases [18]. Therefore, LCA's effectiveness is limited in early product design [76] and provides limited guidance to immature NPD organizations due to methodological problems, lack of knowledge and data [18]. Other problems with using LCA include weighting the various impacts against each other and the limited suitability for radical new products [31].

Evaluating supply chain partner's social sustainability can be difficult as many proposed indicators are dependent upon the economic resources available to a family (poverty, nutritional status, healthcare, life expectancy and living conditions). In the US, corporations may be evaluated on the average wages versus the cost of living in the region, wage equity, gender and minority wage equity, healthcare benefits, philanthropic activities, educational initiatives and workforce job safety [15]. Potential indicators for social sustainability include: labor equity (distribution of employee compensation within an organization measured through average hourly labor costs to the total compensation package for the highest paid employee), healthcare (corporations role in providing and supporting healthcare of its employees and their families measured through healthcare expenses per employee versus market capitalization per employee), safety (of the workplace for its workers possibly measured as the ratio of average days not injured to the total days worked), and philanthropy (corporations play important financial roles within a community potentially measured through the ratio of charitable contributions to market capitalization) [15]. Another possibility is to consider the United Nations Division for Sustainable Development (UNDSD) measures, which promotes meeting basic needs through poverty reductions, human health improvements and ecosystem protection as well as higher level needs such as education and gender equity. The UNDSD framework classified indicators first by primary dimensions (social, environmental and economic), then by theme (e.g., education benefits, health benefits) and then by subtheme (literacy) [77]. For social sustainability, the categories include equity, health, education, housing, security and population [77]; however, many indicators may be difficult to incorporate into decisionmaking [15]. Another method to ensure decent working conditions for the supplier employees is to providing training and expert knowledge [60]. Doing so encourages environmental awareness and prepares the supplier for more advanced work. 


\subsection{Recommendation: Integrated networks (practices/processes \& information technology management)}

In NPD, streamlined processes and coordination between the stakeholders are required [12]. Best practices to develop this includes using product data management, process improvement management and engineering project management to address the globally-dispersed processes that extend across departments, companies and international borders [12]. Formalized processes between supply chain members support doing the NPD project right and clearlydefined routines assist in developing a dedicated output being agreed upon by all development partners [38-40]. Collaboration links structural aspects of the supply chain to business processes including decisions on how to technically and logistically integrate supply chain partners, addresses the quality of information exchange and the operational processes of the SSCM system [14]. To mitigate the increased risks associated with SSCM, companies utilize individual company monitoring, use generalized standards and certifications (such as ISO-14001). In evaluating sustainability efforts, using a product/process approach avoids unnecessary steps that are not environmentally, socially and economically sustainable [12]. Structured process management to guide projects, align targets and manage sustainability targets as demonstrated by companies further along the sustainability maturity [18]. From a NPD and supply chain standpoint, as product complexity increases with a large number of target components, the value of short lead times increase and the environmental impact due to shorter distances decreases [78].

Product Lifecycle Management (PLM) addresses the information integration through all phases - including NPD - to every supply chain member [79]. PLM enhances cross-functional collaboration, reduces product data inconsistencies, and improves coordination and control of product engineers to improve NPD [80]. Information on revenues, costs, time, energy and material information is exchanged across the organization and companies by integrating product-specific processes, skilled people, and product data [29]. PLM's purpose is to streamline product development and assist in innovation. The PLM information system must support data exchange from first conceptualization through its disposal, should allow for any data component to be directly accessible, store relevant information, serve all functional areas, potentially offer reuse of the product information and provide fine-grained information regarding the product's description and rationale [79]. The PLM must support design and manufacturing process components for large volumes of product information both horizontally and vertically to systems such as ERP systems [79]. PLM supports collaboration through a central data provision for product data management [81]. In PLM, processes need to be designed according to the product and material flow in order to facilitate and accelerate product development [12]. Sustainable NPD success factors supported by PLM include formalization of processes (including product-focused sustainable data handling processes, process flexibility improvement; common change management processes for economic and environmental success, and workflow management for economic process execution) and cross-functional work (including cross-company and cross-functional sustainable process alignment) [12]. PLM supports operations management in reducing managerial complexity in NPD [82]. A common product development platform toward economic product development 
balanced with program and project management toward a standardized sustainable product development process is also recommended for a successful NPD [12].

With respect to sustainability, acquiring data on environmental performance and social sourcing is enabled by product data management [12]. An environmental management system (such as ISO-14000) requires organizational structures, routines, and a knowledge base to manage the company's direct environmental aspects [60]. Organizational benefits are connected to legal compliance, while financial benefits originate due to a reduction in resource use, waste reduction and operational efficiency improvements [60]. External driving forces for an environmental management system come from potential corporate image improvement, market advantages, satisfying customer requirements and public pressures, while internal driving forces for working with supply chain related environmental issues include the link between the purchasing function and other functions, purchasing procedures, partnerships with suppliers, technical skills and environmental knowledge that impact upon the adoption of supply chain activities [60]. Product data management supports the idea of a single source for product data and product sharing, which enhances collaboration activities [12]. Data management plays a significant role in PLM to store relevant product data, especially the data that is integrated with development partners [29]. In PLM, a central location for data management and storage is required to reduce data duplication and data inconsistencies [12]. Research implies that investment in environmental management systems is related to the location in the supply chain versus the end consumer [60]. The closer partners are to the end consumer, awareness increases; while the farther partners are less aware. Additionally, security concerns across informational boundaries increase with SCM; however, through trust -building procedures, collaboration between supply chain members improves. Collaborative product development speed increases after the first years when uncertainty in data security is replaced with mutual trust [12].

\subsection{Recommendation: Coordinated, cross-functional team}

Cross-functional collaboration among departments is a success factor for sustainability in NPD [83]. In today's business environment, cross-functional development may include internal organizational integration as well as inter-firm (external) collaboration [61]. Top management must support cross-functional work - where people from different areas work jointly toward a new product [38-40].

Cross-functional teams reflect the core values of sustainable new product development [84]. The development team needs to know their roles and functions in detail, so collaboration can occur [85] and include experts with sustainability capabilities [12] Global design activities require global-acting experts who are responsible for several projects which provides the advantage in standardization and expert-resource utilization [12]. Knowledge management activities support team training and learning for NPD personnel and may facilitate knowledge creation and sharing [18].

Engineering collaboration across companies is essential to develop innovative and sustainable products. Collaboration is critical for product improvement, cycle time and cost reduction [86]. Other benefits to cross-functional integration in NPD include linking 
functional viewpoints, information exchange beyond functional boundaries [87]; efficient resource allocation and pooling of capabilities, providing access to new skills or technologies, and sharing of R\&D costs and risks leading to enhanced NPD [88-89]. Successful collaboration is dependent on technology and organized processes [86]. The first step towards collaboration is for a company to remove functional silos and adopt a product/ process approach [90]. Specific to sustainability, a resource-based view that reviews the inter-firm resources that are valuable for increased competitiveness is needed [12]. Factors that assist in collaboration include: sharing information which focuses the organization on common goals, sharing resources, communication, creating knowledge, using common procedures, trusting and jointly make decisions [26, 29, 86, 91].

A collaborative environment, tools, interoperability standards, and architectures must be coordinated so that barriers do not prevent collaboration. Barriers to collaborations include poor communication and a lack of process harmonization [92] that induce silo thinking [12]. Global teams in NPD require suitable applications supporting communication and collaboration to enable teams to work at different locations [63]. Barriers include: organizational costs, time and efforts for team meetings, coordinating the workflow of team members from various functional units, solving inter-functional conflicts and the potential information overload of NPD members' processing capabilities [93], opportunistic behavior by one, knowledge spillover, distrust, costs of monitoring inter-firm partners, and communication problems due to different organizational cultures [89, 94].

NPD Success Factors supported by PLM includes: cross-functional and cross-company environmental and social data provisioning, avoidance of silo thinking solely focused on economic development, and management of sustainability key resources [12]. In strong collaborative relationships, data management is defined and controlled jointly [12].

3DCE (three-dimensional concurrent engineering) is a concept coined by [51], which is a potential NPD model supported by concurrent engineering [52]. NPD literature focuses on support for concurrent engineering, early supplier involvement, understanding customer requirements and channel structure. While 3DCE extends this view as it focuses on the product, processes and supply chain simultaneous design through multi-functional teams early in the process that may include suppliers and customers. Implementing a new system and effectively managing processes requires active participation and engagement of top management to build a shared vision. These concepts, such as 3DCE and concurrent engineering, need to be extended to include sustainability concepts in NPD.

\subsection{Recommendation: Clear product vision}

During NPD, designers need to evaluate supply chain processes and decisions (such as logistic channels, the optimal location choice, mode and frequency of transport, inventory levels, and degree of postponement appropriate for the particular product and its life cycle stage) as well as predict and understand product life cycle aspects associated with duration, delivery window, volume, variety and variability [9]. The product delivery process and a new product introduction must be as seamless as possible so products flow as required by the customer 
throughout the life cycle. The product and its associated supply chain must match market requirements and value stream objectives in order to best compete [8]. During the introduction stage, the key order winner is the lead time from concept through design availability and capability, which favors a 'design-and-build' strategy [9]. During growth, product availability during the increased demand time period is the order winner and as a result the product moves towards an MRP push-based supply chain [9]. At maturity, the Kanban supply chain becomes the most effective form as cost is the critical order winner [9]. Finally, at decline, as demand decreases, the MRP supply chain becomes relevant, until demand significantly tails off and the 'design-and-build' facility is relevant [9].

Unfortunately, there is a wide gap between consumer's articulated support of sustainability and disproportionately low levels of actual 'sustainable consumption' [95]. To management this implies that only some consumers may be willing to sacrifice some degree of functional performance for sustainability; products must still meet a minimum threshold of acceptable performance, and it is critical to reassure consumers that the product meets an acceptable minimum level of functional performance [49]. Therefore to promote sustainable products to market segments, it is important to find ways to improve consumer's confidence toward these products. As sustainability importance increases, consumers are increasingly likely, due to an increase in guilt, to choose the sustainable-advantaged product. In a case study, companies with a lack of customer demand for sustainable products found that customers tend to stick to conventional products instead of buying eco-products, even if price, quality and functionality are the same [18]. Researchers continue to explore the perceived trade-off between product performance and sustainability [49].

Since consumers often believe there is a trade-off between sustainability and functionality [96], they tend to choose the product with superior functional performance over the sustainabilitysuperior product until a minimum threshold of functional performance is achieved [49]. The trade-off depends upon the degree to which consumers' value sustainability and is mediated by consumers' feelings of confidence and guilt. Superior aesthetic design has a disproportionately positive effect on the likelihood of sustainability-advantaged (versus performanceadvantaged) products due to the effect that superior aesthetic design has on overcoming the potential lack of confidence in sustainable products [49]. Therefore, a key recommendation for company's interested in marketing sustainable products is to develop market-leading product aesthetic design capabilities [49].

Recently, research on green product innovation activities is growing and includes investigating strategy development, market and environmental performance of green product innovations, and design strategies-such as recycling and remanufacturing [31]. Green NPD is related to market orientation and green company policy as antecedents of product characteristics must be balanced (greenness, relative advantage, costs and newness) and introduction characteristics (green targeting and green positioning) must be established [31]. In turn, these product characteristics determine NPD financial, customer, technological and reputation outcomes. Other aspects of green NPD include evaluating environmental concerns, design specifications, project team coordination, upper management support, and 
product outcomes. While reputation may not be a measurable outcome of a green NPD process, managers need to consider both internal and external reputation impact in the NPD process [31]. Methods for addressing specific sustainability issues include: Design for Environment (DfE), design-oriented work for green operations and green supply chain management $[23,56,70]$, and other tools and metrics that can be used to make design decisions more sustainable.

In mature sustainable NPD processes and organizations, sustainability scope and targets are clear and operationalized; customized tools, databases, design for sustainability methods, and supply chain tools are used; sustainability issues are respected in process definitions; roles and responsibilities are defined; and NPD designers have expertise in sustainability and are active in knowledge networks [18]. Management needs to establish specific sustainability targets, such as energy efficiency, carbon dioxide footprint, product weight, materials (recyclables and recycling), sustainable packaging, and hazardous substances [18]. Also, a clear definition of products within product development is needed [97].

In NPD, each component's economic, environmental and social impact needs to be evaluated. Product designers need training to understand each of the three sustainability environments. Designers need to monitor NPD and costs through the all of the NPD phases of idea generation, idea screening, concept development and testing, marketing strategy, business analysis, product development, test marketing and commercialization, and to realize that as more information is gathered, it is easier to estimate NPD costs [98].

Case analysis reveals that companies consider greenness to be a product characteristic that must be balanced throughout the entire NPD process against non-green characteristics, such as newness, product costs and relative advantage [31]. The environmental impact of products occurs across the dimensions of materials, energy and pollution [33] and needs to include all supply chain management processes including packaging and transportation activities. NPD designers need to incorporate environmentally conscious manufacturing and product recovery into design, material selection, manufacturing processes, product delivery to the consumers, and end-of-life product management [99]. They need to understand the entire lifecycle and impact upon the environment at each of its stages, and incorporate product attributes and manufacturing processes into their design for the environment.

DfE addresses designing and developing recoverable products, which are durable, repeatedly usable, harmlessly recoverable and environmentally compatible in disposal [100]. Currently, designers are unfamiliar with the associated manufacturing processes, which in turn lead to coordination issues between supply chain members. Research is particularly lacking in the DfE area [10]. In DfE, sustainability attributes including recyclability, energy efficiency, maintainability, and reusability are treated as design objectives rather than constraints [101]. As seen in Table 2, DfE relies on contextual information to select an appropriate DfE strategy [102] and to establish design specifications and requirements [18]. When contextual factors are not well defined, firms may struggle to manage sustainability efforts. 


\begin{tabular}{|c|c|}
\hline Contextual Factor & Comments \\
\hline $\begin{array}{l}\text { Perceived/expected customer demand for } \\
\text { sustainable products }\end{array}$ & Customers may demand sustainable products or services. \\
\hline $\begin{array}{l}\text { Actual performance of sustainable products } \\
\text { on market. }\end{array}$ & $\begin{array}{l}\text { Actual sales feedback regarding sustainable products in the marketplace. } \\
\text { Positive sales results reinforce sustainable practices, while negative sales } \\
\text { results undermine them. }\end{array}$ \\
\hline Competing on Sustainability & $\begin{array}{l}\text { Competitors' behavior regarding sustainability may force firms to modify } \\
\text { behaviors to stay in the market. Additionally, sustainability may be used } \\
\text { as a competitive advantage. }\end{array}$ \\
\hline $\begin{array}{l}\text { Environmental and Social Laws and } \\
\text { Regulations }\end{array}$ & Firms must comply with laws and regulations. \\
\hline Sustainability pressure groups/stakeholders & $\begin{array}{l}\text { Community and environmental stakeholders may exert pressures to } \\
\text { improve a certain aspect of sustainability }\end{array}$ \\
\hline Supply Chain Complexities & $\begin{array}{l}\text { Customers may 'pull' and suppliers may 'push' sustainable products. } \\
\text { Example: suppliers may develop more sustainable methods to mine } \\
\text { materials or produce parts, or they may not cooperate with sustainability } \\
\text { efforts. }\end{array}$ \\
\hline
\end{tabular}

Table 2. Contextual Factors and Comments (Based upon [18])

Reverse value chain activities (reuse, repair, refurbishing, recycling, remanufacturing or redesign of returned products) may create additional competitive advantages [103]. A centralized, efficiency-driven reverse network is not always the most appropriate for remanufactured goods [104]. When high return rates and recoverable value is high, responsive supply chains focusing on speed through decentralization should be designed. If returned products are unused, consideration to an early product differentiation strategy should be given. Marketing drivers for product re-manufacturability include high production costs for a single-use product, low remanufacturing costs, and low incremental costs to change a singleuse product to a remanufactured one [105]. Re-manufacturing valuation, pricing and design decisions include product/component durability, level of re-manufacturability of products, managing the highly unpredictable return stream, consumer preferences between new and remanufactured products, supply constraints, extent of cannibalization between new and remanufactured products, competitors in both markets, efforts to gather re-manufactured products, and the reverse supply network [11]. Management and new product designers must also consider the timing and volume of used product returns, re-manufacturability, diffusion rate, and repeat purchase. Additional NPD must consider which components may be reused for manufacturing products, which components will retain their original functionality, and how many times a component may be reused for the same kind of product [11].

Extended Producer Responsibility (EPR) policies are being developed to shift responsibility for life-cycle environmental performance toward producers and away from local municipalities through providing incentives to incorporate environmental considerations into the design 
of products [11]. EPR efforts include product take-back and recovery targets (e.g. home appliance recycling in Japan), disposal fees and material taxes (e.g. states that tax disposal of tires in the US), and design/performance standards (such as fuel efficiency laws in the US). Strategies to encourage EPR that impact upon NPD include changing product design to incorporate end-of-life take back, disassembly and reuse; rationalizing parts and components to decrease material usage, eliminate hazardous substances, and facilitate remanufacturing; and choosing optimal product durability to include planned obsolescence and planned takebacks and replacements. Additionally, EPR considers different contractual arrangements with suppliers and distributors toward joint planning and responsibility over the product life cycle to include reverse supply change structure and remanufacturing. EPR contracts, such as pricereplacement interval, two-part tariff and leasing, can assist in supply chain coordination, improve supply chain profitability and lead to environmentally superior product designs [106]. Existing 'fee-upon-sale' types of e-waste regulation cause manufacturers to increase their equilibrium development time and expenditure; however, existing 'fee-upon-sale" types of e-waste regulation fail to motivate manufacturers to design for recyclability. Contrastingly, 'fee-upon-disposal' types of e-waste regulation (such as individual extended producer responsibility) motivate design for recyclability, but often fail to reduce the new product introduction frequency [11].

In recent years, environmental protection programs (such as the Title IV of the Acid rain program developed by the EPA in the US, Regional Greenhouse Gas Initiative in the northeast or the Western Climate Initiative in the western US and the Kyoto Protocol) have been instituted throughout the world to limit and reduce greenhouse gas emissions through 'capand-trade' programs. Relative to the discussion here, questions regarding the impact of these programs on sustainable NPD exist. Specific questions that need to be addressed include [11]:

- How do carbon prices affect product line design decisions when different products require different capacities and have different levels of emissions during production?

- How do different regulatory regimes affect a firm's technology choice?

In the future, supply chain members may trade 'emissions' rights within the supply chain to optimize the value chain.

\section{Sustainability metrics in NPD/SCM}

Many companies are concerned about the measurability of sustainability [18]. Top management needs clear, relevant metrics to track implementation progress, benchmark against other companies and to report their progress to the outside world [20]. The metrics should be linked to business metrics that executives and shareholders care about as sustainability programs built solely upon philanthropy will not survive [20]. For example, to track and monitor customer integration, management may consider using an employee survey or appointing an expert to track benefits customers give to the NPD process and then assess the feasibility of the customers' ideas [61]. To measure the efficiency of internal cross-functional integration, 
management should question employees about how the integration practice contributes to the progress of the NPD process, and track the frequency and quality of NPD teams' meetings [61]. With regard to external partners, management may consider monitoring the level of trust and seek allies that offer complementary capabilities [61]. Corporate attainment of sustainability certifications, such as ISO-14000 and ISO-26000, represent a commitment to sustainability.

Several frameworks to evaluate sustainability for the entire product life cycle exist, such as the Dow Jones Sustainability Index, the Corporate Social Responsibility and Sustainability Ratings and Information Database (CSRHub), and Corporate Executive Board [20]. The DJSI monitors sustainability for the entire product life cycle across many functions and is useful at the company level for benchmarking; however, it is expensive and time consuming. CSRHub, which is a broad-based model that is divided into community, employees, environment and governance, gives corporate social responsibility ratings for several companies, industries and countries. With a paid subscription, CSRHub allows additional benchmarking information. Unfortunately, CSRHub is difficult to use to develop a strategy to improve sustainability maturity within R\&D and NPD functions. CEB uses several dimensions grouped by focus areas and scores each dimension according to its importance to the organization. With CEB, the organization's effectiveness relative to each dimension and information relative to $R \& D$ and NPD is available. Unfortunately, CEB is proprietary and best practice tools and processes for various elements are only available to Council members, which limits its use as an improvement tool.

Specific to NPD and the environment, [107] developed a model that considered the impact of NPD decisions on future resources and environmental conditions. The [107] model uses system analysis to develop the financial performance relative to design and process characteristics that affect future resources and the environment, but does not consider social sustainability. The [107] model focuses on the product definition but is a predictive model rather than an evaluative model. The IRI Sustainability model focuses on R\&D and NPD functions that support them, using 14 dimensions organized by strategy and design tool to give a holistic view of R\&D and NPD sustainability [20]. Strategic dimensions include: corporate sustainability policy, overall sustainability policy, government policy and regulation, impact of trends, supply chain, green labeling and sustainability DfE, while design tool dimensions include: specifications/customer insights, life cycle assessment (LCA) process, DfE-Material and Part Selection, DfE-Supply Chain, DfE-Manufacturing Impact, DfE-Use Phase Impact, and DfEEnd of Life Impact. The IRI Sustainability Maturity Model can be used to measure sustainability process maturity and to benchmark against other sustainability innovation programs; however, a statistically insignificant number of firms to date use this model and each dimension is equal [20].

\section{Conclusions}

In recent years, sustainability is becoming more important in all aspects of business and supply chains. Companies are developing and implementing strategies to incorporate sustainability 
into the products and services that they deliver to the marketplace. In order to remain in business, every company and its associated supply chain must design and deliver new products. These new products must address the growing sustainability movement. However, NPD incorporating sustainability within SCM is not an easy undertaking.

Based upon experience and a literature review of cases, empirical reviews, and other available literature, recommendations for NPD in SCM [35-37] are relevant today for NPD in SSCM. As outlined above, the managerial recommendations include: top management support and development of an integrated NPD-SSCM strategy, resource allocation, financial support, and support for a common, shared information system; a focus on marketing demands; supplier/ customer integration; integrated networks; a coordinated, cross-functional team; and a clear product vision. A single, NPD-SSCM strategy does not exist; however, managers need to consider the specific product, industry, and country factors relevant to their market and supply chains in strategy development.

With respect to economic sustainability, new products that fail to meet the cost-value proposition of the final customer cease to exist in the marketplace. Designers need to carefully analyze sustainable aspects during the design phase, and these sustainability efforts need to continue to be managed throughout the product lifecycle. To be successful, designers should focus on the sustainability requirements of the end customer. Market orientation, green targeting, green positioning, and customer outcomes all influence green NPD. Products - and their companies - that do not meet the economic needs of the end customer will cease to exist. Therefore, economic sustainability is an order qualifier for any new product.

With respect to environmental sustainability, efforts in the past two decades to consider the environmental impact of new products and their associated processes as the product moves through the supply chain have increased significantly. Procedures, such as PLM, DfE, and LCA have all gained in momentum as businesses look to reduce, reuse or recycle their products and associated materials, and reduce the environmental impact of the various processes associated with delivering the product from the raw material supplier to the end customer. However, current research notes that the end customer does not fully recognize the value and is often not willing to pay the additional costs associated with environmentally friendly products. A key recommendation to meet this challenge is to develop market-leading product aesthetic design capabilities geared toward the end customer requirements.

With respect to social sustainability, this is the least researched area of sustainability. To foster, NPD in SSCM, supply chain members should seek other supply chain members with similar socially sustainable values. Trust-building and communication are imperative to developing both internal and external social responsibility surrounding any product and supply chain. Corporate social responsibility toward the local and global communities that surround businesses and their supply chains has also gained momentum in the past decade. Companies have rallied around particular causes, such as the American Cancer Association, or sponsored employee events that give back to society, such as United Way days. To encourage social sustainability with respect to new products, companies need to leverage the brand image that they are creating to foster positive customer perceptions. Similar to environmental sustaina- 
bility, when customers do not associate with the social sustainability efforts of the company, they may be less likely to spend more for the new 'socially' sustainable product.

In general, the recommendations and the discussion about each of the three areas of sustainability - economic, environmental and social, all relate to a critical, underlying requirement: the need for NPD and SSCM to focus on end-customer requirements. In order to develop successful products, NPD-SSCM strategies need to address moving environmental and social sustainability into the 'order winner' category for the end customer.

This chapter represents a sampling of significant research efforts in NPD-SSCM that support the continued promotion of the original recommendations for innovative design in supply chains [35-37]. In general, critical failings for this research include a lack of specific data and test cases as confidentiality agreements hinder discloser, and a lack of testing interactions due to difficulties in analysis and interpretation between factors such as industry, quality, cost, timing, and global factors. As indicated at several points in the above discussion, many unanswered questions remain in both the research and practitioner worlds. As noted above, research avenues include: research to address which company oversees and decides upon the final processes and product; how to resolve differences between sustainability visions between partners; how to develop more holistic, relational research in LCA; how to resolve differences in sustainability practices between partners; how to fully incorporate all three dimensions of sustainability into NPD methods such as 3DCE; how to assess and address customer's perceived trade-offs between the three sustainability dimensions; and how to address the varying prices associated with technology for greenhouse gas emission; and how to address different global regulatory issues and the technology choice associated with NPD? Research opportunities abound!

\section{Author details}

Lynn A. Fish*

Address all correspondence to: fishl@canisius.edu

Department of Management, Canisius College, Buffalo, NY, USA

\section{References}

[1] Heizer, J.,Render, B. Operations Management, Tenth Edition, Upper Saddle River, NJ: Prentice Hall; 2011.

[2] Birou, L., Fawcett, S. Supplier involvement in integrated product development: A comparison of US and European practices. International Journal of Physical Distribution \& Logistics Management 1994; p4-15. doi:10.1108/09600039410063982 
[3] Brown, S., Eisenhardt, K. Product development: Past research, present findings, and future. The Academy of Management Review, Mississippi State, 1995; p343-363.

[4] Clark, K., Fujimoto, T. Product development performance. Boston, MA : Harvard Business School Press; 1991.

[5] Puddicombe,M., Dixon, J., Kim, J., Rosenthal, S. An Examination of the Determinants of Performance in an Interorganizational Project Environment. In: Decision Sciences Institute 2000 Proceedings, Orlando, FL: DSI; 2000; p1147-9.

[6] Simchi-Levi, D., Kaminsky, P., Simchi-Levi, E. Designing \& Managing the Supply Chain: Concepts, Strategies \& Case Studies, Third Edition. NY, NY: McGraw-Hill, Irwin; 2013.

[7] Stock, G., Greis, N., Fischer, W. Absorptive Capacity and NPD. In: Decision Sciences Institute 2000 Proceedings. Orlando, FL: DSI; 2000, p1182-4.

[8] Fisher, M. What is the right supply chain for your product? Harvard Business Review 1997; 75:105-116.

[9] Aitken, J., Childerhouse, P., Towill, D. The impact of product life cycle on supply chain strategy. International Journal of Production Economics 2003, 85: 127-140. doi: 10.1016/S0925-5273(03)00105-1

[10] Ashby, A., Leat, M., Hudson-Smith, M. Making connections: A review of supply chain management and sustainability literature. Supply Chain Management 2012; 17(5): 497-516. doi:10.1108/13598541211258573

[11] Gupta, S., Palsule-Desai, O.D. Sustainable supply chain management: Review and research opportunities. Indian Institute of Management Bangalore Management Review 2011; 23: 234-245.

[12] Gmelin, H., Seuring, S. Achieving sustainable new product development by integrating product life-cycle management capabilities. International Journal of Production Economics 2014; 154: 166-177. doi:10.1016/j.ijpe.2014.04.023

[13] Mu, J., Zhang, G.,MacLachlan, D.L. Social competency and new product development performance, IEEE Trans. Eng. Management 2011; 58(2): 363-376. doi:10.1109/ TEM.2010.2099231

[14] Beske, P., Land, A., Seuring, S. Sustainable supply chain management practices and dynamic capabilities in the food industry: A critical analysis of the literature. International Journal of Production Economics 2014; 152: 131-143. doi:10.1016/j.ijpe. 2013.12.026

[15] Hutchins, M.J., Sutherland, J.W. An exploration of measure of social sustainability and their application to supply chain decisions. Journal of Cleaner Production 2008; 16: 1688-1698.doi:10.1016/j.jclepro.2008.06.001 
[16] Porter, M., van der Linde, C. Green and competitive: ending the stalemate. Harvard Business Review 1995; 73(5): 120-134.

[17] CEOForumGroup (2009). Engaging external stakeholders: Sustainability performance. Retrieved from http://www.ceoforum.com.au/article-detail.cfm?cid=8981\&t=/ Rob-Hogarth-KPMG/Sustainability-performance/ (accessed 11 August 2014).

[18] Allen, M.W., Walker, K.L., Brady, R. Sustainability Discourse within a Supply Chain Relationship: Mapping Convergence and Divergence. Journal of Business Communication 2012; 49(3): 210-236. doi:10.1177/0021943612446732

[19] Seuring, D. Industrial ecology, life cycles, supply chains - differences and interrelations. Business Strategy and the Environment 2004; 3(5): 306-319. doi:10.1002/bse.418

[20] Hynds, E.J., Brandt, V., Burek, S. Jager, W., Knox, P., Parker, J.P. Schwartz, L., Taylor, J., Zietlow, M. A Maturity Model for Sustainability in New Product Development. Research-Technology Management 2014; p50-57. doi:10.5437/08956308X5701143

[21] Carter, C.R., Rogers, D.S. A framework for sustainable supply chain management: moving toward new theory. International Journal of Physical Distribution \& Logistics Management 2008; 38: 360-387. doi:10.1108/09600030810882816

[22] World Commission on Environment and Development (WCED). Our Common Future. Oxford, Oxford University Press; 1987.

[23] Seuring, D., Muller, M. From a literature review to a conceptual framework for sustainable supply chain management. Journal of Cleaner Production 2008; 16(15) 1699-1710. doi:10.1016/j.jclepro.2008.04.020

[24] Campbell, J. L. Why would corporations behave in socially responsible ways? An institutional theory of corporate social responsibility. Academic Management Review 2007; 32(3) 946-967. doi:10.5465/AMR.2007.25275684

[25] Caniato, F., Caridid, M., Cripa, L., Moretto, A. Environmental sustainability in fashion supply chains: an exploratory case based research. International Journal of Production Economics 2012; 135(2) 659-670. doi:10.1016/j.ijpe.2011.06.001

[26] Vachon, S., Mao, Z. Linking supply chain strength to sustainable development: a country-level analysis. Journal of Cleaner Production 2008; 16(15) 1552-1560. doi: 10.1016/j.jclepro.2008.04.012

[27] Crawford, C.M., DiBenedetto, C.A. New Products Management, Noida: Tata McGraw-Hill Education; 2011.

[28] Bhuiyan, N., Thomson, V. A framework for NPD processes under uncertainty. Engineering Management Journal 2010; 22(2) 27-36.

[29] Gmelin, H., Seuring, S. Determinants of a sustainable new product development. Journal of Cleaner Production 2014, 69: 1-9. doi:10.1016/j.jclepro.2014.01.053 
[30] Hsueh, C. An inventory control model with consideration of remanufacturing and product life cycle. International Journal of Production Economics 2011; 122(1) 366-375.

[31] Driessen, P.H., Hillebrand, B., Kok, R.A.W. Verhallen, T.M.M. Green New Product Development: The Pivotal Role of Product Greenness. IEEE Transactions on Engineering Management 2013; 60(2) 315-326. doi:10.1109/TEM.2013.2246792

[32] Cohen, S., Wilkos, D., Garon, A, and Gownder, J.P. Environmental and social responsibility in consumer product strategies: How central is environmental and social responsibility to your product? April 9, 2009. Forrester Research, Inc Retrieved from https://www.forrester.com/Environmental \pm And \pm Social \pm Responsibility $\pm I n \pm$ Consumer \pm Product \pm Strategies/fulltext/-/E-RES53747 (Accessed on 22 Sept. 2014)

[33] Dangelico, R.M., Puhari, D. Mainstreaming green production innovation: Why and how companies integrate environmental sustainability. Journal of Business Ethics 2010; 95(3) 471-486. doi:10.1007/s10551-010-0434-0

[34] Alblas, A.A., Peters, K. and Wortman, J.C. Fuzzy sustainability incentives in new product development: An empirical exploration of sustainability challenges in manufacturing companies. International Journal of Operations \& Production Management 2014; 34(4) 513-545. doi:10.1108/IJOPM-10-2012-0461

[35] Fish, L.A., Forrest, W. C. A Literature Review and Areas for Future Academic Research in New Product Development in Supply Chain Management. In: Proceedings of the Decision Sciences Institute Annual Meeting, DSI, Nov. 2008, Baltimore, MD. 2008; p2291-6.

[36] Fish, L.A., Forrest, W.C. New Product Development in Supply Chain Management: Recommendations for Practitioners and Future Academic Research. In: 2003 Northeast Decision Sciences Institute Conference, NEDSI, March 2003, Providence, RI; 2003; p264-6.

[37] Fish, L.A. Forrest, W.C. A Discussion of Managerial Issues in New Product Development for Supply Chain Management. In: 2002 International Conference on Industry, Engineering, and Management Systems Proceedings, IEMS, March 13-15, 2002, Cocoa Beach, FL; 2002.

[38] Griffin, A. PDMA research on new product development practices: updating trends and benchmarking best practices. Journal of Product Innovation Management 1997; 14(6) 429-458. doi:10.1016/S0737-6782(97)00061-1

[39] Cooper, A.C. Winning at New Products. Cambridge, MA: Perseus Publishing; $2001 .$.

[40] Marion, T.J., Friar, J.H., Simpson, T.W. New product development practices and early-stage firms: two in-depth case studies. Journal of Product Innovation Management 2012; 29(4) 639-654. doi:10.1111/j.1540-5885.2012.00930.x 
[41] Pujari, D., Peattie, K., Wright, G. Organizational antecedents of environmental responsiveness in industrial new product development. Industrial Marketing Management 2004; 33(5) 381-391. doi:10.1016/j.indmarman.2003.09.001

[42] Pujari, D., Wright, G., Peattie, K. Green and competitive influences on environmental new product development (ENPD) performance. Journal of Business Research 2003; 56(8) 657-671. doi:10.1016/S0148-2963(01)00310-1

[43] Klassen, R., Vereecke, A. Social issues in supply chains: capabilities line responsibility, risk (opportunity), and performance. International Journal of Production Economics 2012; 140: 103-115. doi:10.1016/j.ijpe.2012.01.021

[44] Kesidou, E., Demirel, P. On the drivers of eco-innovations: Empirical evidence from the UK. Research Policy 2012; 41(5) 862-870. doi:10.1016/j.respol.2012.01.005

[45] Albino, V., Balice, A., Dangelico, R.M. Environmental strategies and green product development: An overview of sustainability-driven companies. Business Strategy and the Environment 2009; 18(2) 83-96. doi:10.1002/bse.638

[46] Seebode, D., Jeanrenaud, S., Bessant, J. Managing innovation for sustainability. R\&D Management 2012; 42(3) 195-206.

[47] Anonymous. Wal-Mart' earth month efforts circle the globe: Retailer unveils ecofriendly products, mobilizes workforce and engages global communities. PR Newswire 13 April 2009. Retrieved from http://www.prnewswire.com/news-releases/walmarts-earth-month-efforts-circle-the-globe-61799172.html. (accessed on 11 August 2014).

[48] Peters,A., Moore, C., Margarie, A. IBM's Approach To Sustainability Provides A Model For Long-Lasting Competitive Edge. Forrester Research 2011; Retrieved from https://www.forrester.com/IBMs \pm Approach \pm To \pm Sustainability \pm Provides \pm A \pm Model \pm For \pm LongLasting \pm Competitive \pm Edge/fulltext/-/E-RES58152 (Accessed on Sept. 22, 2014)

[49] Luchs, M.G., Brower, J., Chitturi, R. (2012). Product choice and the importance of aesthetic design given the emotion-laden trade-off between sustainability and functional performance. Journal of Product Innovation Management 2012; 29(6) 903-916. doi: 10.1111/j.1540-5885.2012.00970.x

[50] Schulte, S. (2008). Customer centric PLM: Integrating customers' feedback into product data and lifecycle processes. International Journal of Product Lifecycle Management 2008; 3(4) 295. doi:10.1504/IJPLM.2008.027007

[51] Fine, C. Clockspeed, NY, NY: Perseus Books; 1998.

[52] Ellram, L.M., Tate, W.L., Carter, C.R. Product-process-supply chain: an integrative approach to three-dimensional concurrent engineering, International Journal of Physical Distribution \& Logistics Management 2007; 37(4) 305-330. doi: 10.1108/09600030710752523 
[53] Wiskerke, J., Roep, D. Constructing a sustainable pork supply chain: a case of technoinstitutional innovation. Journal of Environment Policy Plan. 2007; 9(1) 53-74. doi: 10.1080/15239080701254982

[54] Tan, C. L., Tracey, M. Collaborative new product development environments: Implications for supply chain management. Journal of Supply Chain Management 2007; 43(3) 2-15. doi:10.1111/j.1745-493X.2007.00031.x

[55] Chiou, T, Chan, H, Lettice, F., Chung, S. The influence of greening the suppliers and green innovation on environmental performance and competitive advantage in Taiwan. Transportation Research Part E Methodological Journal 2011; 47: 822-836. doi: 10.1016/j.tre.2011.05.016

[56] Sarkis, J., Zhu, Q., Lai, K. An organizational theoretic review of green supply chain management literature. International Journal of Production Economics 2011; 130(1) 1-15. doi:10.1016/j.ijpe.2010.11.010

[57] Liu, X, Yang, J., Qu, S., Wang, L, Shishime, T, Bao, C. Sustainable production: practices and determinant factors of green supply chain management of Chinese companies. Business Strategy Environment 2011; 21: 1-16. doi:10.1002/bse.705

[58] Wolfert, J., Verdouw, C, Verloop, C, Beulens, A. Organizing information integration in agree-food - a method based on a service-oriented architecture and living lab approach. Computer and Electronic in Agriculture 2010; 70 389-405. doi:10.1016/ j.compag.2009.07.015

[59] Mazzola, E., Perrone, G. A strategic needs perspective on operations outsourcing and other inter-firm relationships. International Journal of Production Economics 2013; 144(1) 256-267. doi:10.1016/j.ijpe.2013.02.012

[60] Nawrocka, D., Brorson, T., Lindhqvist, T. ISO14001 in environmental supply chain practices. Journal of Cleaner Production 2009; 17: 1435-1443. doi:10.1016/j.jclepro. 2009.05.004

[61] Homburg, C., Kuehnl, C. Is the more always better? A comparative study of internal and external integration practices in new product and new service development. Journal of Business Research 2014; 67: 1360-1367. doi:10.1016/j.jbusres.2013.08.017.

[62] Green, K. Morton, BG. And New, S. Green purchasing and supply policies: do they improve companies' environmental performance? Supply Chain Management 1998; 3(2) 89-95. doi:10.1108/13598549810215405

[63] Vachon, S., and Klasen, R.D. Extending green practices across the supply chain: the impact of upstream and downstream integration. International Journal of Operations \& Production Management 2006; 26(7) 795-821. doi:10.1108/01443570610672248

[64] Tate, W., Ellram, L., Kirchoff, J. Corporate social responsibility report: a thematic analysis related to supply chain management. Journal of Supply Chain Management 2010; 46(1) 19-44. doi:10.1111/j.1745-493X.2009.03184.x 
[65] Wang, T., Fang, L-C., Wu, W-H., Ho, C-F. Development of a collaborative product development framework based on centre-satellite system and service-oriented architecture. International Journal of Production Research. 2009; 47(20) 5637-5656. doi: 10.1080/00207540802098133

[66] Hamprecht, J. Corsten, D., Noll, M, Meier, E. Controlling the sustainability of food supply chain. Supply Chain Management 2005;19: 7-11. doi: 10.1108/13598540510578315

[67] Monczka, R.M., Handfield, R.B., Giunipero, L.C., Patterson, J.L. Purchasing and Supply Chain Management, Fourth Edition. Mason, OH: South-Western Cengage;2009.

[68] Driessen, P.H., and Hillebrand, B. Integrating multiple stakeholder issues in new product development: an exploration. Journal of Product Innovation Management 2012; 30(2) 364-379. doi:10.1111/j.1540-5885.2012.01004.x

[69] Lee, K-H., Kim, J-W. Integrating suppliers into green product innovation development: an empirical case study in the semiconductor industry. Business Strategy Environment 2011; 20(8) 527-538. doi:10.1002/bse.714

[70] Seuring, D., Muller, M. Core issues in sustainable supply chain management: a Delphi study. Business Strategy and the Environment 2008; 17: 455-466. doi:10.1002/bse. 607

[71] Bras, B. Sustainability and product life cycle management - issues and healthy emissions - a strategy for eco-effective product and system design. International Journal of Product Lifecycle Management 2009; 4(1/2/3) 23-47. doi:10.1504/IJPLM.2009.031665

[72] Bevilacqua, M., Ciarapica, F.E., Giacchetta, G. Development of a sustainable product lifecycle in manufacturing firms: a case study. International Journal of Production Research 2007; 45(18-19) 4073-4098. doi:10.1080/00207540701439941

[73] Geffen, C., Rothenberg, S. (2000). Suppliers and environmental innovation: the automotive paint process. International Journal of Operations \& Production Management 2000; 20(2) 166-186. doi:10.1108/01443570010304242

[74] ISO-14040 (2006). Environmental Management - Life Cycle Assessment-Principles and Framework. Switzerland, Geneva.

[75] ISO-14044 (2006). Environmental Management - Life Cycle Assessment - Requirements and Guidelines. Switzerland, Geneva.

[76] Sousa, I., Wallace, D. (2006). Product classification to support approximate life-cycle assessment of design concepts. Technological Forecasting \& Social Change 2006; 73: 228-249. doi:10.1016/j.techfore.2004.03.007

[77] UNDSD (United Nations Division for Sustainable Development) (2001). Indicators of sustainable development, guidelines and methodologies. Retrieved from http:// 
sustainabledevelopment.un.org/content/documents/indisd-mg2001.pdf. (accessed on 19 Sept.2014).

[78] Ferrer, G.. Ketzenberg, M.E. Value of information in remanufacturing complex products. IIE Transactions 2004; 36(3) 265-277. doi:10.1080/07408170490274223

[79] Sudarsan, R., Fenves, S.J., Sriram, R.D., Wang, F. A product information modeling framework for product lifecycle management. Computer-Aided Design 2005; 37: 1399-1411. doi:10.1016/j.cad.2005.02.010

[80] Cantamessa, M., Montagna, F., and Neirotti, P. (2012). Understanding the organizational impact of PLM systems: evidence from an aerospace company. International Journal of Operations \& Production Management, 32(2), 191-215. http://dx.doi.org/ $10.1108 / 01443571211208623$

[81] Cao, H., Folan, P., Mascolo, J., Browne, J. RFID in product lifecycle management: a case in the automotive industry. International Journal of Computer Integrated Manufacturing 2009; 22(7) 616-637. doi:10.1080/09511920701522981

[82] Stark, J. Product Lifecycle Management - the $21^{\text {st }}$ Century Paradigm for Realization, USA: Springer-Verlag; 2005.

[83] Petala, E., Wever, R., Dutilh, C., Brezet, H.C. The role of new product development briefs in implementing sustainability: a case study. Journal of Engineering Technology Management 2010, 27(3-4) 172-182. doi:10.1016/j.jengtecman.2010.06.004

[84] Sarin, S., McDermott, C. The effect of team leader characteristics on learning, knowledge application, and performance of cross-functional new product development teams. Decision Science Journal 2003; 34 (4) 707-739. doi:10.1111/j. 1540-5414.2003.02350.x

[85] Zhang, D.Z. Towards theory building in agile manufacturing strategies - case studies of an agility taxonomy. International Journal of Production Economics 2011; 131(1) 303-312. doi:10.1016/j.ijpe.2010.08.010

[86] Johnson, M.E., Cochran, J.J., Cox, L.A., Keskinocak, P., Kharougeh, J.P., Smith, J.C. Product/service design collaboration. Managing the Product Life Cycle 2010; p1.

[87] Lievens, A., Moenaert, R.K. New service teams as information-processing systems: Reducing innovative uncertainty. Journal of Service Research 2000; 3(1) 46-65. doi: $10.1177 / 109467050031004$

[88] Luo, X., Rindfleisch, A.,Tse, D.K. Working with rivals: The impact of competitor alliances on financial performance. Journal of Marketing Research 2007; 44(1) 73-83. doi: 10.1509/jmkr.44.1.73

[89] Emden, Z., Calantone,R.J., Droge, C. Collaborating for new product development: selecting the partner with maximum potential to create value. Journal of Product Innovation Management 2006; 23(4) 330-341. doi:10.1111/j.1540-5885.2006.00205.x 
[90] Lambert, D.M., Coooper, M.C., and Pagh, J.D. Supply chain management: implementation issues and research opportunities. International Journal of Logistics Management 1998; 9(2) 1-19. doi:10.1108/09574099810805807

[91] Cao, H., Zhang, Q. Supply chain collaboration: impact on collaborative advantage and firm performance. Journal of Operations Management 2011; 29(3) 163-180. doi: 10.1016/j.jom.2010.12.008

[92] Barratt, M. Understanding the meaning of collaboration in the supply chain. Supply Chain Management: International Journal 2004; 9(1) 30-42. doi: 10.1108/13598540410517566

[93] DeLuca, L.M., Atuahene-Gima, K. Market knowledge dimensions and cross-functional collaboration: Examining the different routes to product innovation performance. Journal of Marketing 2007; 71(1) 95-112. doi:10.1509/jmkg.71.1.95

[94] Lui, S.S., Ngo, H., Hon, A.H.Y Coercive strategy in inter-firm cooperation: Mediating roles of interpersonal and inter-organizational trust. Journal of Business Research 2006; 59(4) 466-474. doi:10.1016/j.jbusres.2005.09.001

[95] United Nations Environment Programme (UNEP) Talk the walk: Advancing sustainable lifestyles through marketing and communications. New York: UN Global Compact and Utopies; 2005.

[96] Luchs, M.G., Naylor, R.W., Irwin, J.R., Raghunathan, R. The sustainability liability: potential negative effects of ethicality on product preference. Journal of Marketing 2010; 74(5) 18-31. doi:10.1509/jmkg.74.5.18

[97] Schuh, G., Rosenfeld, H. Assmus, D., Zancul, E. Process-oriented framework to support PLM Implementation. Computers \& Industrial Engineering 2008; 59(2-3) 210-218. doi:10.1016/j.compind.2007.06.015

[98] Chwastyk, P., Kolosowski, M. Estimating the Cost of the New Product in Development Process. In: $24^{\text {th }}$ DAAAM International Symposium on Intelligent Manufacturing and Automation, 2013. Procedia Engineering 2014; 69: 351-360.

[99] Gungor, A., Gupta, S. Issues in environmentally conscious manufacturing and product recover: a survey. Computers and Industrial Engineering 1999; 36(44) 811-853. doi:10.1016/S0360-8352(99)00167-9

[100] Tsoulfas, G.T., Pappis, C.P. Environmental principles applicable to supply chains design and operations. Journal of Cleaner Production 2006; 14: 1593-1602. doi:10.1016/ j.jclepro.2005.05.021

[101] Pujari, D. Eco-innovation and new product development: understanding the influences on market performance. Technovation 2006; 26(1) 76-85. doi:10.1016/j.technovation.2004.07.006 
[102] Kobayashi, H. (2005). Strategic evolution of eco-products: a product life cycle planning methodology. Research in Engineering Design 2005; 16(1/2) 1-16. doi:10.1007/ s00163-005-0001-3

[103] Jayaraman, V., Luo, Y. Creating competitive advantages through new value creation: a reverse logistics perspective. The Academy of Management Perspectives 2007; 21(2) 56-73. doi:10.5465/AMP.2007.25356512

[104] Guide, V.D.R., Jr., Souza, G.C., van Wassenhove, L.N., Blackburn, J.D.The time value of commercial product returns. Management Science 2006; 52(8) 1200-1214. doi: 10.1287/mnsc.1060.0522

[105] Debo, L.G., Toktay, L.B., van Wassenhove, L. N. Market segmentation and product technology selection for remanufacturable products. Management Science 2005; 51(8) 1193-1205. doi:10.1287/mnsc.1050.0369

[106] Subramanian, R., Gupta, S.,Talbot, B. Compliance strategies under permits for emissions. Production and Operation Management 2007; 16(6) 763-779. doi:10.1111/j. 1937-5956.2007.tb00294.x

[107] Carlson, R.C., Rafinejad, D. Modeling sustainability in product development and commercialization. Bulletin of Science, Technology \& Society 2008; 28(6) 478-485. doi: $10.1177 / 0270467608316435$ 

Chapter 6

\title{
Emerging Trends in Healthcare Supply Chain Management - An Italian Experience
}

\author{
Roberta Pinna, Pier Paolo Carrus and \\ Fabiana Marras \\ Additional information is available at the end of the chapter \\ http://dx.doi.org/10.5772/59748
}

\section{Introduction}

The aim of this study is to present the emerging trends in the Pharmaceutical Supply Chain Management and Logistics flow redesign. Logistics and Supply Chain innovation are becoming a highly topical issue in the international research agenda, as well as in practice. The reason is that economic and political factors are raising the attention to healthcare issues: the process of local health corporatization, which involves the introduction into the National Health System of control mechanisms similar to the competitive market models; the aging of population; the increasing demand for healthcare services; the rising cost of inpatient and outpatient care; new technologies and new drugs that will continue to drive up the total healthcare cost. Indeed, limited resources and a steady growth in spending, hence, the need of a public health rationalization, especially for meeting increasingly quality demands. All this requires a profound transformation that affects not only the processes of diagnosis and treatment, but also those of support, especially logistics, which is essential for the processes of service differentiation, efficiency, quality and safety processes improvement.

However, the logistics process of pharmaceutical products in the healthcare sector accuses a relevant gap compared to other sectors: hospital companies tend to behave like "individual agents" with their own purchasing offices, a pharmacy and an internal distribution system based on order-delivery process. Additionally, they have to manage very different kinds of goods, taking care of the impact in the process of patients care. Consequently, a large number of transactions sent to different vendors and purchases of large quantities of drugs from individual departments with the resulting generation of high inventory and storage costs. As a natural consequence of this diversity of assets to manage, the organizational responsibility 
of the logistics function is often fragmented and dispersed across multiple organizational units, with clear coordination and integration problems.

In order to optimize the inventory control and reduce the material handling costs of pharmaceutical products, it is necessary to manage the Supply Chain following an integrated perspective, capable to overcome boundaries between professional specializations and organizations involved in the materials flow from warehouses to wards. This appears to be even more important for the Italian National Health Service, where all the discussions are concentrated in the fact that the hospitals' costs should be decreased, even if the materials managers' duties are still not defined. The state of the art shows that Italian hospital companies are in a condition of delay from the point of view of materials management, from which only recently they have been trying to get out, analyzing and rationalizing their Supply Chain processes [1].

Due to the critical role Supply Chain play in the healthcare sector, cost control and the optimization of material flows of drugs have been the subject of numerous studies, and different approaches and methods have been suggested in the literature [2-10]. They indicate that, starting from the traditional healthcare Supply Chain Management, some organizations are applying innovative transformations in the way of centralization, that is the aggregation under a single organizational unit of all the business functions involved in the overall process of pharmaceuticals purchasing and logistics. The application of these new models, capable of ensuring both the maximum efficiency and cost containment, has proven to allow the achievement of the objectives prescribed by the Italian's National Health Plan, which was developed in 1992 in order to find solutions that improve healthcare services and contain longterm costs increase.

According to these premises, in this chapter we explore the possibilities of Supply Chain and Logistics flows optimization and innovation in the Italian healthcare sector, through a process reengineering project. The literature review and an in-depth analysis of an Italian Local Healthcare Company help us to explain how changes in the pharmaceutical logistics flow can improve efficiency and reduce costs.

\section{Healthcare supply chain: Definition and characteristics}

The Supply Chain (SC) is a process that includes all the activities ranging from the identification of a customer need through product selection, negotiation with suppliers, payment, storage, distribution and redistribution. It is a set of three or more entities directly involved in the upstream and downstream flows of products, services, finances, and information from a source to a customer [11-13].

The Supply Chain Management (SCM) therefore, refers to upstream and downstream relationships with suppliers and customers and to solving problems of functional divisions that occur within and between organizations. In other words, it extends the concept of partnerships into a multi-firm effort to manage the total flow of goods from the supplier to the ultimate customer, 
to achieve greater benefits. SCM was developed initially in the context of manufacturing, but its introduction is beneficial to the healthcare sector, where it shows an important impact on hospital performance, in terms of reducing wastes, preventing medical errors, improving quality of care, service and operational efficiencies [14].

In particular, the healthcare SC in the Italian context generally consists of four main actors: 1 ) producers (pharmaceutical companies); 2) purchasers (dealers/depositaries and wholesalers); 3) providers (healthcare organizations and pharmacies); 4) patients (Figure 1).

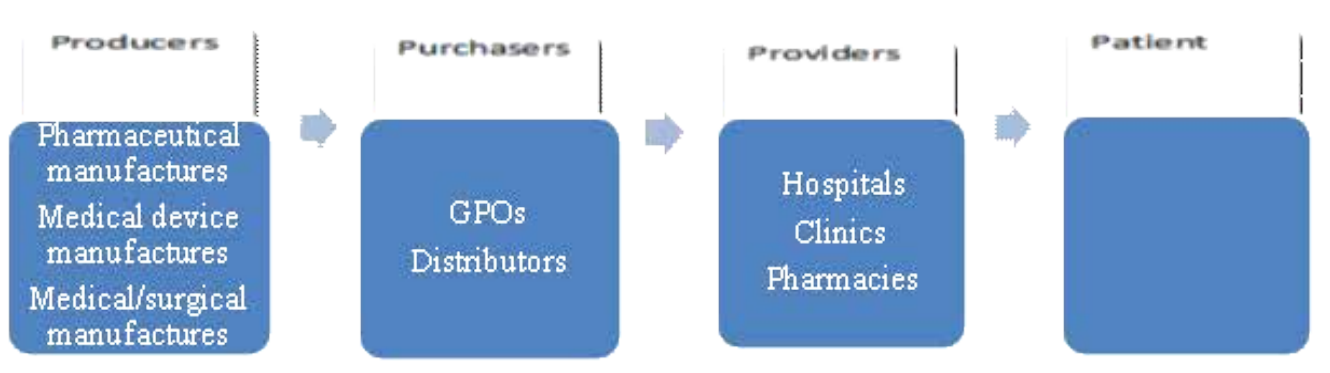

Figure 1. Healthcare Supply Chain

Producers produce goods such as pharmaceuticals, medical devices and implants, and medical/ surgical supplies that are necessary in the delivery of healthcare. Purchasers consist of group purchasing organizations (GPO) and distributors who facilitate the payment for and the shipment of goods from producers to providers. Among them, the main actors are depositaries and wholesalers. The difference between these two subjects is fundamentally linked to the acquisition of the goods ownership: depositaries work in deposit account and they are paid on the basis of a fee-for-service; they carry out temporary storage of products and send them to providers. Wholesalers acquire the ownership of pharmaceuticals and the related business risk, buying the availability of pharmaceuticals from the industry or by depositories. They must satisfy the demand of providers quickly, with a widespread distribution and through the management of a large number of references. To the actors of healthcare SC described above we must add providers, who may purchase goods from purchasers or directly from the producers. They use pharmaceuticals to administer healthcare services to patients. In particular, pharmacies can distribute pharmaceuticals to dismissed patients or to patients who, due to debilitating diseases, cannot get to the hospital to access the necessary pharmaceuticals to their treatment assigned. Patients (both hospitalized and dismissed) are the final customers of the healthcare process.

Healthcare SCM includes business activities and operations that integrate a continuous, seamless flow of materials and services for healthcare delivery [15]. One of the biggest challenges facing healthcare SCM operationally is maintaining sufficient inventory levels to sustain quality and timely patient care reducing wastages, and for this reason, it is designed to assure a high service 
level by maximizing the resource allocation, in order to respond effectively and promptly to the patient care needs. Healthcare SCM processes have three types of flows: physical, information and financial flows. The physical flows includes the supply of pharmaceuticals, medicals, surgical consumables, medical devices, hygiene consumables, food supplies, equipment and other supplementary products necessaries to support doctors, nurses and of course patients. Information and financial flows are related to SC decisions for effective product flow and organizational performance improvement. A successful SCM requires planning, managing and controlling these flows through the integration of key processes [15-19].

Due to the growing influence of patient-associations and to the necessity to deliver health services in a more efficient and effective way, many healthcare organisations have started projects in the area of patient logistics, clinical pathways, data interchange [20]. Moreover, the redesign of hospital services and the implementation of integrated care programmes are frequently addressed as being critical strategies to decrease resource utilization and improve healthcare quality. During the last ten years an impressive number of studies, originated in different disciplines like economics, organisational behaviour and logistics, have drastically enlarged our knowledge regarding the healthcare sector [16, 21-23].

Although many healthcare organizations have recognized the importance of adopting SCM practices, the application of techniques, methods and best practices originally developed in the industrial setting is often problematic. Their implementation has proven to be more complex primarily because it handles a diversity of items in widely varying quantities, in response to the large number of diagnosis types and procedures. Secondly, it requires the participation of many different stakeholders and it is highly influenced by legislations and healthcare professionals [14, 24, 25]. Furthermore, healthcare is a customer driven service, which means that customers are an effective part of the process [26, 27]. However, literature and practice suggest that numerous opportunities exist to reduce costs and improve delivery of healthcare by improving the efficiency and quality of healthcare SC operations. The key drivers of these opportunities are cost and quality of healthcare, and this is the reason why they are two of the most discussed and debated issues of our time. Healthcare SC innovation has been regarded as a critical success factor for organisational performance: it refers to tools that can improve organisational processes needed for effective SCM through seamless interactions with suppliers, manufacturers, distributors and customers. Thus, it allows reductions in cost and lead time, creation of new operational strategies, provision of quality and development of flexibility for dealing with rapid changes in the socio-economic context.

\section{The pharmaceuticals logistic management}

In healthcare the term logistics encompasses the set of techniques, methodologies, tools and infrastructure used in the management of the physicals flows (such as drugs and surgical medical products) and the associated information flows, from the acquisition in the market to the distribution to wards (Figure 2). The proposed definition allows us to make some important specifications as regards to purposes and contents. 
With reference to the first aspect, the pharmaceutical logistics is the task of placing the right drugs and medical supplies, in the right quantities, in the right conditions, at the right health service delivery points, at the right time, for the right patients/users and for the right cost [28]. In other words, logistics seeks to pursue simultaneously efficiency - economical use of resources -, effectiveness - service level maximization - and cost-effectiveness - long term capacity to achieve the economic equilibrium. Referring to the content on the other hand, the logistics system is a set of activities (procurement, storage, physical distribution) that must be managed in an integrated manner.

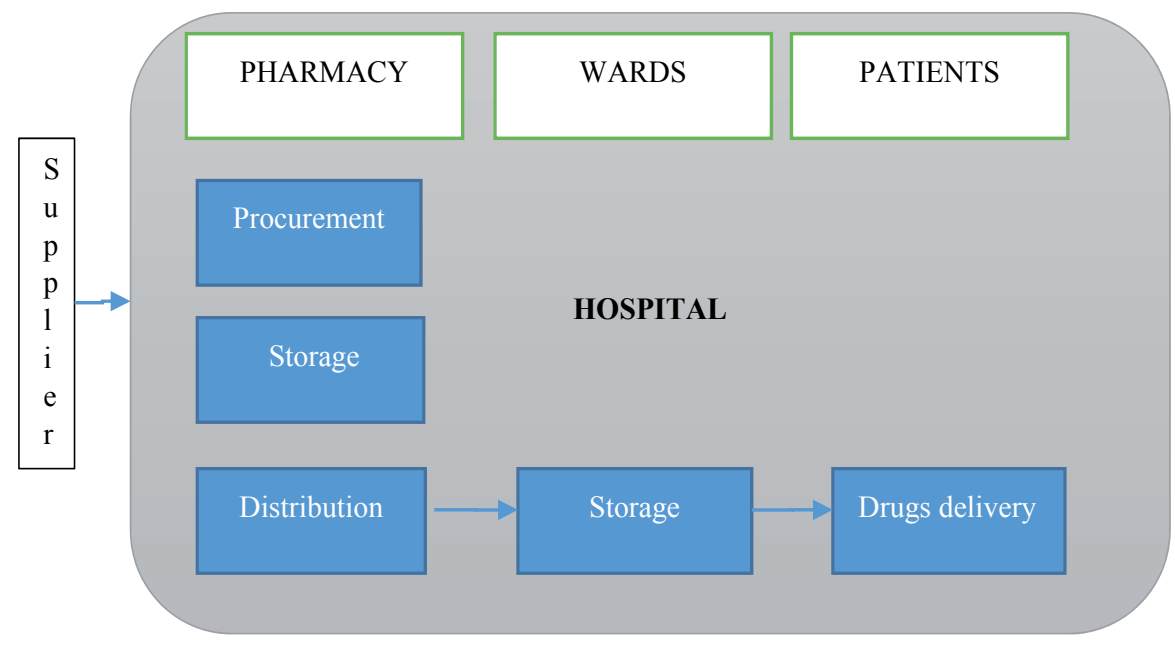

Figure 2. The pharmaceutical logistics process

As some authors point out [28], the mains objectives of a good logistics include:

- improve information systems for accurate collects and reports data when and where needed;

- improve forecasting/procurement;

- improve distribution activities;

- obtain clean, secure, organized storage;

- implement a good transportation system.

The increased complexity that characterizes the management of logistics flows within the healthcare companies is linked to different aspects (Figure 3):

1. Healthcare companies manage at least three broad categories of goods characterized by markedly different physical, logical and managerial requirements, with important problems of storage space;

2. Logistics organizational responsibility is often fragmented and dispersed among several organizational units with obvious problems of coordination and integration; 
3. Healthcare companies treat patients, and this introduces elements of natural variability.

4. Last but not less important point, logistics has an important impact on the processes of care, that is on the quality and safety of care provided to patients. When healthcare actors communicate and share information, they are more likely to improve the quality in terms of patient safety, cycle time reduction and operational efficiency [29-32]. The safety of patients is the top priority in healthcare, and pharmaceutical managers play a crucial role in protecting their interest: their biggest responsibility is to ensure that the products purchased for clinical use are good quality ones. This can be achieved by developing a product evaluation system, consisting of well-defined parameters, to guarantee that only approved products can enter a hospital's stockroom. Additionally, timely placement factor is probably not as crucial in any other field as it is in healthcare delivery, where delay of a few seconds can cost a life.

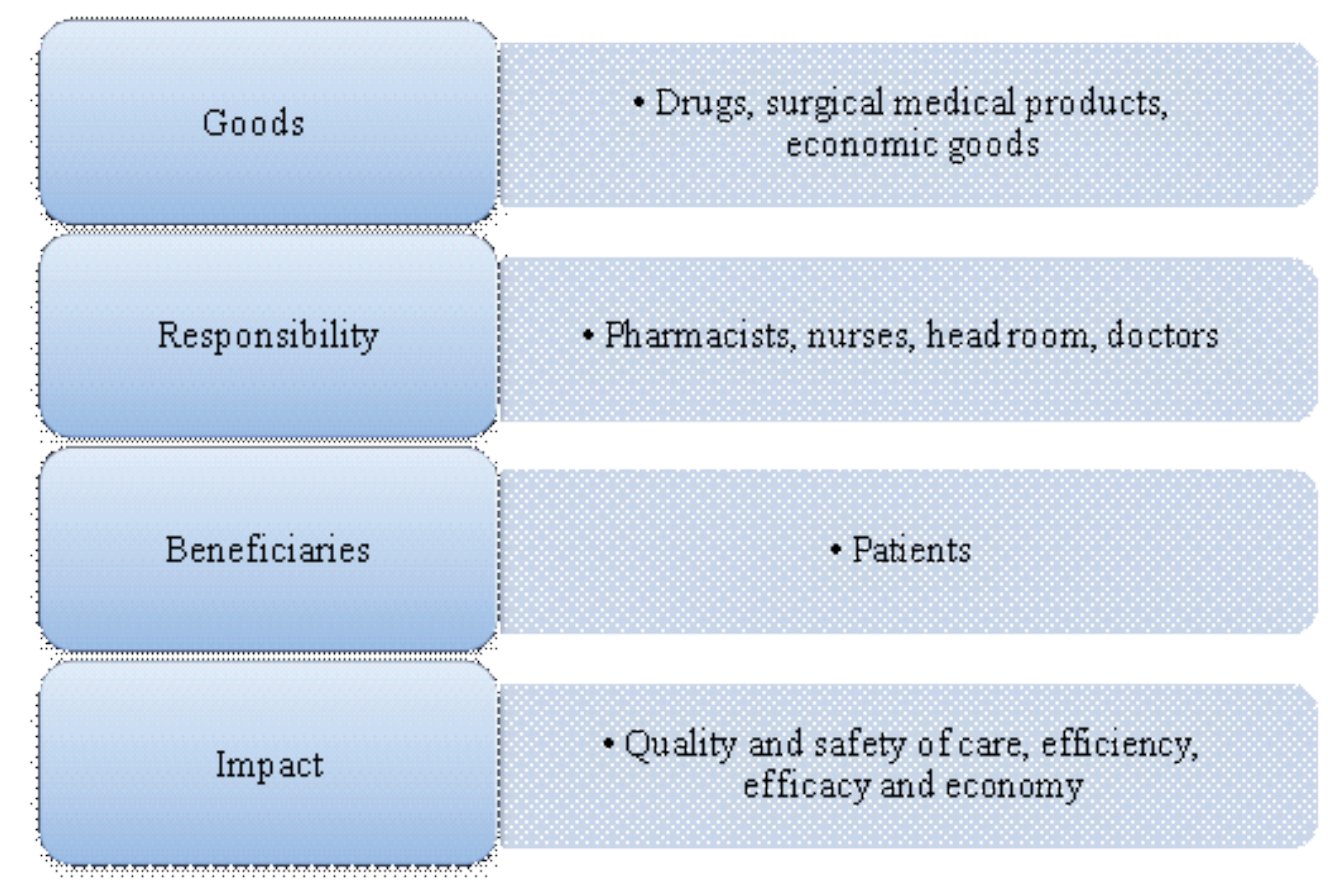

Figure 3. Factors of complexity in the pharmaceutical logistics process.

\subsection{Pharmaceutical logistics and information systems}

Managers operating in the pharmaceutical logistics process face many problems related to data quality: products are various and constantly changing, and this results in product data that is often inaccurate and obsolete; furthermore, product identification codes may not be consistent between hospitals in the same network or even between floors of the same hospital. The effects of poor data quality are widespread throughout the healthcare SC: incorrect product data leads 
to increased costs due to pricing errors, and this results in wasted time and rework for managers trying to resolve rebate, return, and credit issues with suppliers. In addition, the quality of healthcare can be adversely impacted, because data problems can result in healthcare procedure delays due to necessary products not being on hand [33].

Optimization of information storage and use requires that the organization and storage of data throughout the SC is consistent, so that all the data are accessible to multiple entities at different levels. The results are well coordinated movements of inventories, products that are delivered quickly and reliably when and where they are needed, as well as high responsiveness to short lead times [34]. A solution is given by implementing a Logistics Management Information System (LMIS): managers gather information about each activity in the system and analyse that information to coordinate future actions [28]. The LMIS provides method feedback for [35]:

- tracking the storage and movement of goods at every level within the supply system in order to obtain stocks ready for use in healthcare structures;

- ensuring proper stock rotation so that items of earliest expiry dates are used first;

- enabling managers to know the total amounts of commodities that are within the supply and where they are located.

The purpose of LMIS is to collect, organise, and report the logistics data in order to improve the customer service by improving the quality of management decisions. A well-functioning LMIS provides decision makers with accurate, timely, and appropriate data for managing and monitoring the flow of supplies, accounting for products, reducing supply imbalances, and improve costeffectiveness.

There are four essential data items in any LMIS (Table 1):

\begin{tabular}{cl}
\hline Stock on hand & Quantities of usable stock available at all levels of the system. \\
\hline Rate of consumption & An average of stock dispensed to users during a particular period of time. \\
\hline Losses & Include the quantity of stock removed for any reason other than consumption. \\
\hline Adjustments & $\begin{array}{l}\text { They are created when quantities are issued to or received from other facilities } \\
\text { at the same level. }\end{array}$ \\
\hline
\end{tabular}

Table 1. Types of LMIS data items.

These data must be available for every product, at every level, and in all times. The additional data item is known as service statistics and it may be added depending on the needs of the users. It helps logistics managers to evaluate the success of health programs. Essential data can be recorded through three different recording systems:

1. the stock keeping records keep quantity of stock on hand and quantity of losses information about products, and they are completed by anyone who receives or issues stocks from storage, or who takes a physical inventory of stock; 
2. the transaction records keep information about the movement of stock from one storage facility to another and are prepared by the warehouse personnel or nurses at both issuing and receiving facilities when a facility issues or requests supplies;

3. the consumption records keep information about quantity of each item dispensed to the customer (dispensed-to-user data) and they are completed by the service personnel at the service delivery point whenever supplies are dispensed to the customers. Only the transaction records move from one facility level to another with the product, while both stock keeping and consumption records remain where they are prepared.

At the end of a certain period, particularly monthly or quarterly, reports should be prepared and sent to the higher levels in the logistics systems for decision making, policy making, and planning. Reports are used to move the essential data to the logistics decision makers and the data should be available to the managers in a form suitable for decision making. For this reason, literature suggests six "rights" for LMIS data: the managers must receive the right data (essential data), in the right time (in time to take action), at the right place (where decisions are made), in the right quantity (having all essential data from all facilities), in the right quality (correct or accurate), and for the right cost (not spend more to collect information than spend on supplies) [28].

Additionally, the summary report contains all essential data items for a specific facility and for a specific time period (usually monthly or quarterly) in the form of simple report, aggregate summary report, or report and request report. The feedback report informs the lower levels about their performance and even inform higher level managers about how the system is performing.

\section{The Italian National Health Service: Mains trends and change forces}

The Italian National Health Service (NHS) is the institution through which the State guarantees its citizens the constitutional right to health (article 32 of the Italian Constitution), in conditions of equality throughout the national territory. The NHS is a public system with universal nature, that is to say that it guarantees healthcare to all citizens (all citizens are equal and enjoy equal rights); it is funded through general taxation, direct incomes (health tickets) and fees. The NHS is organized according to the National Health Plan, from which the Regional Health Plans are derived, and it includes the primary healthcare (services to which citizens have direct access) and secondary and tertiary healthcare (services to which citizens access via the General Practitioner).

The public healthcare service considers different levels of responsibility and government at central, and regional level. In particular, at the national level, the Ministry of Health has the responsibility to guarantee all citizens the right to health, ensure equity, quality and efficiency of healthcare and promote actions of improvement, innovation and change. The middle level has the task of setting the basic level of benefits that the health service is required to provide to all citizens, for free or with a cost-sharing. In addition, it allocates resources devoted to healthcare. The regional level has legislative, administrative, planning, funding and monitoring 
responsibilities for the essential levels of assistance, and functions are established by the Regional Health Plans for three years. Services are operationally delivered from ASL through internal structures, according to agreements with other public health institutions (Hospitals Companies, Hospitalization and Healthcare Institutes, University Polyclinics) or with accredited private structures and healthcare providers.

The need for change the management of public healthcare structures is due to some fundamental reasons: 1) the process of local health corporatization, which involves the introduction of control mechanisms into the national healthcare system. Hospitals assume managerial and economic-financial autonomy, and they must set their own goals for quality of service and cost management in order to ensure the survival over time; 2) limited resources and a steady growth in spending, hence, the need for a public health rationalization, especially for meeting increasingly quality demands. All this requires a profound transformation that affects not only the processes of diagnosis and treatment, but also those of support, especially logistics, which is essential for the processes of service differentiation and quality improvement [36]. As some researchers point out [37-40] a significant portion of healthcare costs can be reduced by implementing effective pharmaceutical SC through the redesign and reorganization of the materials and information flows with the aim to optimize inventory control and reduce material handling costs. Actually, the pharmaceutical logistics in most of the Italian Hospitals is characterized by dispersion and fragmentation, which does not allow efficiency and patient safety. In particular, the current organization is expressed by a multiplication of warehouses, diversified by product type and destination end-users; the growth of managed products types; the absence of economies of scale in the procedures for storage, with a duplication of used resources; a high number of transactions addressed to a multitude of suppliers.

All these has contributed to the continuous improvement of the healthcare organizational and management complexity and to the increase in transactions put into place within them. Hence, the need to make radical changes in the way healthcare companies operate and to provide clear logistics objectives. In particular, they must ensure a multi-dimensional decision making process that involves more figures and professional skills, in order to analyze the operational needs across the board (technical, health, economic and organizational aspects), together with a graduated scale of intervention, of increasing complexity and directed to the realization of an operational model based on pre-assessments of opportunities.

In the healthcare sector there is a growing awareness of the significant weight that investment in consumables and the cost of managing them have on the corporate balance sheet. Therefore, in order to increase the efficiency it is necessary to operate in the direction of simplifying the flows of materials and replace the current high level of stocks with a greater amount of accurate information available in real time about the various stages of the SC.

Unlike what happened in manufacturing companies, in which the SCM is a strategic element of management, in the world of healthcare it is still anchored, in most cases, to a distribution with the traditional system (Figure 4): a distribution source - pharmacy - in every hospital decides what and how to buy according to requests, and delivers medications to the wards (Cost Centers - CC), where a standard stock of frequently prescribed drugs is always available. 
As a consequence, this system produce highs inventory costs, and deals with different problems related to:

- the high value of departments fixed deposits;

- the difficult drug consume control at the ward level;

- the high risk of product obsolescence;

- the staff time devoted to administrative and medical medication management;

- the wards stocks location;

- unpredictability of requests for wards and frequency of urgent requests;

- the risk of failure in the early stages of association and patient care, preparation, administration and manual transcription of prescriptions from paper medical records to the nursing register paper.

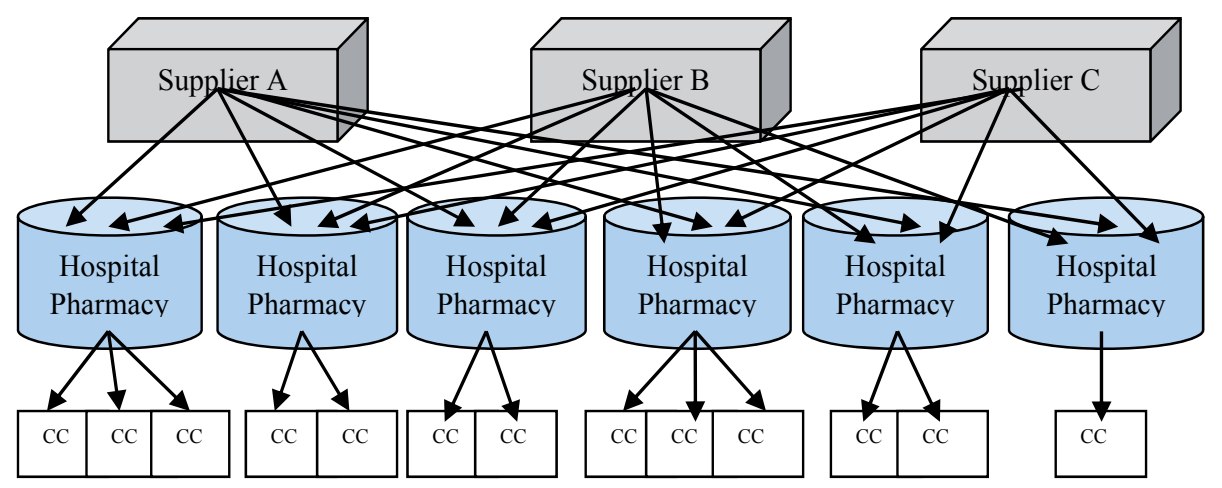

Figure 4. Traditional system of drugs management.

However, starting from this traditional healthcare SCM [7-9], some healthcare realities are testing the centralized managing: a unique district or regional center among multiple hospitals recognizes needs, contacts the supplier and deals with pharmaceutical management. Therefore, the general future trend seems to be the aggregation under a single organizational unit of all business functions involved in the overall process of purchasing and logistics.

\section{The healthcare supply chain redesign: An Italian experience}

The Local Healthcare Company n. 8 of Cagliari-Sardinia, Italy - (hereinafter ASL) [41] was formed in 1995 from the merger of former Local Health Units. It has authority in 71 municipalities, with an area of approximately 4,569 square kilometers (equal to $19 \%$ of the total regional area of Sardinia) and for a population of about 550.000 inhabitants. It occupies a number of approximately 6,000 employees distributed among 7 hospitals units, 20 clinics and 10 accred- 
ited nursing homes. For dimensions, characteristics, geographical distribution and organization it is considered as one of the most complex healthcare companies currently operating in Italy. The extent of the territory, the population served, services and resources managed place it among the top five national healthcare companies.

In order to complete the process of SC redesign and pharmaceutical logistics reorganization, among the ASL has been set up the experimentation of the Pharmaceutical Department, with the aim to coordinate all the activities in the drugs area, in order to ensure uniform and centralized processes and procedures (Table 2).

Ensure the organization and operation of activities and processes aimed at the government of pharmaceutical care; Ensure the quality of service delivery, at both hospital and community level;

Promote the development of integrated actions for the clinical management of drugs and medical devices;

Support the human resources training process for the improvement of professional qualification;

Identify guidelines for carrying out the activities of clinical pharmacy and patient care at hospital, outpatient, home and residential level;

Act within the criteria of effectiveness, efficiency, appropriateness and transparency.

Table 2. Pharmaceutical Department functions.

The organizational structure has been defined according to the functions of pharmaceutical care, attributing coordination and management specialist of the main tasks to specific operating units. This reorganization also took into account the problems related to the government of pharmaceuticals expenditure and the information derived from the ministerial projects relating to drugs policies. For this reason, in order to facilitate the reorganization and rationalization of processes, the Department consists of six operational units (Table 3):

\section{Operational Units:}

Pharmaceutical Assistance in Agreement

Hospital Parmaceutical Assistance

Direct Distribution

Pharmacovigilance and Pharmacoeconomics

Pharmaceutical Warehouse

Central Pharmaceutical Unit

Table 3. The Pharmaceutical Department structure.

With this configuration, skills are reconfigured and redistributed in order to provide greater support to corporate governance to all the units of the network. In particular: 
1. The Pharmaceutical Assistance in Agreement Unit develops activities and processes related to the pharmaceutical assistance organization in the territorial field and to the administrative control of the prescribing activities carried out by the healthcare personnel.

2. The Hospital Parmaceutical Assistance Unit guarantees the supply and distribution of medicines, medical supplies and medical surgical devices to hospitalized and discharged patients.

3. The Direct Distribution Unit ensures the direct delivery of drugs to patients in their own home, or the dispensing to the patient via pharmacies affiliated with the ASL, in accordance with specific agreements.

4. The Pharmacovigilance and Pharmacoeconomics Unit develops activities and processes to facilitate the proper use of medications, guide treatment decisions and formulate strategies and programs aimed at the appropriateness and containment of pharmaceutical expenditure.

5. The Pharmaceutical Warehouse Unit manages the inventory of drugs through the distribution to the hospitals and the supply requests for the Central Pharmaceutical Unit. Additionally, it ensures, through the consumption analysis, rationalizing processes, avoiding the accumulation of stocks not justified by current usage or predictable, at the central level, in peripheral storages and wards. It also optimizes the inventory through the definition of procedures, distribution processes and balanced choices in terms of frequency distribution and minimization of inventories at the peripheral level. Finally, it prepares detailed perspective programs for the supply, in order to rationalize the timing for the execution of supply contracts and the preparation of new contracts.

6. The Central Pharmaceutical Unit governs the centralized purchasing process of drugs and medical surgical devices at the company level. It operates with the Pharmaceutical Warehouse Unit for the management of supply contracts and whit the Purchases Service for the preparation of new contracts. It also operates with the Pharmacovigilance and Pharmacoeconomics units for the technical evaluation of drugs to be purchased, and for the choice of substitutes and new products. Additionally, it prepares needs programs to fit the timing of supplies, preventing stock breakages or increased costs for the company due to urgent situations. It contributes for the implementation of regional guidelines for the realization of the regional program about rationalization and containment of pharmaceutical expenditure and strategic planning in the field of corporate purchases. Hence, it operates in order to constantly ensure the availability of drugs and medical devices.

\subsection{Pharmaceutical Logistics Hub Project}

The current logistics organization of the ASL presents strengths but especially criticalities. In particular, the presence of six pharmaceutical warehouses located in six different hospitals guarantees some advantages when compared to a possible centralized management of warehouses:

a. a reduction of the time for the procurement of health goods by Cost Centers; 
b. the optimization of emergencies management;

c. a cost reduction for the transport of goods from the pharmacy to the user centers.

Conversely, weaknesses resulting from the presence of six pharmaceutical warehouses are the following:

a. the replication of the same activities in the six hospitals, such as order management, receiving and distribution to Cost Centers;

b. inefficient management of stocks, as each pharmacy define their own needs independently from the others, with a resulting disproportionate total data compared to the real needs of the company;

c. ineffective management of stocks, because each pharmacy is completely independent from the other, whereby in case of drug stock breaking in a pharmaceutical warehouse the pharmacy purchase it even if it is present in sufficient quantity. In fact, the exchange from one warehouse to another is activated only in case of emergency;

d. the need for a large number of operators resulting from the localization of stocks in the different six warehouses and from the replication of the same activities;

e. a difficult inventory management with the multiplication of activities and different timings for each pharmaceutical warehouse;

f. inadequate places with inappropriate surfaces and volumes, architectural barriers that make it inadequate the storage and handling of goods;

g. high risk of consistent stocks in the wards.

The aim of the project is the outsourcing of logistics services and the unification and standardization of all the logistics procedures related to the supply, storage and distribution of health and non-health goods in the ASL, by improving the effectiveness, efficiency and safety of all logistics processes. The main objective is the rationalization of pharmaceuticals management, in order to contain risks associated with clinical processes for medication management, and to improve efficiency and effectiveness of supply logistics management, storage and distribution/administration of pharmaceuticals and medical devices. The overall project involves the concentration of existing warehouses in one site, and the structuring of stocking points of proximity, coinciding with the current hospital pharmacies and local pharmaceutical services, together with the centralized management and unified inventory of materials through an integrated information system (Figure 5).

The project involves the reengineering of the main logistics processes (order management, procurement, inventory management, distribution) through the centralization of the commons activities, in order to contain the pharmaceutical expenditure. 


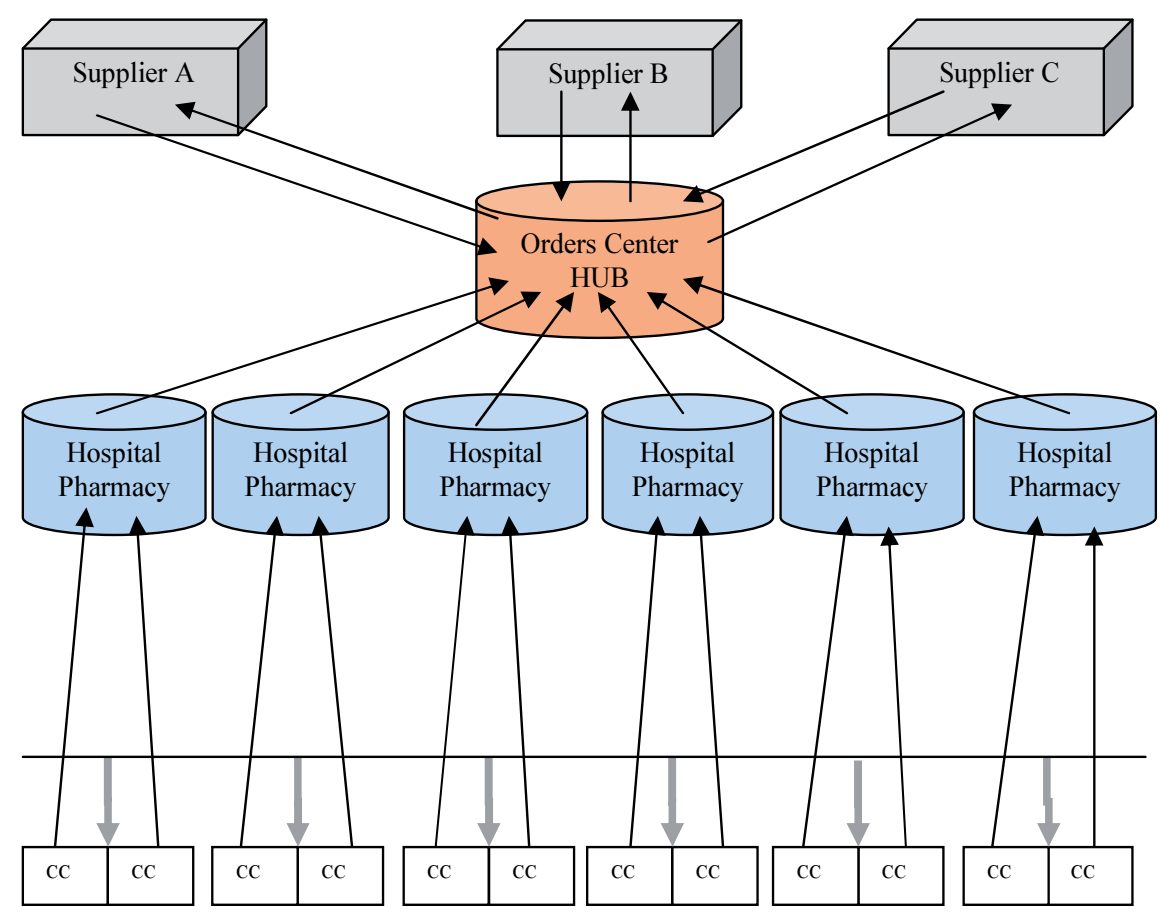

Figure 5. The reorganized pharmaceutical management with the Centralized Warehouse.

This centralization will cause an effect even in the organization of the drugs and medical devices procurement requests process to Cost Centers, which will be managed exclusively by computerized means (Figure 6).

As already pointed out, the reengineering includes the transition from an empirical management of inventories to a computerized management (Figure 6). Therefore, it becomes essential to implement an information system with the indication of under-stock and reorder point for drugs and medical devices in stock in pharmacies, in order to create a virtuous circle that will eliminate the empirical management, which in the past has led to frequent stock-outs, with obvious negative consequences. The redesign provides, firstly, the analysis of historical consumption data, the definition of under-stocks and reorder point by the pharmacist and, in the next phase, the weekly print execution of under-stocks by administrative operators. At this point pharmacists validate the under-stocks for the order execution, the administrative operators predispose the supply orders and pharmacist validates orders. Finally, the administrative operators send orders to the economic operators. The pharmacist then will provide for the periodic revaluation of under-stocks and reorder point of pharmaceuticals and medical devices in stock. 


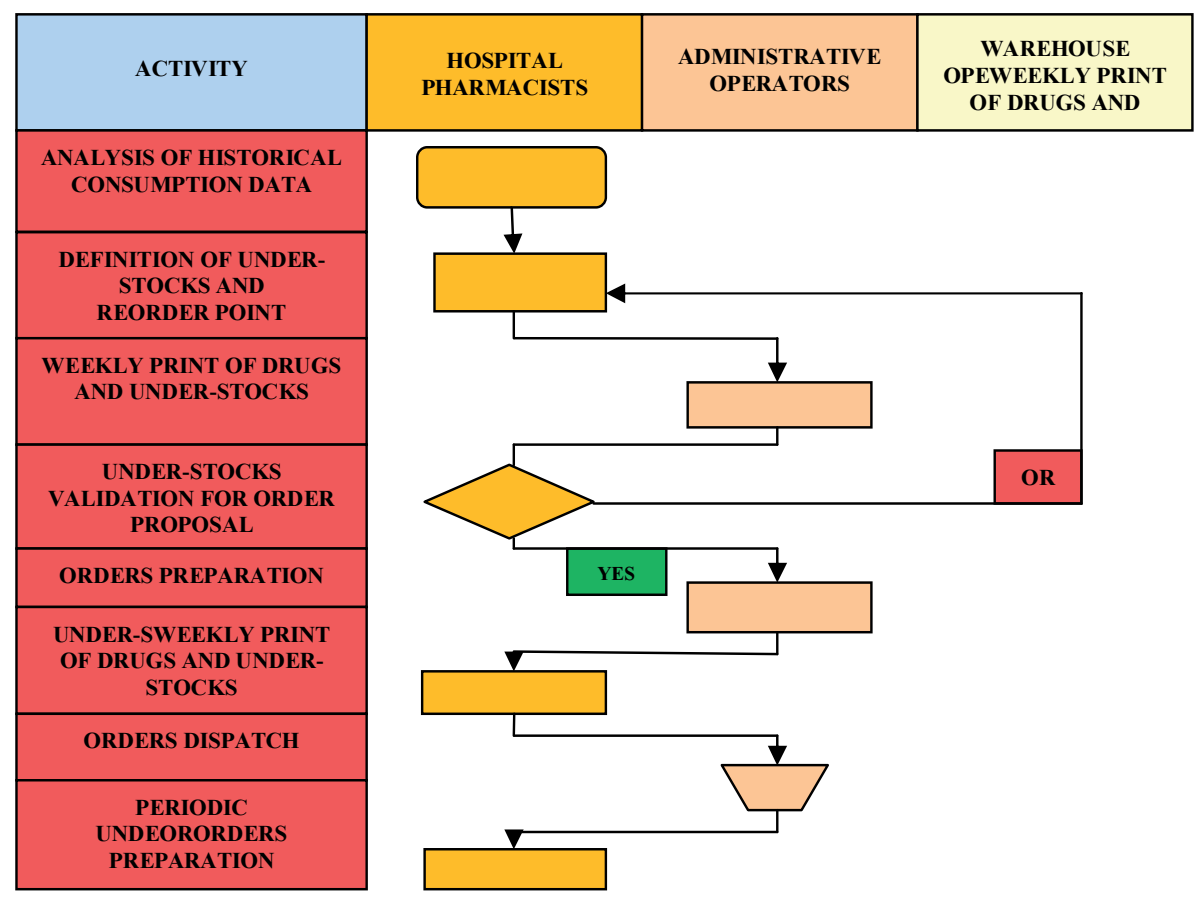

Figure 6. Inventory management in case of centralized warehouse

\subsection{The rationalization of pharmaceuticals flows}

Actually, the predominant activity of the pharmacists is represented by the orders issuance, which requires the $20 \%$ of their time/work; the control of healthcare goods entering and leaving the ASL requires approximately the $60 \%$ of the time/work available; the remaining $10 \%$ of the workload is dedicated to procurement practices, and only the $10 \%$ of the time is dedicated to give information in the wards. Therefore, it is clear that the management processes related to logistics absorb almost all the work of the pharmacist, which is mainly spent in non-strategic activities and that may be delegated to non-management figures.

With regard to the orders management, the phase of issuance actually entails that each hospital pharmacy produce supply orders for the same supplier, the same drug and the same day, with a useless replication activity. Additionally, inventories are not managed according to a computerized management with under-stocks and reorder point, but with a merely empirical verification. This generates the emission of orders for the same supplier at a distance of a few days, with obvious managerial repercussions.

Conversely, with the centralized warehouse, the under-stock and reorder point will be indicated and orders will be created on the basis of computerized data, assembling goods for the same supplier with a reduction in the number of orders: it will be generated only one order, and not six different orders for the same supplier. Additionally, the order will be prepared 
on the basis of a date processed electronically and not according to an empirical verification. In the centralized warehouse there will be an area dedicated to the acceptance of drugs and medical devices in stock, followed by a qualitative and quantitative control, with the loading of transport documents in the computer system, followed by the print of the position in the central warehouse and the storage of medicines and medical devices.

As regards to medical devices in transit, after the qualitative and quantitative control and the loading of the document in the computer system, the delivery of the material will take place. The expected result is a significant reduction of supply orders and a consequent reduction in the number of bills that will affect positively the timing of their settlement. In addition, the replication of activities in the various hospital pharmacies by pharmacists will be avoided, allowing a reduction in the time/effort devoted to the orders issuance management, and consequently prescription appropriateness increase.

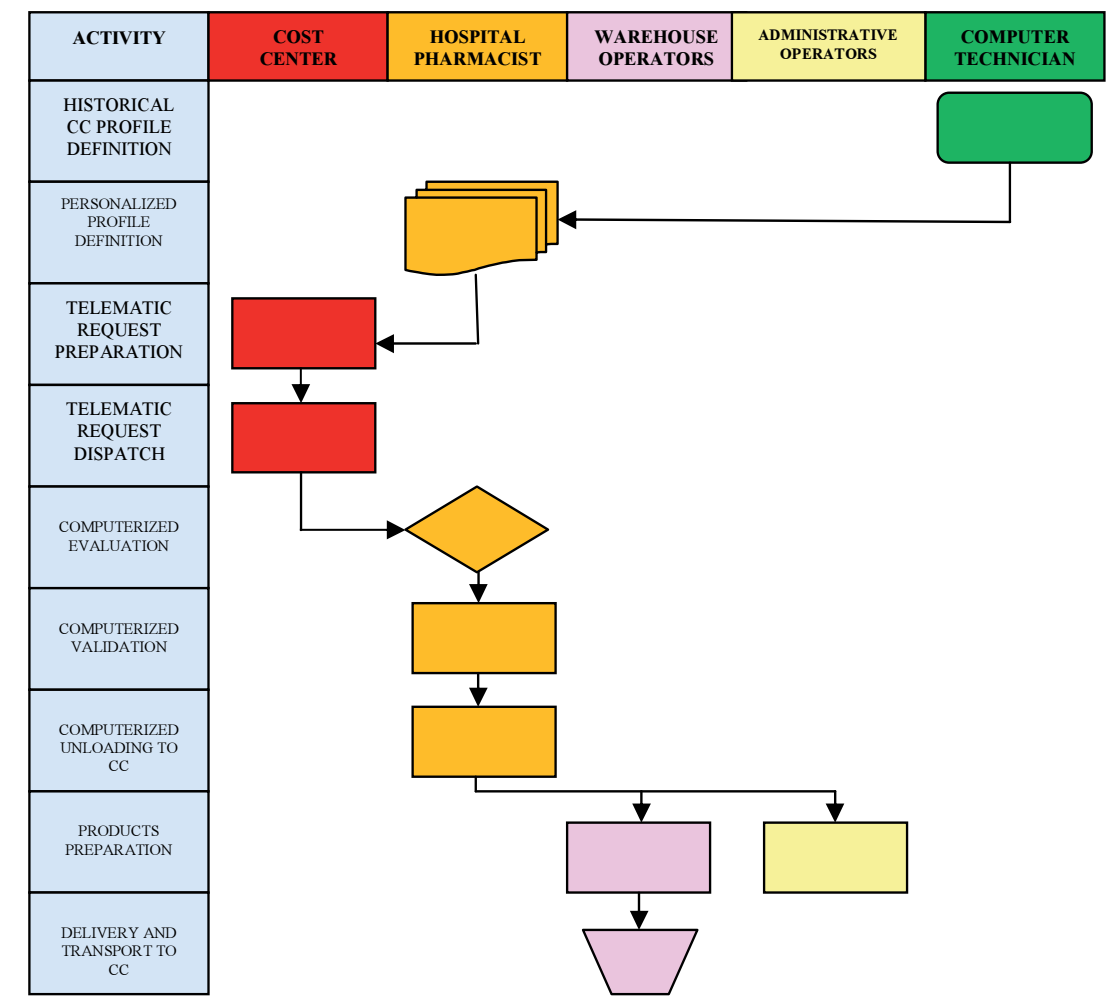

Figure 7. The reorganized procurement process to Cost Centers

As regards the procurement process managed, the Figure 7 shows how the process will change with the exclusive use of the computerized procedure. The figure describes the new drugs and medical devices procurement requests process to Cost Centers. It will start with the "coarse profile" preparation, on the basis of historical consumption by Cost Centers, to 
be followed by a custom profiling managed by the pharmacist. The next phase will involve the preparation of the computerized request of the Cost Center and the subsequent electronic transmission to the pharmacy. At this point, the pharmacist performs qualitative and quantitative computerized assessment of health goods required, and prints the request that is then delivered to warehouse personnel, who will provide for the preparation of pharmaceuticals and medical devices. If a discrepancy turns out during the preparation, it will be reported and the appropriate changes in the information technology will take place. At this point, the administrative operator closes the request, and the computerized unloading to Cost Centers will take place. The final demand of drugs and medical devices will be printed and delivered to Cost Centers. The expected result of this innovation is a constantly updated inventory and a full Cost Centers expenditure monitoring, as well as the possibility of providing an annual program of supply on the basis of consumption data.

\section{Conclusions}

The motivation for this research field is driven by the need to lower healthcare costs and to improve patient care quality by identyfing opportunities for healthcare organizations to improve their logistics processes, considering that hospitals represent the largest cost component of the national healthcare expenditures in most of the countries.

In the first part of the chapter we have provided general definitions and charactersitics of Healthcare Supply Chain and pharmaceutical logistics. We have emphasized the importance of both concepts in relation to emerging trends in healthcare system. Healthcare Supply Chain has become an important research topic in the past decade and its popularity is still increasing. This has resulted in the need to reenginering the Healthcare Supply Chian and, in particular, the pharmaceutical management, the importance of which is fundamental to the delivery of quality services to patients and reduction of costs.

There are two opportunities in this work where reenginering is applied: a) centralized supply system, and b) material management. In the redisigned system, several benefits have been achieved, in terms of:

1. cost and inventory reduction, due to more frequent deliveries, and the minimization of hospital central stores;

2. staff reduction in terms of amount of work of both hospital pharmacies and patient care staff, previously occupied in the point-of-use replenishment;

3. higher level of service;

4. exploitation of economies of scale, due to large orders and the absorption of uncertainty on the estimates due to the large numbers.

The transformation of the SCM model requires three mains conditions: collaborative governance structures, efficient processes and integrated information system. The right governance structure for SCM allows hospitals to maintain the balance between reducing costs and providing high- 
quality care. It requires that the SCM governance evolves to a collaborative approach involving all stakeholders, without which all other efforts to move to the transformation model simply will fail. This collaboration requires the appropriate governance structure and processes. Indeed, when processes are fragmented or incomplete, they cause errors in terms of ordering the wrong item or wrong quantities of an item.

At last, automating and integrating IT systems will allow hospitals to seamlessly link their logistics processes. The centralized management requires that hospitals in the network dialogue continuously with the warehouse, together with a flow of information that travels in both directions (from the hospital to the Central Warehouse and vice versa).

\section{Acknowledgements}

Fabiana Marras gratefully acknowledges Sardinia Regional Government for the financial support of her PhD scholarship (P.O.R. Sardegna F.S.E. Operational Programme of the Autonomous Region of Sardinia, European Social Fund 2007-2013-Axis IV Human Resources, Objective 1.3, Line of Activity 1.3.1.).

\section{Author details}

Roberta Pinna*, Pier Paolo Carrus and Fabiana Marras

*Address all correspondence to: pinnar@unica.it

Department of Economics and Business, University of Cagliari, Italy

\section{References}

[1] Cagliano A.C., Carcangiu C.E., Pilloni T., Rafele C. Supply Chain Ospedaliere: Esperienze a Confronto. In: proceedings XXXVI Convengo Nazionale Ingegneria e Impiantistica Italiana, 11-12 June 2009, Roma, Italia.

[2] Chunning, Z., Kumar, A. JIT application: process-oriented supply chain management in a health care system. In: Management of Innovation and Technology, 2000. ICMIT 2000. Proceedings of the 2000 IEEE International Conference on; (2) 788-791, 12-15 November, Singapore.

[3] Rivard-Royer H., Landry S., Beaulieu M. Hybrid stockless: A case study: Lessons for health-care supply chain integration. International Journal of Operations \& Production Management 2002; 22(4) 412-424. 
[4] Kumar A., Ozdamar L., Zhang C. N. Supply chain redesign in the healthcare industry of Singapore. Supply Chain Management: An International Journal 2008; 13(2) 95-103.

[5] Parker J., DeLay D. The future of the healthcare supply chain. Healthcare financial management: journal of the Healthcare Financial Management Association 2008; 62(4) 66-69.

[6] Agwunobi J., London P. A. Removing costs from the health care supply chain: lessons from mass retail. Health affairs 2009; 28(5) 1336-1342.

[7] Bensa G., Giusepi I., Villa S. Riprogettare la logistica nelle aziende sanitarie: esperienze a confronto. In: Cantù E. (ed.) Rapporto OASI 2009. L'aziendalizzazione della sanità in Italia. Milano: Egea; 2009. p331-366.

[8] Kazemzadeh R. B., Sepehri M. M., Jahantigh F. F. Design and Analysis of a Health Care Supply Chain Management. Advanced Materials Research 2012; 433-440(2012) 2128-2134.

[9] Smith B. K., Nachtmann H., Pohl E. A. Improving Healthcare Supply Chain Processes Via Data Standardization. Engineering Management Journal 2012; 24(1).

[10] Pinna R., Carrus P.P., Marras F. The Drug Logistics between Efficiency and Safety for Patients: The Experience of an Italian Region. In: proceedings of the 17th Toulon-Verona Conference Excellence in Services, 28-29 August 2014, Liverpool, UK.

[11] Colletti J. J. Health care reform and the hospital supply chain. Hospital material management quarterly 1994; 15(3) 28-35.

[12] Mentzer J.T., DeWitt W., Keebler J.S., Min S., Nix N.W., Smith C.D., Zacharia Z.G. Defining supply chain managemen. Journal of Business Logistics 2001; 22(2) 1-25.

[13] Meijboom B. R., Bakx S. J., Westert G. P. Continuity in health care: lessons from supply chain management. The International journal of health planning and management 2010; 25(4) 304-317.

[14] Ford E. W., Scanlon D. P. Promise and problems with supply chain management approaches to health care purchasing. Health care management review 2006; 32(3) 192-202.

[15] Lee S. M., Lee D., Schniederjans M. J. Supply chain innovation and organizational performance in the healthcare industry. International Journal of Operations \& Production Management 2011; 31(11) 1193-1214.

[16] Beier F.J. The management of the supply chain for hospital pharmacies: a focus on inventory management practices. Journal of Business Logistics 1995; 16 (2) 153-73.

[17] Bowersox, D. J., D. J. Closs. Logistical Management: The Integrated Supply Chain Process. New York: McGraw-Hill; 1996. 
[18] Lambert D. M., Stock J. R., Ellram L. M. Fundamentals of logistics management. Boston: Irwin/McGraw-Hill; 1998.

[19] Shou Y. Perspectives on Supply Chain Management in the Healthcare Industry. 2nd International Conference on Science and Social Research 2013, Atlantis Press.

[20] Aptel O. Pourjalali H. Improving activities and decreasing costs of logistics in hospitals: a comparison of US and French hospitals. The International Journal of Accounting 2001; 36(1) 65-90.

[21] Jarrett P. G. Logistics in the health care industry. International Journal of Physical Distribution \& Logistics Management 1998; 28(9/10) 741-772.

[22] Jennett P.G., Igras E., Harrison A.C., Premkumar K. Health information technology, its role in healthcare management: a regional case study, International Journal of Health Care Technology and Management 1999; 11 (1/2) 1-10.

[23] Bazzoli G.J., Dynan L., Burns L.R., Yap C. Two decades of organizational change in health care: what have we learned? Medical Care Research and Review 2004; 61 (3) 247-331.

[24] Bhakoo V., Chan, C. Collaborative implementation of e-business processes within the health-care supply chain: the Monash Pharmacy Project. Supply Chain Management: An International Journal 2011; 16(3) 184-193.

[25] AbuKhousa E., Al-Jaroodi J., Lazarova-Molnar S., Mohamed N. Simulation and Modeling Efforts to Support Decision Making in Healthcare Supply Chain Management. Scientific World Journal 2014; 1-16; Article ID 354246.

[26] Rossetti M. D., Liu Y. Simulating SKU proliferation in a health care supply chain. In: M. D. Rossetti, R. R. Hill, B. Johansson, A. Dunkin and R. G. Ingalls (eds.) Proceedings of the 2009 Winter Simulation Conference; 2365-2374. 13-16 December, Austin, TX; 2009.

[27] Aronsson H., Abrahamsson M., Spens K. Developing lean and agile health care supply chains. Supply Chain Management: An International Journal 2011; 16(3) 176-183.

[28] Chikumba P. A. Application of Geographic Information System (GIS) in Drug Logistics Management Information System (LMIS) at District Level in Malawi: Opportunities and Challenges. Master Thesis. University of Oslo; 2009.

[29] Carr A. S., Pearson J. N. Strategically managed buyer-supplier relationships and performance outcomes. Journal of operations management 1999; 17(5) 497-519.

[30] Kotabe M., Martin X., Domoto H. Gaining from vertical partnerships: knowledge transfer, relationship duration, and supplier performance improvement in the US and Japanese automotive industries. Strategic management journal 2003; 24(4) 293-316. 
[31] Prahinski C., Benton W. C. Supplier evaluations: communication strategies to improve supplier performance. Journal of operations management 2004; 22(1) 39-62.

[32] Giunipero L., Handfield R. B., Eltantawy, R. Supply management's evolution: key skill sets for the supply manager of the future. International Journal of Operations \& Production Management 2006; 26(7) 822-844.

[33] Carrus P. P., Pinna R. Information Technology and Supply Chain Management Coordination: The Role of Third Party Logistics Providers. International Journal of E-Services and Mobile Applications (IJESMA) 2011;3(4) 21-36.

[34] Pinna R., Carrus P.P., Pettinao D. Supply Chain Coordination and IT: the role of third party logistics providers. In: D'Atri A., De Marco M., Braccini A.M., Cabiddu F., (eds) Management of the Interconnected World. Springer; 2010. p299-306.

[35] Roy S., Sivakumar K., Wilkinson L.F. Innovation generation in supply chain relationships: a conceptual model and research propositions. Journal of the Academy of Marketing Science 2004; 32(1) 61-79.

[36] Cagliano A., Carlin A., Grimaldi S. La logistica del farmaco in ambito ospedaliero. In: proceedings XXXIV Convegno nazionale ANIMP OICE UAMI, 26-28 April, 2007, Isola d'Elba, Italia.

[37] Haavik, S. Building a demand-driven, vendormanaged supply chain. Healthcare Financial Management 2000; 54(2) 56-61.

[38] Poulin, E. Benchmarking the hospital logistics process. CMA Management 2003; 77(1) 20-23.

[39] De Vries, J. The shaping of inventory systems in health services: a stakeholder analysis. International Journal of Production Economics 2011; 133(1) 60-69.

[40] Bhakoo V, Singh P., Sohal A. Collaborative management of inventory in Australian hospital supply chains: practices and issues. Supply Chain Management: An International Journal 2012; 17(2) 217-230.

[41] ASL Cagliari. http://www.aslcagliari.it/index.html (accessed 15 September 2014). 

Chapter 7

\title{
A Systems Science/Cybernetics Perspective on Contemporary Management in Supply Chains
}

\author{
Isaías Badillo, Ricardo Tejeida, Oswaldo Morales and Abraham Briones \\ Additional information is available at the end of the chapter
}

http://dx.doi.org/10.5772/59970

\section{Introduction}

The management of supply chain is a special field of the general management for production and services systems. This special kind of management is required to be adaptive to the nature of the industry evolution. The current industry is distributed around geographic places different for the main production plan.

In this chapter it is going to be described, from a systems science perspective, how will the new nature of the industrial processes be managed. In systems sciences, there is one management principle - to know the Ashby's law: "the variety of ability to response to the industrial processes and the environment change should be greater than the variability on industrial processes and of the environment

To describe accurately Supply Change Management (SCM), we are going to use the official concepts of the American Production and Inventory Control Society (APICS) Dictionary "The design, planning, execution, control, and monitoring of supply chain activities with the objective of creating net value, building a competitive infrastructure, leveraging world-wide logistics, synchronizing supply with demand, and measuring performance globally" [1]. There are several functions included in the definition of SCM which are represented in Systems Science with a Mode called Viable System Model (VSM) [2]. For example, the scheduling and execution is the main function of component number 1 of the VSM. The control is the task of component number 2 of VSM. The monitoring and auditing is the task of component number 3 and $3^{*}$ of VSM. The planning is the function of a component number 4 of VSM. The creation of net value is the main task of component number 5 of VSM.

The design and diagnosis of the full SCM system is the main function in VSM. All the five components of VSM interact inside by information systems called Enterprise Resources Planning System (ERP). 
In this chapter we are going to make a brief description of SCM and VSM. At the end of the chapter an application emphasizing the bullwhip effect is presented.

In [3] it is reported an industrial case of DuPont"credit the corporate survival and success during the recession, to their employees' strong SCM knowledge which has given them visibility across business units. DuPont started in this area with Kaisen, Lean and Six Sigma. Once low cost sourcing was added, SCM was a natural segue".DuPont management started its SCM with ERP implementing several modules like Material Requirement Planning (MRP), Customer relationship management (CRM), etc.

\section{Systems/cybernetics sciences}

In accordance with the title of this chapter, it is convenient to define some systems concepts.

Cybernetics. Studies the flow of information around a system, and the way in which this information is used by the system as a means of controlling itself: it does this for animate and inanimate systems indifferently [4].

Environment. The set of systems in which is immersed the system in focus.

Function. The main activities performed by the system to reach the purpose.

Human activity system. A special system composed mainly for functions performed by human beings.

Model building. To abstract the main attributes from a portion reality interest, in order to obtain a conceptual representation.

Recursion (a level of). A level at which a viable system is in operation as an autonomous part of a higher-level viable system, and contains within itself parts which are themselves autonomous viable systems [5].

Subsystem. Is a component which is embedded in a superior system.

System. A set of interrelated components with a purpose whose boundary are defined by the observer

Systems science. A scientific field to research taxonomies, concepts, theories, and methodologies. According to [6] the field of scientific inquiry whose objects of study are systems.

Variety. Number of possible states that a system is capable of exhibiting [7].

Viability. The ability of a system to maintain a separate existence [7].

Viable system model (VSM). According to [2], is a system able to maintain a separate existence, capable of maintaining its identity and transcend independently.

Systems science uses the construction of models to represent real systems; for example, the viable system model (VSM) was elaborated by Beer [7] to represent human activity systems like as SCM. 
The VSM is a recursive model that represents viable organizations, the viability are based on five functions or subsystems. A viable organization is integrating by viable sub-organisations and at the same time the organization is embedded. In the VSM there are five interactive systems [8]. In order for an organizations to survive changes on the environment it is necessary to have the five subsystems of VSM. Change in the environment could include socio-political new laws, change in the global economy, etc. The five subsystems are designated in this chapter as follows: operations 1, coordination 2, and plant management 3 which includes auditing/ monitoring $3^{*}$, strategic management 4 , and board of directors 5 .

All the five subsystems should be interconnected by a management information systems like as ERP. There are several information systems in the market, the selection of any one depends on the characterization of each SCM.

\section{The VSM: Brief narrative}

In figure 1 it is shown the three basic components: environment system, operating system and management. The three basic components are interrelated by information channels, subject to the Ashby's law. The Ashby's law established that the variety of the management system should be grater or equal to the variety of the operating system. The variety of operating system should be larger or equal to the variety of the environment system [9].

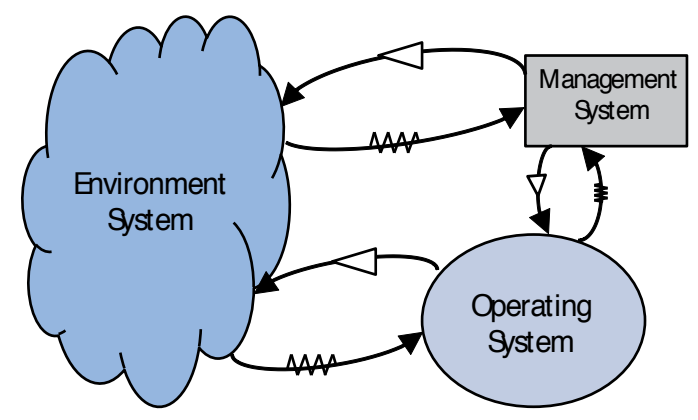

Figure 1. A simplified model of a production system

Human organizations are much more complex than we are usually prepared to admit. Organizational charts do not show how the organization really works, and in fact, real-world systems have variety which is effectively almost infinite. Consider Fig. 2 as a model of a simplified production system.

The VSM has the ability to maintain its identity according to the general purpose on the organization. The VSM model could be used to design new organization or diagnosing current organizations [10]. Not only in the management of the manufacturing industry, e.g., the explanation of the general production management model of the enterprise resources planning systems [11], but also in financial management and in the service industry.

For further details of the five subsystems components and its interrelations see [7] and [8]. 


\subsection{Modelling a general SCM with VSM and ERP}

In Fig. 2 we present an SCM according to the VSM interconnected with ERP.

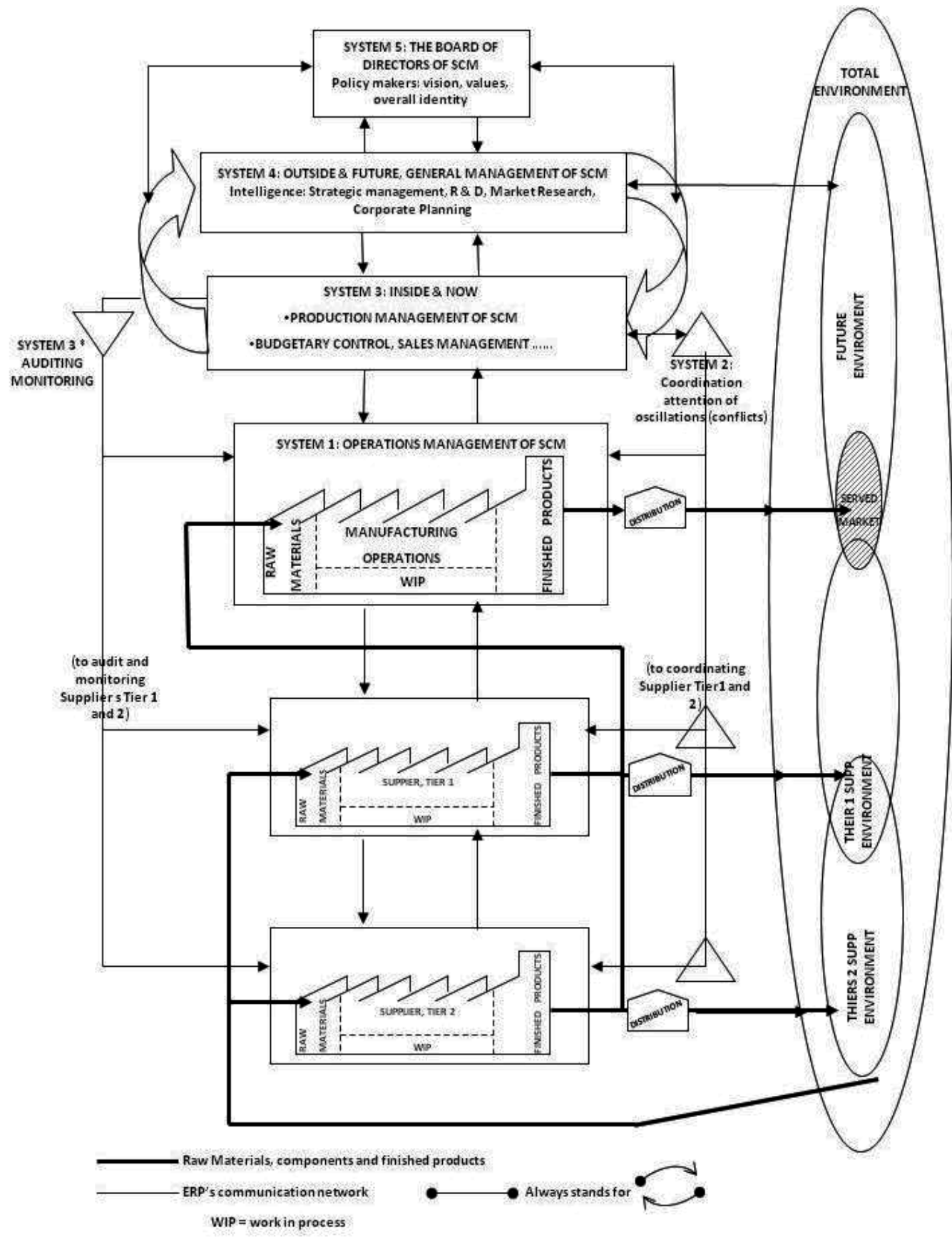

Figure 2. A general supply chain management model based on VSM. 
System 1: It is the component of a production system that perform tasks which produce what the systems is supposed to do. Some of the task performer by system one are facilitated by ERP modules like those shown in table 1.

\begin{tabular}{|c|c|}
\hline $\begin{array}{l}\text { 1. Sales and operation management (SOP) to develop } \\
\text { tactical and strategic plans to achieve competitive } \\
\text { advantage }\end{array}$ & $\begin{array}{l}\text { 2. Customer relationship management } \\
\text { (CRM) to understand and support existing and potential } \\
\text { customers' needs }\end{array}$ \\
\hline $\begin{array}{l}\text { 3. Quality function deployment (QFD) to ensure that all } \\
\text { major requirements of the "voice of the customer" are } \\
\text { incorporated in the product or service }\end{array}$ & $\begin{array}{l}\text { 4. Master production schedule (MPS) to reflect the } \\
\text { anticipated production schedule }\end{array}$ \\
\hline $\begin{array}{l}\text { 5. Material requirement planning (MRP) and informatics } \\
\text { algorithm that processes data from BOM, IM and MPS }\end{array}$ & $\begin{array}{l}\text { 6. Capacity requirement planning (CRP) to determine in } \\
\text { detail the amount of labour and machine resources required } \\
\text { to accomplish the MPS }\end{array}$ \\
\hline $\begin{array}{l}\text { 7. Bill of material (BOM), an organization of the product } \\
\text { structure }\end{array}$ & $\begin{array}{l}\text { 8. Bill of processes (BOP), an organization of the processes } \\
\text { of manufacturing }\end{array}$ \\
\hline $\begin{array}{l}\text { 9. Shop floor control (SFC) Control of manufacturing } \\
\text { activities }\end{array}$ & $\begin{array}{l}\text { 10. Production activity control (PAC), control of } \\
\text { manufacturing activities. }\end{array}$ \\
\hline $\begin{array}{l}\text { 11. Supplier relationship management } \\
\text { (SRM), relationships with vendors. }\end{array}$ & 12. Total quality management (TQM) \\
\hline $\begin{array}{l}\text { 13. Maintenance management (MM), Preferably total } \\
\text { quality maintenance. }\end{array}$ & $\begin{array}{l}13 \text { Distribution requirement planning (DRP), to improve } \\
\text { logistic of parts and finished products. }\end{array}$ \\
\hline
\end{tabular}

Table 1. ERP's modules for system 1 of VSM [11].

All components of the supply chain, are interconnected between them and to a management suprasystem. In order to facilitate management of variety, currently screens to receive instructions and to report performance, are used. The organization viability of the total systems and its components are inherent to the VSM. Which include communications of decisions according to Master Production Schedule. The ERP system reduce the bullwhip effect, with the help of one of the modules of ERP called distribution requirement planning (DRP). The algorithm of this module avoids the quantitative subjective process of planning order receipts (see Fig. 3).

System 2: Is a system that coordinates the activities of various productions departments, in order to avoid conflicts between them when using common resources of services. This coordination activity avoid the problematic situation known in systems dynamic, as "tragedy of the commons". Coordination activities are based on what is best for the whole (see table 2).

Systems 3 and $3^{*}$ : System 3 activities are the command and control of the operations of system 1, with the help of information from system 2 and the monitoring or auditing information from system $3^{*}$.The main activities of system 3 are supported by the modules of ERP shown in table 3. 


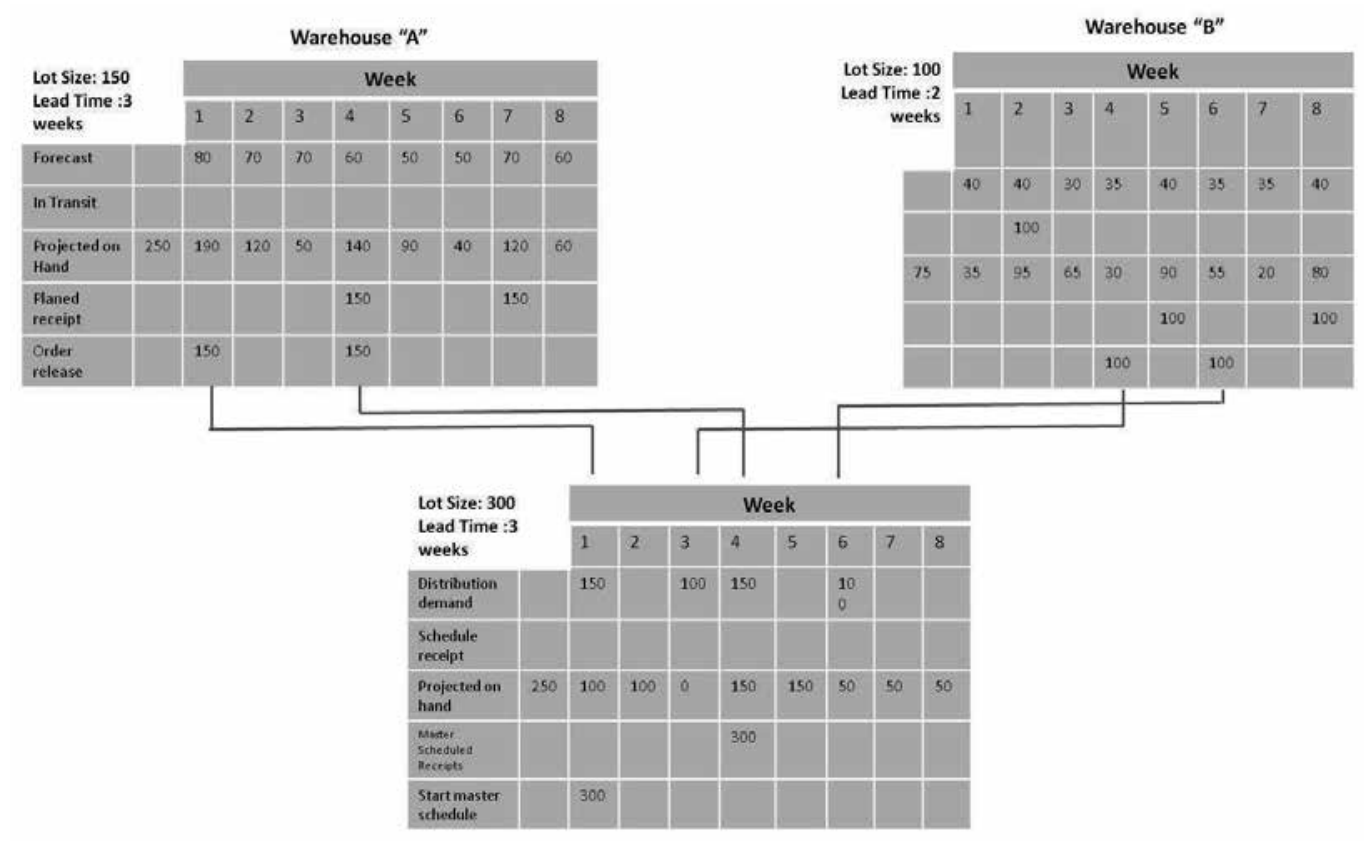

Source: APICS

Figure 3. Two-tier distribution requirement planning (DRP) example.

\begin{tabular}{ll}
\hline - Production scheduling (MPS) & - Quality control of major raw materials \\
\hline - Work procedures/bill of processes & - Maintenance management (MM) \\
(BOP) & \\
\hline - Supply chain event management & - Manufacturing auditing (MA) \\
(SCEM) & \\
\hline
\end{tabular}

Table 2. ERP's modules for system 2 of VSM [11].

The work of the accountants will be facilitated with the online data communications [13], this online data collections is performer with one module of ERP [14]. The free time of the accountants now will be dedicated to assist management in the system 3 . In addition to the free time of the accountants could be used to improve performance of management (system 3). Real time data will be filtered to adjust variety of system 1 .

In others words auditing/monitoring coordinates and control system 1 through some ERP modules, such as: 1) advanced planning system (APS); 2) available to promise and capable to promise functions (ATP); 3) production activity control (PAC); and 4) inventory management (IM); which are standard modules of ERP

System 4: System 4 performs strategic planning and interpretation of polices elaborated by system 5 . Some of the tasks of system 4 are supported by modules of ERP shown on table 4 . System 4 is the point where internal and external information can be brought together. 


\begin{tabular}{|c|c|}
\hline Shop floor control (SFC) & Financial business modules such as: \\
\hline $\begin{array}{l}\text { Manufacturing execution system (MES) } \\
\text { (to control and monitor plant-floor machines and } \\
\text { electromechanical systems) }\end{array}$ & $\begin{array}{l}\text { Activity-based costing }(\mathrm{ABC}) \text { to obtain real cost of } \\
\text { finished products or services }\end{array}$ \\
\hline $\begin{array}{l}\text { Input-output control and production activity control (PAC) } \\
\text { (to control details of production flow) }\end{array}$ & Accounts payable (AP) \\
\hline $\begin{array}{l}\text { Human resource management (HRM) } \\
\text { (for payroll, time management benefits administration, etc.) }\end{array}$ & Accounts receivable (AR) \\
\hline $\begin{array}{l}\text { Plant and equipment management (FA) } \\
\text { (fixed assets management) }\end{array}$ & General ledger (GL) \\
\hline Cost Accounting of BOM's and BOP's (CA) & Financial supply chain management (FSCM) \\
\hline $\begin{array}{l}\text { Manufacturing execution system (MES) } \\
\text { (to control and monitor plant-floor machines and } \\
\text { electromechanical systems) }\end{array}$ & Payroll (PR) for salary administration \\
\hline
\end{tabular}

Table 3. ERP's modules for system 3 and system $3^{*}$ of VSM.

\begin{tabular}{ll}
\hline Human resources (HR) & Advanced planning system (APS) \\
\hline Product life cycle (PLC) & Long-range forecasts (LRF) \\
\hline Legal and fiscal planning & Business planning under various scenarios \\
\hline
\end{tabular}

Table 4. ERP's modules for system 4 of VSM [11].

According to [11]:"The database of the human resources module (HR) helps to build a portfolio of human resources, by identification of employees. The system 4 use modules of ERP like shown in table 4 . This system maintain procedures to forecast future changes of equipment in other resources for example $3 \mathrm{D}$ printers instead of traditional tool-room equipment.

System 5: System 5 keeps enterprise identity and congruency with its environment. This System is integrated by board of directors. One of the main the outputs of the board of directors is to issue general management policies for inside operation system as well as the interrelation with the environment. ERP is lacking appropriated modules for the activities of system 5, this fact is an opportunity to improve ERP [11]. At the present there are not modules of ERP to help activities of system 5. For example, to improve decision taking on consensual agreements, strategies and policies, could be based on methodologies such as Syntegrity [15], Interactive Management [16] or CogniScope [17]. In case of critical situations, the algedonic channels communicate this situations directly to system 5 .

\section{Case Study: VSM applied in an aftersales spare parts service in telecommunications industry}

According to [18] "all economic activities whose output is not a physical product or construction, is generally consumed at the time it is produced, and provides added value in forms (such 
as convenience, amusement, timeliness, comfort or health) that are essentially intangible concerns of its first purchaser". Fitzsimmons and Fitzsimmons says the society is changing from a manufacturing-based society to service based society [19]. Modern telecommunications are like a catalyst of states' sustainable development: these represent a vital element in the proper functioning of enterprises, and are part of the quotidian life of almost every individual on this planet [20]. The telecommunications industry requires main preventive and corrective maintenance of high service level which includes, spare parts, technical support and training. This kind of maintenance offered by original equipment manufacturer (OEM). The corrective maintenance is offered after sales [21]. This case of study concerns only the level of an OEM dedicated to aftersales spare parts service. Customer operators (CO) try to reduce capital expenditures and inventory cost, as well as to improve cash flow. In reference [22] it is say, that $47 \%$ of mobile $\mathrm{CO}$ outsource spare parts activities.

In the area of service parts, the relationships between OEMs and COs are often established through detailed service contracts. In this contracts are specified the delivery time, prices, etc.

The purpose in this section is the VSM application in an aftersales spare parts service in telecommunications industry. If the organization adopt the VSM it will improve the total performance. For example reduces inventory, reduces delivery time, better relationships with suppliers and customers, etc.

\section{Service of spare parts to an original equipment manufacturing telecommunications industry}

There are different aftersales services that OEMs provide to their customers, for example return for repair (RfR), advance and exchange (AE), spare parts, field corrective maintenance, etc. As stated before, OEMs and COs establish the service scope through an agreement. In this agreement it is specify several aspects of service delivery, for example the metrics to measure the effectiveness of the service [23]. According to [24] the service level agreement (SLA) should be identify include the geographic region.

In this particular industry the two kind of repair services are AE and RfR (see Fig. 4). Some details of the process are as follows: issue of a requisition of spare parts which should be delivery in two, four or twenty four hours in according to SLA document. The delivery is done from the near warehouse $\left(\mathrm{W}_{1-\mathrm{n}}\right)$. At the same time, the main warehouse centre (DC), delivers the parts to the local warehouse in order to maintain inventory level. As soon the goods parts are on hand at the OEM, it returns the failed part, afterward the defective part is delivery to the repair centre; when repaired part it is delivered to the distribution centre (DC). The total time elapsed since the requirement order to the delivery of the repaired part, is called the turnaround time (TAT). In case of urgent repair service the best alternative is the AE.

There are two types of variability in the AE services: 1) the variety of the demand/failure of parts process; 2 ) the variety in defective collection process. In order to tackle the first variability. To cope the variety 1), the OEM uses a database and part failure rate [25] to forecast require- 
ments (demand). The other source of variability is located inside the OEM operator and depends on the speed on return of failed spare parts [26].

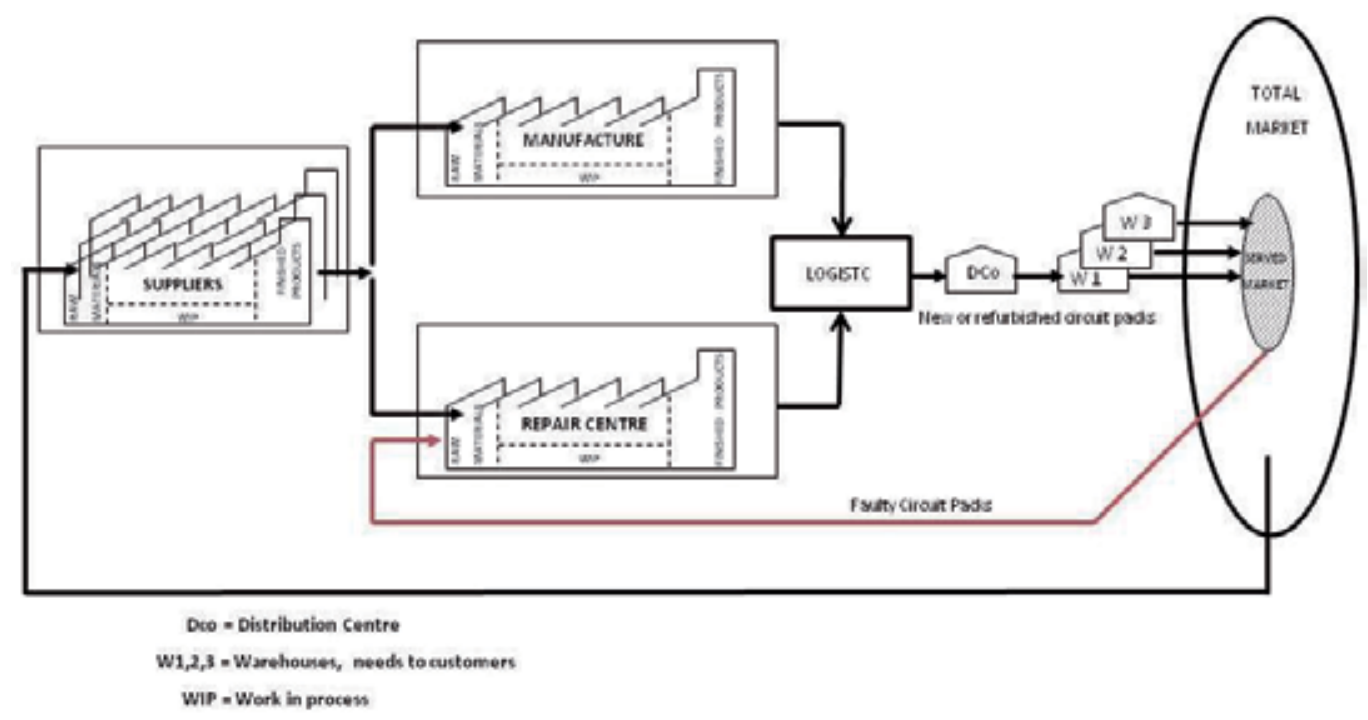

Figure 4. Schematic of materials flow in an aftersales AE spare parts service SC.

\section{Modelling an OEM's SC spare parts service with VSM and ERP}

Organizations need a link between the strategy and operations. OEMs compete on services but they need to make a trade-off between the service level and the costs.

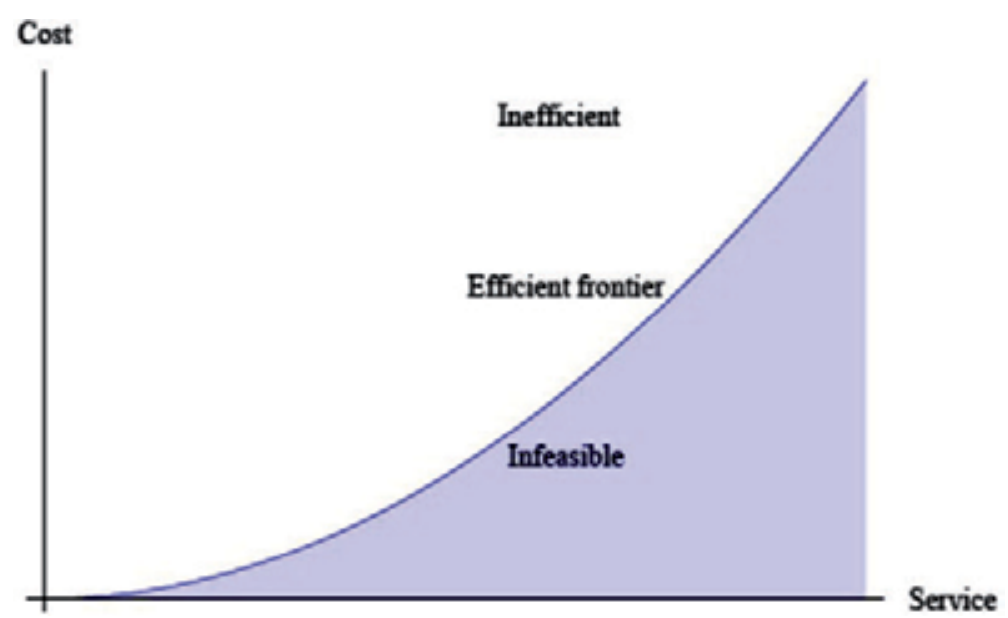

Figure 5. Service cost trade-off and the efficient frontier. 


\subsection{System 1: Operations of SC of OEM}

This system develop the physical operations required to give AE and RfR services. The main operations performed in System 1 are: replenishment, rebalances, redeployment, new purchase and disposal of scrap inventory. In order to reduce inventory cost and service failure risk, it is recommended RfR services (see Fig. 5). The ERP system consider all the above transactions.

\subsection{System 2: Coordination and anti-oscillatory actions}

In Fig. 6 the supply chain shown several organizations levels. According to [27], it is necessary to coordinate: (i) bottlenecks, (ii) variability; (iii) conflicts on of resource utilization, (iv) lot size. The increase variability is referred to as the inefficient bullwhip effect [28]. To reduce the bullwhip effect it is required a good coordination between supply and demand. There is another needed coordination between the information flow and the spare parts flow; the last taking in consideration that the repair centres are located in several countriesThe lack of coordination between the flows of information and spare part, are very expensive in money and [29]. According to Bar-Yam [30], the structure of the hierarchical organization also coordinates the tasks of different individuals in the supply chain. All flows: material, data and money are properly registered by the ERP system.

\subsection{System 3 and $3^{*}$ : General management and auditing/monitoring activities}

System 3 attended the now and here activities of the aftersales spare part service. For example: quality and punctuality of delivery are KPI's. The customer relationship management (CRM) module of ERP helps to perform this activities. MRP helps to perform the material planning activities for example: identification of failed and missing parts.

At the same time, system 3 perform the activities related to the supplier relationship management (SRM) and purchasing activities.

System $3^{*}$ the surveillance and audit of system 3, control the quality of the service operations management. The control information is used to improve the output of System 1. The auditing information of system 3 together with the strategic management information of system 4 is used to establish the master operation plan.

System 3 knows that sales forecast and other variables are always wrong. Following [31], employees working in systems 1, 2 and 3 interpret strategies of system 4, corporate policies and business plan of system 5 with the help of ERP identified lead times, capacities, level of quality service and production schedules.

To improve the inventory management of spare parts, considering the bullwhip effect, in section 7 it is applied the fractal theory to characterize the number of failures in spare parts.

\subsection{System 4: Strategy management of SC of OEM}

System 4 see the future in the outside of services enterprise, for example budget, human capital in future organization change; market research and research and development of future kind 
of services. Briefly system 4 use internal and external information to position the services enterprise and suggest future orientation, according to the growth market.

\subsection{System 5: OEM's SC board (policy purpose)}

System 5 The mains roles of this system is to establishing cultural and social identity, for example to establish values and purposes, social benefits and others internal policies. In reference to [30], "the rule of thumb is that the complexity of the organization has to match the complexity of the environment at all scales in order to increase the likelihood of survival", which is an extension of the Ashby law of requisite variety; "only variety can absorb variety" [2].

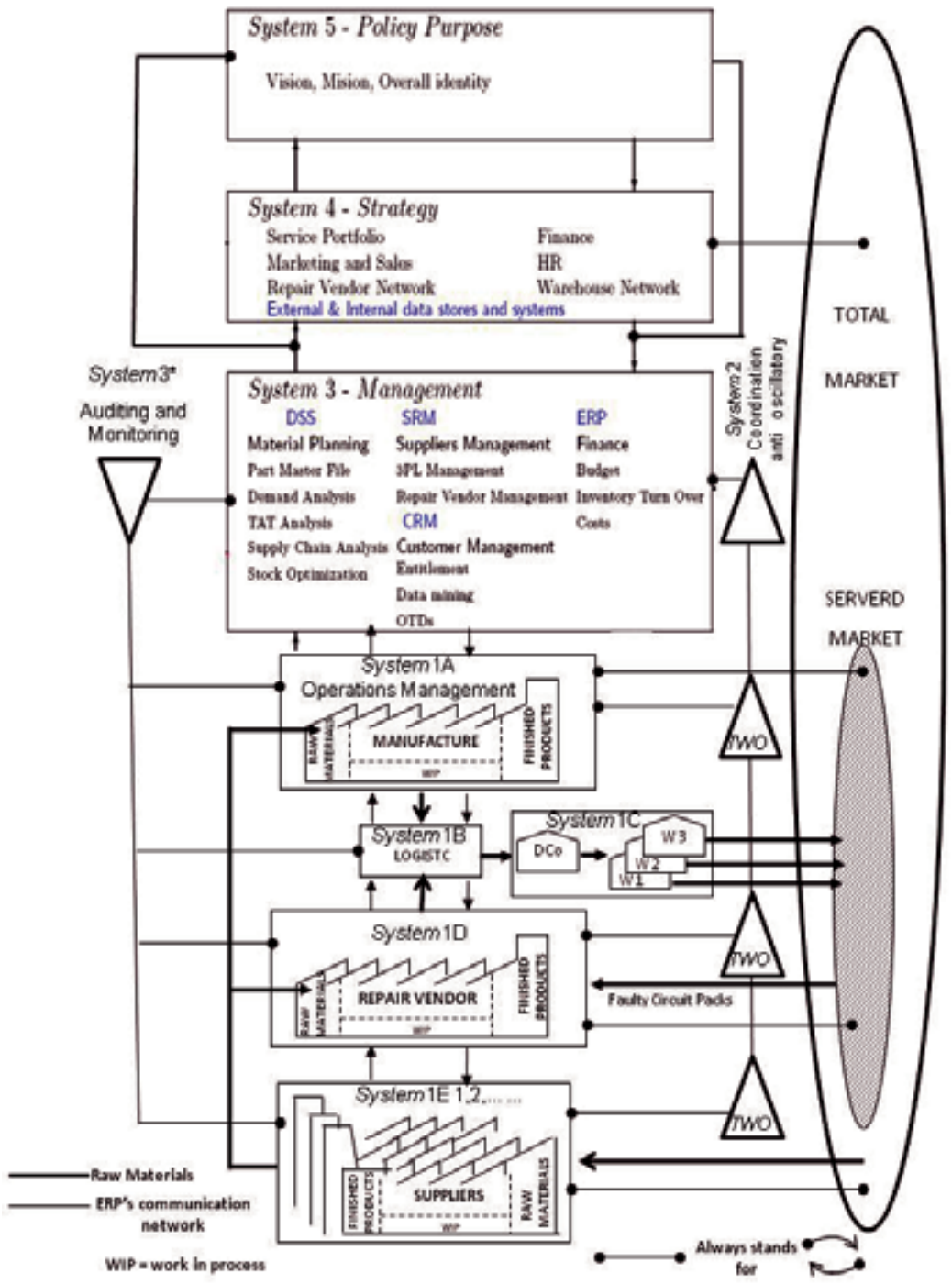

Figure 6. The OEM's SC aftersales spare parts services according to VSM and ERP. 


\section{Bullwhip effect in aftersales spare parts supply chain, Case: telecommunications industry}

\subsection{General description}

The "bullwhip effect" is defined in [1] as "an extreme change in the supply position upstream in a supply chain generated by a small change in demand downstream in the supply chain. Inventory can quickly move from being backordered to being excesses". An example of this effect was reported by [28] in Procter \& Gamble where variability of supply order to replenish the upstream distribution inventory was larger than the variability of downstream retail inventories. To cope with unexpected variability it is necessary to increase the safety buffer levels upstream, causing cost inefficiency to the total system of SC.

Of course the bullwhip effect is not new since the foundation of industrial dynamic in 1958 by Forrester [32] up to S Lee, Padmanabhan and Whang [33], and Sterman [34] have published about this effect. Some authors have identified several causes of the bullwhip effect, for example [1] attributed the effect to "the serial nature of communicating orders up the chain with the inherent transportation delays of moving product down the chain. [33] Identified four factors: batching, forecasting, pricing and gaming.

Chen et al. introduced quantitative relations in supply chain [35]. [36, 37 and 38] used control theory to illustrate the bullwhip effect. The study of supply chain from the point of view of complex dynamical systems theory has only recently begun [39]. Concepts from statistical physics and nonlinear dynamics have recently been used for the investigation of supply networks [40]. The authors Helbing [39] and Radons \& Neugebauer [40] have researched nonlinear causes of the stability of SC.

By simulation of a supply chain model, Larsen et al. [41] showed a wide range of nonlinear dynamic phenomena that produce an exceedingly complex behaviour in the production distribution chain model. Hwarng and Xie [42] used chaos theory through the Lyapunov exponent.

In figure 7 it is shown the interaction/transportation relationships, under the service level agreement (SLA), between telecommunications equipment manufacturer (TEM), repair vendors (RV) and Carriers (C)

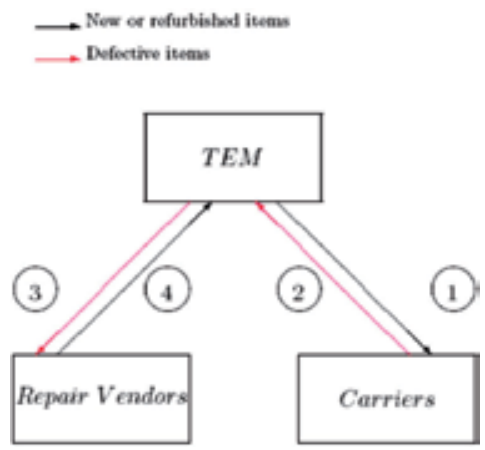

Figure 7. Closed-loop supply chain of repairable items. 
The fractal behavioural study of complex systems consists, in general, of three major approaches: theoretical, experimental and computational. The goal is to create the most parsimonious description of the phenomena under study and the most faithful representation of the observed characteristics [30, 43 and 44].

One of the fractal characterization technics is based in the methods of Scale range (R/S). This is the method that will be explained in nest section.

\subsection{Fractal characterization}

The fractal characterization applied in this chapter is oriented to the self-affine processes [45].The standard definition of self-affine states that a process of continuous time $Y=\{Y(t), t>0\}$ is self-affine if the distribution probability of $\{\mathrm{Y}(\mathrm{t})\}$ has the same distribution probability of $\{\mathrm{aHY}(\mathrm{at})\}$ for $\mathrm{a}>0$ [46].

The parameter $\mathrm{H}$ takes values between 0 and 1, and it is known as the Hurst exponent. This parameter measures the correlation persistence of data of the process over a long time.

- For $0<\mathrm{H}<0.5$, the process is said to have anti-persistent correlation.

- For $0.5<\mathrm{H}<1$, the process has persistent correlation and infinite variance.

- For $\mathrm{H}=0.5$, the time series is said to be memoryless or short-range dependent.

To estimate $\mathrm{H}$, we use the method rescale range $(\mathrm{R} / \mathrm{S})$ analysis. This method allows the calculation of the self-similarity parameter $\mathrm{H}$, which measures the intensity of long-range dependence in a time series [ 47 and 48].

The time series are plotted using cumulative data of each echelon of the process of the supply chain $[36,37]$. In Figure 8, the vertical axes show the cumulative units in queue of spare part. In the horizontal axes show the average difference of elapsed time that one spare part need to be transported from one echelon to the next one. The curves should be almost statistically the same in the each echelon and statistically symmetric. The meaning of each curves are: $D(t)=$ Demand, $D C(t)=$ collect spare parts, $R(t)=$ Repair processes.

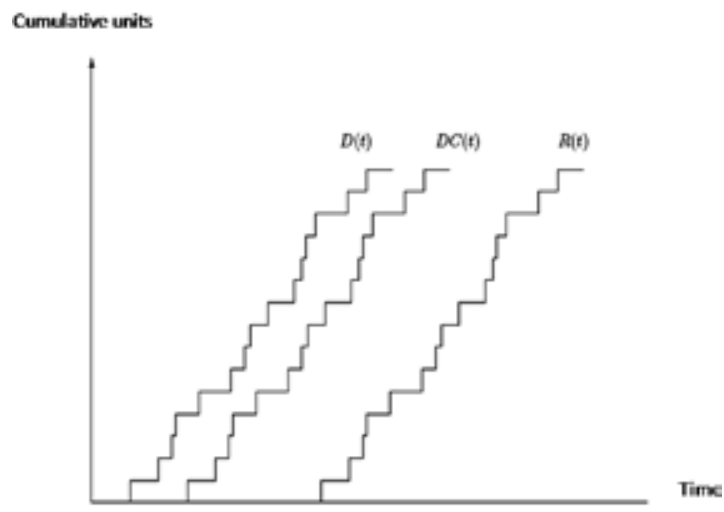

Figure 8. Data of Demand, Collect and Repair 


\subsection{Results}

The actual data for spare parts are 4217, due to some exceptions, the number of spare parts was reduces to 3617 . In Figure 8 it is observed some symmetry between the three curves. After some statistics of the time series it is detected a large variance between demand and others processes (see Table 5), which suggest bullwhip effect.

\begin{tabular}{lcccc}
\hline & Demand & $\begin{array}{c}\text { Defective } \\
\text { Collect }\end{array}$ & $\begin{array}{c}\text { Inbound } \\
\text { Repair }\end{array}$ & $\begin{array}{c}\text { Outbound } \\
\text { Repair }\end{array}$ \\
\hline Median & 9.909589041 & 8.334101382 & 8.334101382 & 7.795258621 \\
\hline $\begin{array}{l}\text { Standard } \\
\text { Deviation }\end{array}$ & 7.087757678 & 8.592998291 & 11.46805537 & 9.128734872 \\
\hline
\end{tabular}

Table 5. Simple statistics of the time series of the supply chain

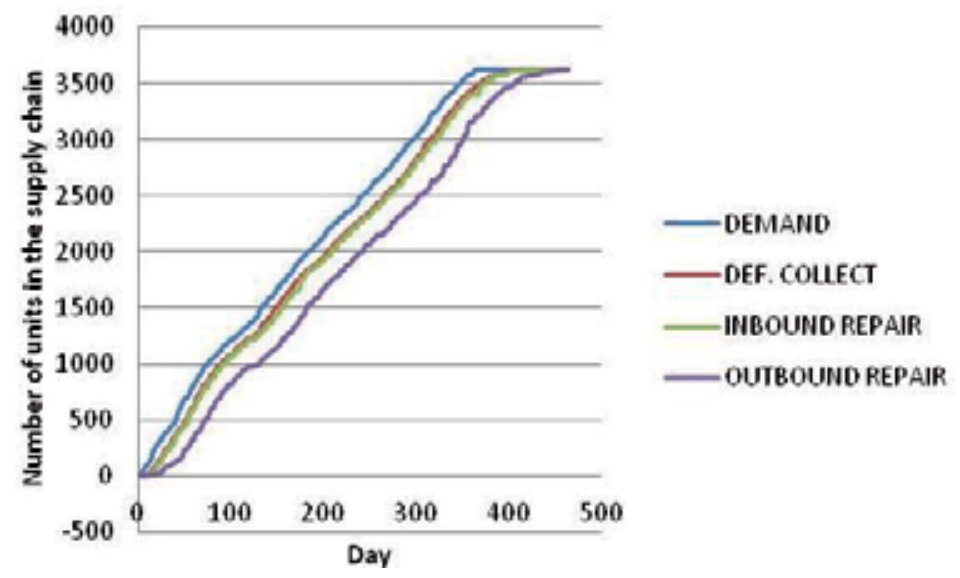

Figure 9. Data of the spare parts in SC.

Another way to look at the data is by calculating the difference between two cumulative curves of the process, i.e., the queue of material waiting to be processed by the following steps of the SC.

In Fig. 10 it is shown statistical characteristics of tree queues: the average of the repair queue (223.42 units), standard deviation (105.03 units). Average of collection queue (147.70 units), standard deviation (60.91 units). Spare parts waiting to the repair process: average (32.40 units), standard deviation (19.49 units).

In summary, using the R/S method to obtain the Hurst exponent are shown in Table 6 . The value of the Hurst exponent for defective collection process (0.6481) suggest persistence. The value of the Hurst exponent (near 0.5) suggest a random behavoiur for the inbound and outbound repair. 

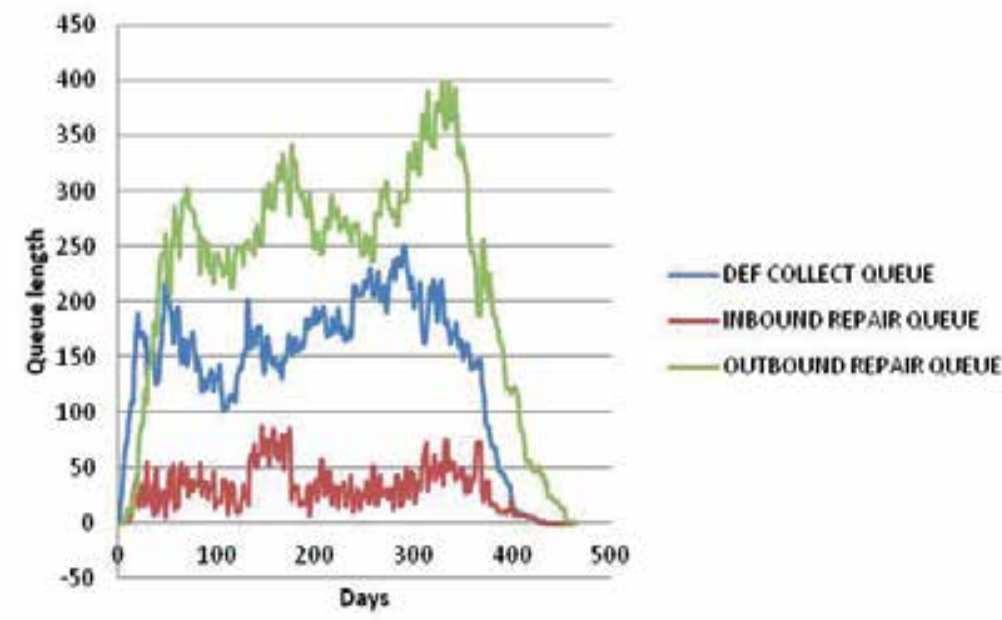

Figure 10. Queue of parts waiting to be processed in each echelon.

\begin{tabular}{ll}
\hline Summary & H \\
\hline Demand & 0.8449 \\
\hline Defective collect & 0.6481 \\
\hline Inbound repair & 0.5164 \\
\hline Outbound repair & 0.5649 \\
\hline
\end{tabular}

Table 6. Hurst exponent value of each process of the supply chain.

In Annex 1 there are four figures that refer to the log-log graphs of the Hurst exponents analysis, computed with the Benoit 1.3 software, for demand, defective collection process, inbound to repair process, and outbound process.

\section{Conclusions and recommendations}

Some conclusions are:

The systems science perspective provides a framework to better comprehend the supply chain management system. This approach describes how to equate the VSM and ERP to the case of an OEM's SC of a telecommunications firm. The bullwhip effect is a phenomenon experienced by supply chains when demand at the top tends to exhibit more variability than demand at the bottom.

Some recommendations are:

1. Improve trust and reliability of communications between the components of SC.

2. Implement ERP modules in the suppliers and customers information systems. 
3. Train suppliers and customers in the basic modules of ERP: MPS, MRP, BOM, IM, CRP, DRP and S\&OP

4. Some future researches could be included knowledge of system dynamics, complex systems and others systems concepts to improve understanding and diagnosis of systems.

\section{Annex 1}

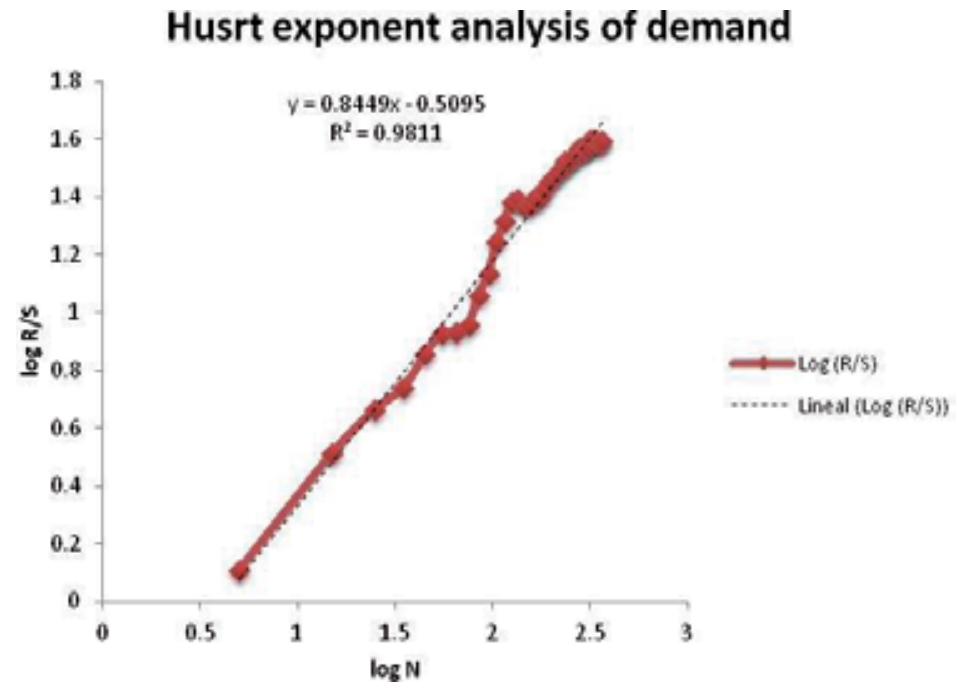

Figure 11. $\mathrm{R} / \mathrm{S}$ analysis of demand data $(\mathrm{H}=0.8449)$.

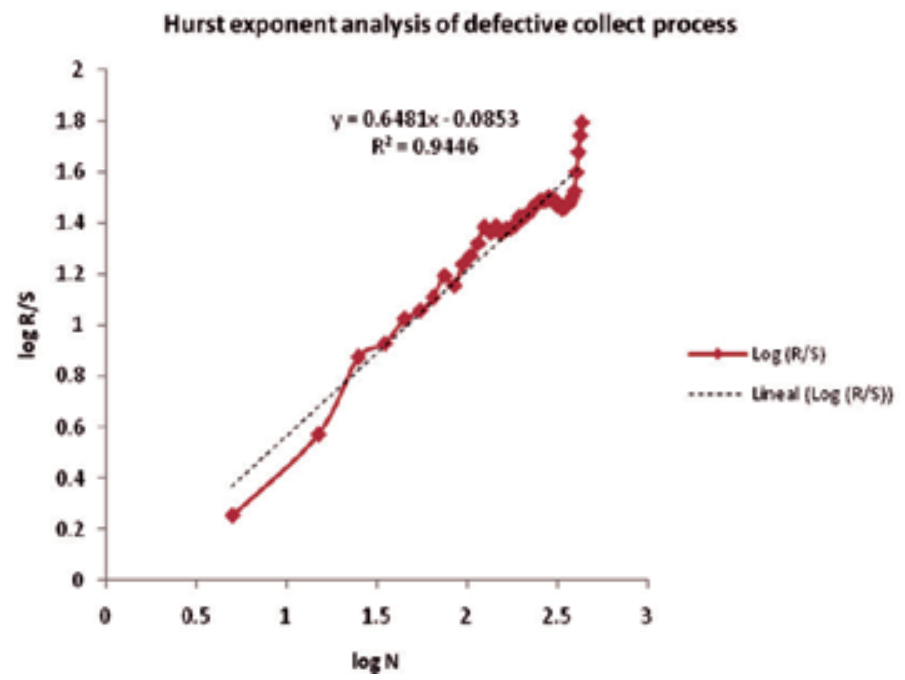

Figure 12. $\mathrm{R} / \mathrm{S}$ analysis of defective collection process data $(\mathrm{H}=0.6481)$. 


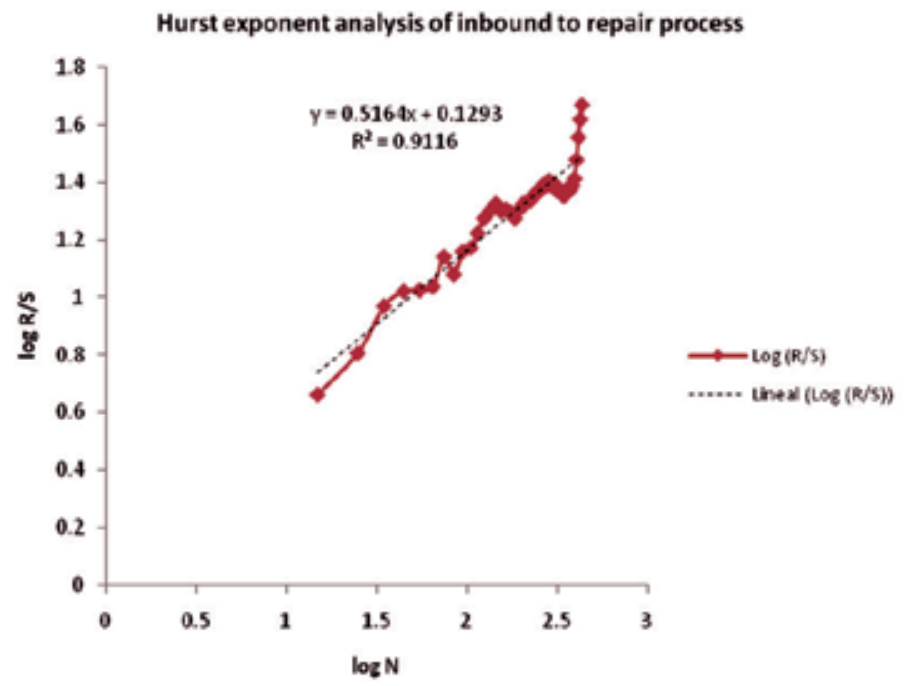

Figure 13. $\mathrm{R} / \mathrm{S}$ analysis of inbound to repair process data $(\mathrm{H}=0.5164)$.

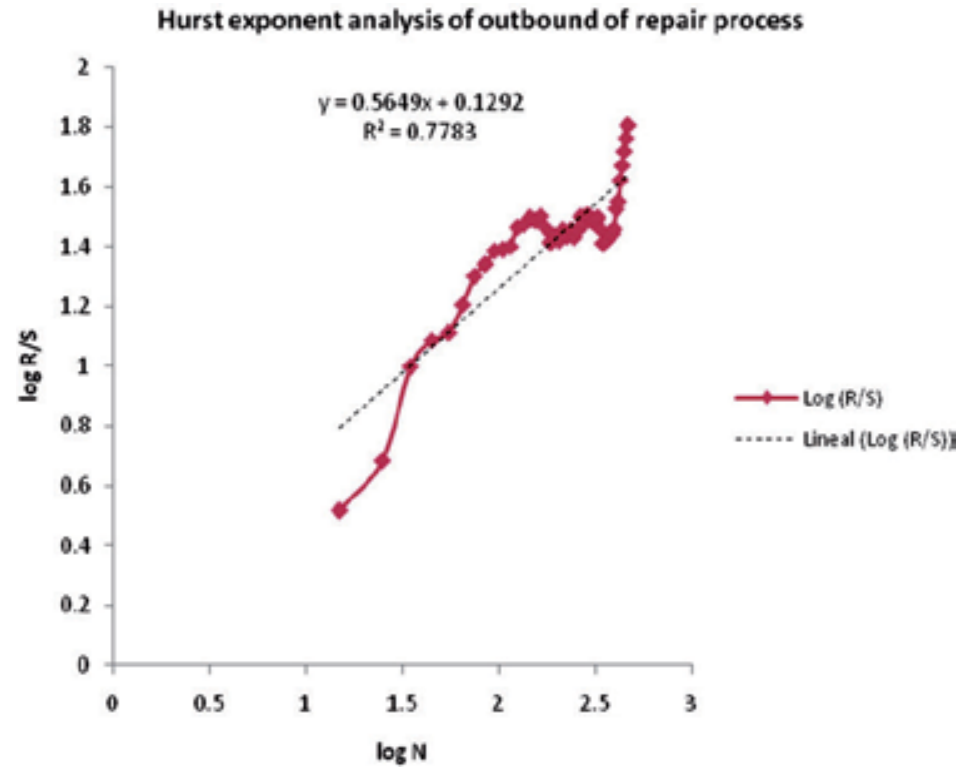

Figure 14. $\mathrm{R} / \mathrm{S}$ analysis of outbound of repair process data $(\mathrm{H}=0.5649)$. 


\section{Author details}

Isaías Badillo $^{1 *}$, Ricardo Tejeida ${ }^{1}$, Oswaldo Morales ${ }^{1}$ and Abraham Briones ${ }^{2}$

*Address all correspondence to: ibadillop@ipn.mx

1 Instituto Politécnico Nacional, México

2 Universidad Autónoma del Estado de Hidalgo, México

\section{References}

[1] Blackstone J H. APICS Dictionary. USA: University of Georgia; 2013.

[2] Beer S. Diagnosing the System for Organization. New York: John Wiley; 1985.

[3] Proctor J. Supply chain management as a transformation strategy. APICS 2011; 20(2)12-13.

[4] Beer S. Decision and Control. UK: Wiley; 1966.

[5] Beer S. Brain of the Firm. UK: The Penguin Press; 1972.

[6] Francoise C. International Encyclopedia of Systems and Cybernetics. München:K.G. Saur, 2004.

[7] Beer S. The Heart of the Enterprise. Chichester: Wiley; 1979.

[8] Beer S. The viable system model: Its provenance, development, methodology and pathology, in The Viable System Model, Interpretations and Applications of Stafford Beer's VSM, ed. Espejo R and Harnden R. UK: John Wiley \& Sons, 1989.

[9] Ashby WR. An Introduction to Cybernetics. London: Chapman and Hall; 1957.

[10] Espejo R, Harnden R, eds. The Viable System Model, Interpretations and Applications of Stafford Beer's VSM. UK: John Wiley \& Sons; 1989.

[11] Tejeida R, Badillo I, Morales O. A systems science approach to enterprise resource planning systems. Systems Research and Behavioral Science 2010; 27(1) 87-95.

[12] Leonard A. Integrating sustainability practices using the viable system model. Systems Research and Behavioral Sciences 2008; 25(5) 643-654.

[13] Turbide D. Getting real about real time. APICS The Performance Advantage 2007; 17(18) 115.

[14] Curran T, Keller G, Ladd A. SAP R/3 Business Blueprint. Understanding the Business Process Reference Model. US: Prentice Hall; 1998. 
[15] Beer S. Beyond Dispute: The Invention of Team Syntegrity (The Management Cybernetics of Organization). UK: Wiley, 1994.

[16] Warfield J, Cardenas R. A Handbook of Interactive Management. USA: Iowa State Press; 1994.

[17] Christakis A. CogniScope. 2007. http://www.globalagoras.org/optin.html (accessed 11 April 2007).

[18] Quinn JB, Baruch JJ, Paquette PC. Technology in services. Scientific American 1987; 257(6) 50-58.

[19] Fitzsimmons JA, Fitzsimmons MJ. Service Management. USA: McGraw-Hill; 2007.

[20] Kuhlman F, Alonso A. Información y telecomunicaciones. México: Fondo de Cultura Económica; 2003.

[21] Cohen M, Agrawal N, Agrawal V. Winning in the Aftermarket. Harvard Business Review 2006; May 129-138.

[22] Pyramid Research. Demystifying operator network budgets. 2006. http://www.pyramidresearch.com/points.htm (accessed 5 November 2007).

[23] Hartley KL. Defining effective service level agreements for network operation and maintenance. Bell Labs Technical Journal 2005; 9(4) 139-143.

[24] Cohen M, Agrawal N, Agrawal V. Achieving breakthrough service delivery. Through dynamic asset deployment strategies. Interfaces 2006; 36(3) 259-27.

[25] Trindade D, Nathan S. Simple plots for monitoring the field reliability of repairable systems. IEEE RAMS 2005; 539-544.

[26] Frei FX. Breaking the trade-off between efficiency and service. Harvard Business Review 2006; November 92-101.

[27] Hopp W. Supply Chain Science. USA;McGraw-Hill; 2008.

[28] Lee H, Padmanabhan P, Whang S. The bullwhip effect in supply chains. Sloan Management Review 1997; 38 93-102.

[29] Bailey K. Boundary maintenance in living systems theory and social entropy theory. Systems Research and Behavioral Science 2008; 25 (5): 587-597.

[30] Bar-Yam Y. Dynamics of Complex Systems.USA: Perseus Books; 1997.

[31] Schlegel G L, Murray P. Next generation of S\&OP: Scenario planning with predictive analytics \& digital modeling. Journal of Business Forecasting 2010; 21.

[32] Forrester J. Industrial dynamics: A major breakthrough for decision makers. Harvard Business Review 1958; 36: 37-66. 
[33] Lee H, Padmanabhan P, Whang S. Information distortion in a supply chain: The bullwhip effect. Management Science 1997; 43 546-558.

[34] Sterman J. Modeling managerial behavior: Misperceptions of feedback in a dynamic decision making experiment. Management Science 1989; 35(3): 321-339.

[35] Chen F, Drezner Z, Ryan J, Simchi-Levi D. Quantifying the bullwhip effect in a single supply chain: The impact of forecasting, lead times, and information. Management Science 2000; 46(3) 436-443.

[36] Daganzo C. A Theory of Supply Chains. Germany: Springer; 2003.

[37] Daganzo C. On the stability of supply chains. Operations Research 2004; 52(6) 909-921.

[38] Dejonckheere J, Disney S, Lambrecht M, Towill D. Measuring and avoiding the bullwhip effect: A control theoretic approach. European Journal of Operational Research 2003; 147 567-590.

[39] Helbing D, ed. Managing Complexity: Insights, Concepts, Applications. Berlin Heidelberg: Springer; 2008.

[40] Radons G, Neugebauer R, ed. Nonlinear Dynamics of Production Systems. Federal Republic of Germany: Wiley-VCH; 2004.

[41] Larsen E, Morecroft J, Thomsen J. Complex behavior in a production distribution model. European Journal of Operational Research 1999; 119 61-74.

[42] Hwarng H, Xie N. Understanding supply chain dynamics: A chaos perspective. European Journal of Operational Research 2008; 184 1163-1178.

[43] Bar-Yam Y. Making Things Work, Solving Complex Problems in a Complex World. USA: NECSI Knowledge Press; 2004.

[44] Morales O, Tejeida R, Badillo I. Fractal behavior of complex systems. Systems Research and Behavioral Science, 2010; 27(1) 71-86.

[45] Mumford D, Series C, Wright D. Indra's Pearls: The Vision of Felix Klein. UK: Cambridge University Press; 2002.

[46] Gao J, Cao Y, Tung W, Hu J. Multiscale Analysis of Complex Time Series. UK: Wiley; 2007.

[47] Mandelbrot B. The Fractal Geometry of Nature. San Francisco: Freeman; 1982.

[48] Barnsley M. Fractals Everywhere. USA: Academic Press; 1988. 



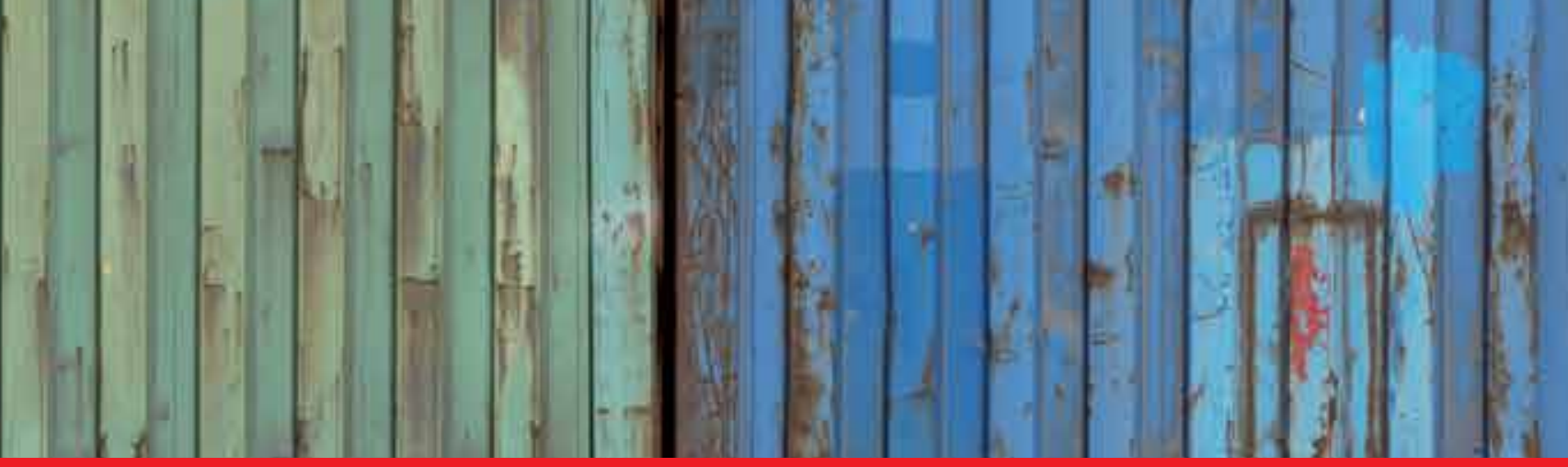

\section{Edited by Hakan Tozan and Alper Ertürk}

In today's rapidly changing business environment, strong influence of globalization

and information technologies drives practitioners and researchers of modern supply chain management, who are interested in applying different contemporary management paradigms and approaches, to supply chain process. This book intends to provide a guide to researchers, graduate students and practitioners by incorporating every aspect of management paradigms into overall supply chain functions such as procurement, warehousing, manufacturing, transportation and disposal. More

specifically, this book aims to present recent approaches and ideas including experiences and applications in the field of supply chains, which may give a reference point and useful information for new research and to those allied, affiliated with and peripheral to the field of supply chains and its management. 